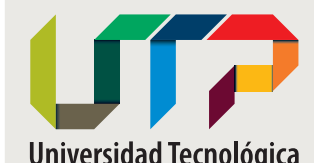

Universidad Tecnológica de Pereira

Facultad

de Tecnología

\title{
Fundamentos de mantenimiento industrial
}

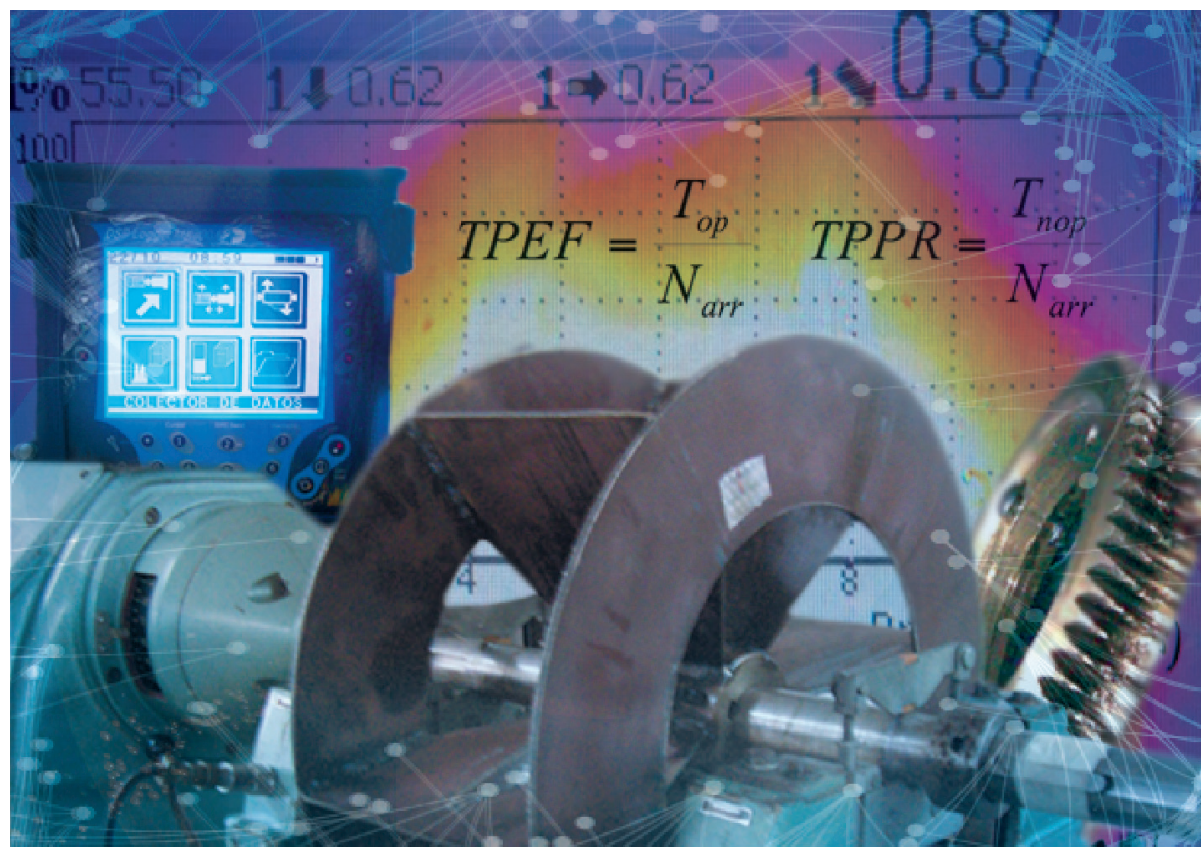

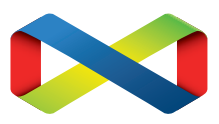

Editorial UTP

Carlos Alberto Montilla Montaña 


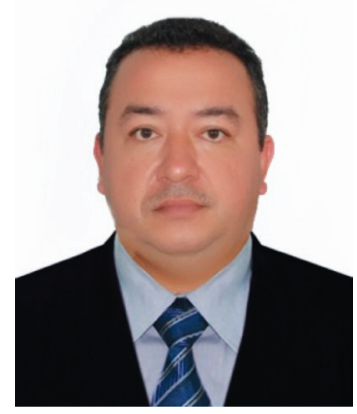

Carlos Alberto Montilla Montaña, (La Celia, Risaralda, Colombia, 1971). Cursa el Doctorado en Ingeniería en la Universidad Tecnológica de Pereira. M.Sc. en Sistemas automáticos de producción, Ingeniero Mecánico de la Universidad Tecnológica de Pereira.

Profesor asociado de la facultad de Tecnología de la Universidad Tecnológica de Pereira.

Autor del libro Manual de prácticas de Instrumentación y control (2009). Ha publicado artículos en revistas especializadas nacionales.

Pertenece al grupo de investigación en Procesos de Manufactura y Diseño de Máquinas. 




\section{FUNDAMENTOS DE MANTENIMIENTO INDUSTRIAL}

Carlos Alberto Montilla Montaña

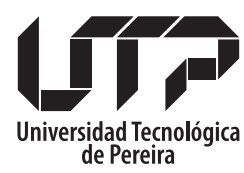

Colección Textos Académicos

Facultad de Tecnología

2016 
Montilla Montaña, Carlos Alberto.

Fundamentos de mantenimiento industrial / Carlos Alberto, Montilla Montaña

Pereira : Editorial Universidad Tecnológica de Pereira, 2016.

208.: p. : ilustraciones. - (Colección de textos académicos)

ISBN: 978-958-722-238-8

e-ISBN: 978-958-722-409-2

1. Administración industrial 2. Administración de la producción 3. Costos de

Producción. 4. Mantenimiento industrial 5. Maquinaria y equipos.

CD.658.202

(C) Carlos Alberto Montilla Montaña, 2016

(C)Universidad Tecnológica de Pereira

Primera edición

Universidad Tecnológica de Pereira

Pereira, Colombia

Universidad Tecnológica de Pereira

Vicerrectoría de Investigaciones, Innovación y Extensión

Editorial Universidad Tecnológica de Pereira

Coordinador editorial:

Luis Miguel Vargas Valencia

luismvargas@utp.edu.co

Conmutador 3212221 Ext. 381

Edificio 9, Biblioteca Central "Jorge Roa Martínez"

Cra. 27 No. 10-02 Los Álamos

Pereira, Colombia

www.utp.edu.co

Montaje y producción:

Centro Recursos Informáticos y Educativos

Universidad Tecnológica de Pereira

Impresión y acabados:

Publiprint

Pereira

Reservados todos los derechos 


\section{AGRADECIMIENTOS}

Al supremo Creador.

A la Universidad Tecnológica de Pereira, a su personal docente, estudiantil y administrativo, quienes me han apoyado y me han permitido enriquecerme y crecer en todos los aspectos.

Dedicado a mi familia, y a los estudiantes en general. 



\section{PRÓLOGO}

Este libro texto introduce a estudiantes de Ingeniería y Tecnología, a la teoría y práctica básica de la administración del Mantenimiento industrial, campo sumamente importante en las organizaciones productivas modernas y donde se ocupan laboralmente la mayoría de egresados de Ingeniería y afines. El libro es el resultado de la experiencia adquirida por el autor durante nueve años de servicio a la industria, y nueve años de experiencia docente en el campo específico de Mantenimiento.

En la forma que fue concebido y redactado el libro, es susceptible de ser leído y comprendido no solo por estudiantes universitarios, sino también por otros profesionales y personas ajenas al ámbito académico directo, pero con interés en el amplio mundo del Mantenimiento.

\section{Características de la obra:}

- Al inicio de la obra se presenta un panorama amplio del Mantenimiento, para que el lector pueda dimensionar su importancia.

- La obra consta de diez capítulos, iniciando con nociones y fundamentos básicos, pasando por un breve recuento histórico de la evolución del Mantenimiento y las efectividades alcanzadas por cada metodología. Se describen las diferentes metodologías o sistemas de mantenimiento, iniciando con el primitivo correctivo o "reparar" hasta llegar a las metodologías más modernas como el Basado en el riesgo RBM. A lo largo de la obra se tiene presente en todo momento que por tratarse de tareas técnico-administrativas no pueden estar desligadas de los presupuestos, costeos y sus respectivos controles. En el capítulo 10 se da una mirada integradora, a los temas previos, por intermedio de los Modelos o políticas de Mantenimiento.

- Hasta donde ha sido posible, se trata de dar una mirada holística entre Manufactura, Mantenimiento y Costos.

- Algunos temas se presentan concatenados con la realidad local y de Colombia y en algunos casos con realidades foráneas.

- Se hace uso de los resultados de diversos trabajos de grado (Ingeniería y Tecnología Mecánica), para concatenar lo expuesto con las realidades de la región y para resaltar recursos existentes en la UTP.

- Para la mayoría de capítulos, en un sitio web del autor, se ha dejado disponible una lectura adicional, con interrogantes que servirán como invitación al lector a reflexionar e ir encadenando los diferentes temas tratados, motivando el interés en su profundización.

- En el sitio web del autor se han dejado disponibles algunos estudios de caso, para que el estudiante no se quede solamente en la mirada académica, sino que visualice su aplicación en el contexto real.

- Se proponen consultas, talleres o ejercicios de aplicación en la mayoría de los temas tratados. 
- En el sitio web del autor se han dejado disponibles algunos anexos que servirán como respaldo a algunos tópicos específicos, estrechamente relacionados con Mantenimiento.

- Para algunos de los temas tratados se indica la forma de sistematizar su operación con el uso de software comercial (Hoja electrónica Excel, Microsoft Project, etc.).

El autor

Perfil Linkedln:

https://www.linkedin.com/pub/carlos-alberto-montilla-monta\%C3\%B1a/17/612/414

CVLac:

http://scienti1.colciencias.gov.co:8081/cvlac/visualizador/generarCurriculoCv.do?cod_rh $=0000822663$ 


\section{CONTENIDO}

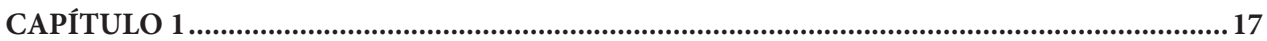

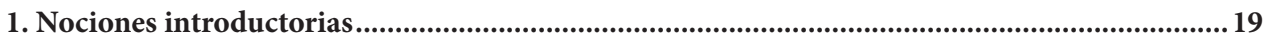

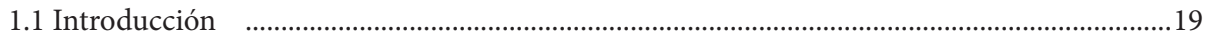

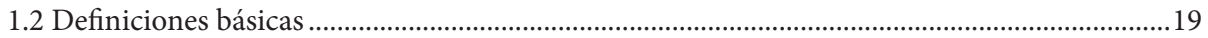

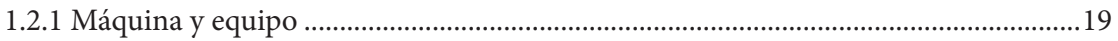

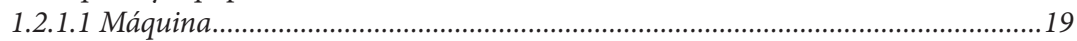

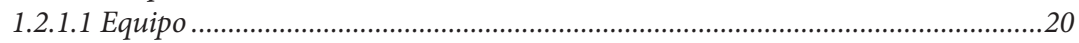

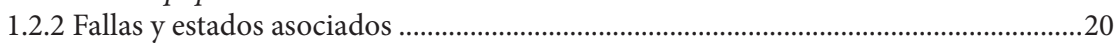

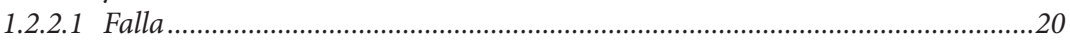

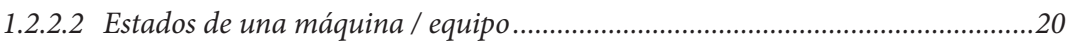

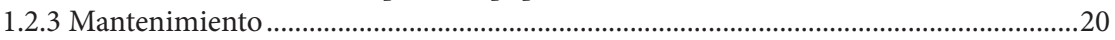

1.2.4 Ejemplo para aclarar algunas definiciones básicas ....................................................23

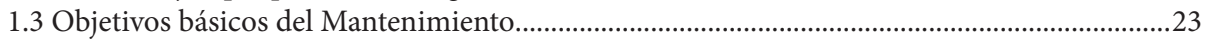

1.3.1 Minimizar las fallas funcionales (paradas imprevistas) de los equipos, y los

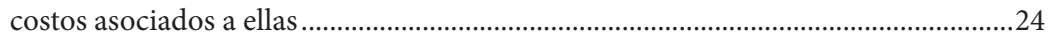

1.3.2 Asegurar unos costos operativos razonables de los equipos, y procurar

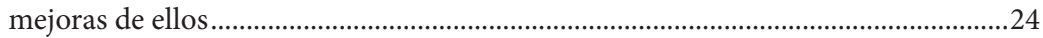

1.3.3 Maximizar la inversión en planta y equipos, asegurando el cumplimiento de .............. mínimo su vida útil esperada ...................................................................................2. 25

1.3.4 Asegurar que los equipos operen de manera segura para los Usuarios y para .............

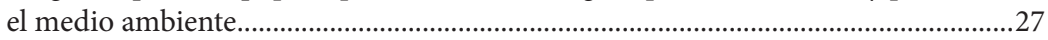

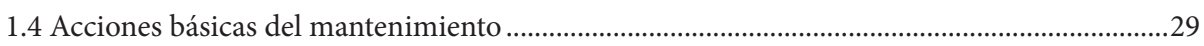

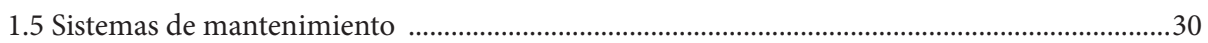

1.5.1 Mantenimiento Correctivo o a la falla o de emergencia CM .......................................30

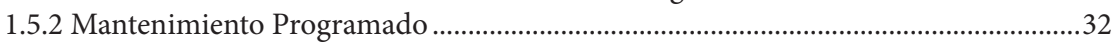

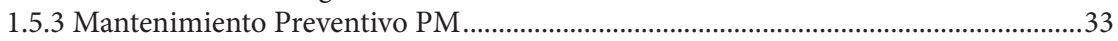

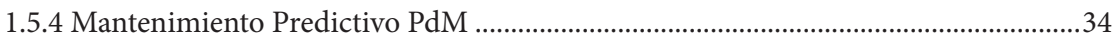

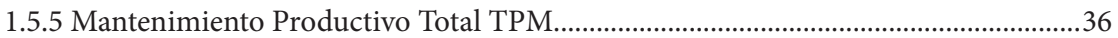

1.5.6 Mantenimiento Centrado en la Confiabilidad RCM .......................................................37

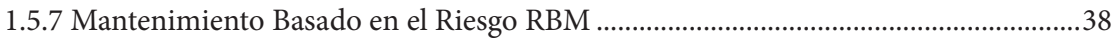

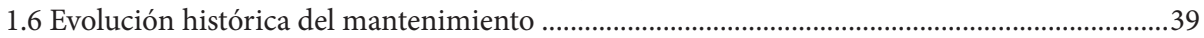

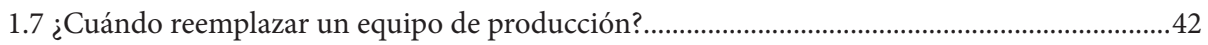

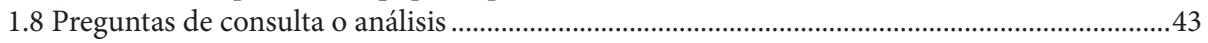

1.9 Para reflexionar. Mantenimiento ¿una vía de escape al subdesarrollo? .....................................43

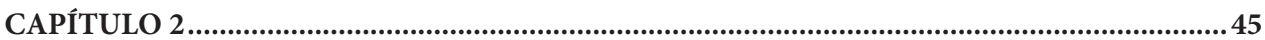

2. Organización del Departamento de Mantenimiento ......................................................................4 47

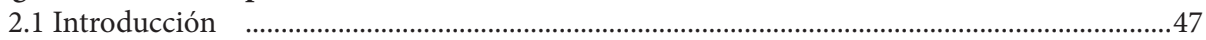

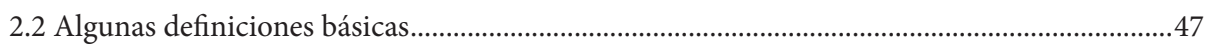

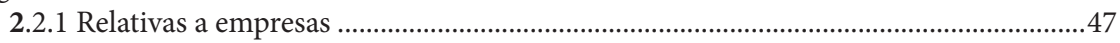

2.2.2 Definiciones relativas a cargos relacionados con Mantenimiento...............................50

2.3 Ubicación de la función Mantenimiento dentro de la empresa ....................................................50

2.4 Algunas estructuras típicas de los Departamentos de Mantenimiento..........................................53

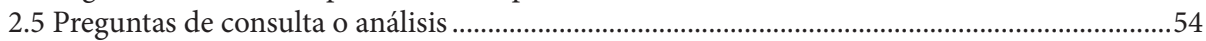

2.6 Para reflexionar. funciones genéricas del ingeniero y del tecnólogo de Mantenimiento en Colombia 
CAPÍTULO 3

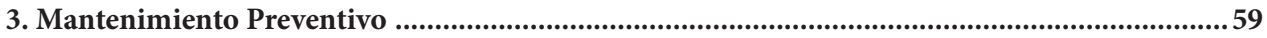

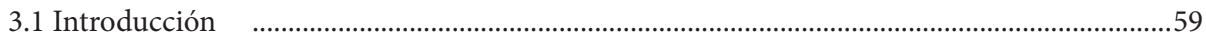

3.2 Pasos para implantar un plan de Mantenimiento Preventivo ........................................................62

3.2.1 Inventario de equipos, inmuebles y vehículos ............................................................63

3.2.2 Codificación de los equipos ......................................................................................63

3.2.3 Creación de la Tarjeta Maestra de Datos TMD, para cada máquina/equipo.............65

3.2.4 Creación de las hojas de vida de máquinas/equipos .....................................................49

3.2.5 Relación de requerimientos de Mantenimiento.................................................................6

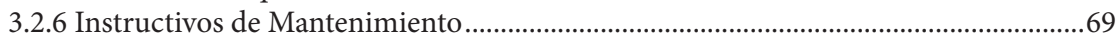

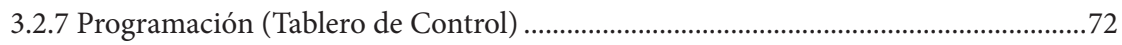

3.2.7.1 Tableros de control por tiempo transcurrido ....................................................... 72

3.2.7.2 Tableros de control por horas reales de servicio trabajadas o distancias recorridas.................................................................................................73

3.2.7.3 Tableros de control por unidades producidas .....................................................74

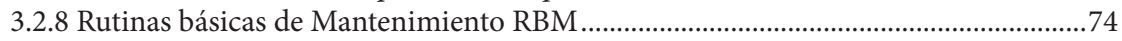

3.2.9 Formatos y documentación básica para la administración del

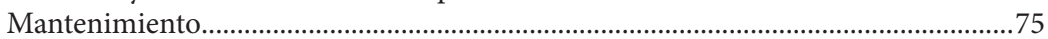

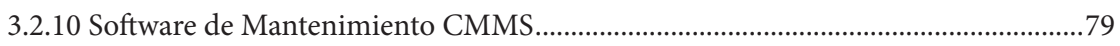

3.2.11 Dinámica de operación del Mantenimiento Preventivo .............................................80

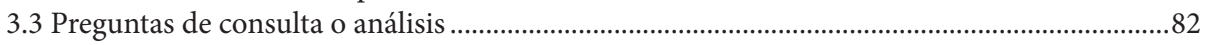

3.4 Para reflexionar. El mantenimiento en Risaralda y la competitividad ........................................82

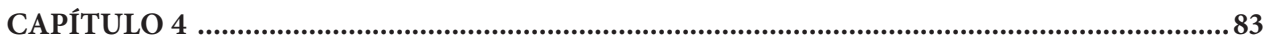

4. Programación y planeación en Mantenimiento ................................................................................. 85

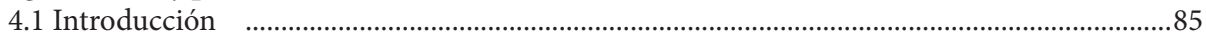

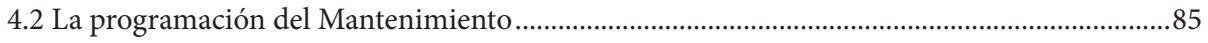

4.2.1 Tiempo Programable Para Mantenimiento TPPM ......................................................8

4.2.2 Carga de trabajo programable o Carga de trabajo de Mantenimiento CTM.............86

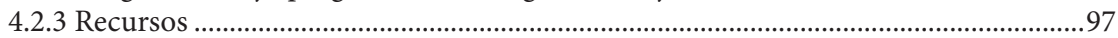

4.2.4 Balanceo de un tablero de control .....................................................................................97

4.2.4.1 Método teórico para balancear un tablero de control por tiempo trascurrido................................................................................................. 87

4.2.4.2 Método real (heurístico) para balancear un tablero de control por

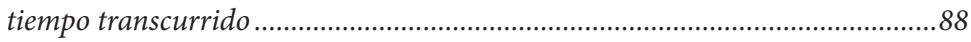

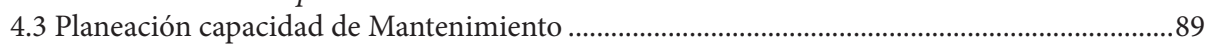

4.4 Preguntas de consulta o análisis y ejercicios .............................................................................. 91

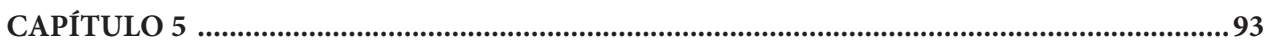

5. Mantenimiento analítico (indicadores e índices) ….........................................................................95

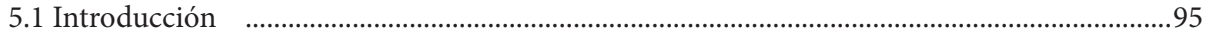

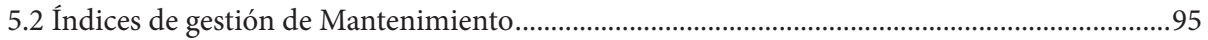

5.2.1 Indicadores de eficacia del Mantenimiento ..............................................................96

5.2.2 Indicadores de administración del Mantenimiento .....................................................98

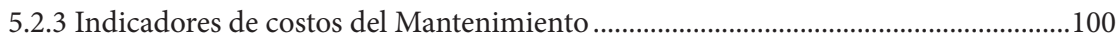

5.2.4 Ejemplo de cálculo de indicadores..........................................................................102

5.3 Fuentes de información para la construcción de índices ............................................................102

5.4 Algunos indicadores de producción relacionados con Mantenimiento ...................................103 


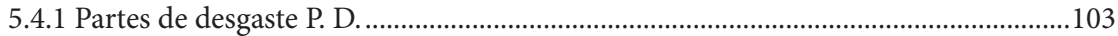

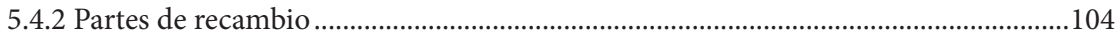

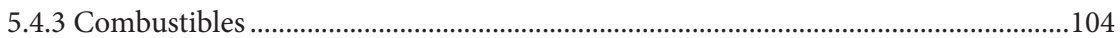

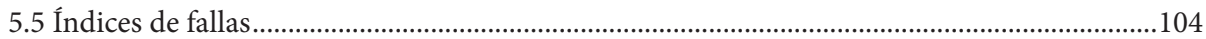

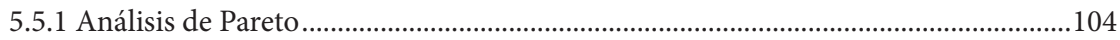

5.5.2 El Diagrama de Causa - Efecto, o Diagrama de Ishikawa o Espina de Pescado

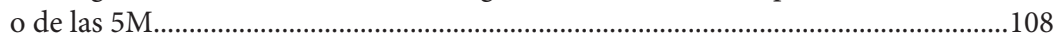

5.6 Preguntas de consulta o análisis y ejercicios propuestos .........................................................110

5.7 Para reflexionar. Un estudio de caso en la empresa colombiana de petróleos Ecopetrol ......111

CAPÍTULO 6

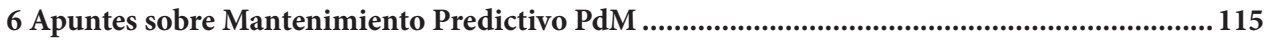

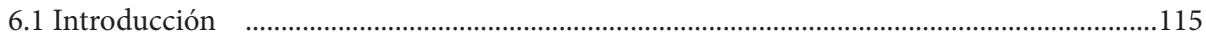

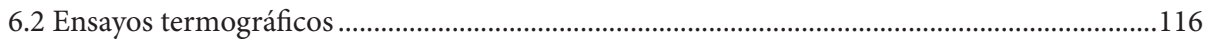

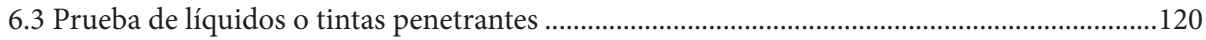

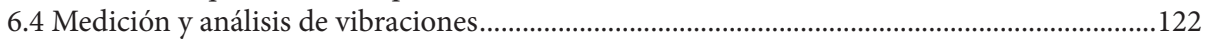

6.4.1 Algunos términos y definiciones a tener en cuenta................................................123

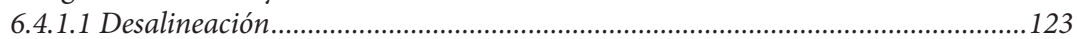

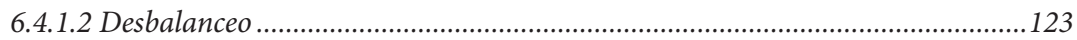

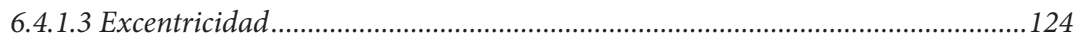

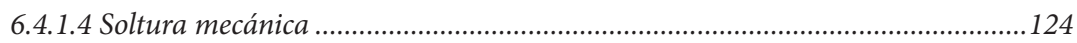

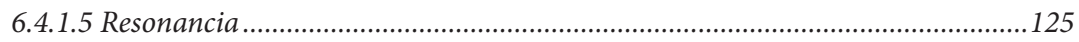

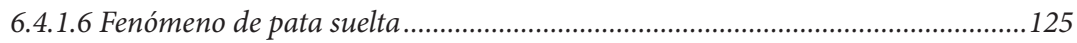

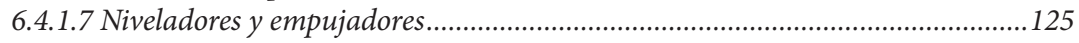

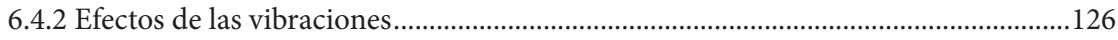

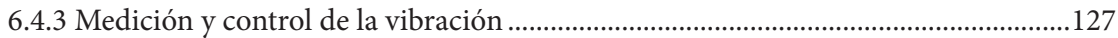

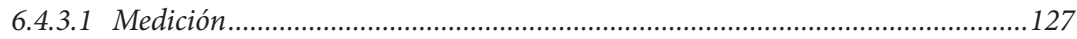

6.4.3.2 Corrección de la vibración …………………..................................................128

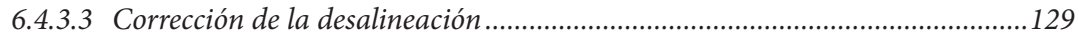

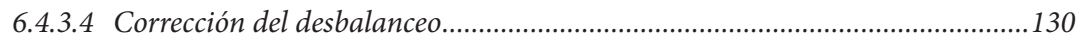

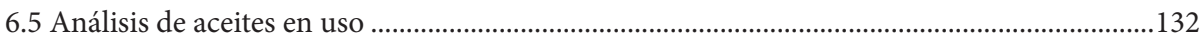

6.6 Un estudio de caso. Análisis de falla en rodamiento de motor eléctrico en ladrillera

(Cartago - Valle del cauca), con prueba combinada de balanceo y análisis

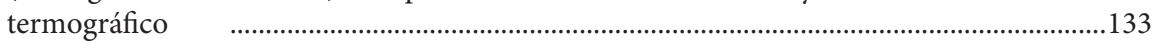

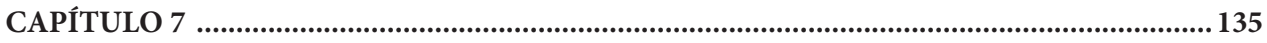

7 Apuntes sobre Mantenimiento Productivo Total TPM ................................................................. 137

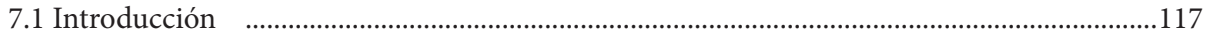

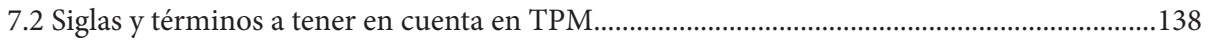

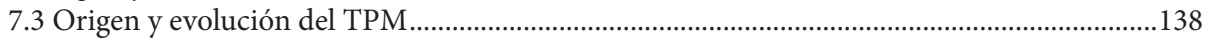

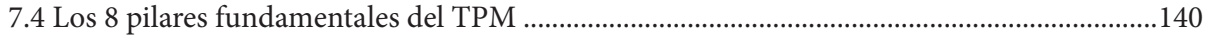

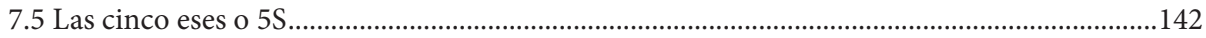

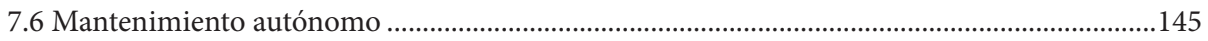

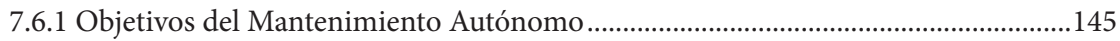

7.6.2 Pasos para la implementación del Mantenimiento Autónomo.....................................145

7.6.2.1 Limpieza inicial....................................................................................... 145

7.6.2.2 Eliminación de fuentes de contaminación y áreas inaccesibles..........................146

7.6.2.3 Inspección autónoma, desarrollando listas de verificación del

Mantenimiento Autónomo... 
7.6.2.4 Definir estándares para condiciones básicas e inspección general

7.6.2.5 Organización y Mantenimiento del lugar de trabajo, estandarizando los elementos del mismo.

7.6.2.6 Implementación del programa de Mantenimiento Autónomo,

desarrollando metas para la compañía......................................................................148

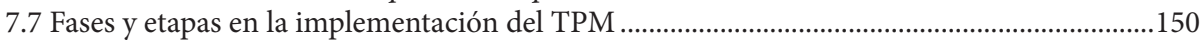

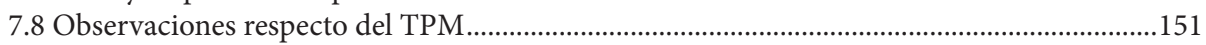

CAPÍTULO 8

8 Apuntes sobre Mantenimiento centrado en la confiabilidad RCM............................................ 155

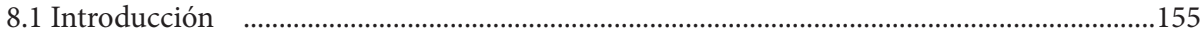

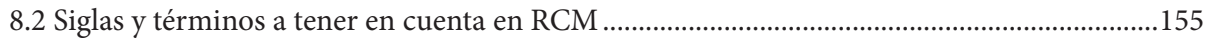

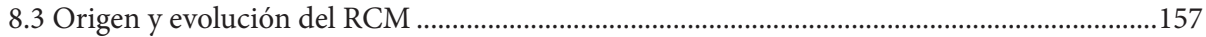

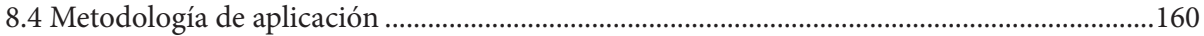

8.4.1 Efectuar un Análisis de criticidad CA ......................................................................160

8.4.2 Determinar la criticidad de los subsistemas ................................................................162

8.4.3 Toma de decisiones a partir de los análisis arrojados...................................................163

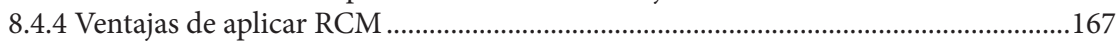

8.4.5 RCM y TPM como sistemas de Mantenimiento Complementarios ..........................167

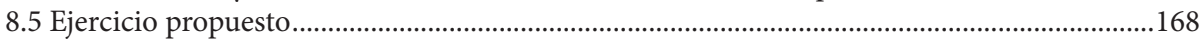

8.6 Caso de estudio. ejemplo de aplicación de RCM .........................................................................169

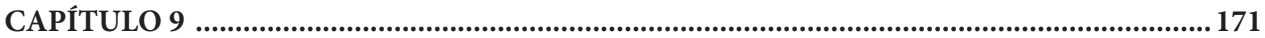

9 Apuntes sobre mantenimiento basado en el riesgo RBM............................................................. 173

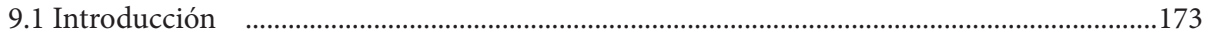

9.2 Algunos antecedentes del manejo del riesgo ..........................................................................173

9.2.1 Normatividad sobre riesgo en instalaciones industriales .......................................173

9.2.2 Algunos mega-accidentes previos a las convenciones ...............................................174

9.2.3 Algunas Premisas en RBM ........................................................................................178

9.3 Algunos términos y definiciones a tener en cuenta en RBM ..................................................178

9.4 Metodología general para la definición y aplicación de un plan de mantenimiento RBM ..179

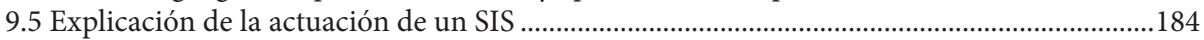

9.6 Algunas normas y estándares relacionados con prevención y manejo del riesgo ...................188

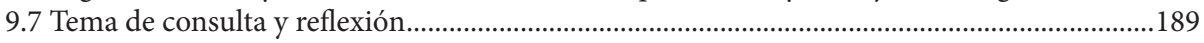

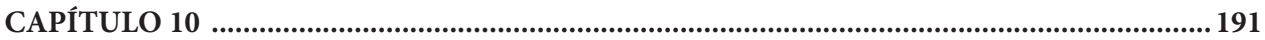

10 Selección de un modelo o política de Mantenimiento ................................................................ 193

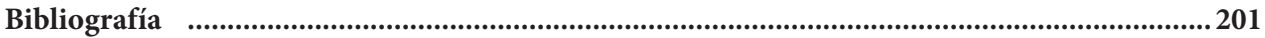

Anexo 1 Layouts o distribuciones en planta de producción.........................................................Web

Anexo 2 Conceptos básicos de mecanización y automatización ....................................................Web

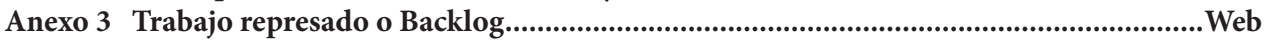

Anexo 4 Costeo básico de horas de labor de un empleado.....................................................Web

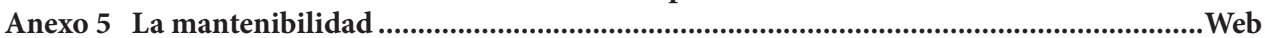

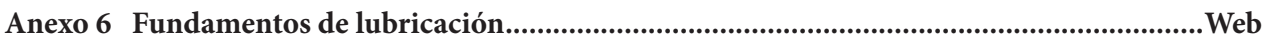

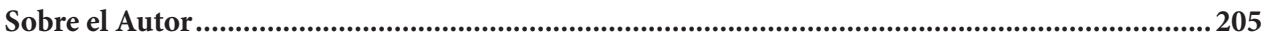

Nota 1. Todos los anexos se encuentran en el sitio web: http://carlos-montilla-utp.jimdo.com/ complementos-libro-de-mantenimiento/anexos/

Nota 2: El sitio web del autor es http://carlos-montilla-utp.jimdo.com/ 


\section{ILUSTRACIONES}

Figura 1 Sistema de control realimentado (feedback) .......................................................................21

Figura 2 Representación de la dinámica de un Sistema de Mantenimiento .......................................22

Figura 3 Esquema general de entradas y salidas de una máquina para producción..........................23

Figura 4 Comportamiento de los costos fijos, variables y totales de una empresa.............................27

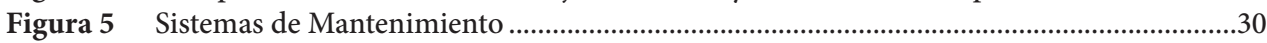

Figura 6 Ciclo gráfico del Mantenimiento Correctivo ........................................................................

Figura 7 Ciclo gráfico del Mantenimiento Programado ........................................................................32

Figura 8 Ciclo gráfico básico del Mantenimiento Preventivo.................................................................34

Figura 9 Ciclo gráfico del Mantenimiento Predictivo ............................................................................35

Figura 10 Esencia del Mantenimiento Basado en el Riesgo ...................................................................38

Figura 11 Evolución histórica del Mantenimiento................................................................................39

Figura 12 Indebido direccionamiento de la función Mantenimiento ....................................................40

Figura 13 Escala de trabajo del Mantenimiento en el TPM .................................................................41

Figura 14 Efectividad de los resultados en función del sistema o Tecnología de Mantenimiento empleada ...............................................................................................................................42

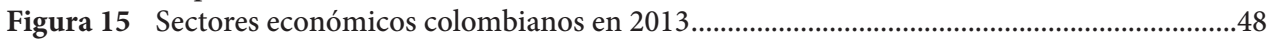

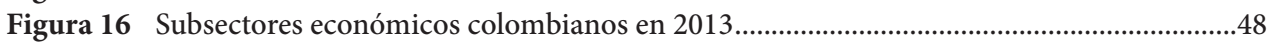

Figura 17 Ubicación del Depto en una empresa pequeña 1 .........................................................50

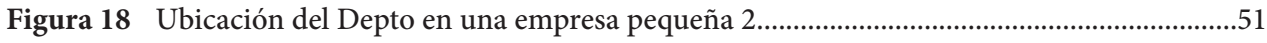

Figura 19 Ubicación del Depto en una empresa pequeña 3 ................................................................51

Figura 20 Ubicación del Depto en una empresa mediana ...................................................................51

Figura 21 Ubicación del Depto en una empresa grande 1 ................................................................52

Figura 22 Ubicación del Depto en una empresa grande 2 .................................................................52

Figura 23 Ubicación del Depto en una empresa grande 3 .................................................................52

Figura 24 Organigrama Depto de Mtto. Sistema formal centralizado .................................................53

Figura 25 Organigrama Depto de Mtto. Sistema formal descentralizado ...........................................53

Figura 26 Organigrama Depto de Mtto. Sistema formal descentralizado ............................................54

Figura 27 Ciclo gráfico del Mantenimiento Preventivo ....................................................................60

Figura 28 Ciclo gráfico del Mantenimiento Preventivo. (a) Aspecto de carga de Trabajo. (b) Aspecto económico ...................................................................................................................61

Figura 29 Directriz de codificación para una gran empresa ...............................................................64

Figura 30 Tarjeta Maestra de Datos de banda transportadora ................................................................66

Figura 31 Depósito y mirilla del nivel de aceite ......................................................................................69

Figura 32 Compresor alternativo de acople directo...............................................................................70

Figura 33 Orden de trabajo emitida por un CMMS .....................................................................77

Figura 34 Diagrama de flujo de administración de las órdenes de trabajo ..........................................81

Figura 35 Comportamiento de algunos patrones de falla ........................................................................86

Figura 36 Comportamiento ideal de la Carga de Trabajo de Mantenimiento CTM versus

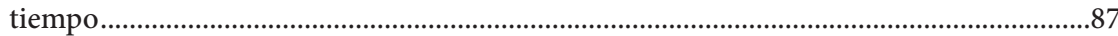

Figura 37 Diagrama de Pareto para fallas en salas de calderas.......................................................... 107

Figura 38 Diagrama de Ishikawa o Espina de pescado........................................................................ 109

Figura 39 Comportamiento esperado de una variable controlada en Mantenimiento Predictivo 
Figura 40 Espectro de longitudes de onda visibles por el ojo humano............................................. 117

Figura 41 Estructura genérica de un bolómetro .............................................................................. 117

Figura 42 Vista general de una cámara termográfica Wuhan Guide TP8S ....................................... 119

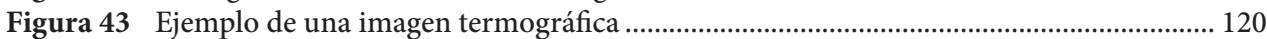

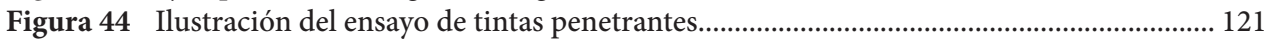

Figura 45 Resultado de prueba de tintas penetrantes a troquel ........................................................ 122

Figura 46 Desalineación angular y espectro de vibración asociado................................................. 123

Figura 47 Esquema de una pieza balanceada y una desbalanceada .................................................. 124

Figura 48 Excentricidad y espectro de vibración asociado .................................................................. 124

Figura 49 Excentricidad y espectro de vibración asociado ................................................................. 125

Figura 50 Bastidor de máquina/equipo con niveladores y empujadores.......................................... 126

Figura 51 Equipo para medición y análisis de vibraciones UTP...................................................... 128

Figura 52 Dinámica general de la medición y control de vibraciones............................................... 129

Figura 53 Comparación de los métodos de alineación...................................................................... 129

Figura 54 Equipo de alineamiento por el método de los comparadores invertidos......................... 130

Figura 55 Montaje en máquina balanceadora, para realizar balanceo en dos planos de un ventilador

Figura 56 Relación variedad de partes versus volumen de producción, en función del sistema de manufactura

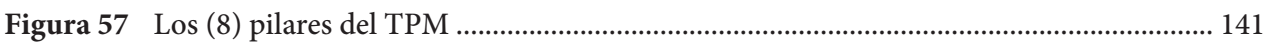

Figura 58 Proceso de clasificación de aceites, grasas, filtros y herramientas .................................... 142

Figura 59 El antes y el después al aplicar SEITON a un Taller de lubricación................................. 143

Figura 60 Ejemplo de aplicación de SEITON para organizar repuestos............................................ 143

Figura 61 El antes y el después al aplicar SEISO a un Taller de lubricación ...................................... 144

Figura 62 Aplicación de SHITSUKE en un taller de lubricación ...................................................... 144

Figura 63 Aplicación inicial y continuidad de Limpieza..................................................................... 146

Figura 64 Contra-ejemplo de no eliminación de fuentes de contaminación y conservación

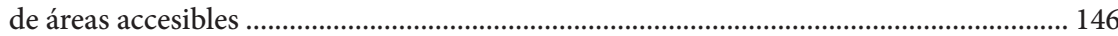

Figura 65 Ejemplo un estándar de mantenimiento en una industria alimenticia ............................ 147

Figura 66 Ejemplos de inspección autónoma ............................................................................. 148

Figura 67 Ejemplos de uso de cuadros de sombra para la organización del lugar de trabajo......... 148

Figura 68 Ejemplo de implementación del mantenimiento autónomo .............................................. 149

Figura 69 Ejemplo de implementación del mantenimiento autónomo.............................................. 149

Figura 70 Ejemplo de comunicación visual de indicadores y metas en Mantenimiento

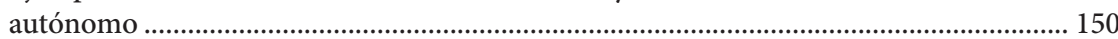

Figura 71 Cadena de razonamiento RCM ........................................................................................ 166

Figura 72 Sistema de producción de panela utilizando vapor ............................................................ 169

Figura 73 Intentos fallidos de contener el derrame de petróleo del Exxon Valdez .......................... 174

Figura 74 Limpieza de las orillas de Prince William Sound ............................................................ 175

Figura 75 Esquema general de accidente en la Planta Union Carbide ............................................ 176

Figura 76 Nube tóxica de MIC sobre Bhopal. .................................................................................. 176

Figura 77 Imagen aérea de la planta de Chernóbil, posterior a la explosión ..................................... 177

Figura 78 Imagen del sarcófago que actualmente se construye, para contener la radiación del

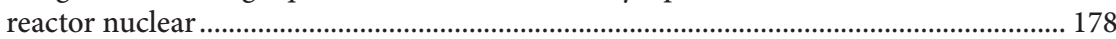

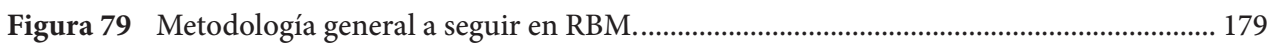

Figura 80 Diagrama de flujo para la Estimación del riesgo ............................................................. 180

Figura 81 Diagrama de flujo para la Evaluación del Riesgo............................................................. 181

Figura 82 Diagrama de flujo para la Planeación del Mantenimiento ............................................... 182 
Figura 83 Esquema de ¿Cómo reducir el riesgo a un nivel aceptable? .............................................. 183

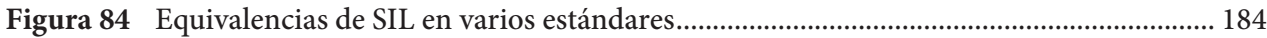

Figura 85 Planta de proceso a controlar....................................................................................... 185

Figura 86 Esquema general sistema de control realimentado o feedback........................................ 185

Figura 87 Sistema de control feedback para el tanque de la figura 85 ............................................ 186

Figura 88 Sistema de control feedback real para tanque de la Figura 85......................................... 186

Figura 89 Planta de proceso protegida por un SIS .................................................................... 187

Figura 90 Niveles de protección antes que ocurra la catástrofe......................................................... 188

Figura 91 Elección de un Modelo de Mantenimiento ....................................................................... 197 


\section{TABLAS}

Tabla 1 Estructura de costos de una micro-empresa ..........................................................................28

Tabla 2 Actividades básicas del Mantenimiento..........................................................................29

Tabla 3 Ventajas y desventajas del Mantenimiento Correctivo ......................................................32

Tabla 4 Ventajas y desventajas del Mantenimiento Programado .........................................................33

Tabla 5 Ventajas y desventajas del Mantenimiento Preventivo .......................................................34

Tabla 6 Ventajas y desventajas del Mantenimiento Predictivo ................................................... 36

Tabla 7 Algunas estadísticas de empresas colombianas, de acuerdo a su tamaño...........................49

Tabla 8 Actividades generales desarrolladas por un Ingeniero/Tecnólogo de Mantenimiento ....55

Tabla 9 Modelo básico de Historial de Mantenimiento......................................................................68

Tabla 10 Listado de requerimientos para compresor de pistón.............................................................70

Tabla 11 Tablero de control diario ...................................................................................................

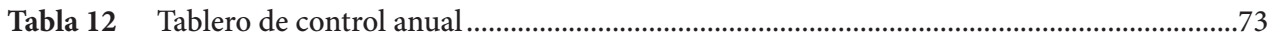

Tabla 13 Fragmento de tablero de control por horas reales trabajadas .............................................74

Tabla 14 Formato básico para control de tareas de Mantenimiento rutinario ...................................76

Tabla 15 Formato básico para control ejecución de OT .................................................................78

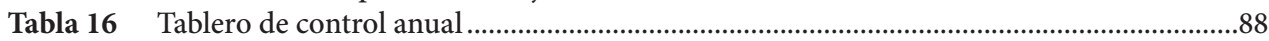

Tabla $17 \%$ CDM versus Costo operativo total, según el subsector económico ................................90

Tabla 18 Indicadores de eficacia del Mantenimiento ..........................................................................98

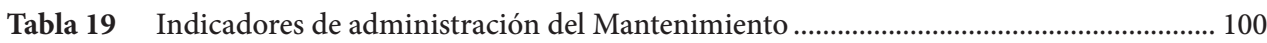

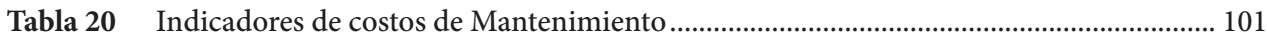

Tabla 21 Cuadro para control de partes de desgaste......................................................................... 104

Tabla 22 Cuadro para control de consumo de combustibles ........................................................ 105

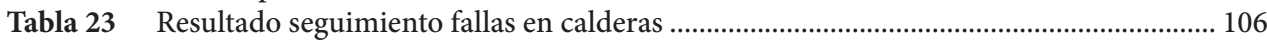

Tabla 24 Categorización y cálculo de porcentajes acumulativos ...................................................... 107

Tabla 25 Tipos de fallas y frecuencias para refrigeradores........................................................ 111

Tabla 26 Fuentes de vibración en maquinaria y estructuras ............................................................ 122

Tabla 27 Criterio provisional de vibración para un grupo específico de máquinas

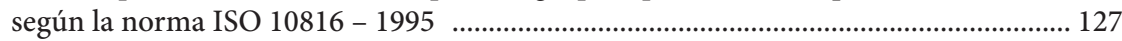

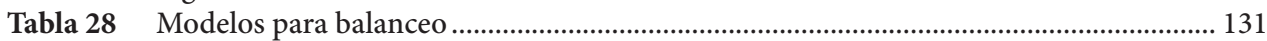

Tabla 29 Fases y etapas para la implementación del TPM en una organización ............................ 151

Tabla 30 Patrones de falla de componentes de la industria aeronáutica de EE. UU....................... 159

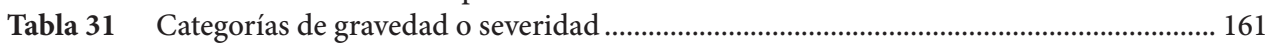

Tabla 32 Categorías de probabilidad de ocurrencia......................................................................... 162

Tabla 33 Valores recomendados para la evaluación de NPR .......................................................... 164

Tabla 34 Valores estandarizados de SIL y características asociadas .............................................. 183

Tabla 35 Panorama de los modelos de Mantenimiento ..................................................................... 198

Tabla 36 Modelos de Mantenimiento y sistemas de mantenimiento .............................................. 199 


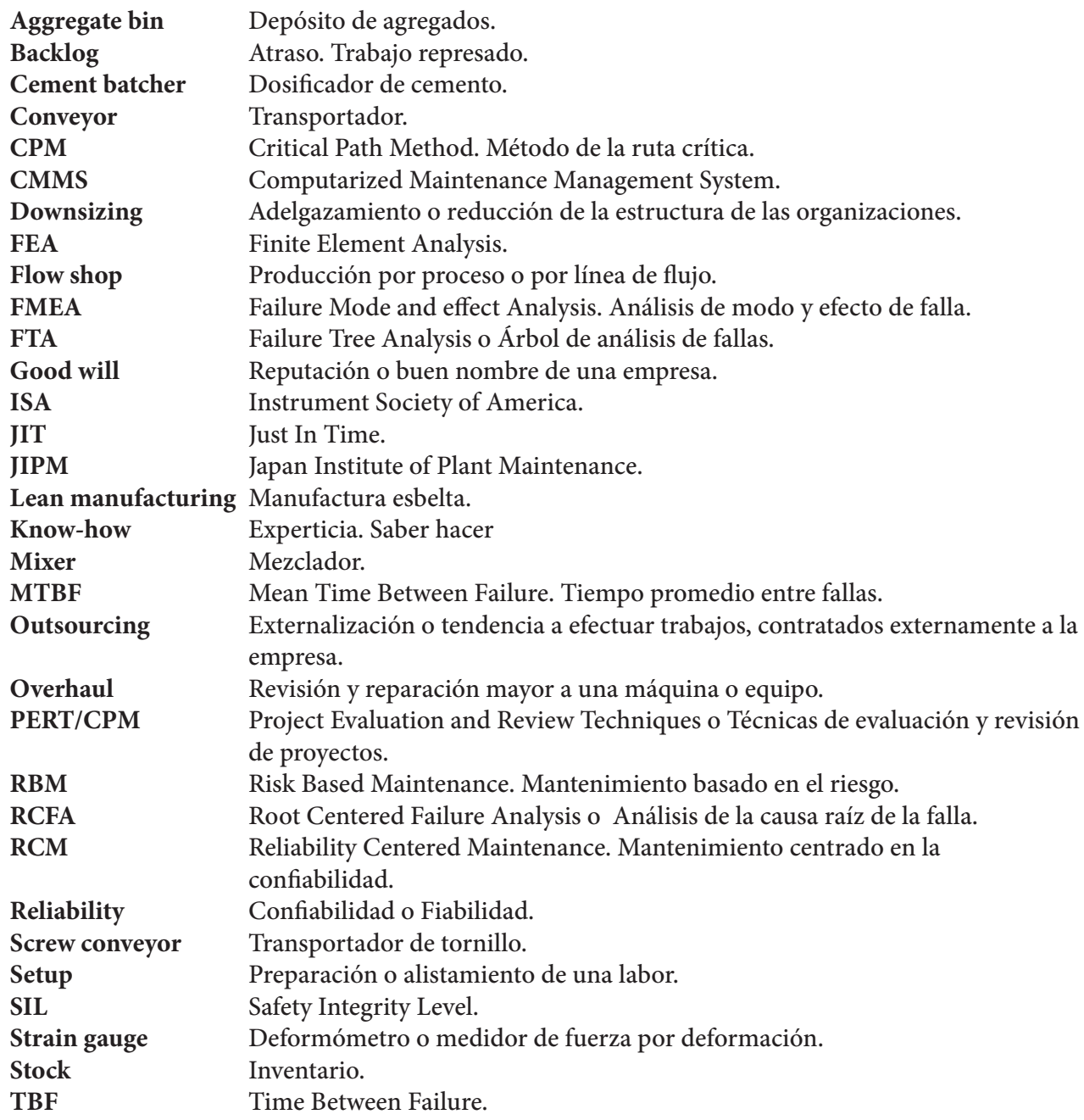



Capítulo 1 



\section{Nociones introductorias}

\subsection{Introducción}

El Mantenimiento es una disciplina que soporta constantemente el desenvolvimiento de los sistemas productivos modernos. Su aplicación mínima comienza con tareas tan sencillas como orden, aseo, lubricación básica y ajustes menores, pasando paulatinamente a niveles más avanzados como rutas de inspección y lubricación, mediciones puntuales con instrumentos especializados y mediciones totales u online, con sistemas de adquisición de datos, todo ello acompañado de procesos técnicoadministrativos, soportados cada vez más por las tecnologías de la informática y las telecomunicaciones TIC.

\subsection{Definiciones básicas}

Las definiciones que se presentan a continuación pretenden dar un referente común a lo largo del presente libro, y dependiendo del contexto o autor, pueden darse a diferentes interpretaciones. Es necesario tener en cuenta que las definiciones han sido presentadas en los contextos de producción o fabricación y del mantenimiento. La pluriculturalidad conlleva a que en los ámbitos no académicos se utilice de manera indistinta ( $\mathrm{y}$ a veces errónea) un término $\mathrm{u}$ otro.

\subsubsection{Máquina y equipo}

\subsubsection{Máquina.}

Conjunto de elementos móviles y fijos, cuyo funcionamiento posibilita aprovechar, dirigir, regular o transformar energía, o realizar un trabajo con un fin determinado. Regularmente en el ámbito industrial se asume que una máquina entrega algún tipo de producto tangible, es decir, transforma una materia prima en una pieza verde, o una pieza verde en un producto semi-terminado o terminado. Ejemplos: tornos, fresadoras, máquina de corte con láser, etc. 


\subsubsection{Equipo.}

Colección de utensilios, instrumentos y aparatos especiales para un fin determinado (por ejemplo, "equipo quirúrgico", "equipo de salvamento", etc.). También recibe el nombre de equipo cada uno de los elementos de dicho conjunto. Regularmente en el ámbito industrial se asume que un equipo presta un servicio, o modifica las propiedades de la materia prima/ pieza verde/producto semi o terminado que transite por él. Ejemplos: equipos de ventilación, de aire acondicionado, de cómputo, para temple de piezas, etc.

\subsubsection{Fallas y estados asociados}

\subsubsection{Falla.}

Toda condición que afecta la operación normal de una máquina/equipo.

\section{Falla funcional.}

Tipo de falla que impide que una máquina/equipo continúe en operación (ocurre avería mayor).

Falla potencial. Tipo de falla que no inhabilita a la máquina/equipo para que opere, pero en determinado momento propicia las condiciones para que ocurra una varada. En otras palabras, una falla potencial es una falla funcional en gestación.

\subsubsection{Estados de una máquina/equipo}

Estado teórico o nominal de una máquina/equipo. Aquella condición operativa y de funcionamiento que debe poseer una máquina/equipo cuando sale de fábrica; el estado teórico debe ser redefinido en la medida que el equipo haya trabajado $\mathrm{x}$ cantidad de tiempo, debido a que sufre una degradación normal que aleja su nivel de rendimiento del inicial, en este caso se habla de estado nominal.

Estado real de una máquina/equipo. Aquel estado que exhibe la máquina/equipo en cualquier momento de su operación. El estado real puede coincidir o no, con los estados teórico y nominal.

\subsubsection{Mantenimiento}

Definición 1. Es mantener un ítem de producción en condiciones óptimas o hacer que recupere esa característica. Disciplina inherente a la producción y no se puede concebir aparte de ella [1].

Definición 2. Parte de la Ingeniería que con su acción ayuda a la conservación de los elementos de una empresa, sea cual fuere, además haciendo mínimas las fallas inesperadas con lo cual se obtendrá más economía, seguridad y eficiencia dentro de la empresa.

Definición 3. Conjunto de recursos físicos (tierra, capital, equipos), recursos humanos, tecnología e información, que acoplados buscan mejorar la eficiencia del sistema de producción disminuyendo los paros, aumentando la confiabilidad del equipo y garantizando la seguridad y un nivel de costos rentable; todo ello dentro del marco del desarrollo propio de la empresa y del país [2]. 
Definición 4. Conjunto de actividades (planificadas y coordinadas) que propende a mantener los equipos (de diversa índole), en una condición operativa, lo más cercana posible de su estado teórico o nominal, con el mínimo de inversión (económica, tiempo, insumos), de manera segura para el personal y el medio ambiente, apoyando de manera positiva el cumplimiento de las metas de una organización [3].

De las definiciones anteriores, se pueden puntualizar varios asuntos:

- El Mantenimiento no es una actividad estática que se planee y se ejecute de manera indefinida, por el contrario, es una actividad dinámica que permanentemente amerita revisiones, cambios y mejoras.

- El Mantenimiento es inherente a la producción.

- Es transversal a todas las dependencias de una compañía.

La dinámica del Mantenimiento puede ser representada de manera análoga a la forma como opera un lazo de control realimentado (feedback), tal como se muestra en las figuras 1 y 2.

Figura 1. Sistema de control realimentado (feedback) [el Autor]

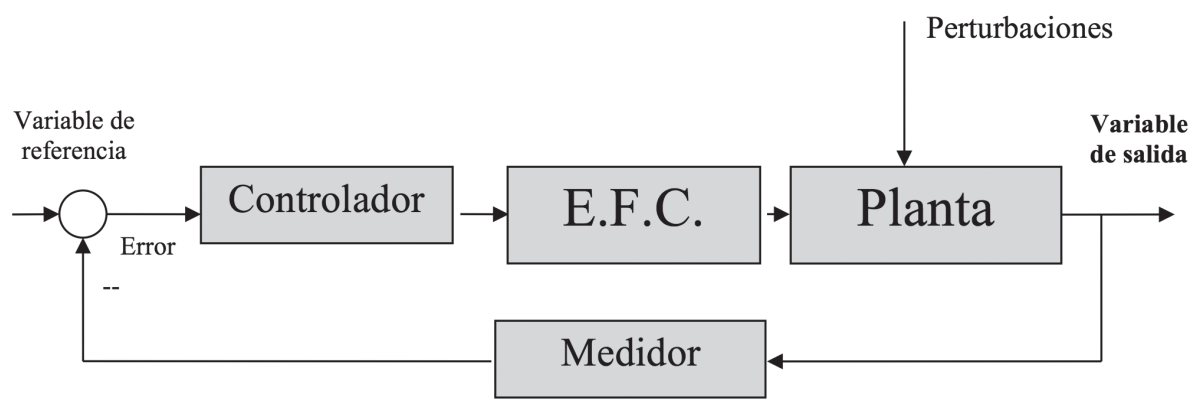

La figura 1 recuerda que un sistema de control realimentado se plantea para mantener en el tiempo una variable de operación o variable de salida de una planta dentro de un margen considerado como "aceptable". Para tal fin un medidor o sensor constantemente captura el valor de la variable de operación y la envía a distancia a un elemento comparador. El comparador realiza una resta entre un valor fijado como aceptable, llamado variable de referencia o set point y el valor actual de la variable de salida, dicha diferencia recibe el nombre de error. La señal de error es tomada por un controlador, el cual genera una acción correctora y la envía a un elemento final de control E.F.C. o actuador (válvula, motor, cilindro, etc.), el cual adiciona o retira energía de la planta con el fin de minimizar el error. Sobre la planta real actúan las inevitables entradas indeseables o perturbaciones, cuyo efecto debe ser minimizado por el sistema de control.

La figura 2 ilustra cómo las consideraciones anteriores se pueden hacer extensivas (en una relación uno a uno) a la operación de un Departamento de Mantenimiento de una empresa, cuyo objetivo fundamental es que el estado real de un equipo/proceso en el tiempo se asemeje a una condición nominal o teórica (regularmente fijada por el fabricante o proveedor). Para tal fin se dispone de una infraestructura en la cual, vía construcción de reportes e indicadores y/o de instrumentación, se determina el estado real del equipo y se compara contra la condición nominal o teórica y fruto de 
dicha comparación regularmente aparecen diferencias. Con base en las diferencias se deben llevar cabo labores de planeación (estrategias, costos, personal, etc.), las cuales se deben llevar al día a día por intermedio de una programación y ejecución de actividades (limpieza, orden, lubricación, cambios, etc.), acompañadas de sus respectivos imprevistos.

En la medida que pasa el tiempo de uso del equipo/proceso, y al margen de la consecuente obsolescencia, inevitablemente se introducirán desajustes y desgastes en él, con lo cual los consumos de energéticos, las velocidades de operación, la calidad de la producción y su estado operativo (ruidos, humos, gases, etc.) desmejorarán, mientras que la cantidad y profundidad de las intervenciones de mantenimiento aumentarán, haciendo necesario replantear el estado nominal y las tareas de planeación, programación y ejecución subsecuentes; a estas situaciones hace alusión el comportamiento dinámico del mantenimiento (similar al del sistema de control Feedback).

En Mantenimiento las tareas de planeación, programación, ejecución, construcción de indicadores y comparación, son actividades técnico-administrativas que requieren de una permanente gestión para que los resultados sean satisfactorios y sostenibles en el tiempo.

Figura 2. Representación de la dinámica de un Sistema de Mantenimiento [el Autor]

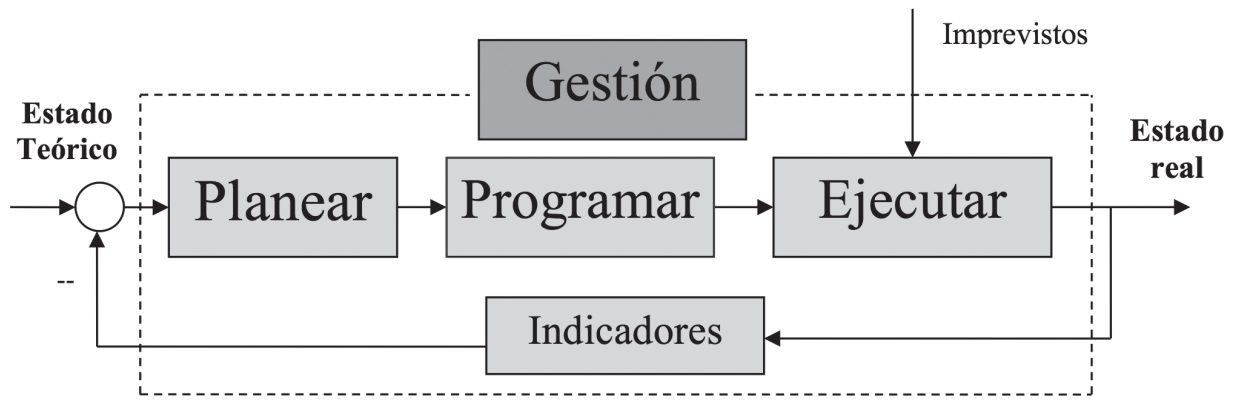

El Mantenimiento en una disciplina transversal al quehacer humano y su aplicación es muy amplia, tocando campos tan diversos como:

- Edificaciones

- Vías terrestres de comunicación

- Electrodomésticos

- Instalaciones eléctricas domiciliarias e industriales

- Maquinaria industrial

- Vehículos de la industria del transporte terrestre de carga y pasajeros

- Maquinaria agrícola

- Equipo de minería y de transporte fuera de carretera

- Agroindustria

- Equipos de informática y telecomunicaciones

- Navegación marítima, aérea y espacial

- Todo tipo de máquinas y artefactos militares 
Ejemplo para aclarar algunas definiciones básicas

En el hipervínculo http://carlos-montilla-utp.jimdo.com/complementos-libro-demantenimiento/complementos-capitulo-1/ se presenta este Ejemplo.

\subsection{Objetivos básicos del mantenimiento}

Una de las conclusiones del análisis de las definiciones tratadas en el numeral 1.2.1 dice "El Mantenimiento es inherente a la producción", por lo se considera pertinente recordar la definición de empresa y recordar brevemente las entradas y salidas de una máquina, antes de formular los objetivos del Mantenimiento.

Empresa: Actividad organizada, apoyada por recursos físicos, humanos y financieros, con el fin de fabricar productos, proveer servicios y generar utilidades para los accionistas. Para una empresa de producción, una máquina o equipo productivo puede ser esquematizada acorde a lo mostrado en la figura 3.

Figura 3. Esquema de entradas y salidas de una máquina para producción [el Autor]

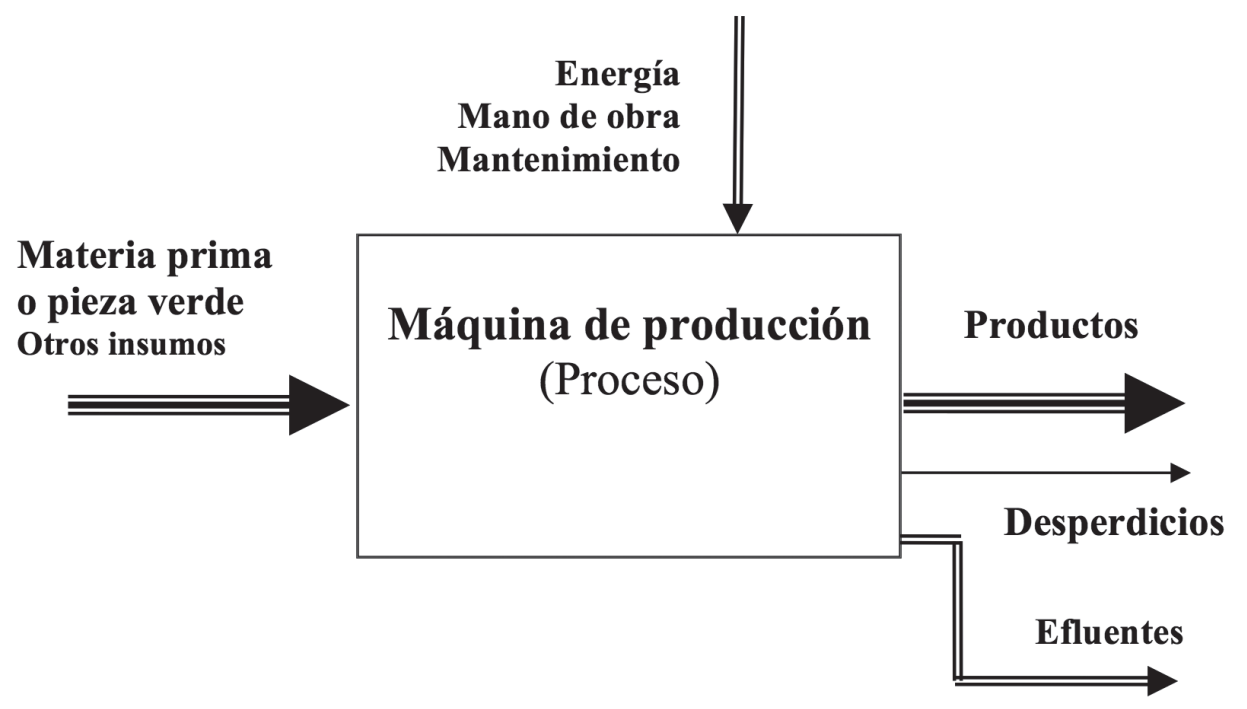

Mediante la adición de energía, mano de obra, repuestos, mantenimiento y otros insumos, la materia prima se transforma en productos y regularmente quedan unos desperdicios (retales). Los efluentes son diferentes de los desperdicios, generalmente se constituyen en contaminantes, como humos de combustión, gases, vapores, aguas calientes o con químicos, ruido, etc.

Con base en los planteamientos anteriores debe haber claridad en que Mantenimiento es una disciplina que debe entrar a apoyar el cumplimiento de los logros de una empresa, mediante el cumplimiento de los objetivos propuestos a continuación. 


\subsubsection{Minimizar las fallas funcionales (paradas imprevistas) de los equipos, y los costos asociados a ellas}

Las máquinas y equipos están diseñados para proveer una rata o tasa de producción $\left(\mathrm{m}^{3} / \mathrm{h}\right.$, ton $/ \mathrm{h}$, piezas/h, etc.). La producción puede ser discreta, continua o una combinación de ellas. Discreta cuando se producen lotes de piezas o partes de piezas (ejemplo, ensambladora de motocicletas, inyectora de plástico). Continua cuando la producción se materializa en flujo de masa o flujo volumétrico (ejemplo la producción en barriles día de una refinería de petróleo, los $\mathrm{m}^{3} /$ día tratados en una planta de tratamiento de agua). Los efectos y consecuencias de la ocurrencia de una falla funcional dependen de la distribución de planta o layout de planta (ver Anexo 1).

Algunos de los efectos y consecuencias que acarrea una falla funcional son:

- Detención de la producción

- Pérdidas de materia prima y producto en proceso

- Defectos de calidad

- Riesgo de accidente laboral

- Riesgo de daño al medio ambiente

- Incremento de gastos por repuestos y mano de obra de mantenimiento correctivo de emergencia (que regularmente son mayores si la reparación se hubiese hecho a tiempo)

- Incumplimiento a los clientes

- Lucro cesante durante el tiempo que demora la reparación de la planta

- Incremento del consumo de energía en el re-arranque una vez terminada la reparación

- Horas extras de personal de producción para culminar los pedidos

- Pérdida de productividad por desmotivación del personal

- Afectación al buen nombre (Good will) de la empresa

\subsubsection{Asegurar unos costos operativos razonables de los equipos, y procurar mejoras de ellos}

Los costos de operación CO (fórmula 1) son aquellos en que se incurre cuando se hace uso de la máquina/equipo para producir un bien o servicio.

$$
C O=C_{c o}+C_{l u}+C M+C_{r m}+C_{p d}
$$

Donde

CO Es el costo de operación de una máquina/equipo.

$C_{c o} \quad$ Es el costo de los combustibles necesarios para la operación de la máquina (electricidad, gas, gasolina, ACPM, bagazo de caña, etc.).

$C_{l u} \quad$ Es el costo asociado a la lubricación (aceites, grasas y filtros).

CM Es el costo de las labores rutinarias de Mantenimiento. Incluye mano de obra, repuestos (partes de recambio), herramientas y equipos para tal propósito. 
$\boldsymbol{C}_{\boldsymbol{r} m}$ Es el costo de las reparaciones mayores no rutinarias (overhaul), por ejemplo reparaciones anuales; también comprende las modificaciones del equipo, incluyendo mano de obra, repuestos, herramienta y equipo necesarios para tal propósito.

$\boldsymbol{C}_{\boldsymbol{p}} \quad$ Es el costo de las partes de desgaste, es decir las partes que entran en contacto con la materia prima, pieza verde o producto semi-terminado e inevitablemente van a perder peso, forma, tamaño, etc. Ejemplos: cuerpos moledores, troqueles, cuchillas de corte, llantas, pastillas para frenos, etc.

\section{¿Cómo ayuda Mantenimiento a cumplir con costos de operación razonables?}

- Asesorando al personal que opera el equipo, para que apliquen "buenas prácticas de manufactura", acorde a recomendaciones de fabricante, a las experiencias adquiridas de máquinas similares en la propia compañía o en otras del ramo.

- Haciendo seguimiento y analizando las causas de las variaciones en los consumos de combustibles, lubricantes, filtros, análisis a aceites en uso, e implementando acciones correctivas cuando se detecten desviaciones sensibles.

- De manera conjunta con los Departamentos de producción, fijando estándares de rendimiento de las partes de recambio y desgaste, bajo condiciones predeterminadas.

- Haciendo seguimiento y analizando las causas de las variaciones en los rendimientos de partes de recambio y desgaste, e implementando acciones correctivas cuando se detecten desviaciones sensibles.

Es necesario tener en cuenta que una empresa que tenga control de sus costos y gastos debe manejar Indicadores o referentes que le permitan determinar si la situación está bajo control o se está desviando del debiera.

Los indicadores se tratarán adecuadamente en el Capítulo 5, pero a modo de ejemplo, algunos de ellos son:

- Costo Mantenimiento/unidad producida

- Costo combustible/unidad producida

- Unidades producidas/entre reafilados de un troquel

\subsubsection{Maximizar la inversión en planta y equipos, asegurando el cumplimiento de mínimo su vida útil esperada}

Para comprender este objetivo es necesario hablar del Costo de Posesión CP (fórmula 2), es decir el costo en que se incurre por el sólo hecho de adquirir la máquina/equipo, así opere o no. 
Donde

$C P \quad$ Es el costo de posesión de una máquina/equipo.

$V R N$ Es el valor de reposición o nuevo; es el costo del equipo al momento de la adquisición o el costo de reponer el equipo una vez que llegó al final de su vida útil. Nota: Vida útil es la duración o rendimiento que puede alcanzar una máquina, equipo u objeto, cumpliendo correctamente con la función para la cual ha sido creado.

$D P \quad$ Es la depreciación o reducción paulatina de valor que sufre una máquina debido al deterioro normal que sufre durante su operación. Regularmente la depreciación está asociada a la vida útil. Existen modelos de Ingeniería económica para la DP, de ellos se destacan los modelos de depreciación constante y de depreciación variable.

SI Es el valor de las pólizas de seguros de toda índole e impuestos que se deben pagar por la posesión del equipo. Estos seguros no deben confundirse con la seguridad social.

Cuando una Compañía adquiere una máquina/equipo se hace una proyección de costos tomando como referencia una cierta vida útil de $\mathrm{n}$ años, operando a una cierta rata de producción, con unos determinados $\mathrm{CO}$ y adicionalmente en cada período contable se debe provisionar la fracción respectiva de VRN. Se espera que al finalizar la vida útil la inversión hecha en la máquina/equipo debe haber retornado completamente y debe estar disponible el dinero para comprar la máquina de reemplazo.

En el contexto anterior pueden suceder varias situaciones:

- Operando a una rata de producción normal, y con una buena política de Mantenimiento la máquina/equipo complete su vida útil de n años. Este es el "debiera".

- Operando a una rata de producción normal, y con una mala política de Mantenimiento la máquina/equipo no alcance a completar su vida útil. Esta es la situación que debe evitarse.

- Operando a una rata de producción normal, y con una buena política de Mantenimiento la máquina/equipo complete su vida útil de $\mathrm{n}$ años, $\mathrm{y}$ aun presente unos costos de operación bajos. Ésta sería una situación ideal, ya que contablemente el equipo vale cero, se encuentra en condiciones disponible y aun se puede percibir ingresos con su uso.

- Si el deterioro de la máquina/equipo por mal mantenimiento o mal uso es muy elevado, se debe evaluar conjuntamente con la división financiera de la compañía el costo de llevar el equipo a un nivel cercano al nominal (overhaul) y decidir si justifica económicamente la inversión, o si es mejor dar de baja al equipo.

A partir de los costos y posesión se extrae el Costo de Operación y Posesión COP (fórmula 3).

$$
C O P=C O+C P
$$


Una forma alterna y complementaria de visualizar la fórmula 3 empleada por algunas empresas, es manejar una estructura de costos conformada por Costos fijos $C F$ y Costos variables $C V$. Los costos fijos CF corresponden a pagos que deben efectuarse así la empresa produzca o no produzca, por ejemplo arrendamientos, nómina administrativa y operativa del personal de planta, vigilancia, impuestos, etc. Los costos variables CV son aquellos cuyo monto depende de que haya mayor o menor producción, por ejemplo materia prima, combustibles, horas extras, nómina de personal temporal, etc. La figura 4 ilustra el comportamiento de CV y CF, los cuales se suman para conformar los Costos Totales CT.

De la figura 4 fácilmente se puede inferir que lo ideal en una empresa es que los costos fijos fuesen cero, es decir que el costo total solo estuviera conformado por costos variables. Esta situación es por supuesto muy difícil de alcanzar en la realidad, pero los gerentes y administradores de Mantenimiento deben tenerla como un ideal y direccionar su gestión en ese sentido.

Es conveniente recordar además que solo en el momento que la Curva de Ingresos corte la curva de Costos Totales CT, de allí en adelante será rentable la operación de la empresa; a este punto en particular se le denomina punto de equilibrio P. E., y es función de los gerentes y administradores determinar su valor, para la situación particular de cada empresa.

Figura 4. Comportamiento de los costos fijos, variables y totales de una empresa [el Autor]
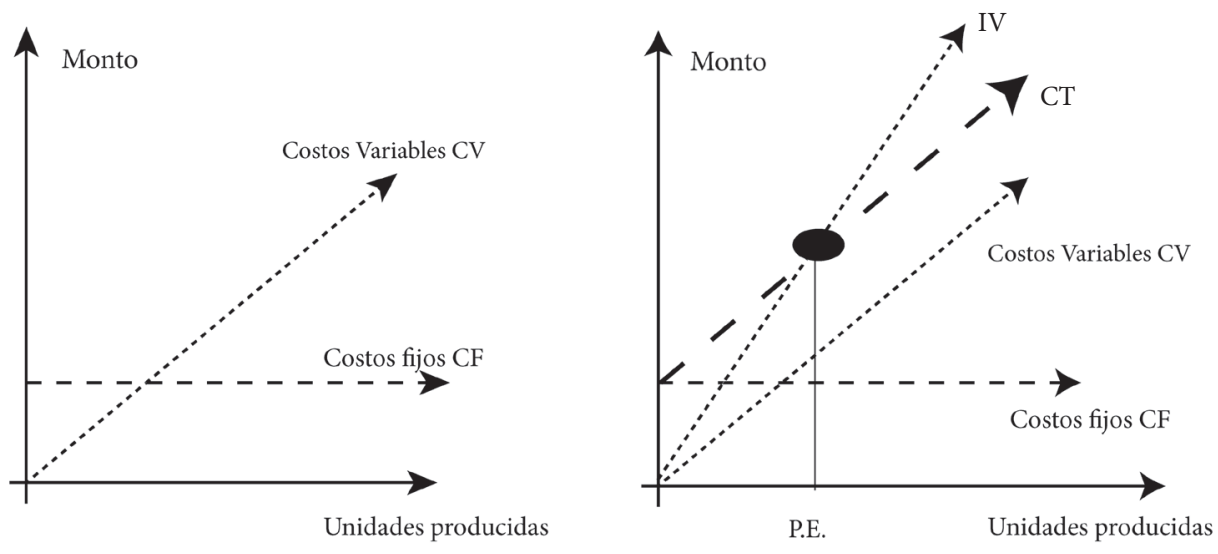

Por último en este breve panorama de costos, la Tabla 1 muestra una estructura de costos de una microempresa, la cual en el mes en estudio está dando pérdida. A título de ejercicio se le plantea al lector el ejercicio de identificar en la Tabla 1 los rubros correspondientes a Costos de Operación, Costos de Posesión, e identificar algunas medidas que ayudarían a la empresa a salir del estado temporal de pérdida.

\subsubsection{Asegurar que los equipos operen de manera segura para los usuarios y para el medio ambiente}

No sólo se debe asegurar que los equipos operen, sino que además deben operar de manera segura para los usuarios y evitando arrojar efluentes que sobrepasen los límites permitidos por las autoridades ambientales, en cuyo caso se generan multas y sanciones para la empresa, que pueden llevar a su cierre. 
Mantenimiento debe tener en cuenta las señas de normas ambientales (ISO 14000) y las de Seguridad Industrial y Salud Ocupacional (OHSAS 18000) durante sus diferentes labores, de forma tal que se garantice la integridad física, mental y emocional de sus colaboradores, y adicionalmente se preserve el medio ambiente.

Tabla 1. Estructura de costos de una microempresa [el Autor]

\begin{tabular}{|lcc|}
\hline Ingresos & $\$$ & 10000000 \\
Unidades producidas & & 1000 \\
Costo promedio de venta & $\$$ & $10,000.00$ \\
\hline
\end{tabular}

\begin{tabular}{|c|c|c|c|}
\hline \multicolumn{2}{|c|}{1 Costos fijos (miles) } & \multicolumn{2}{|r|}{ Aquellos que se pagan haya o no haya producción } \\
\hline 1.1 & Capacidad instalada & & \\
\hline & Arrendamientos & $\$$ & 600000 \\
\hline & Depreciación & $\$$ & 500000 \\
\hline & Leasing y amortizaciones & $\$$ & 300000 \\
\hline \multirow[t]{7}{*}{1.2} & Operación & & \\
\hline & Fijo Energía eléctrica & $\$$ & 100000 \\
\hline & Fijo Agua & $\$$ & 100000 \\
\hline & Seguros a la propiedad & $\$$ & 300000 \\
\hline & Impuestos a la propiedad & $\$$ & 100000 \\
\hline & Vigilancia & $\$$ & 1500000 \\
\hline & Nómina corporativa & $\$$ & 1500000 \\
\hline \multirow[t]{4}{*}{1.3} & Programados & $\$$ & - \\
\hline & Publicidad & $\$$ & 100000 \\
\hline & Inversiones & $\$$ & 300000 \\
\hline & Total costos fijos & $\$$ & 5400000 \\
\hline & Costo marginal & $\$$ & 5400 \\
\hline
\end{tabular}

\section{Costos variables (unitario)}

Aquellos que varían en función de la producción

\begin{tabular}{|c|c|c|c|c|c|}
\hline \multirow[b]{2}{*}{2.1} & \multirow[b]{2}{*}{ Materia prima } & \multicolumn{2}{|c|}{ (\$/unidad producida) } & \multicolumn{2}{|c|}{ Total (millones) } \\
\hline & & $\$$ & 3000 & $\$$ & 3000000 \\
\hline 2.2 & Mantenimiento & $\$$ & 600 & $\$$ & 600000 \\
\hline 2.3 & Nómina de producción & $\$$ & 2000 & $\$$ & 2000000 \\
\hline 2.4 & Otros materiales producción & $\$$ & 100 & $\$$ & 100000 \\
\hline 2.5 & Energía eléctrica producción & $\$$ & 150 & $\$$ & 150000 \\
\hline \multirow[t]{3}{*}{2.6} & Agua producción & $\$$ & 120 & $\$$ & 120000 \\
\hline & Total costos variables & $\$$ & 5970 & & \\
\hline & & & & $\$$ & 5970000 \\
\hline
\end{tabular}




\subsection{Acciones básicas del Mantenimiento}

Por compleja que sea la estructura de Mantenimiento en una organización, su operación como Departamento siempre podrá fraccionarse en acciones básicas como las mostradas en la Tabla 2. Cabe señalar que las actividades están fraccionadas acorde con la estructura dinámica propuesta previamente en la figura 2 (Numeral 1.2.3).

Tabla 2. Actividades básicas del Mantenimiento [el Autor]

\begin{tabular}{|c|c|c|}
\hline Tipo de actividad & Actividad & Acción básica \\
\hline \multirow[t]{4}{*}{ Administrativa } & Planear & Elección de los sistemas de Mantenimiento a seguir \\
\hline & & Elaborar presupuestos generales \\
\hline & & Recomendar cambio máquinas/equipos \\
\hline & & Seleccionar máquinas/equipos \\
\hline \multirow[t]{5}{*}{ Administrativa } & Programar & Cronograma actividades \\
\hline & & Instrucción actividad \\
\hline & & Insumos, repuestos, herramientas \\
\hline & & Personal ejecutante \\
\hline & & Tiempo de ejecución \\
\hline \multirow[t]{9}{*}{ Operativa } & Ejecutar & Instalar \\
\hline & & Poner a punto (ajustar) \\
\hline & & Calibrar \\
\hline & & Inspeccionar \\
\hline & & Limpiar \\
\hline & & Lubricar \\
\hline & & Cambiar \\
\hline & & Reparar \\
\hline & & Modificar \\
\hline Operativa & Medir & Recolectar y procesar información de campo \\
\hline Administrativa & & Elaborar indicadores \\
\hline Administrativa & & Registrar actividades desarrolladas \\
\hline Administrativa & Controlar & $\begin{array}{l}\text { Comparar resultados obtenidos versus lo planeado, y } \\
\text { tomar decisiones (revisar y ajustar los planes) }\end{array}$ \\
\hline
\end{tabular}




\subsection{Sistemas de Mantenimiento}

Existen unas metodologías o estrategias generales que adoptan las empresas para administrar y ejecutar el Mantenimiento, las cuales pueden ser tan simples como el no hacer (Mantenimiento Correctivo) hasta las más modernas como el Mantenimiento Basado en el Riesgo MBR. En la figura 5 se presenta un panorama gráfico de dichos sistemas, los cuales serán descritos seguidamente. Puede notarse que aparece un recuadro titulado Mantenimiento de preparación, entendiéndose este como todas las actividades necesarias de realizar antes de proceder a efectuar una intervención de mantenimiento; como ejemplos de actividades de preparación o alistamiento se tienen consecución de repuestos, alistamiento de herramientas y equipos de apoyo, fabricación de partes, preparación de espacios para desensamble, etc. El Mantenimiento de preparación se debe aplicar en todos los sistemas de Mantenimiento.

Figura 5. Sistemas de Mantenimiento [el Autor]

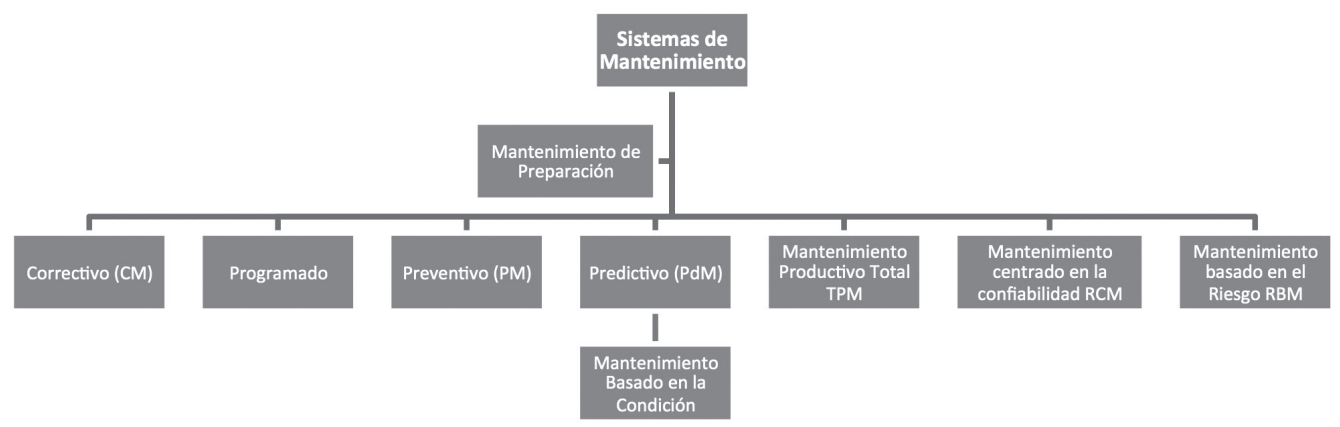

\subsubsection{Mantenimiento Correctivo o a la falla o de emergencia CM (Corrective Maintenance)}

Sistema de Mantenimiento en el que se interviene un equipo una vez que ha ocurrido una falla funcional o que se hace evidente que va a ocurrir una avería mayor (falla potencial). Atendiendo a las definiciones de Falla funcional y Falla potencial descritas en 1.2.2 el Mantenimiento Correctivo se subdivide en:

- Correctivo de emergencia

- Correctivo programado

El Correctivo de emergencia tiene lugar cuando ocurre una falla funcional de manera inesperada dentro de la jornada de producción de la empresa, y generalmente detiene o trastorna la producción. Puede generar pérdidas de producción, accidentes laborales, incumplimientos a los clientes, problemas de calidad, daños ambientales. El Correctivo programado tiene lugar cuando se hace evidente una falla potencial, pero su efecto no es dramático y permite culminar la jornada o el ciclo de producción, para proceder a realizar las correcciones necesarias. 
La figura 6 presenta un gráfico de nivel de rendimiento versus tiempo transcurrido, correspondiente al ciclo de Mantenimiento Correctivo. Se observa claramente como el Tiempo entre Fallas (Time Between Failure TBF) se va reduciendo paulatinamente, en la medida que ocurre cada avería, hasta que por último ocurre la falla cataléctica o catastrófica; una falla cataléctica obliga a evaluar la relación costo - beneficio de cambiar el equipo o efectuarle una reparación general u overhaul; en relación con lo anterior, en la medida que disminuye el TBF es más alto el nivel de rendimiento en el cual ocurre la falla.

Una curva de interés en la figura 6 corresponde a la marcada con el texto Desvare, la cual representa la situación muy común en el ámbito colombiano consistente en efectuar una reparación de baja calidad y dar prontamente al servicio la máquina/equipo. En el desvare no se lleva la máquina a su nivel de rendimiento previo a la varada, y adicionalmente se corre el riesgo de volver a vararse prontamente y con mayor severidad.

Figura 6. Ciclo gráfico del Mantenimiento Correctivo [4]

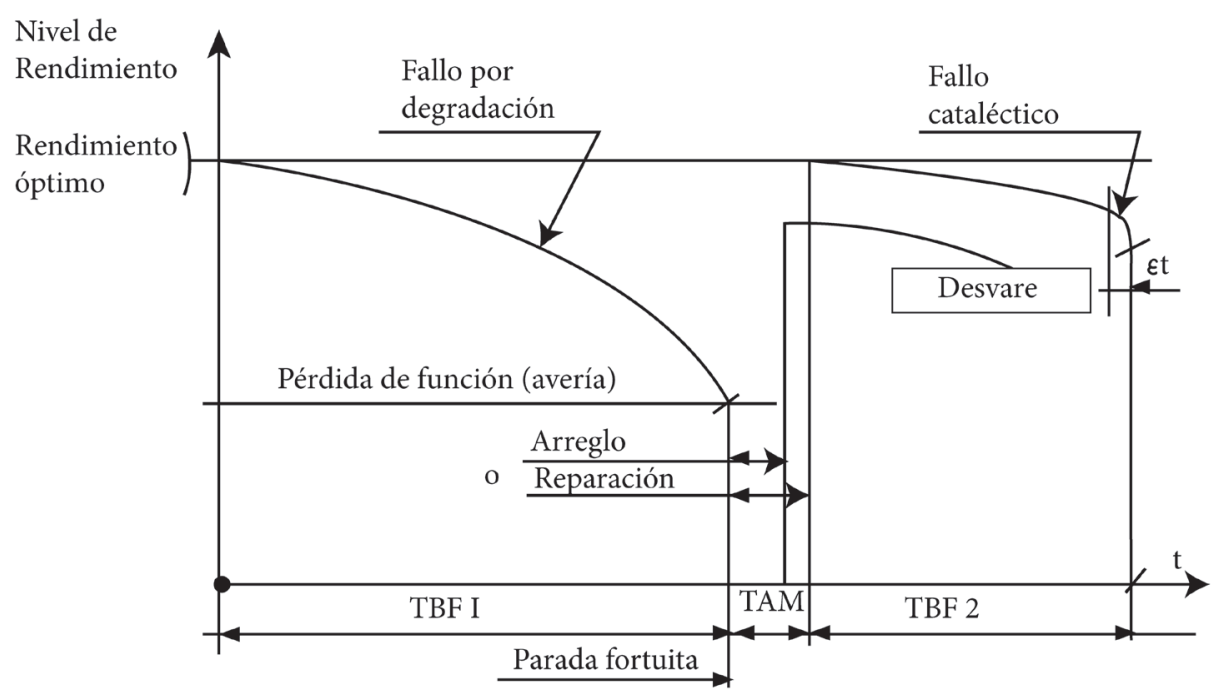

Se debe evitar a toda costa la ocurrencia de correctivos de emergencia en las máquinas/equipos indispensables en la producción, pero se puede tolerar en equipos que no sean vitales en ella, por ejemplo, lámparas, prensas de banco. Por bien administrado que esté el Mantenimiento en una empresa siempre será necesario un porcentaje de Mantenimiento Correctivo programado, debido al normal desgaste y deterioro de los diferentes componentes de las máquinas/equipos. La Tabla 3 relaciona las ventajas y desventajas de aplicar Mantenimiento Correctivo. 
Tabla 3. Ventajas y desventajas del Mantenimiento Correctivo [el Autor]

\begin{tabular}{|l|l|}
\hline \multicolumn{1}{|c|}{ Ventajas } & \multicolumn{1}{|c|}{ Desventajas } \\
\hline $\begin{array}{l}\text { No implica detalladas planificaciones o } \\
\text { programaciones. }\end{array}$ & $\begin{array}{l}\text { Conlleva a la ocurrencia de fallas funcionales, } \\
\text { con todas las consecuencias que ello acarrea. } \\
\text { (Ver numeral 1.3.1). }\end{array}$ \\
$\begin{array}{l}\text { No exige organización técnico-administrativa. } \\
\text { En el corto plazo es un sistema de mantenimiento } \\
\text { económico. }\end{array}$ & En el mediano y largo plazo es muy costoso. \\
\hline
\end{tabular}

\subsubsection{Mantenimiento Programado}

Es aquel que se ejecuta deteniendo el equipo cada que se cumpla un lapso predeterminado, procediendo luego a llevar unas actividades de limpieza, lubricación, desarme, cambio de partes de recambio y posterior rearme; generalmente el lapso es el recomendado por el fabricante del equipo, desconociendo la cantidad e intensidad real de trabajo que haya efectuado el equipo. La figura 7 presenta un gráfico de Nivel de rendimiento versus tiempo, correspondiente al ciclo de Mantenimiento Programado.

Figura 7. Ciclo gráfico del Mantenimiento Programado [4]

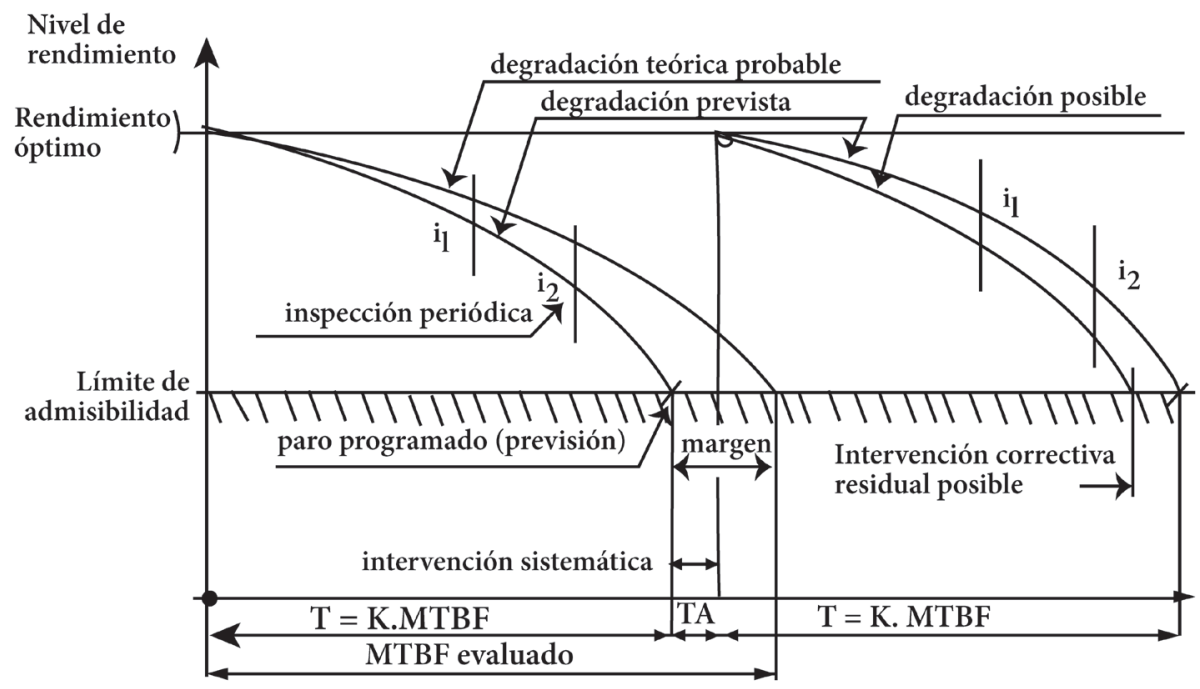

Ley de degradación conocida

Del gráfico anterior, se pueden hacer varias precisiones, respecto de lo predicho por el fabricante:

- El equipo se inspecciona periódicamente (puntos $i_{i}$ de la gráfica) con base al tiempo medio entre fallas (Mean Time Between Failure MTBF). 
- Una vez definido el MTBF, se calcula un límite de admisibilidad del nivel de rendimiento (K x MTBF), punto en el cual el equipo se detiene de manera programada, se interviene y se recupera su nivel de rendimiento óptimo, antes de "echarlo a andar" de nuevo.

Premisa: Se puede disponer de dos máquinas/equipos idénticos físicamente, pero no se pueden hacer predicciones generalizadas frente a su comportamiento, estado y deterioro, debido a que en la realidad entran a formar parte de una trilogía máquina/equipo - operador - medio ambiente, que en muchas ocasiones hace que máquinas idénticas de fábrica, presenten en la realidad rendimientos, estados y vida útil muy diferentes. A la luz de lo anterior, el Mantenimiento programado presupone falsamente que las partes se desgastan y deterioran de la misma manera y a la misma velocidad. La Tabla 4 presenta un resumen de las ventajas y desventajas del Mantenimiento Programado.

Tabla 4. Ventajas y desventajas del Mantenimiento Programado [el Autor]

\begin{tabular}{|c|c|}
\hline Ventajas & Desventajas \\
\hline $\begin{array}{l}\text { Es más científico que el } \\
\text { Mantenimiento Correctivo. }\end{array}$ & $\begin{array}{l}\text { Se van introduciendo pérdidas sucesivas de los ajustes de fábrica } \\
\text { a la máquina debido a los continuos desarmes del equipo, lo que } \\
\text { puede ser contraproducente en el mediano y largo plazo. }\end{array}$ \\
\hline $\begin{array}{llr}\text { Se anticipa } & \text { y reduce la } \\
\text { ocurrencia } & \text { de } \quad \text { Fallas } \\
\text { funcionales. } & \end{array}$ & $\begin{array}{l}\text { Genera sobrecostos puesto que las partes se cambian estén o no lo } \\
\text { suficientemente desgastadas. }\end{array}$ \\
\hline
\end{tabular}

\subsubsection{Mantenimiento Preventivo PM (Preventive Maintenance)}

Es un sistema de Mantenimiento cuyo objetivo esencial es prevenir la ocurrencia de fallas en un sistema productivo, con base en la ejecución de unas tareas básicas (Observar, Inspeccionar, calibrar, ajustar, cambiar, lubricar, reparar, etc.), a unas frecuencias predeterminadas, asociadas a cada ciclo productivo en particular. La ejecución de las tareas básicas puede indicar la necesidad de realizar tareas programadas adicionales (mantenimiento correctivo programado, modificaciones, overhaul, etc.). La figura 8 presenta un gráfico básico de Nivel de rendimiento versus tiempo, correspondiente al ciclo de Mantenimiento Preventivo.

En la Tabla 5 se presenta un listado de ventajas y desventajas del Mantenimiento Preventivo. 
Figura 8. Ciclo gráfico básico del Mantenimiento Preventivo [el Autor]

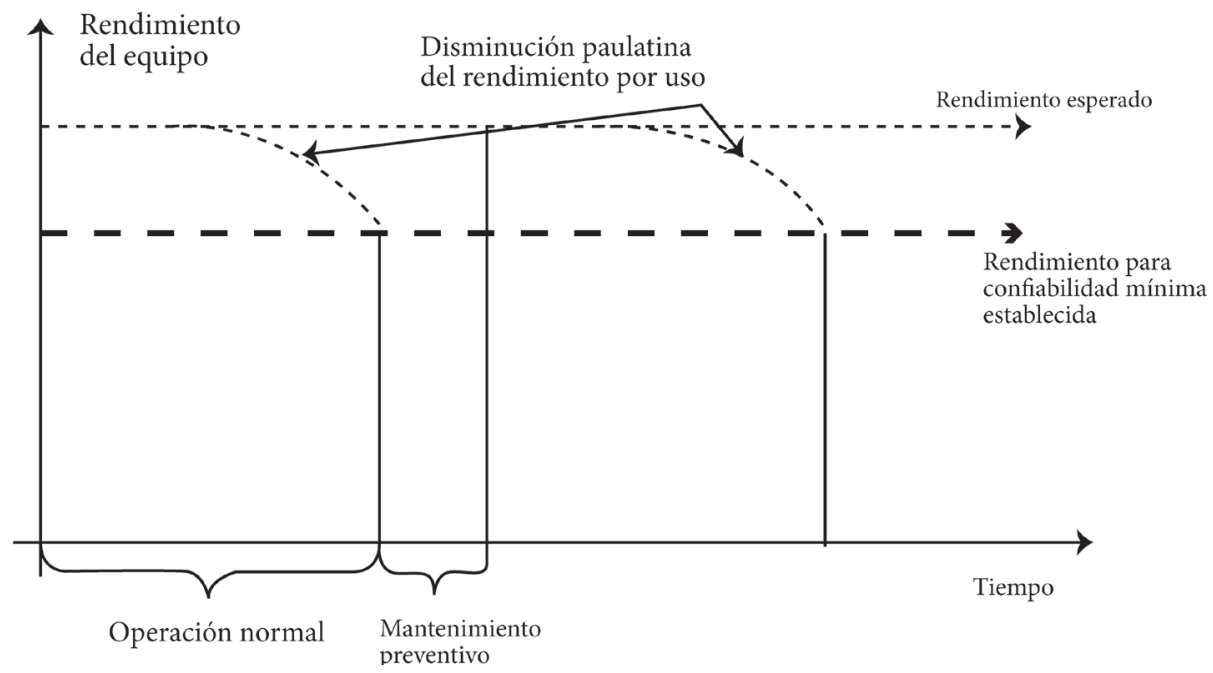

Tabla 5. Ventajas y desventajas del Mantenimiento Preventivo [el Autor]

\begin{tabular}{|c|c|}
\hline Ventajas & Desventajas \\
\hline $\begin{array}{l}\text { Aumenta la confiabilidad de las máquinas / equipos puesto } \\
\text { que operan en mejores condiciones de seguridad ya que se } \\
\text { conoce su estado y sus condiciones de funcionamiento. }\end{array}$ & $\begin{array}{l}\text { Implica realizar una inversión inicial } \\
\text { y sostenida en infraestructura y } \\
\text { mano de obra. }\end{array}$ \\
\hline $\begin{array}{l}\text { Uniformidad en la carga de trabajo para el personal de } \\
\text { Mantenimiento debido a una programación de actividades. } \\
\text { Mayor duración de los equipos e instalaciones. } \\
\text { Disminución de repuestos en existencia y los costos } \\
\text { asociados. }\end{array}$ & $\begin{array}{l}\text { Si no se priorizan y eligen } \\
\text { adecuadamente la cantidad y } \\
\text { profundidad de las tareas de } \\
\text { mantenimiento, se llegan a generar } \\
\text { sobrecargas de trabajo que no } \\
\text { aportan al desempeño y rendimiento } \\
\text { de las máquinas. }\end{array}$ \\
\hline $\begin{array}{l}\text { Disminución del tiempo muerto, tiempo de parada de } \\
\text { máquinas y equipos. } \\
\text { Menor costo de las reparaciones. }\end{array}$ & Alto costo en inspecciones. \\
\hline
\end{tabular}

\subsubsection{Mantenimiento Predictivo PdM (Predictive Maintenance)}

Se basa en estudiar los síntomas de falla y predecir la ocurrencia de la falla de una máquina, midiendo y analizando los cambios en las variables de operación de la misma. El Mantenimiento Predictivo es una fase avanzada del Preventivo, y se efectúan por un lado ensayos o pruebas sobre partes de las máquinas, y complementariamente se hacen mediciones de variables de operación. 
La figura 9 presenta un gráfico de Nivel de rendimiento versus tiempo, correspondiente al ciclo de mantenimiento Predictivo. Para la variable en estudio debe definirse el valor del límite de admisibilidad y el valor de la señal de alarma. Periódicamente se harán mediciones de la variable, y en el momento que su valor alcance el valor de la señal de alarma, deberá programarse una intervención al equipo, para restituir su nivel de rendimiento. Si la señal de alarma es ignorada por el personal de mantenimiento se correrá el riesgo de sobrepasar el límite de admisibilidad, exponiéndose a la ocurrencia una avería mayor.

El Mantenimiento predictivo se apoya en tecnologías y técnicas específicas tales como: Análisis de vibraciones, Termografías, Análisis de aceites en uso, ensayo de tintas penetrantes, ultrasonidos, rayos $\mathrm{X}$, ensayos con partículas magnéticas, etc. En la tabla 6 se presenta un resumen de ventajas y desventajas del Mantenimiento Predictivo.

Figura 9. Ciclo gráfico del Mantenimiento Predictivo [4]

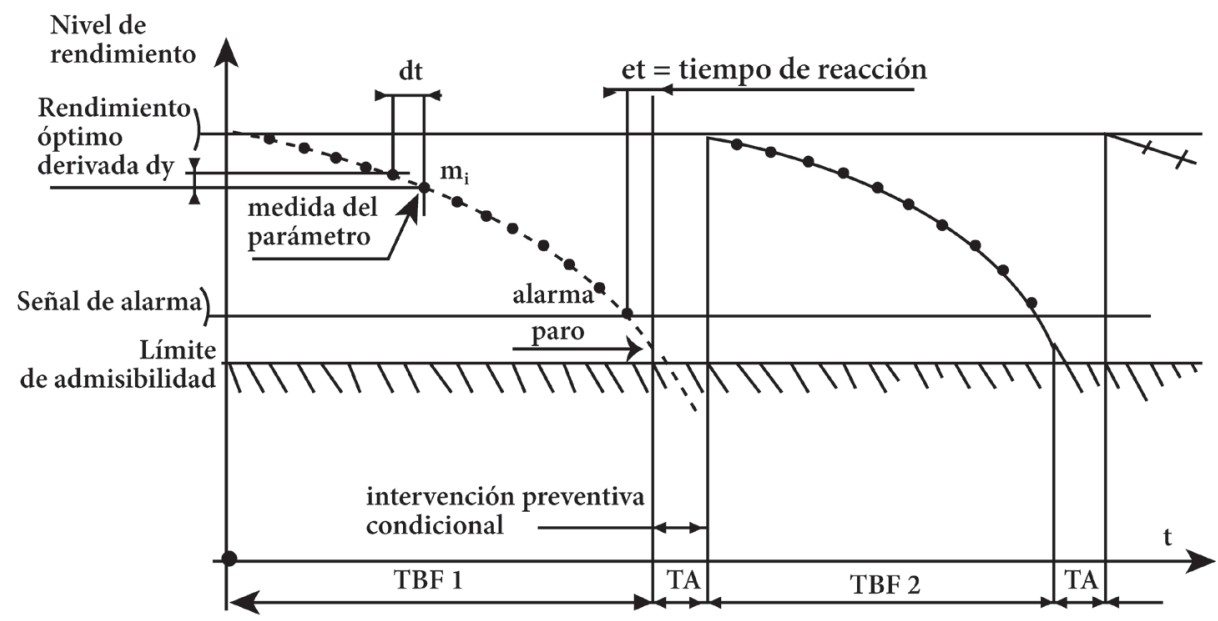

Ley de degradación innecesaria 
Tabla 6. Ventajas y desventajas del Mantenimiento Predictivo [el Autor]

\begin{tabular}{|l|l|}
\hline \multicolumn{1}{|c|}{ Ventajas } & \multicolumn{1}{|c|}{ Desventajas } \\
\hline $\begin{array}{l}\text { Brinda una alta posibilidad de anticiparse a la } \\
\text { ocurrencia de las fallas, ya que se evidencia la } \\
\text { gestación de la misma, en la medida que la variable } \\
\text { de referencia se salga de control. }\end{array}$ & $\begin{array}{l}\text { Muchas de sus técnicas y ensayos implican } \\
\text { inversión en equipo costoso. }\end{array}$ \\
$\begin{array}{l}\text { Muchas de los ensayos, pruebas y mediciones se } \\
\text { Imacen con la máquina en operación, por lo tanto la } \\
\text { afectación al proceso productivo es mínima. }\end{array}$ & $\begin{array}{l}\text { para la utilización del equipo como para el } \\
\text { análisis de información. }\end{array}$ \\
$\begin{array}{l}\text { Minimización de los tiempos de intervención del las técnicas y ensayos del PdM } \\
\text { equipo. El equipo se interviene cuando las pruebas } \\
\text { y ensayos confirman que hay falla en gestación. }\end{array}$ & $\begin{array}{l}\text { pueden indicar la falla en gestación pero no } \\
\text { su causa, por lo que es fundamental la labor de } \\
\text { personal calificado. }\end{array}$ \\
\hline
\end{tabular}

\subsubsection{Mantenimiento Productivo Total TPM (Total Productive Maintenance)}

Más que un sistema de Mantenimiento, es la aplicación de toda una filosofía empresarial y personal, que busca maximizar la productividad en los procesos productivos. La Productividad (fórmula 4), es la maximización de la relación entre los resultados obtenidos versus los recursos empleados. Productividad no es producir más, sino producir bien lo máximo con lo mínimo.

$$
\operatorname{Pr}=\frac{i}{r}
$$

\section{Donde}
$\operatorname{Pr} \quad$ Es la productividad o maximización de la producción.
$i \quad$ Son los productos obtenidos.
$r \quad$ Son los recursos empleados.

El TPM busca alcanzar sistemas altamente productivos, eliminando las seis grandes pérdidas que los aquejan (daños de las máquinas, tiempos de alistamiento largos, productos de mala calidad, máquinas funcionando en vacío o a baja velocidad, accidentes en la planta y plantas contaminantes) y pretende alcanzar plantas con:

- Cero averías

- Cero setup o tiempo de alistamiento

- Cero defectos

- Cero despilfarros

- Cero accidentes

- Cero. contaminación 
En el TPM el operario del equipo toma un papel protagónico en el Mantenimiento Preventivo de su unidad productiva y se compromete en el incremento de la productividad a la totalidad del personal de una empresa, incluyendo la alta gerencia; para tomar ese papel protagónico el operador debe ser sensibilizado y capacitado, para ejecutar tareas básicas contempladas en el Mantenimiento Autónomo, tales como:

$$
\begin{aligned}
& \text { - Limpieza } \\
& \text { - Lubricación } \\
& \text { - Ajustes menores } \\
& \text { - Reportes }
\end{aligned}
$$

Una fase inicial del TPM es la implementación del sistema de las 5S, o sistema de mejoramiento continuo, el cual puede ser implementado en cualquier empresa, independiente de su tamaño y tecnología. Las 5S (Seiri, Seiton, Seiso, Seiketsu y Shitsuke) están asociadas con orden, aseo y mejoramiento continuado.

\subsubsection{Mantenimiento Centrado en la Confiabilidad RCM (Reliability Centered Maintenance)}

RCM es una filosofía de gestión de Mantenimiento, que optimiza la confiabilidad operacional de un sistema que funciona bajo condiciones de trabajo definidas, en función de cuán críticos son los activos, tomando en cuenta los posibles efectos que originarán los modos de falla de dichos activos, sobre la seguridad, al ambiente, a las operaciones [5]. En este sistema de mantenimiento se pone especial énfasis en el funcionamiento global del sistema, más que en el de cada equipo individualmente; un equipo no es intrínsecamente importante, sino por la función que desempeñe dentro de un proceso productivo. En RCM la palabra clave es la Confiabilidad o Fiabilidad (Reliability).

La Confiabilidad de un equipo es posible evaluarla en términos cuantitativos, tal como lo indica la fórmula 5. El conocimiento de la confiabilidad y la disponibilidad de un equipo permiten planear la producción e incluso disponer de planes de contingencia.

$$
T P E F=\frac{T_{o p}}{N_{a r r}}
$$

Donde

TPEF Es la confiabilidad o tiempo promedio entre fallas.

$T_{o p} \quad$ Es el tiempo real de operación de la planta.

$N_{\text {arr }} \quad$ Es el número de arranques de planta.

El RCM se apoya en estadísticas de falla, con las cuales se llevan a cabo un análisis de criticidad $\boldsymbol{C A}$ de las secciones o áreas de la planta y posteriormente se determina la criticidad de los subsistemas que conforman las máquinas/equipos que hayan sido determinados como críticos, aplicando una metodología de Análisis de Modo y Efecto de Falla AMEF (o FMEA por sus siglas en Ingles) por intermediode un parámetro llamado Número de Prioridad de Riesgo NPR; posteriormente se pasa a determinar un plan de acción para dicho subsistema; el plan de acción puede indicar la aplicación de correctivo, preventivo, predictivo, instalar unidades redundantes o rediseñar el subsistema. 


\subsubsection{Mantenimiento Basado en el Riesgo RBM (Risk Based Maintenance)}

Sistema de Mantenimiento de última generación, en el que se direccionan los recursos de mantenimiento hacia los equipos que un análisis probabilidad-riesgo determine que son los más riesgosos. El RBM es especialmente apto para ser aplicado en plantas cuya operación encarna alta peligrosidad, como las petroquímicas, nucleares, biológicas, etc. La figura 10 ilustra de manera básica la esencia del RBM; el área verde indica que hay poca probabilidad de que una máquina/equipo $A$ falle de manera catastrófica $y$ en el caso que ocurriese, las consecuencias (sobre la salud, sobre el medio ambiente y sobre otros equipos) serían poco importantes. Por el contrario, para una máquina/equipo $B$, ubicado en la región roja indicaría una alta probabilidad de que ocurra una falla catastrófica, y las consecuencias serían elevadas, por lo tanto a la máquina $B$ hay que aplicarle planes de acción más elaborados y asignarle mayores recursos que a la máquina $A$. En RBM se hace uso de Sistemas Integrados de Seguridad SIS, con el objetivo de llevar el Riesgo a niveles aceptables o tolerables (el Riesgo no se puede llevar a un valor cero). A nivel industrial este tipo de mantenimiento lo desarrollan equipos multidisciplinarios de profesionales.

Figura 10. Esencia del Mantenimiento Basado en el Riesgo [el Autor]

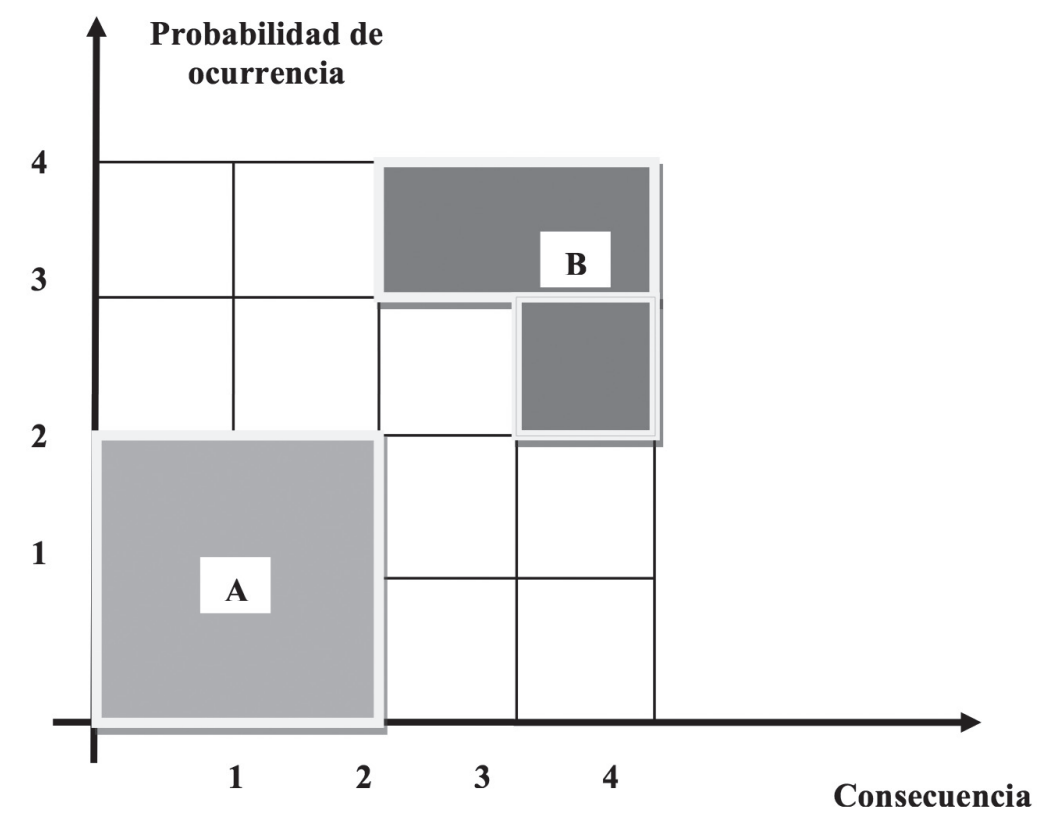

Por último en este vistazo a los diferentes sistemas de Mantenimiento, es conveniente mencionar el Mantenimiento Analítico, el cual en sí mismo no es un sistema de Mantenimiento, pero brinda herramientas que son transversales a los diferentes sistemas de Mantenimiento tratados en este breve resumen. El Mantenimiento Analítico se basa preferentemente en el uso y análisis de las estadísticas de falla, para determinar la causa raíz de un problema y facilitar la posterior toma de decisiones. Primeramente hace uso de Indicadores de Mantenimiento y posteriormente hace uso de técnicas como: 
- Root Centered Failure Analysis R.C.F.A. o Análisis de la causa raíz de la falla

- Failure Tree Analysis F. T. A. o Árbol de análisis de fallas.

- Análisis de Pareto

- Diagrama Causa - Efecto.

\subsection{Evolución histórica del Mantenimiento}

Todas las actividades que el hombre realiza han sufrido una evolución ligada a los diferentes momentos históricos, políticos y económicos. El Mantenimiento no escapa a dicha situación, tal como lo muestra la figura 11. El Anexo 2 amplía los conceptos de Mecanización y Automatización mencionados en la figura 11 y presenta un ejemplo de aplicación.

Las máquinas de la primera generación se caracterizaban por su elevada robustez física y en consecuencia su baja productividad; es decir, no se elaboraban diseños esbeltos debido a la baja resistencia específica de los materiales, entonces se entraba a compensar esta falencia con mayores espesores y tamaños. Esta situación de alguna manera generaba máquinas confiables, pero con costos de operación muy elevados (mayor consumo energético para poner en marcha elementos grandes y pesados) y por ende las velocidades de operación eran reducidas minimizando la productividad.

Lamentablemente y como ha ocurrido de manera recurrente en la historia de la humanidad, las guerras son las que jalonan las investigaciones y los desarrollos.... En la década de 1940 hubo una necesidad sentida de aumentar la productividad de los procesos productivos de toda índole, en especial los de orden militar para poder suplir el apetito voraz de la Segunda Guerra Mundial, y fue allí donde se hizo necesario fabricar máquinas más productivas, por ende menos robustas, más esbeltas, más económicas y sin que hubiera avanzado sensiblemente la ciencia de los Materiales. Esta situación culminó en el advenimiento del Mantenimiento Preventivo, el cual reinó como el sistema de Mantenimiento por excelencia hasta la década de 1980, es decir en la segunda generación.

Figura 11. Evolución histórica del Mantenimiento

Aumento de la Mecanización y Automatización

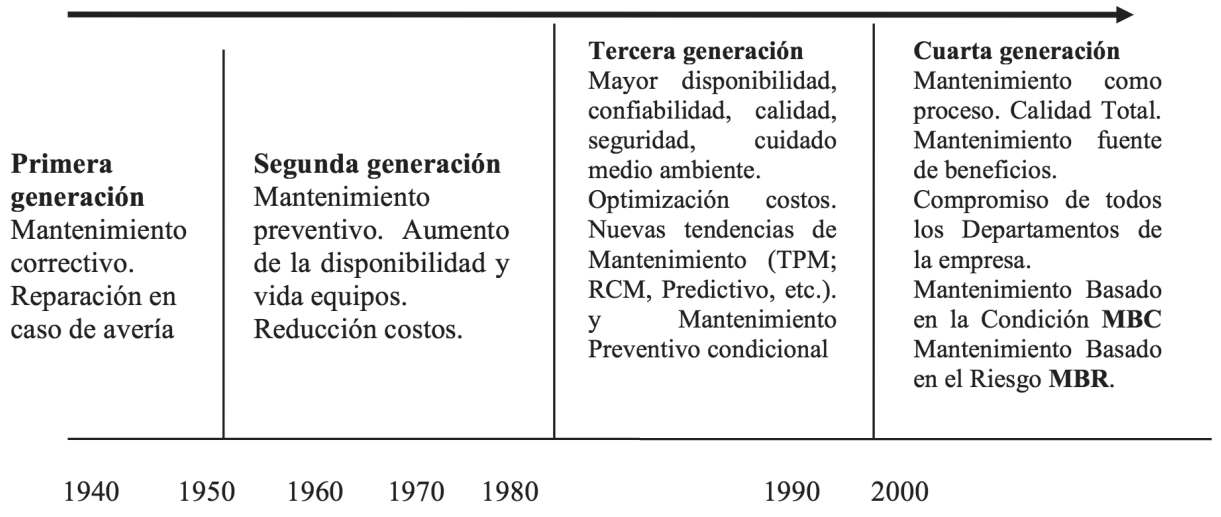


Desde la década de 1970, diversos estudiosos en los países más industrializados del mundo (especialmente en Japón) llegaron a un punto de encuentro en el que consensuaron que a pesar de las bondades del Preventivo, generaba excesos de trabajo y no siempre los resultados eran los mejores. La figura 12 ilustra dicha situación y un análisis rápido de ella, muestra la predisposición de un Departamento de Mantenimiento a concentrarse en "apagar incendios", es decir a atender averías importantes y averías mayores. Fruto de estos análisis diversos expertos propusieron que quien estaba al frente de la máquina/equipo a diario, es decir el operario, era la persona más indicada para resolver de primera mano los 1000 problemas pequeños que se iban escalando hasta convertirse en una avería grave, fue así como surgió el TPM.

Figura 12. Indebido direccionamiento de la función Mantenimiento [6]

\section{Por cada avería grave hay 1000 fuentes que avisan disfunciones}

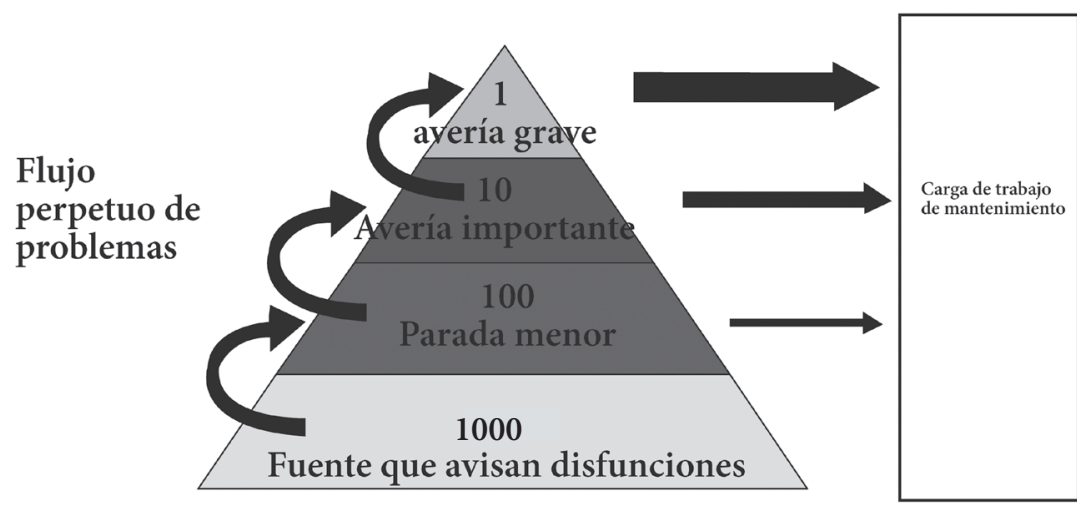

El mantenimiento está sofocado por el tope de la pirámide!

Con la aplicación del TPM, la pirámide de la figura 12 se escaló y se convirtió en el trapecio y la pirámide de la figura 13, en donde la labor de apagar incendios del Mantenimiento casi desaparece y el operario cumple una labor vital, atacando los problemas en la fuente, es decir en la minucia del día a día. 
Figura 13. Escala de trabajo del mantenimiento en el TPM [6]

\section{Averías con TPM}

Los 1000 signos indicadores de disfunciones, nos ayudan a prevenir las averias

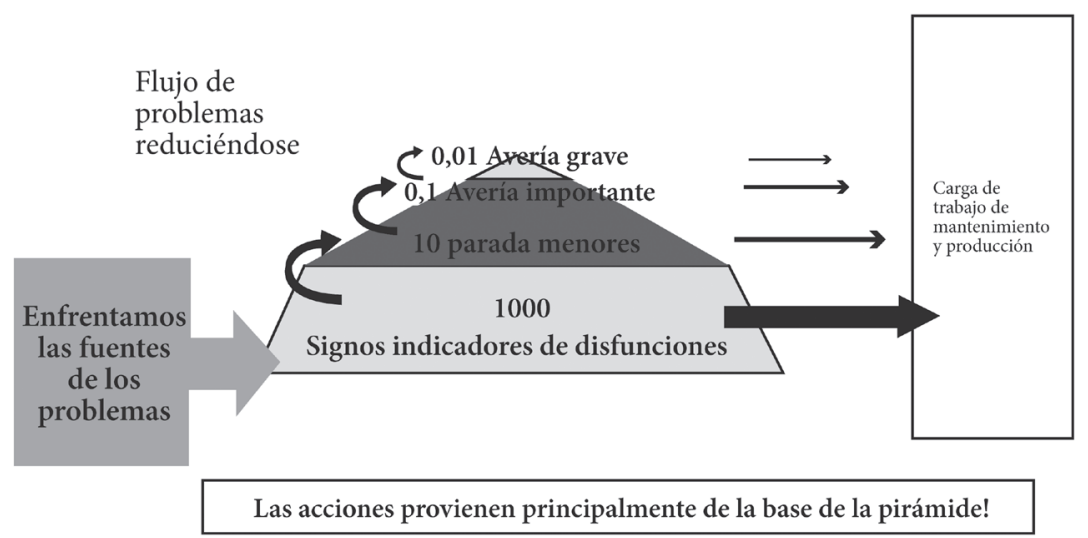

En la misma década de 1970 otros análisis bajo otras perspectivas dieron origen al RCM (Fuerza aérea de Estados Unidos), al PdM, al Mantenimiento Preventivo Condicional (MP asistido por instrumentación y con alarmas para puntos de disparo de acciones), completando así la Tercera generación del mantenimiento.

Por último, y bajo miradas globales, holísticas, se llega a la cuarta generación del mantenimiento en la que se habla de Ingeniería y Gerencia de Mantenimiento, puesto que se trata de una fuente de beneficios para las empresas, diferente de lo que se pensaba 60 años atrás, cuando Mantenimiento era gastar.

La figura 14 ilustra cómo el sistema de Mantenimiento empleado conlleva al logro en mayor o menor medida de los resultados previstos. En este gráfico no aparece el Mantenimiento Correctivo, dada la alta aleatoriedad de sus resultados, y en el primer peldaño aparece el Mantenimiento Preventivo básico con una efectividad de resultados del $46 \%$, y va ascendiendo hasta llegar al $90 \%$ ofrecido por el Mantenimiento Basado en el Riesgo. 
Figura 14. Efectividad de los resultados en función del sistema o Tecnología de Mantenimiento empleada [7]

Fuente: HSB Realiability Tecnologies

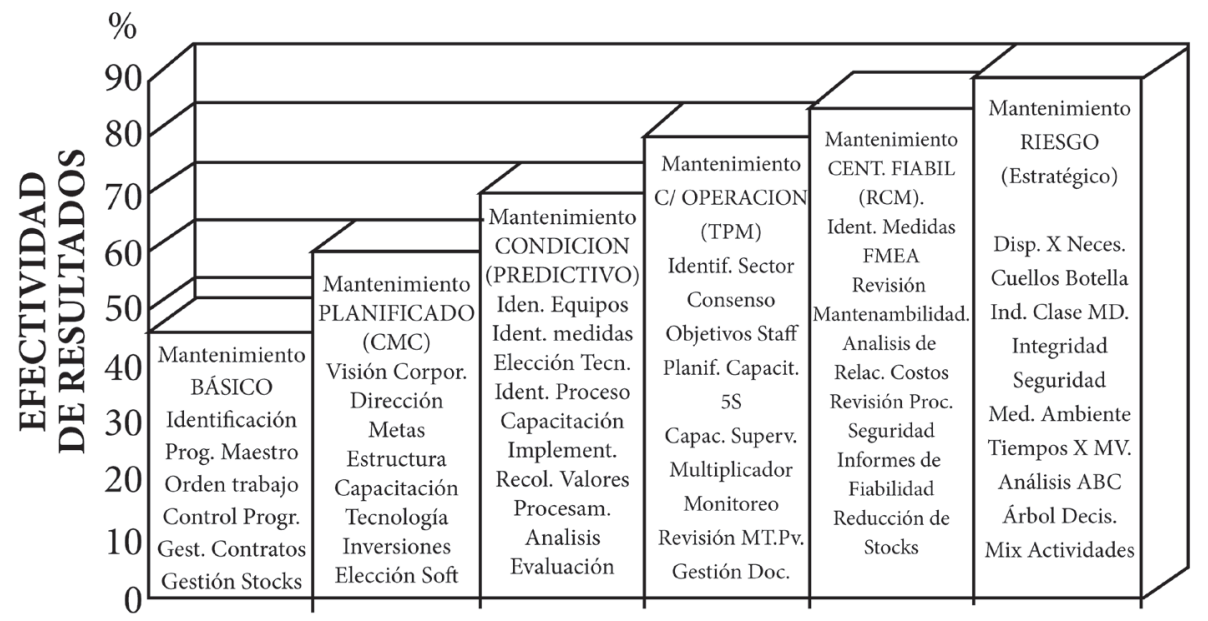

TECNOLOGIAS DE MANTENIMIENTO

Nota sobre Análisis ABC: Metodología de costeo de una empresa, que no solo atiende el análisis numérico por rubros como en la contabilidad tradicional, sino que pone en marcha una metodología de búsqueda de costos encubiertos, para identificar puntos críticos y tomar los planes de acción correspondientes.

Lamentablemente para la industria local Pereira - Dosquebradas en la que el grueso de las industrias grandes aplica Preventivo [8], el panorama es sombrío y desalentador al observar que la efectividad de resultados con dicho sistema de Mantenimiento es muy baja, del orden del $46 \%$. Este resultado puede hacerse extensivo a casi la totalidad del país, en donde diferentes estudios [9], han informado que el sistema de Mantenimiento que mayoritariamente se aplica es también Preventivo y eso explica en gran parte porque regularmente estamos lejos de los resultados exitosos de otras latitudes.

\section{7. ¿Cuándo reemplazar un equipo de producción?}

En este apartado se presenta un análisis financiero simple, con el fin de determinar cuándo es el momento adecuado de pensar en reemplazar una máquina/equipo, en función del punto de cruce de la curva de costos totales de la máquina/equipo con su curva de valor remanente.

Adicionalmente, se presenta un análisis de la influencia de la calidad de la máquina/equipo (y por ende su costo de adquisición) en la variación de las curvas de Costo de reemplazo CR y en las curvas de Costos de Mantenimiento CM, en relación al tiempo en que el equipo es económicamente útil.

Este apartado puede ser consultado en el hipervínculo http://carlos-montilla-utp.jimdo.com/ complementos-libro-de-mantenimiento/complementos-capitulo-1/ 


\subsection{Preguntas de consulta o análisis}

- Consulte sobre la esencia y modelos matemáticos de los modelos de Depreciación constante y variables.

- Tomando como base la Tabla 1 (Numeral 1.3.4), reprodúzcala en una hoja electrónica Excel y gráfica y analíticamente determine el valor del punto P.E.

- ¿Será posible erradicar por completo el Mantenimiento Correctivo en una organización? Justifique la respuesta.

- Suponga la siguiente situación, Ud. va a ejecutar un proyecto puntual por un término no superior a un año, y los equipos que utilizará no le interesa tenerlos después de finalizar la obra. Con base en la Figura 2 del numeral 1.7, ¿Qué tipo de equipos elegiría y por qué?

- Ejercicio Propuesto 1 (con base al numeral 1.7)

Haciendo uso de la hoja electrónica Excel, construir las curvas CR y CM versus tiempo para la siguiente situación: Un administrador de una mediana empresa, asesorado por un Jefe de Mantenimiento adquieren un equipo cuyo costo inicial IV es de $\$ 10000000$ y se espera que opere continuamente durante 10 años. El fabricante recomendó adquirir repuestos iniciales SV por un valor de $\$ 400000 \mathrm{y}$ su valor se incrementará \$200 000 cada año El costo rutinario de Mantenimiento CM tendrá un valor estimado de \$300 000 el primer año y posteriormente se incrementará \$100 000 cada año. ¿Cuál es el factor de depreciación Fd y el valor remanente RV, año a año? Al finalizar el quinto año, ¿Cómo estará la situación para propósitos de reemplazo del equipo? ¿Será que económicamente tiene sentido que el equipo trabaje la vida útil esperada? Si así es, ¿Cuántos años será económicamente rentable el equipo? ¿En qué región de la curva de la figura 2 del numeral 1.7 podría estar ubicado este equipo? Asuma Fo $=\mathrm{Fi}=\mathrm{Fe}=$ constante $=0,9$.

\section{Para reflexionar. Mantenimiento ¿Una vía de escape al subdesarrollo?}

En este apartado el autor presenta una mirada del aporte que a su juicio, ha tenido el Mantenimiento productivo total TPM en el paulatino desarrollo económico de la India.

En el hipervínculo http://carlos-montilla-utp.jimdo.com/complementos-libro-demantenimiento/complementos-capitulo-1/ se puede realizar esta lectura complementaria. 

Capítulo 2 



\section{Organización del Departamento de Mantenimiento}

\subsection{Introducción}

El presente capítulo entrega una visión acerca de dónde está ubicado el Departamento o área de Mantenimiento con respecto al organigrama o estructura de mando de una organización. Una vez presentada dicha ubicación se ilustran algunas composiciones internas típicas al interior de los Departamentos de Mantenimiento, válidas para medianas y grandes empresas. Es necesario precisar cuánto la ubicación como la composición de un Departamento de Mantenimiento dependen entre otros factores, del tamaño de la empresa, de su layout de planta (ver Anexo 1), y de sus políticas financieras y económicas. Es conveniente antes de tratar los temas enunciados recordar los conceptos de empresa y su clasificación en micro, pequeña, mediana y gran empresa, en el contexto colombiano, y las definiciones de algunos cargos relacionados con Mantenimiento.

\subsection{Algunas definiciones básicas}

\subsubsection{Relativas a empresas}

Empresa: toda actividad organizada dedicada a realizar todos o algunos de los siguientes procesos: fabricación, transformación, distribución, comercialización, alquiler, de bienes o servicios, con el fin de satisfacer necesidades de los clientes y generar rentabilidad a los accionistas.

Según los enfoques clásicos, la economía se subdivide en tres sectores:

- Primario o agropecuario. Es el sector que obtiene un producto ejerciendo actividades directamente sobre la naturaleza, sin ningún proceso de transformación, tales como agricultura, la ganadería, la silvicultura, la caza y la pesca.

- Secundario o industrial. Comprende todas las actividades económicas de un país relacionadas con la transformación industrial de los alimentos y otros tipos de bienes 
o mercancías, los cuales se utilizan como base para la fabricación de nuevos productos. Se divide en dos sub-sectores: industrial extractivo (minería y petróleo) e industrial de transformación (envasado de legumbres y frutas, embotellado de refrescos, fabricación de abonos y fertilizantes, vehículos, cementos, aparatos electrodomésticos, etc.).

- Terciario o servicios. Incluye todas aquellas actividades que no producen una mercancía en sí, pero que son necesarias para el funcionamiento de la economía, como por ejemplo el comercio, los restaurantes, los hoteles, el transporte, los servicios financieros, las comunicaciones, los servicios de educación, los servicios profesionales, el Gobierno, etc.

En la actualidad y debido a su inusitado auge en cuanto a desarrollo y utilización, diversos estudiosos incluyen un sector cuaternario, correspondiente al manejo de la información y datos, aplicando tecnologías de punta. La figura 15 ilustra la composición de la economía colombiana basada en los sectores clásicos y la figura 16 discrimina el aporte de los principales subsectores.

Figura 15. Sectores económicos colombianos en 2013. Adaptado de [10]

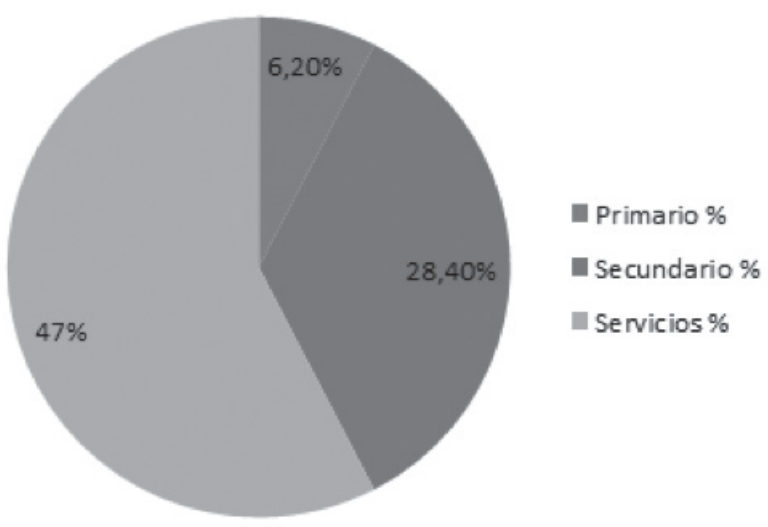

Figura 16. Subsectores económicos colombianos en 2013. Adaptado de [10]

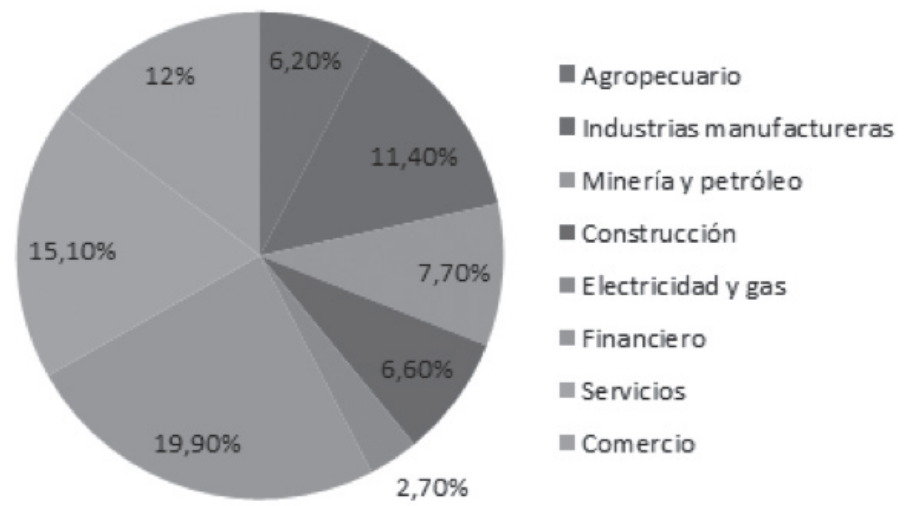


A continuación se presentan unas definiciones alusivas a las clasificaciones de empresa, en función de su tamaño; estas definiciones se basan en la Ley para el fomento de la micro, pequeña y mediana empresa, Ley 590 (modificada posteriormente por la Ley 905 de 2004).

- Microempresa. Aquellas empresas cuyo número de empleados es igual o inferior a $\mathbf{1 0}$ personas y el volumen de activos del año (acorde al balance general anual) es inferior a $\mathbf{5 0 1}$ salarios mínimos legales vigentes SMLV. Microempresa también comprende las personas autónomas o independientes o auto-empleado (tendero, electricista, asadero de arepas, etc.).

- Pequeña empresa: Su personal entre oscila entre 11 y 50 trabajadores y los Activos totales son mayores a 501 y menores a 5001 SMLV.

- Mediana empresa: Personal entre 51 y 200 trabajadores y Activos totales entre 5001 y 30000 SMLV.

Comúnmente a las pequeñas y medianas empresa, se les conoce con el nombre de PYME. De manera combinada, las PYMES corresponden al 3,84\% del total de empresas del país (ver Tabla 7). Por sectores las PYME, se concentran en actividades industriales basadas en el aprovechamiento de los recursos naturales, tanto de origen agropecuario como minero tales como Alimentos, Cuero y Calzado, Muebles y Madera, Textil y Confecciones, Artes Gráficas, Plástico y Químico, Metalúrgico y Metalmecánico, Autopartes y Minerales no Metálicos. Este grupo de sectores representa el $71 \%$ de la producción industrial. Si se excluye la refinación de petróleo y la industria petroquímica, la manufactura basada en el aprovechamiento de los recursos naturales representa aproximadamente el $60 \%$ del total industrial.

Es común agrupar las micros, pequeñas y medianas empresas haciendo uso del término MIPYME, y a su vez las MIPYME representan el 99,87\% de los establecimientos, aproximadamente el $80,53 \%$ del empleo; el 12,22\% de la producción manufacturera del país (ver Tabla 7).

- Gran empresa. Es aquella cuya planta de personal es mayor a $\mathbf{2 0 0}$ trabajadores y cuenta con activos totales por un valor superior a $30000 \mathrm{SMLV}$.

En la Tabla 7 se pueden apreciar algunas estadísticas tomadas y adaptadas del Departamento Administrativo Nacional de Estadística DANE, 2005 ([11, 12]). No hay censos más recientes.

Tabla 7. Algunas estadísticas de empresas colombianas, de acuerdo a su tamaño [11, 12]

\begin{tabular}{|c|c|c|c|c|}
\hline & $\begin{array}{c}\text { Micro } \\
\text { empresa }\end{array}$ & $\begin{array}{c}\text { Pequeña } \\
\text { empresa }\end{array}$ & Mediana empresa & Gran empresa \\
\hline $\mathbf{N}^{\circ}$ empleados & $<10$ & $11 \leq \mathrm{E}<50$ & $51 \leq \mathrm{E}<200$ & $>200$ \\
\hline $\begin{array}{c}\text { Activos fijos AF } \\
\text { SMLV }\end{array}$ & $<501$ & $\begin{array}{c}501 \leq \mathrm{AF}< \\
5001\end{array}$ & $5001 \leq \mathrm{AF}<30000$ & $>30000$ \\
\hline $\begin{array}{c}\text { \% empresas en } \\
\text { Colombia }\end{array}$ & $96,0 \%$ & $3,2 \%$ & $0,5 \%$ & $0,13 \%$ \\
\hline $\begin{array}{c}\mathbf{N}^{\circ} \text { empresas en } \\
\text { Colombia }\end{array}$ & 1338220 & 46200 & 7447 & 1845 \\
\hline $\begin{array}{c}\text { \% Mano obra que } \\
\text { ocupan }\end{array}$ & $50,2 \%$ & $17,4 \%$ & $12,50 \%$ & $19,5 \%$ \\
\hline
\end{tabular}




\subsubsection{Definiciones relativas a cargos relacionados con Mantenimiento}

- Gerencia: proceso que implica la coordinación de todos los recursos disponibles en una organización (humanos, físicos, tecnológicos, financieros), para que por intermedio de los procesos de: planificación, organización, dirección y control se logren objetivos previamente establecidos.

- Gerente: Es aquella persona que en una determinada empresa u organización tiene la responsabilidad y las tareas de guiar a los demás, de ejecutar y dar órdenes y de lograr que las cosas se hagan para poder cumplir cierta y correctamente con el objetivo y la misión que promueve la organización. Haciendo la salvedad de las diferencias que se puedan dar en las diferentes organizaciones, existen seis responsabilidades básicas que constituyen la esencia de la acción de un gerente: (1) incrementar el estado de la tecnología de la organización; (2) perpetuar la organización; (3) darle dirección a la organización; (4) incrementar la productividad; (5) satisfacer a los empleados; (6) contribuir con la comunidad.

- Jefe: Persona que manda o dirige a otras, que serán sus subalternos en una oficina, empresa, corporación, gobiernos, club, organismo, entre otros. Sobre el jefe recae la responsabilidad de definir, decidir, escoger las mejores opciones alternativas para que el funcionamiento del ámbito que dirige funcione, se desarrolle, crezca y por sobre todas las cosas, reine la armonía y el equilibrio, imprescindible para que todo ello se concrete y llegue a buen puerto.

- Director: Persona encargada de dirigir una determinada actividad.

- Superintendente: Persona encargada de la dirección de algo y que ejerce autoridad sobre el resto de las personas que trabajan en lo mismo.

- Supervisor: Se aplica a la persona que se encarga de supervisar un trabajo o una actividad.

- Capataz: Persona que manda y vigila a un grupo de trabajadores.

\subsection{Ubicación de la función Mantenimiento dentro de la empresa}

La ubicación de la función Mantenimiento en el organigrama (estructura de mando) de una empresa, depende del tamaño de la misma (grande, mediana, pequeña). Las figuras 17 a 23 muestran la ubicación del Mantenimiento en algunos organigramas genéricos de empresas.

Figura 17. Ubicación del Departamento en una empresa pequeña 1 [2]

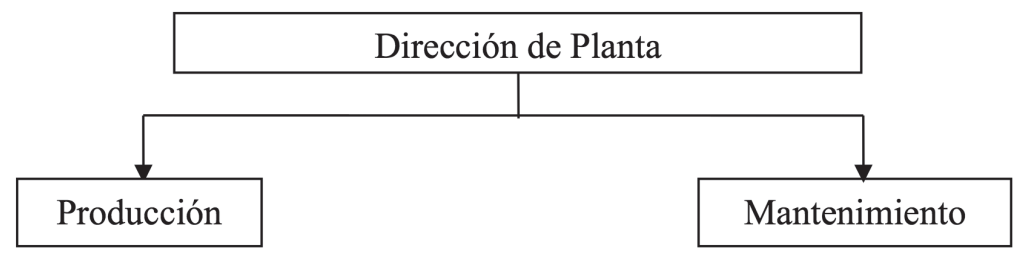


Figura 18. Ubicación del Depto en una empresa pequeña 2 [2]

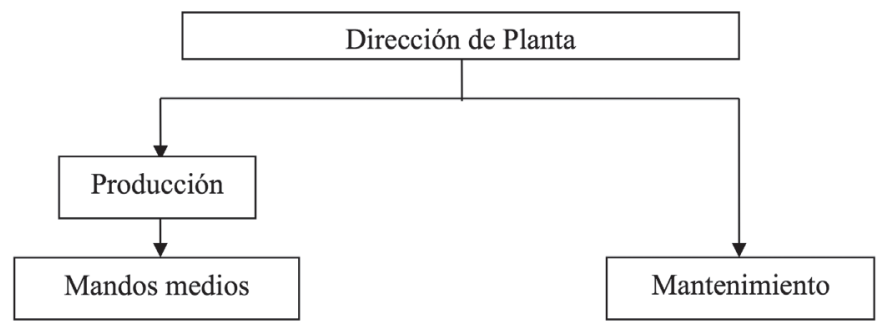

Figura 19. Ubicación del Departamento en una empresa pequeña 3 [2]

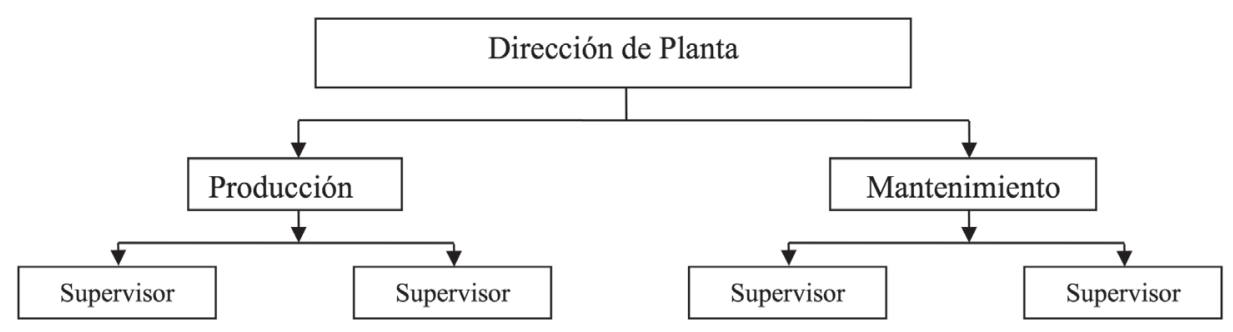

Figura 20. Ubicación del Departamento en una empresa mediana [2]

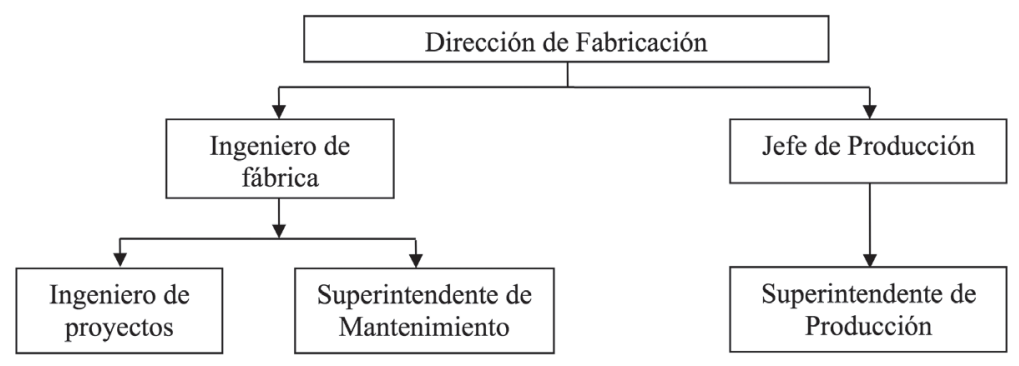


Figura 21. Ubicación del Departamento en una empresa grande 1 [2]

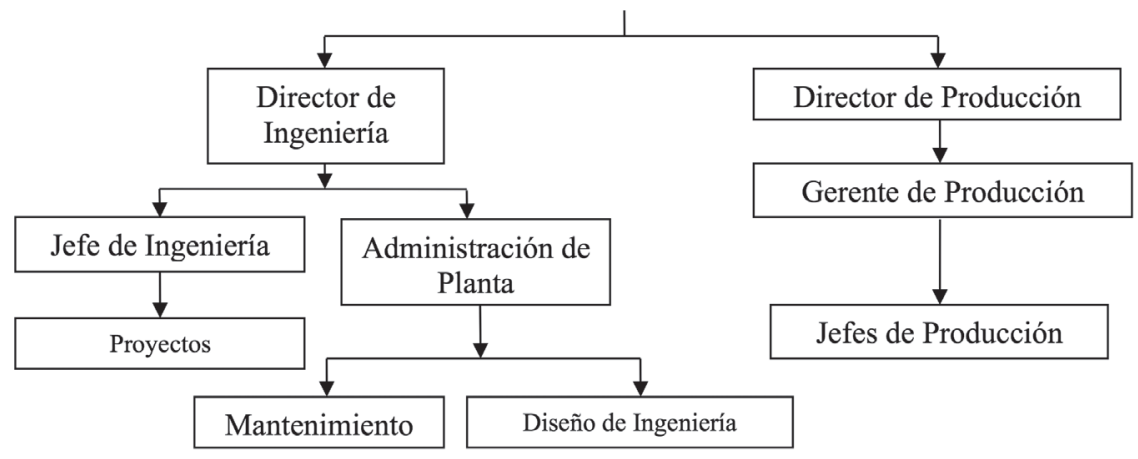

Figura 22. Ubicación del Departamento en una empresa grande 2 [2]

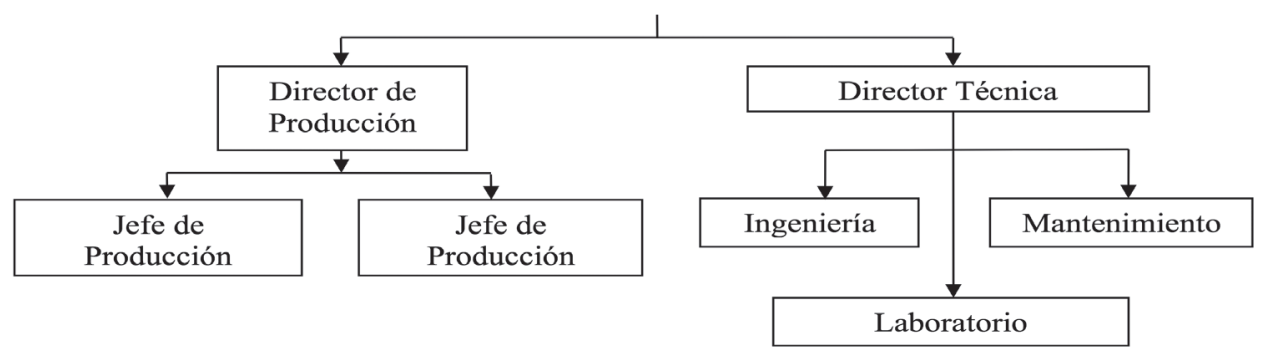

Figura 23. Ubicación del Departamento en una empresa grande 3 [2]

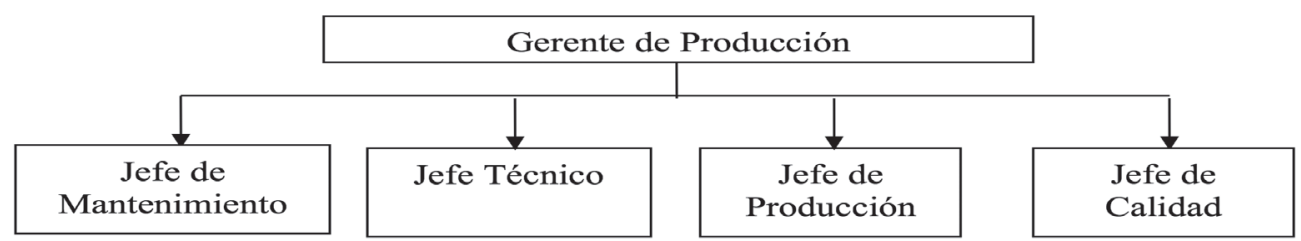

Como una constante, en los diagramas anteriores, se puede apreciar que los Departamentos de Mantenimiento y producción no dependen jerárquicamente entre sí, pero deben manejar una relación funcional sana y coordinada, en lo posible estando al mismo nivel jerárquico. En esquemas de administración antiguos (décadas de 1980 y anteriores), el Departamento de Mantenimiento estaba supeditando al Departamento de Producción, lo que tenía como consecuencia, que la prioridad la tuviese la producción, generando conflictos entre las dos áreas, con las consecuencias económicas y anímicas que ello acarrea. 


\subsection{Algunas estructuras típicas de los Departamentos de mantenimiento}

En el interior de un Departamento de Mantenimiento, existen también diferentes composiciones y organigramas típicos. Las figuras 24 a 26 ilustran algunas de dichas estructuras, válidas para grandes y medianas empresas.

Figura 24. Organigrama Depto de Mantenimiento. Sistema formal centralizado [2]

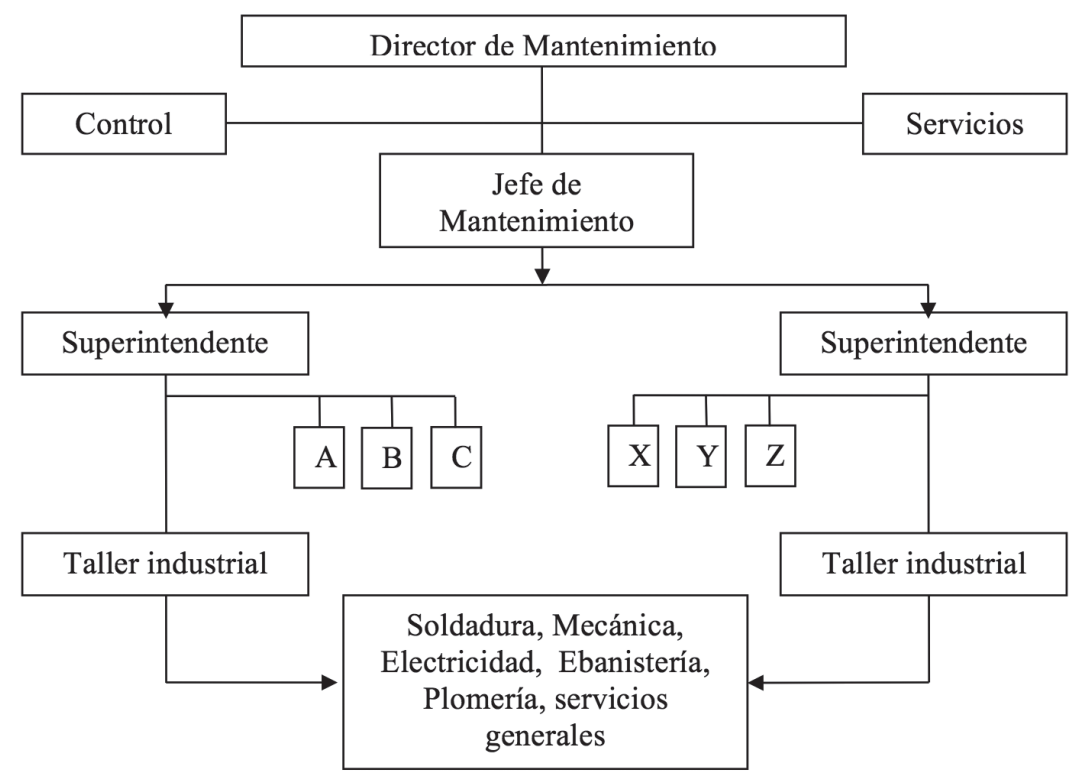

Figura 25. Organigrama Depto de Mantenimiento. Sistema formal centralizado [2]

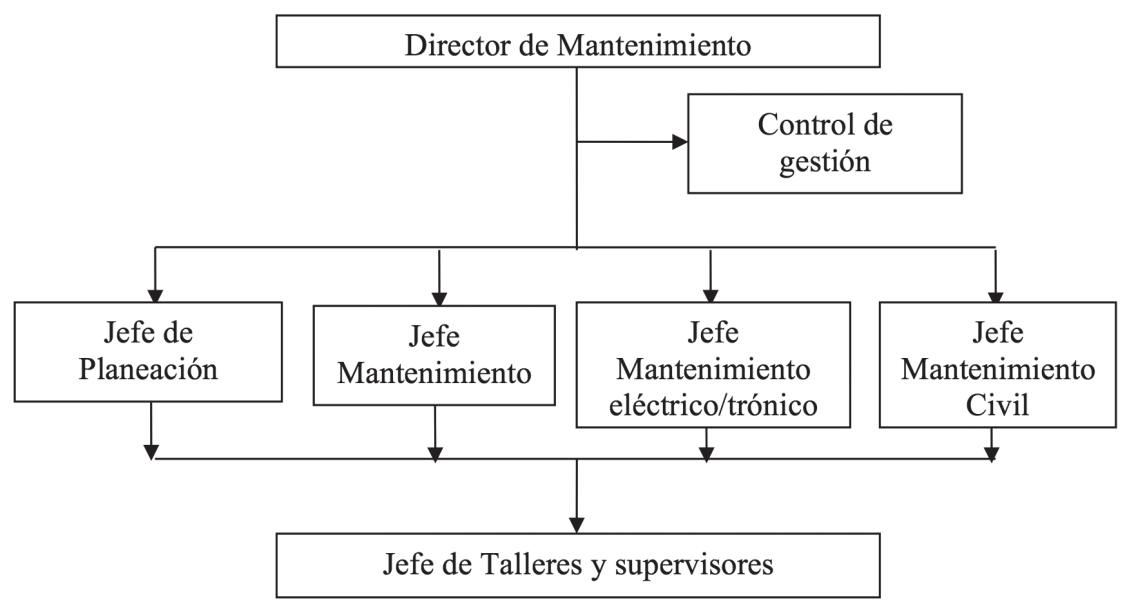


Figura 26. Organigrama Depto de Mtto. Sistema formal descentralizado [2]

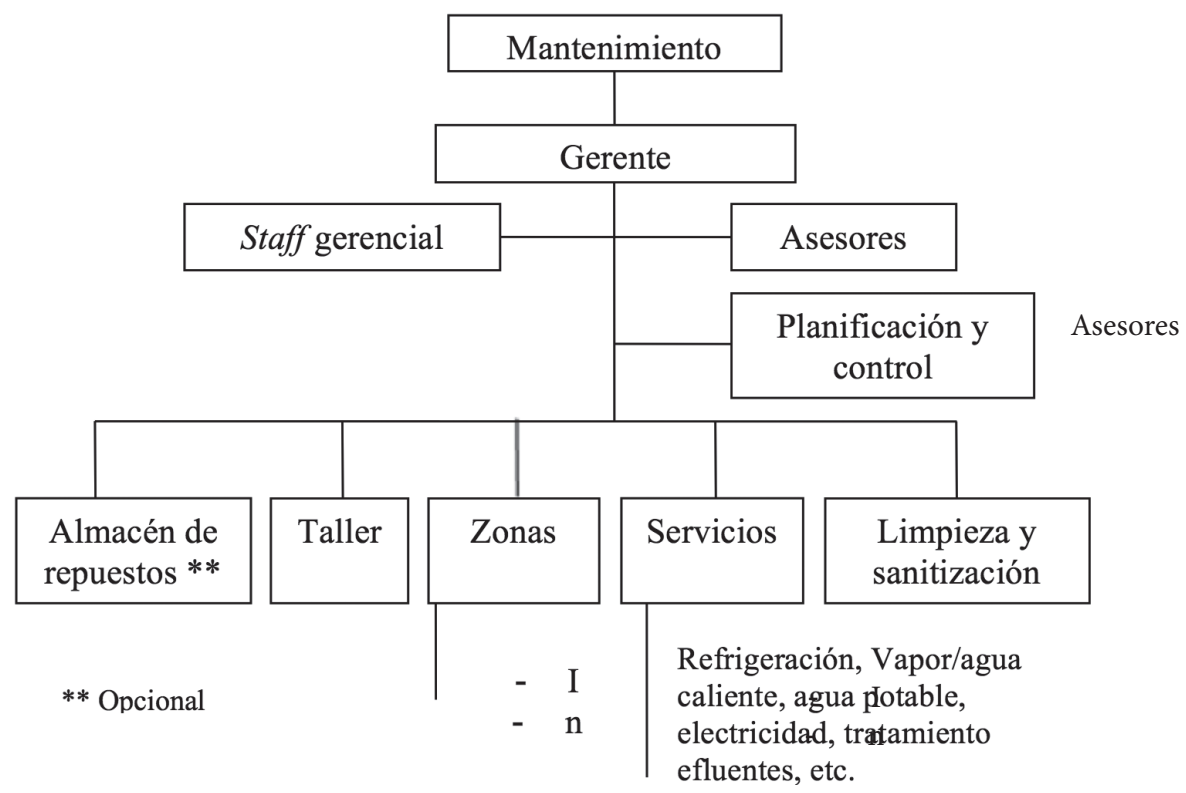

\subsection{Preguntas de consulta o análisis}

- Consulte nombre, ubicación y actividad económica de algunas pequeñas, medianas y grandes empresas del área metropolitana Pereira - Dosquebradas.

- Para el listado previo identifique a qué sector y subsector económico pertenecen.

- Analice los organigramas de las figuras 17 a 23, e identifique a qué Layout de Planta corresponde cada uno de ellos, y probablemente a qué tamaño de empresa.

- En lo posible, indague la ubicación del Departamento de Mantenimiento de las empresas consultadas en la primera pregunta del presente numeral; compare, analice y obtenga conclusiones, con respecto a las figuras 17 a 23.

- En lo posible, indague los organigramas de Mantenimiento de las empresas consultadas en la primera pregunta del presente numeral; compare, analice y obtenga conclusiones con respecto a las figuras 24 a 26.

\subsection{Para reflexionar. Funciones genéricas del Ingeniero y del Tecnólogo de mantenimiento en Colombia}

En el medio colombiano la mayoría de egresados de los programas de Ingeniería y Tecnología (en especial de Mecánica y afines) poseen perfiles ocupacionales que se puede resumir como se describe a continuación: 
- Administración de empresas y dependencias técnicas.

- Planeación y desarrollo de proyectos de Ingeniería.

- Control técnico-administrativo de Departamentos de producción.

- Mantenimiento de toda índole.

- Planeación, dirección y supervisión de montajes.

- Ventas técnicas.

Dadas las características (en cuanto a tamaño) de la industria colombiana (ver numeral 2.2.1) en la que solo el $0,13 \%$ de las compañías corresponden a grandes empresas, y siendo ellas las que regularmente cuentan con Departamentos de Ingeniería, diversas estadísticas muestran que no son muchos los profesionales que pueden acceder a cargos de diseño, planeación y desarrollo de proyectos, mientras que la gran mayoría de ingenieros/tecnólogos ingresan a laborar a Departamentos de Mantenimiento.

A la luz de lo anterior una pregunta válida que se debe hacer el estudiante de Ingeniería y Tecnología (afines a Mecánica) que está a punto de culminar su programa de pregrado es ¿Qué me corresponderá hacer si ingreso a un Departamento de Mantenimiento? La Tabla 8 presenta un panorama típico de actividades que desarrolla un ingeniero/tecnólogo en tal situación.

Respecto de la Tabla 8 hay varias anotaciones:

- Está basada en la partición de tareas básicas de un Departamento de Mantenimiento propuesta en la Tabla 2 (Capítulo 1)

La distribución de actividades está pensada para medianas y grandes empresas, en las cuales regularmente el tecnólogo hace las veces de asistente del ingeniero, razón por la cual aparecen muchas tareas de campo, de levantamiento de información y de preparación de informes asignadas a este último, mientras que las tareas de análisis de información, toma de decisiones, elaboración de informes gerenciales y su respectiva sustentación le corresponden al ingeniero.

Tabla 8. Actividades generales desarrolladas por un ingeniero/tecnólogo de Mantenimiento [el

Autor]

\begin{tabular}{|l|c|c|}
\hline \multicolumn{1}{|c|}{ Tarea } & Ingeniero & Tecnólogo \\
\hline \multicolumn{1}{|c|}{} & $\mathbf{X}$ & \\
\hline Planear sistemas de Mantenimiento a usar y dirigir cambios en ellos & $\mathbf{X}$ & \\
\hline $\begin{array}{l}\text { Estudiar existencias y costos de almacén de Mantenimiento y definir } \\
\text { políticas al respecto }\end{array}$ & $\mathbf{X}$ & \\
\hline Preparar presupuestos anuales de Mantenimiento & $\mathbf{X}$ & \\
\hline $\begin{array}{l}\text { Asesorar la gerencia en planes de inversión/reposición en maquinaria/ } \\
\text { equipo }\end{array}$ & $\mathbf{X}$ & $\mathbf{X}$ \\
\hline Programar paradas mayores u overhaul & $\mathbf{X}$ & $\mathbf{X}$ \\
\hline $\begin{array}{l}\text { Estudiar indicadores y costos de operación de procesos/máquinas/ } \\
\text { equipos }\end{array}$ & $\mathbf{X}$ \\
\hline $\begin{array}{l}\text { Preparar términos de referencia para compra/cambio de procesos/ } \\
\text { equipos, conjuntamente con Departamentos de Ingeniería }\end{array}$ & \\
\hline
\end{tabular}




\begin{tabular}{|l|c|c|}
\hline Programar tareas anuales de Mantenimiento rutinario & $\mathbf{X}$ & $\mathbf{X}$ \\
\hline $\begin{array}{l}\text { Levantar información de campo y redactar instructivos de } \\
\text { Mantenimiento }\end{array}$ & $\mathbf{X}$ \\
\hline Levantar planos e información técnica de piezas/procesos & $\mathbf{X}$ \\
\hline $\begin{array}{l}\text { Validar existencias de insumos, repuestos, herramientas y realizar los } \\
\text { respectivos pedidos }\end{array}$ & $\mathbf{X}$ \\
\hline $\begin{array}{l}\text { Programador de Mantenimiento (creación, cierre, retro- alimentación } \\
\text { y reprogramación de órdenes de trabajo) }\end{array}$ & $\mathbf{X}$ \\
\hline $\begin{array}{l}\text { Ejecución (Instalar, poner a punto, inspeccionar, limpiar, lubricar, } \\
\text { cambiar, reparar, modificar, etc.) }\end{array}$ & $\mathbf{X}^{*}$ & $\mathbf{X}$ \\
\hline $\begin{array}{l}\text { Supervisión de ejecución de tareas de Mantenimiento rutinario o en } \\
\text { paradas mayores }\end{array}$ & $\mathbf{X}$ \\
\hline Liquidación de nómina y costos de Mantenimiento & $\mathbf{X}$ & $\mathbf{X}$ \\
\hline Interventoría de proyectos y paradas mayores) & $\mathbf{X}$ \\
\hline $\begin{array}{l}\text { Supervisión de labores de outsourcing, recepción y cotejo de la } \\
\text { facturación respectiva }\end{array}$ & $\mathbf{X}$ \\
\hline $\begin{array}{l}\text { Acopio y procesamiento de información para la conformación de } \\
\text { indicadores de Mantenimiento }\end{array}$ & $\mathbf{X}$ \\
\hline Capacitación de personal operativo y administrativo & \\
\hline
\end{tabular}

$\mathbf{X}^{\star}$ : Válido regularmente para la operación de equipos especializados, como por ejemplo instrumental médico, equipos para Mantenimiento Predictivo, etc.

Para el caso de pequeñas empresas frecuentemente ocurre que hay un jefe o responsable de Mantenimiento con carácter de polivalente o "todero", es decir, todas las tareas (planeación, programación, supervisión, elaboración de informes, etc.) están concentradas en una persona, regularmente la misma que tiene a su cargo el personal operativo (interno o por outsourcing).

Respecto de las microempresas regularmente el caso es más dramático en la realidad colombiana, donde por cuestiones económicas y de visión no hay un encargado de mantenimiento y casi todo es correctivo (programado o de emergencia), liderado por un operario experto, o directamente por el propietario de la microempresa. 
Capítulo 3 



\section{Mantenimiento preventivo (Preventive Maintenance)}

\subsection{Introducción}

El Mantenimiento Preventivo es el sistema de Mantenimiento cuyo objetivo esencial es prevenir la ocurrencia de fallas en un sistema productivo, con base en la ejecución de unas tareas básicas (Observar, inspeccionar, calibrar, ajustar, cambiar, lubricar, reparar, etc.), a unas frecuencias predeterminadas, asociadas a cada ciclo productivo en particular. La ejecución de las tareas básicas puede indicar la necesidad de realizar tareas programadas adicionales (mantenimiento correctivo programado, modificaciones, overhaul, etc.). El Mantenimiento Preventivo es el sistema de Mantenimiento más ampliamente aplicado por las grandes empresas del Eje Cafetero y del país $[8,9]$.

La figura 27 ilustra el comportamiento del Mantenimiento Preventivo, en función del nivel de rendimiento óptimo y del tiempo de operación de la máquina/equipo. Las letras $V_{i}$ corresponden a las visitas preventivas periódicas a la máquina/equipo; el ideal es que con base al conocimiento que se tenga del comportamiento y rendimiento de la máquina/equipo (límite de admisibilidad investigado) se efectúe una parada preventiva antes de que ocurra un fallo cataléctico; la parada preventiva dura un lapso TA (tiempo de alistamiento), durante el cual se deben efectuar unas tareas programadas y otras emergentes en función de los resultados de las inspecciones (Mantenimiento correctivo programado). Con el pasar del tiempo los Tiempos entre Fallas $T B F_{i}$ (Time Between Failure) se irán acortando, por efectos de inadecuación, obsolescencia e ineficiencia (ver numeral 1.7), en otras palabras, el estado real poco a poco se irá alejando del estado teórico o nominal, razón por la cual el estado nominal deberá ser revaluado paulatinamente (Ver numeral 1.2.2.2); los encargados del mantenimiento deberán ir ajustando los $T B F_{i}$ para que las paradas programadas o intervenciones preventivas se realicen antes de que el nivel de rendimiento sea igual o inferior al límite de admisibilidad investigado, o en términos simples antes de que ocurra una avería mayor o falla funcional. 
Figura 27. Ciclo gráfico del Mantenimiento Preventivo [4]

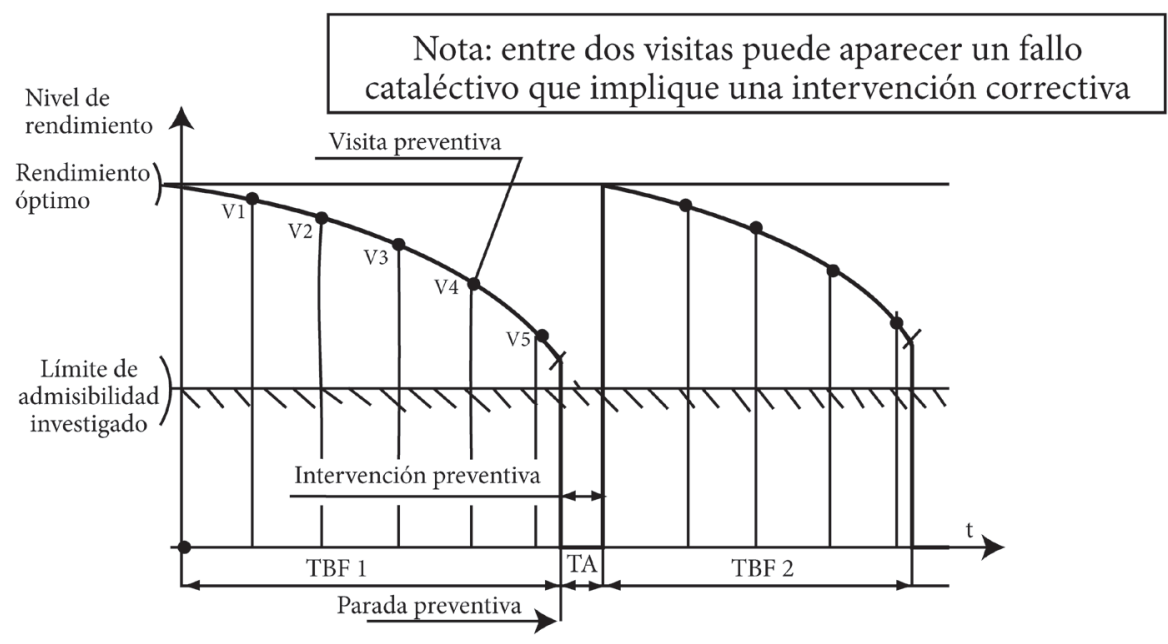

La figura 28 (a) recuerda que se debe alcanzar un punto de equilibrio entre la Carga de Trabajo de Preventivo y la de Correctivo, llamado carga optimizada. A la derecha de la carga optimizada, por mucho más preventivo que se haga, siempre habrá una carga residual (e irreducible) de Mantenimiento Correctivo (que se espera que en lo posible sea Correctivo programado).

Como se mencionó en la Tabla 5 (numeral 1.5.3), una de las principales desventajas del Preventivo radica en que se puede llegar fácilmente a excesos en carga de trabajo y obviamente a sobrecostos innecesarios. La figura 28 (b) refleja esta realidad, la cual es aplicable a muchos otros ámbitos, en el sentido de que "Poco es malo y mucho también"; el anterior adagio aplicado en Mantenimiento Preventivo, indica que hacerlo de manera deficiente (poco o nulo Preventivo y mucho Corrrectivo) es muy costoso y hacer Preventivo en exceso es también sumamente costoso, sin que reporte beneficios adicionales. La curva de Costo Total de Mantenimiento presenta sus valores más bajos, en los rangos comprendidos entre el (22-42) \% de Preventivo y entre el (52-72)\% de Correctivo, observándose una relación "ideal" desde el punto de vista de costos, de 30\% de Preventivo y 56\% de Correctivo. Por supuesto, estos son rangos generales, hay industrias específicas que requieren mayores o menores cantidades de horas de Preventivo o de Correctivo. 
Figura 28. Ciclo gráfico del Mantenimiento Preventivo. (a) Aspecto de carga de Trabajo. (b) Aspecto económico [4]

\section{a) Influencia en la carga de trabajo}

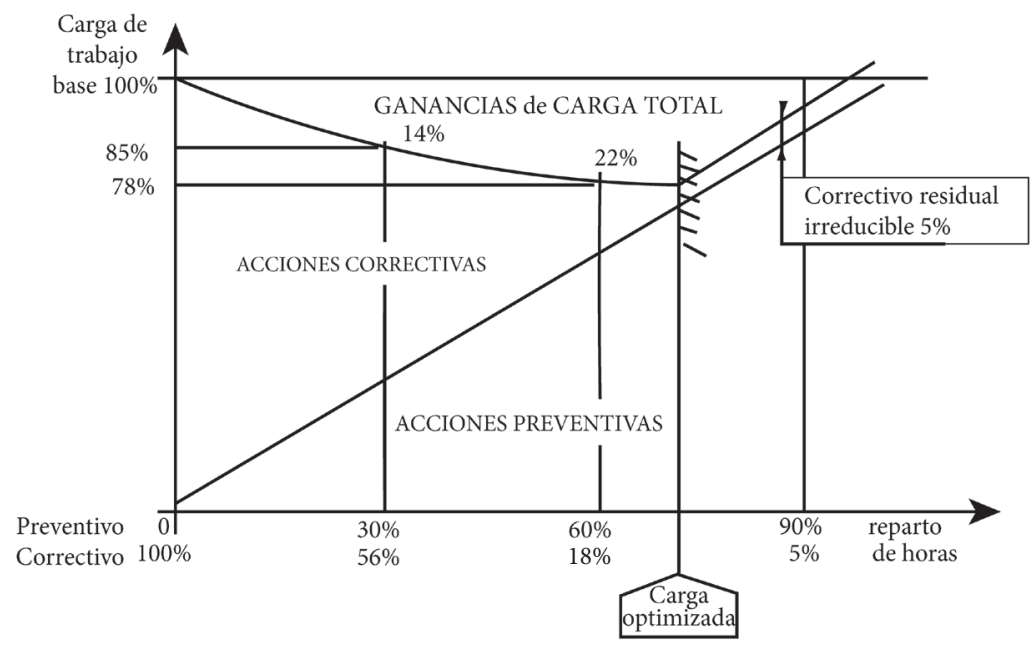

El 5\% de correctivo llamado "residual" es inevitable 
Continuación Figura 28. Ciclo gráfico del Mantenimiento Preventivo. (b) Aspecto económico [4]

\section{B) Aspecto económico}

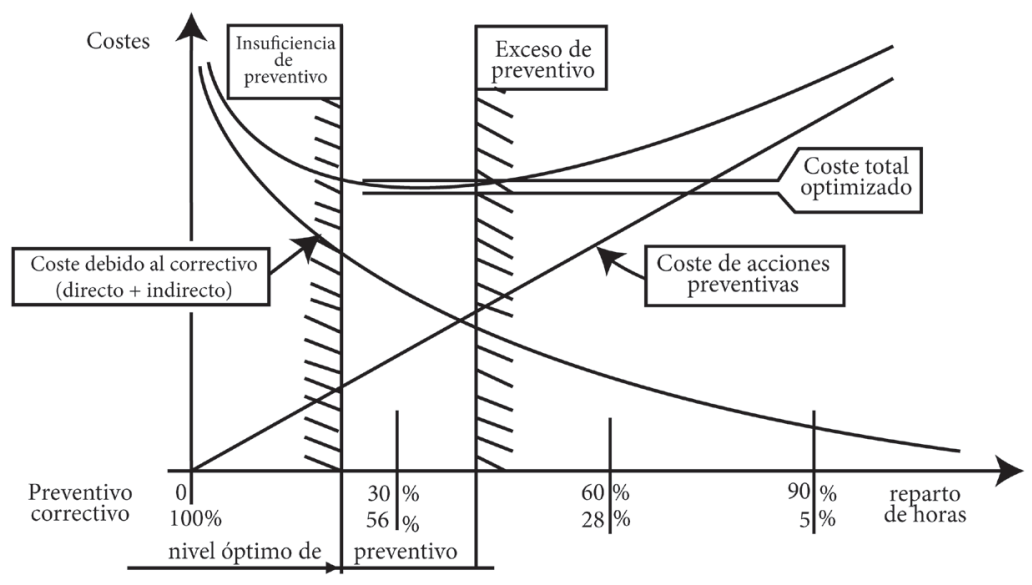

\section{"Hacer mantenimiento no es el preventivo a cualquier precio"}

\subsection{Pasos para implementar un plan de Mantenimiento Preventivo}

A continuación se presenta una metodología general para estructurar un plan de Mantenimiento Preventivo, tomando como punto de partida la situación real muy común "que no hay nada", o en otras palabras se viene haciendo estrictamente Correctivo. En este contexto surge la siguiente serie de preguntas lógicas mínimas:

¿Sobre qué máquinas/equipos se va a intervenir? ¿Qué tareas se van a hacer? ¿Con qué gente / equipos de apoyo / herramientas / insumos / materiales? ¿Cuándo se van a realizar? ¿Cuál es el procedimiento de ejecución? ¿Cuánto duran las tareas? ¿Qué formatos van a apoyar la recolección de información, de manera ordenada? ¿Cómo se va a medir la efectividad de resultados?

La solución a las anteriores preguntas entrega el orden descrito a continuación:

- Inventario de máquinas, equipos, inmuebles y vehículos que serán cobijados por el plan de mantenimiento.

- Codificación de las máquinas, equipos, inmuebles y vehículos.

- Creación de la Tarjeta Maestra de Datos TMD 
- Creación de las Hojas de vida de los equipos

- Relación de requerimientos e instructivos

- Programación de actividades (tablero de control) y balanceo

- Elaboración de las Rutinas Básicas de Mantenimiento RBM

- Definición y creación de formatos de apoyo a la gestión del Mantenimiento (TMD, hojas de vida, órdenes de trabajo, indicadores, etc.)

- Sistematización de la información.

\subsubsection{Inventario de equipos, inmuebles y vehículos}

Se busca con esta tarea elaborar el censo o listado de las máquinas y equipos que serán cobijados en el Programa de mantenimiento, es decir responder la pregunta ¿Sobre qué máquinas/equipos se va a intervenir? Con este inventario se conforma un archivo Maestro de máquinas, debidamente codificado. En este punto es necesario tener en cuenta que este archivo puede ser elaborado en Hoja electrónica (para micros y pequeñas empresas) o en el módulo respectivo de un Software de Mantenimiento o CMMS (Computarized Maintenance Management System (ver numeral 3.2.10), para el caso de las medianas y grandes empresas.

Las personas responsables de elaborar el inventario deben prestarle la atención adecuada, para evitar sub o sobre-valoraciones que podrían llevar a situaciones en las cuales máquinas/equipos no relevantes queden cobijados por el programa de Mantenimiento, o por el contrario, máquinas/equipos importantes queden fuera de él.

\subsubsection{Codificación de los equipos}

Una vez que se ha levantado el censo de las diferentes máquinas y equipos que han de ser cobijados por un programa de Mantenimiento, es necesario realizar una decodificación de los mismos, es decir, asignar una identificación numérica o alfanumérica, con el fin que haya una identificación precisa y unívoca de cada uno de ellos. La codificación de la maquinaria y equipo es un asunto propio de cada empresa, y existen diferentes métodos para ello, pasando por diferentes niveles de complejidad, sin embargo existen unas directrices generales para este proceso:

- Deben permitir una identificación rápida del equipo.

- Deben ser cortos, sencillos y fáciles de desglosar.

- El costo de su implementación debe ser razonable (pintura, adhesivos, placas identificadoras de activo fijo, códigos de barras, etc.).

- La codificación usada debe guardar relación con otros sistemas de codificación de la empresa, particularmente con los códigos contables.

Una forma de realizar la codificación de maquinaria y equipos, es dividiendo una planta o empresa en áreas, secciones, máquinas/equipos, componentes y partes o elementos, teniendo presente el respectivo Layout de Planta (Ver Anexo 1).

Áreas de Planta: Son procesos en operación o zonas completamente definidas en la Planta, por ejemplo: molienda caña, refinación, transporte, etc.

Sección o grupo: Son conjuntos de máquinas/equipos que materializan un proceso dentro de un área específica, por ejemplo: torres de destilación, torres de enfriamiento, hornos, generación de vapor, etc. 
Máquina/Equipo: Recurso físico que hace parte de una sección, tales como unidad compresora, sistema de bombeo, banda transportadora, torno, inyectora de plástico, etc.

Componente: Son partes de una máquina/equipo, que a su vez están formadas por elementos, pero que individualmente no pueden ser consideradas como un equipo. Ejemplo, motores eléctricos, motores hidráulicos, reductores de velocidad, actuadores (cilindros hidráulicos y neumáticos), válvulas, etc.

Parte o elemento: cada una de las subdivisiones de un componente, por ejemplo: tornillería, sellos, rodamientos, etc.

Seguidamente se presenta un ejemplo de directriz de codificación de máquinas/equipos, aplicable a una gran empresa (figura 29).

Figura 29. Directriz de codificación para una gran empresa [el Autor]

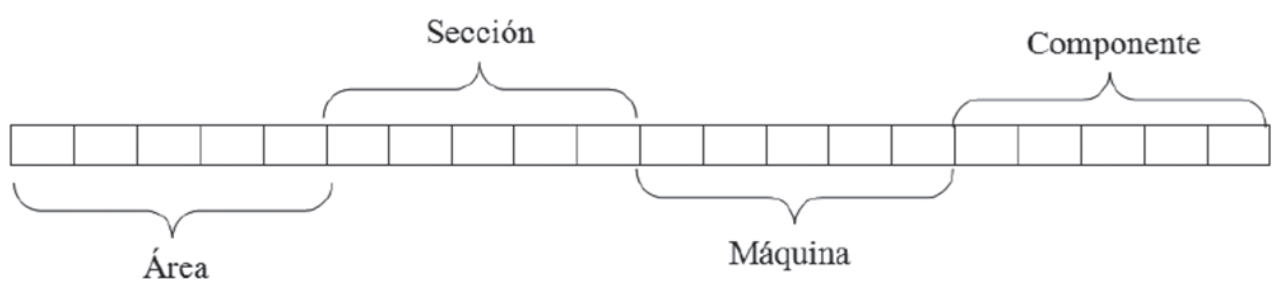
$\begin{array}{lll}\text { Para área } & : & \text { (2) caracteres alfabéticos y (3) numéricos } \\ \text { Para sección } & : & \text { " }\end{array}$
Para máquina : $\quad$ ler dígito. Indica clase de máquina
$2^{\circ}$ dígito. Indica el tipo dentro de la clase. 1
$3^{\circ}, 4^{\circ}$ y $5^{\circ}$ dígito. Indican el consecutivo.

Para componente : $\quad$ (1) carácter alfabético y (3) numéricos.

Como un complemento adicional, se puede llegar al nivel de parte o repuesto, en cuyo caso regularmente se utiliza una serie predefinida de números.

Tomando como base la directriz anterior, se presenta un ejemplo de codificación, aplicado a una Planta Cementera, Área de molienda de materia prima (puzolana, yeso y mineral de hierro), dosificación de materia prima (por peso), banda-báscula, reductor de velocidad.

$\begin{array}{llll}\text { Área } & : & \text { SI } \mathbf{1 0 0} \text { Molienda materia prima } \\ \text { Sección } & : & \text { SS } \mathbf{1 0 0} \text { Dosificación materia prima } \\ \text { Equipo } & : & \mathbf{0 1 0 0 1} 0 \text { Banda-báscula arena }\end{array}$
0: Bandas transportadoras
1: Con báscula
001: Consecutivo
Componente: R-001
R: Reductor de velocidad
001: Consecutivo. 
Una vez hecha la codificación de maquinaria y equipos es posible:

- Recopilar datos e información acerca de las labores de Mantenimiento, asociándolas a un equipo en particular, a una familia de equipos, a una sección o a un área.

- Con la ayuda de software contable y de Mantenimiento es posible establecer el coste del mantenimiento (Mano de obra y repuestos), bien sea por máquina/equipo, por familias de máquinas/equipos, por secciones, por áreas, etc.

- Enlazar de manera clara las políticas y estrategias de Mantenimiento, con máquinas/equipos plenamente identificados física y contablemente.

- Realizar traslados de máquinas/equipos entre áreas, secciones o sucursales, minimizando los traumatismos operativos y contables.

\subsubsection{Creación de la Tarjeta Maestra de Datos TMD, para cada máquina/equipo}

Una TMD es un formato donde se consigna información general y específica de una máquina/equipo/ proceso, tales como su identificación, información comercial de vendedor y representante, capacidades de trabajo, condiciones operativas y especificaciones técnicas de los componentes principales.

No hay un formato estandarizado para las TMD, sin embargo, su diseño debe contener la información suficiente para conocer de manera rápida y sencilla la máquina/equipo/proceso. Un modelo de Tarjeta Maestra de datos puede constar de:

Información general de la empresa. Nombre. Identificación ISO 9000 del formato (código, fecha modificación).

Características generales de la máquina/equipo. Se menciona la información básica de la maquina como código de activo fijo, nombre, marca, modelo, serie, año de fabricación, año de instalación, código o número de catálogo, fotografía (opcional), etc.

Información comercial. Hace referencia a la información necesaria para ubicar el proveedor y al representante comercial, en el país o en la ciudad (país y ciudad de origen, razón social empresa, dirección, teléfono, e-mail, página web, $\mathrm{n}^{\circ}$ de pedido).

Este tipo de información tiene como propósito el tener disponible un contacto vigente para solicitud de garantías, de catálogos, de repuestos, de servicio técnico, consultas operativas, etc.

Características operativas. Corresponden a información sobre las dimensiones principales, especificaciones y condiciones de trabajo de la máquina/equipo. Dentro de dimensiones principales se tiene longitud, altura, profundidad y el peso bruto. Las especificaciones y condiciones de trabajo informan la capacidad productiva del equipo, la criticidad del equipo en el proceso productivo, los turnos de trabajo, los servicios que requiere para poder operar (electricidad, vapor, aire comprimido, etc.).

Es importante resaltar que a cualquier máquina/equipo siempre será posible definirle su capacidad productiva o de trabajo, en variables de Ingeniería. Ejemplos: flujos volumétricos o másicos, flujos de calor, fuerzas aplicadas y sobre qué área, piezas/hora, recorridos, etc. En lo concerniente a servicios requeridos por la máquina/equipo también es necesario y conveniente definirlos en función de variables de ingeniería, como por ejemplo corrientes, tensiones, flujo de vapor con la presión y temperaturas asociados, presión y flujo de aire, etc. 
Características de los componentes principales. Da cuenta de los reductores, bombas, ventiladores, actuadores, etc., (y de sus especificaciones principales), vitales para la operación de la máquina/equipo. Este apartado es importante para la solicitud de reposiciones (refacciones) y de unidades de repuesto. Dado que muchas máquinas poseen componentes genéricos, el disponer de una relación de este tipo de componentes ayudará posteriormente a identificar la estandarización e intercambiabilidad de componentes y partes, con el fin de minimizar el número de unidades de repuesto.

La figura 30 ilustra una tarjeta maestra de datos correspondiente a una banda transportadora.

Es necesario aclarar que en los casos de secciones o grupos (numeral 3.2.2) que materializan un producto, por ejemplo una línea de corte longitudinal o Slitter en una fábrica de tubos o láminas a medida, se suele elaborar una TMD principal para la sección o grupo de máquinas (vistas como un todo), y luego se elaboran TMD auxiliares para cada uno de las máquinas/equipos de la línea. Las TMD auxiliares son invocadas o referenciadas en la parte correspondiente a componentes principales de la TMD principal.

Figura 30. Tarjeta Maestra de Datos de banda transportadora [13]

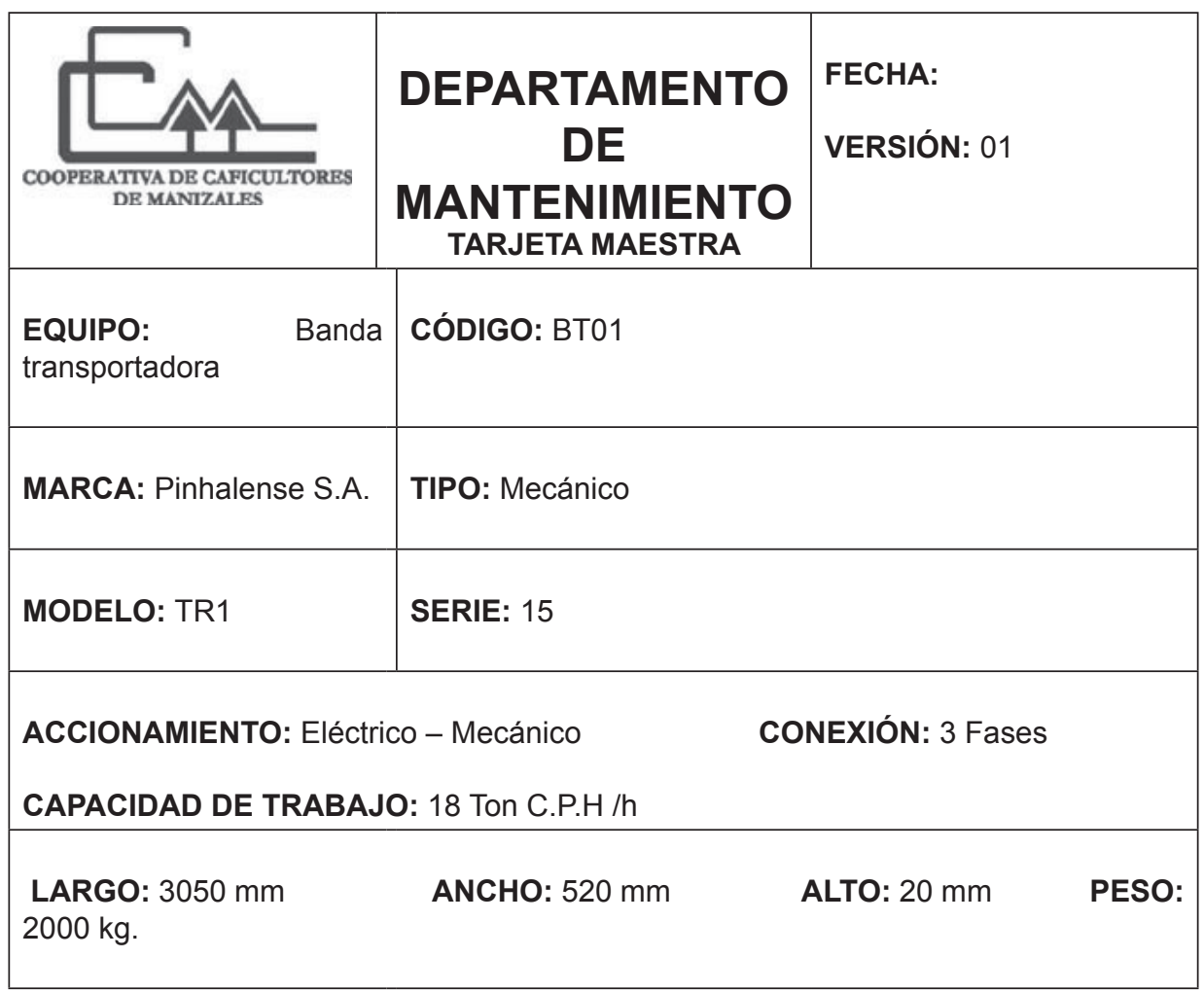




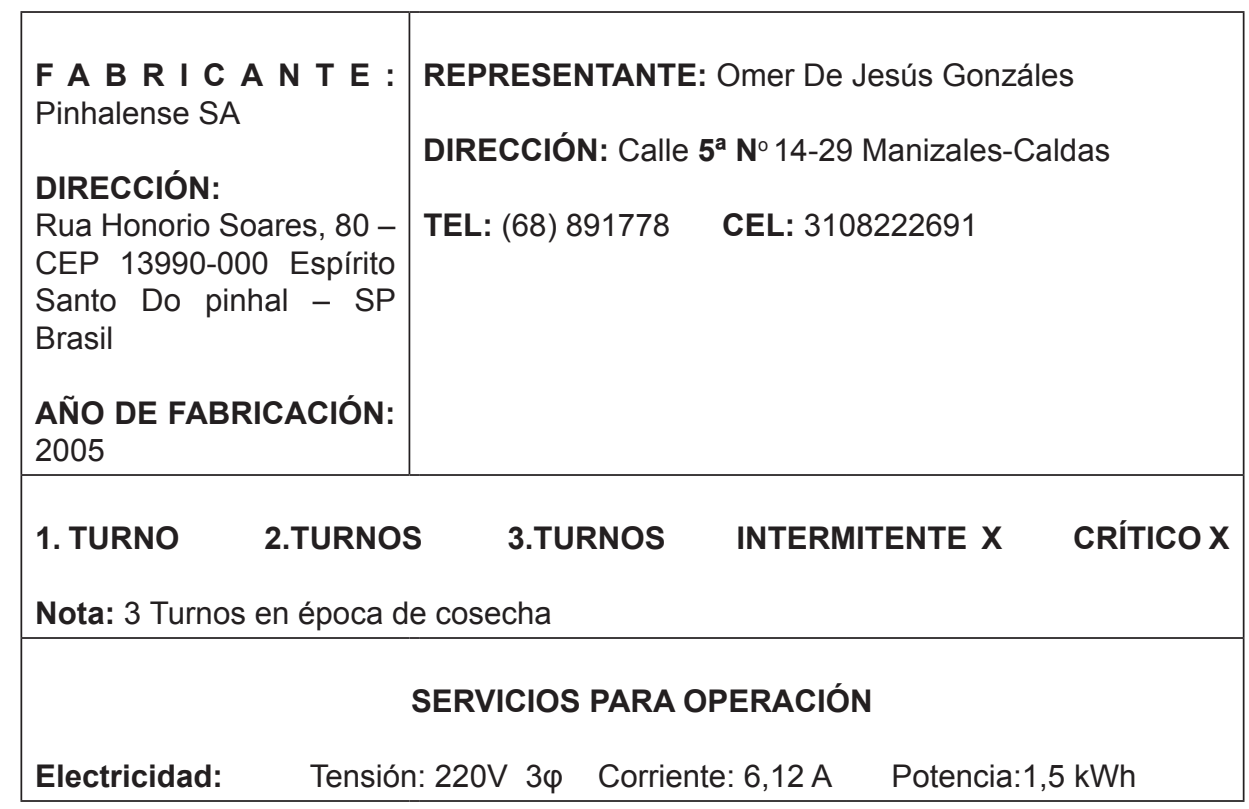

\subsubsection{Creación de las Hojas de Vida de máquinas/equipos}

Respecto de la hoja de vida hay dos visiones, dependiendo de la empresa y de cómo manejen la información.

Visión completa. La Hoja de Vida es la carpeta que contiene toda la información de la máquina/equipo, referente a Tarjeta Maestra de Datos, relación de requerimientos, Instructivos de mantenimiento, cronogramas de actividades, Rutinas Básicas de Mantenimiento RBM, catálogos de partes y de servicio, listados de repuestos, planos y por último el Historial de Mantenimiento. Este es el "debiera", es decir que de manera centralizada y ordenada se disponga de la información completa de la máquina/equipo.

Visión simple. En muchas pequeñas y micro empresas la cultura de manejo de la información es muy pobre y la Hoja de Vida se limita a un Historial de Mantenimiento.

El Historial de Mantenimiento es un formato (símil de la Historia clínica de un paciente) donde se consignan en orden cronológico las reparaciones y modificaciones importantes hechas a la máquina. El Historial de Mantenimiento puede estar en copia dura o archivo electrónico. La Tabla 9 ilustra un modelo básico de un Historial de Mantenimiento. 
Tabla 9. Modelo básico de Historial de Mantenimiento [el Autor]

\begin{tabular}{|l|l|l|l|l|}
\hline Ítem & Fecha & Descripción & Repuestos e insumos & Observaciones \\
\hline & & & & \\
\hline & & & & \\
\hline
\end{tabular}

Es importante aclarar que en el Historial de Mantenimiento regularmente no se consigna la información correspondiente a mantenimientos rutinarios (limpiezas, lubricaciones periódicas, refacciones menores, etc.), exceptuando casos especiales. Un cambio de aceite y filtros de un motor diesel no se consigna regularmente en el Historial de Mantenimiento, pero si por ejemplo, ocurrió un daño de la empaquetadura de la bomba de agua con lo cual se contaminó el aceite (por emulsión), se hace entonces necesario el recambio de empaques (de la bomba), aceite y filtros (del motor), y en este caso sí es pertinente hacer la anotación en la Hoja de Vida.

En muchas situaciones reales se presenta el caso que no hay memoria escrita al momento de elaborar el plan de mantenimiento preventivo, por lo cual es necesario acudir a la memoria colectiva e individual de los ejecutantes, personas que pueden ayudar a recordar sucesos importantes relacionados con refacciones importantes y overhaul.

En las grandes empresas que poseen CMMS (ver numeral 3.2.10) embebidos en software corporativos estilan diligenciar en el Historial de Mantenimiento solo el número de la orden de trabajo OT (ver numeral 3.2.9) y el vale de salida de almacén (Documento que referencia los elementos consumidos del Almacén para una cierta OT), para referenciar los Mantenimiento rutinarios, con el objetivo de no atiborrar el Historial con información no relevante, y solo en el caso de reparaciones mayores o modificaciones amplían la descripción.

\subsubsection{Relación de requerimientos de Mantenimiento}

Este numeral busca definir las actividades o tareas que se efectuarán sobre las máquinas/equipos cobijados por el Plan de Mantenimiento, o en otras palabras, responder la pregunta ¿Qué tareas se van a hacer?

Con base en el estudio y conocimiento de los procesos/máquinas/equipos debe elaborarse un listado de actividades de mantenimiento requeridos por cada máquina/equipo, asociadas a una frecuencia propia del proceso (horas de servicio, distancia recorrida, unidades producidas, etc.). A este listado también suele llamarse Maestro de Actividades.

Las fuentes principales de información para conformar el Listado de requerimientos son:

- Manuales de servicio

- La internet

- Información disponible en asociaciones gremiales (por ejemplo Asocaña, Fedemetal, ACIEM)

- Consultas con colegas que laboren en otras empresas del mismo gremio.

Una forma usual de subdividir las tareas de Mantenimiento Preventivo es clasificándolas en los siguientes grupos genéricos: 
Lubricación

Electricidad

Mecánica

Instrumentación

Una vez clasificadas las tareas en estos subgrupos, se les asigna un consecutivo (L01 a L $x y$ ), lo que arroja el nombre genérico de Requerimientos LEMI o LEM, y es usual escuchar el nombre de Mantenimiento Preventivo o Mantenimiento LEMI.

\subsubsection{Instructivos de Mantenimiento}

También llamados Estándares o Protocolos, son documentos (copia dura o digitales) en los que se consigna la información necesaria para la ejecución física de cada requerimiento de mantenimiento, es decir, nombre y código de la máquina, nombre y código del instructivo, medidas de seguridad, materiales e insumos necesarios, herramientas necesarias, procedimiento de ejecución, y tiempo estimado de ejecución. Básicamente los instructivos de Mantenimiento responden a la preguntas: ¿Con qué gente / equipos de apoyo / herramientas / insumos / materiales se hará la intervención de Mantenimiento? y ¿Cuánto duran las tareas?

Los instructivos se pueden dividir en genéricos y específicos. Los instructivos genéricos describen procedimientos generales que se pueden aplicar de manera similar en distintas máquinas/equipos, mientras que los instructivos específicos por su parte se aplican a mecanismos o partes de máquinas que o son "únicos" (por complejidad, por tamaño, por reglaje específico, etc.) o difícilmente se encontrarán en otras secciones de la planta o fábrica, por ejemplo "ajuste del gap de los mantos de un hidro-cono (en la industria minera)”. Un ejemplo de un instructivo genérico se describirá seguidamente.

Muchas máquinas y equipos poseen un cárter o depósito de aceite (elemento 4, figura 31). Para inspeccionar el nivel de aceite del cárter, sin retirar el separador aceite - aire (elemento 2, figura 31), se hace uso de una mirilla de vidrio (elemento 3, figura 31). El instructivo genérico para este procedimiento se podría llamar L-01 Revisión de nivel de aceite, y consistiría básicamente en: ... inspeccionar visualmente el nivel en la mirilla. Completar en caso de ser necesario... El mismo código L-01 se aplicará para todas las máquinas/equipos que posean cárter, sin necesidad de crear nuevos instructivos que sobrecarguen al sistema de información. Cuando se presentan instructivos genéricos, no son asignados a una máquina/equipo en particular, sino que quedan disponibles para invocarlos o referenciarlos en las diferentes máquinas/equipos en que serán aplicados.

Figura 31. Depósito y mirilla del nivel de aceite [14]

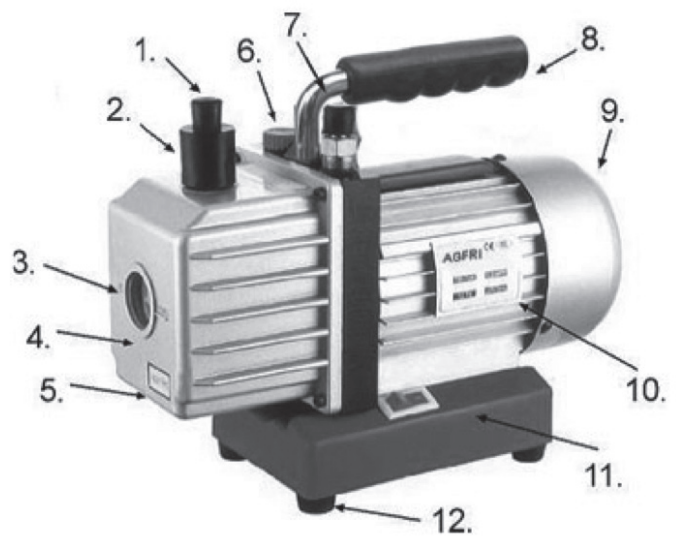


Los Instructivos de Mantenimiento cumplen varias funciones:

- Plasman por escrito parte de la experticia que adquieren los ejecutantes, evitando que haya "empleados indispensables".

- Documentan los procedimientos y sirven de respaldo para los círculos de calidad.

- Retroalimentación inquietudes, observaciones, tiempos, etc., propios de la ejecución física de las tareas de Mantenimiento.

Para ilustrar un poco lo concerniente a listado de requerimientos y redacción de un Instructivo de Mantenimiento, se tomará como objeto de estudio el compresor de pistón (de acople directo) mostrado en la figura 32. Este equipo es posible dividirlo en los siguientes subsistemas:

$\begin{array}{ll}\text { - Estructura y depósito } & \text { - Grupo motor } \\ \text { - Grupo compresor } & \text { - Instrumentación }\end{array}$

Figura 32. Compresor alternativo de acople directo [15]

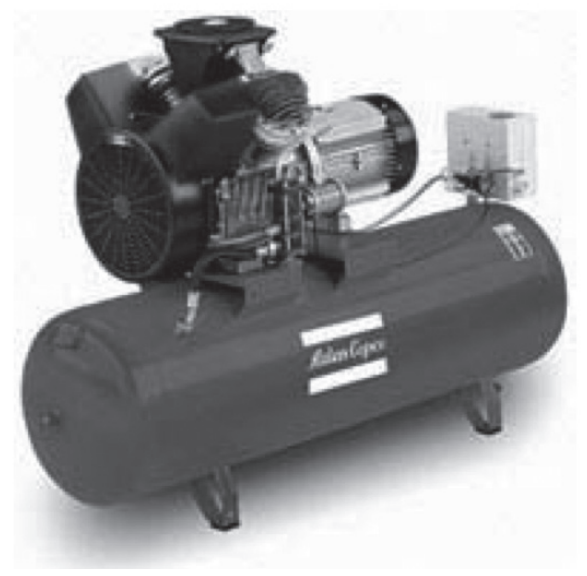

Un listado básico de tareas (con sus respectivas frecuencias) a efectuarle al compresor es el descrito en la Tabla 10, y a cada tarea le debe corresponder luego su respectivo Instructivo.

Tabla 10. Listado de requerimientos para compresor de pistón [el Autor]

\begin{tabular}{|c|c|c|c|}
\hline Subsistema & Tareas diarias & Tareas mensuales & Tareas semestrales \\
\hline $\begin{array}{c}\text { Estructura y } \\
\text { depósito }\end{array}$ & $\begin{array}{c}\text { Drenar el agua } \\
\text { del depósito }\end{array}$ & & $\begin{array}{c}\text { Chequear estado de la estructura en } \\
\text { busca de fisuras y tornillería suelta o } \\
\text { faltante }\end{array}$ \\
\hline Grupo motor & & $\begin{array}{c}\text { Mantenimiento eléctrico a bornera y } \\
\text { guardamotor }\end{array}$ \\
\hline
\end{tabular}




\begin{tabular}{|c|c|c|c|}
\hline $\begin{array}{c}\text { Grupo } \\
\text { compresor }\end{array}$ & $\begin{array}{c}\text { Chequear el nivel } \\
\text { de aceite del } \\
\text { cárter }\end{array}$ & $\begin{array}{c}\text { Limpieza de filtro } \\
\text { de aire }\end{array}$ & Cambio de aceite y filtros \\
\hline Instrumentación & & $\begin{array}{c}\text { Verificar estado del } \\
\text { manómetro }\end{array}$ & $\begin{array}{c}\text { - Chequear la correcta operación del } \\
\text { presóstato. } \\
\text { - Verificar la correcta operación de la } \\
\text { válvula de seguridad }\end{array}$ \\
\hline
\end{tabular}

Ahora bien, el Instructivo correspondiente a la tarea Cambio de aceite y filtros es descrito a continuación.

\section{06 \\ Cambio de aceite y filtros a compresor de pistón}

\section{Recomendaciones}

- Preferiblemente poner en operación el compresor por un lapso de $5 \mathrm{~min}$, antes de ejecutar el instructivo, con el fin de que la suciedad del aceite fluya fácilmente al momento de drenarlo.

- Tener en cuenta el programa RESPEL de la empresa, en lo concerniente a disposición de residuos.

\section{Medidas de seguridad.}

- Apagar la máquina y desconectar la fuente de alimentación.

\section{Material necesario.}

Embudo mediano

Aceite SAE 50, cantidad: 1 gal

Estopa

Recipiente de 1gal (para recoger el aceite usado)

Filtro LPA 001, cantidad: 1 unidad

\section{Herramientas necesarias.}

Llave bocafija o estría, de $14 \mathrm{~mm}$.

\section{Procedimiento.}

Limpiar externamente el cárter con la estopa. Utilizando la llave bocafija retirar el tapón de llenado del cárter, colocarlo a un lado de la máquina.

Ubicar el recipiente para aceite usado justo abajo del tapón de drenaje, y con la llave bocafija retirar el tapón de drenaje para que fluya el aceite sucio.

Mientras drena el aceite sucio, remover la tapa del porta-filtro (desenroscar tuerca mariposa) y retirar el filtro viejo, limpiar cuidadosamente el porta-filtro, instalar el filtro nuevo y asegurar nuevamente la tapa. 
Una vez que haya drenado todo el aceite sucio, instalar nuevamente el tapón de drenaje y aplicar el aceite nuevo. Instalar el tapón de llenado. Verificar el correcto nivel en la mirilla.

Energizar nuevamente el compresor, ponerlo en funcionamiento validando su correcta operación. Disponer el aceite y filtro usados en los sitios indicados por el RESPEL.

Retirar herramientas y dejar el sitio limpio y ordenado.

Tiempo estimado de ejecución: 30 minutos.

Si en un Instructivo de Mantenimiento el procedimiento a ilustrar es muy complejo, es usual que haya apoyo gráfico de fotografías o imágenes del procedimiento, sobre las cuales se realizan indicaciones de ajustes, identificación de puntos específicos, etc.

\subsubsection{Programación (Tablero de control)}

En este numeral la pregunta a responder es ¿Cuándo se van a realizar las tareas LEMI? Esta pregunta se responde con la elaboración de los Cronogramas de Mantenimiento o Tableros de control, los cuales indican a los planeadores y ejecutantes del mantenimiento el momento preciso en que se deben llevar a cabo las labores de Mantenimiento. La indicación de la ejecución física de la labor se lleva a cabo generando una Orden de trabajo (ver numeral 3.2.9). Un Tablero de control debe ir acompañado de un mecanismo para su administración, es decir, alimentación de horómetros, contadores de producción, odómetros, etc.), de tal forma que haya control de cuándo se hizo la última tarea y cuándo será la próxima (ver numerales 3.2.9 y 3.2.11).

Los Tableros de control o Cronogramas de Mantenimiento se pueden elaborar en medio físico (cartelera) o digital, y una vez definidos es necesario hacerles un balanceo (ver Capítulo 4), para evitar que haya semanas sobrecargadas de trabajo, y otras desocupadas.

La elaboración de los Tableros de control, puede estar basada en las siguientes variables, dependiendo del tipo de industria en estudio:

- Por tiempo transcurrido.

- Por horas reales de servicio trabajadas o distancias recorridas.

- Por unidades producidas u otras variables.

3.2.7.1. Tableros de control por tiempo transcurrido. Se aplican en empresas que trabajan por turnos (regularmente de ocho horas) y el ritmo de producción es aproximadamente constante. Basado en este panorama se definen unas frecuencias de ejecución que pueden ser diarias, semanales, trimestrales, anuales. Correspondientemente con las frecuencias anteriores aparecen Tableros de control diario y anual.

Los Tableros de control diarios (Tabla 11) se elaboran para un lapso de una semana y en ellos se consignan las actividades que deben ejecutarse todos los días o en lapsos inferiores a una semana. Cabe resaltar que el Instructivo L - 01 es común a las tres máquinas presentadas, lo que indica que se trata de un instructivo genérico (ver numeral 3.2.6). Algunas empresas estilan elaborar Protocolos o Rutas diarias de Mantenimiento (ver numeral 3.2.8), a cambio de elaborar los Tableros de control diarios. 
Tabla 11. Tablero de control diario. Adaptado de [1]

\begin{tabular}{|l|l|l|l|l|l|l|l|}
\hline Código & Máquina & Lunes & Martes & Miércoles & Jueves & Viernes & Sábado \\
\hline & & & & & & & \\
\hline Mn01 & Manejadora & $\mathrm{L}-01$ & $\mathrm{~L}-01$ & $\mathrm{~L}-01$ & $\mathrm{~L}-01$ & $\mathrm{~L}-01$ & $\mathrm{~L}-01$ \\
\hline & & & $\mathrm{L}-02$ & & $\mathrm{~L}-02$ & & $\mathrm{~L}-02$ \\
\hline Ev 01 & Evaporadora & $\mathrm{L}-01$ & $\mathrm{~L}-01$ & $\mathrm{~L}-01$ & $\mathrm{~L}-01$ & $\mathrm{~L}-01$ & $\mathrm{~L}-01$ \\
\hline Cn 01 & Condensadora & $\mathrm{L}-01$ & $\mathrm{~L}-01$ & $\mathrm{~L}-01$ & $\mathrm{~L}-01$ & $\mathrm{~L}-01$ & $\mathrm{~L}-01$ \\
\hline & & $\mathrm{M}-22$ & & & $\mathrm{M}-22$ & & \\
\hline
\end{tabular}

Los Tableros de control anuales (Tabla 12) se elaboran para un período de un año, subdividiéndolos en 52 semanas (un año comercial) y en ellos se consignan las actividades que deben ejecutarse por períodos semanales o múltiplos de ellas.

Tabla 12. Tablero de control anual [1]

\begin{tabular}{|c|c|c|c|c|c|c|c|c|}
\hline Código & Semanas & $\mathbf{1}$ & $\mathbf{2}$ & $\mathbf{3}$ & $\mathbf{4}$ & $\ldots \ldots \ldots .$. & $\mathbf{5 1}$ & $\mathbf{5 2}$ \\
\hline & Máquinas & & & & & & & \\
\hline Mn01 & Manejadora & $\mathrm{L}-01$ & $\mathrm{E}-17$ & $\mathrm{~L}-02$ & $\mathrm{~L}-10$ & & $\mathrm{~L}-01$ & $\mathrm{M}-15$ \\
\hline & & $\mathrm{L}-12$ & & $\mathrm{E}-23$ & & & $\mathrm{~L}-12$ & \\
\hline Ev 01 & Evaporadora & $\mathrm{L}-02$ & $\mathrm{E}-25$ & $\mathrm{~L}-16$ & $\mathrm{E}-10$ & & $\mathrm{~L}-02$ & $\mathrm{E}-26$ \\
\hline & & $\mathrm{L}-15$ & $\mathrm{M}-17$ & $\mathrm{M}-11$ & & & $\mathrm{~L}-10$ & $\mathrm{M}-18$ \\
\hline Cn 01 & Condensadora & $\mathrm{L}-01$ & $\mathrm{E}-15$ & $\mathrm{E}-18$ & $\mathrm{M}-10$ & & $\mathrm{~L}-01$ & $\mathrm{M}-22$ \\
\hline & & $\mathrm{M}-22$ & & & & & $\mathrm{M}-20$ & $\mathrm{E}-31$ \\
\hline
\end{tabular}

Con los Tableros de control por tiempo transcurrido es necesario ser cuidadoso en los casos, en que haya incremento o reducción de turnos, con respecto al ritmo de trabajo normal, para no ejecutar mantenimiento en exceso o en defecto, puesto que en ambos casos habrá pérdidas y despilfarros.

3.2.7.2. Tableros de control por horas reales de servicio trabajadas o distancias recorridas. Este tipo de tableros de control se aplica mucho en el área automovilística, para equipo minero, equipo fuera de carretera, industria de la construcción, entre otros; en los casos anteriores importa ¿Cuánto tiempo el equipo estuvo en operación (la distancia recorrida es muy corta)? o ¿Cuánta distancia recorrió el equipo (sin importar mucho la carga movilizada)? En ambos casos se hace necesario dotar los equipos de medidores de tiempo (horómetros como se les llama normalmente en la industria) o de cuentakilómetros (Odómetros). Con este tipo de tableros de control se racionalizan mejor los recursos de mantenimiento empleados (y el lucro cesante de producción), en relación a los Tableros de control por tiempo transcurrido. La Tabla 13 presenta un fragmento de un Tablero de control por horas reales de servicio laboradas. 
3.2.7.3. Tableros de control por unidades producidas. Entre otras, se aplican en industrias como la metalmecánica y la petroquímica, donde es posible establecer contadores de producción, bien sea discreta o continua. Al igual que con los tableros de control por horas reales de servicio laboradas, se racionalizan mejor los recursos de mantenimiento empleados (y el lucro cesante de producción), en relación a los Tableros de control por tiempo transcurrido.

Tabla 13. Fragmento de Tablero de control por horas reales trabajadas [13]

\begin{tabular}{|l|c|c|c|c|c|c|}
\hline \multicolumn{2}{|c|}{ Actividad y horas de servicio } & 16 & 24 & 64 & 160 & 200 \\
\hline \multicolumn{2}{|c|}{ Código equipo } & & & & & M04 \\
\hline (G01-SA01 hasta G08-SA08), O01-SA09 & & & & M04 \\
\hline (G01-EH01 hasta G08-EH08), (O01-EH09) & M07 & & & & \\
\hline (G01-H01 hasta G08-H08), (O01-H09) & & & M11,M12 & & M04 \\
\hline G01-TR01 & & L04 & & & M04 \\
\hline (G02-TR02 hasta G08-TR08) & & L04 & & & \\
\hline
\end{tabular}

\subsubsection{Rutinas básicas de Mantenimiento RBM}

Las Rutinas Básicas de Mantenimiento RBM, constituyen un conjunto de tareas de Lubricación, Electricidad, Mecánica e Instrumentación, definidas en formatos estandarizados, que deben ser ejecutadas por un(os) operario(s), siguiendo una determinada ruta lógica dentro de la planta, sus áreas, las máquinas y al interior de estos, reduciendo el desperdicio de tiempo y recursos durante los traslados de los ejecutantes.

Para aclarar la intención de las RBM obsérvese el fragmento del Tablero de control mostrado en la Tabla 13, en la frecuencia correspondiente a 200 horas; el instructivo M-04 se le debe efectuar a veintiséis máquinas, distribuidas en cuatro secciones diferentes de la planta. Supóngase que una sola cuadrilla se encargará de ejecutar la tarea M-04, y que iniciará en la primera sección de la planta; podría ser que iniciaran con G01-SA01 y continuaran consecutivamente hasta llegar a G08-SA08, seguidamente intervendrían O01-SA09; en este punto se ha culminado la primera sección, la pregunta sería ahora ¿cuál es la sección más cercana a la primera? La que sea, hasta allí se deberá trasladar el personal con sus herramientas e insumos, minimizando distancias y tiempos, y así hasta culminar la tarea. El orden lógico de ejecución de este grupo de tareas deberá estar plasmado en una RBM.

Las frecuencias de las RBM por lo regular son: diarias, semanales, quincenales, mensuales, pero también pueden estar regidas por las frecuencias explicadas en 3.2.7.1, 3.2.7.2 y 3.2.7.3.

\section{El ¿quiénes y cuántos operarios ejecuten las RBM? depende entre otros aspectos de:}

- El layout de Planta y el tamaño de la empresa. Producción continua o discreta, una sola línea de producción o varias repartidas en diferentes áreas o secciones (ver Anexo 1), cantidad de máquinas/equipos, complejidad de los equipos, etc.

- El tiempo programable para Mantenimiento TPPM (ver Capítulo 4). Antes de iniciar la jornada, entre turnos, en las noches, al finalizar la jornada, entre cambios de referencia, etc. 
- El nivel de especialización de los operarios. Puede ser ejecutada por operarios "toderos", mecánicos, electricistas, lubricadores, instrumentistas, etc.

- El tipo de contratación. Personal propio o subcontratado (outsourcing).

\section{El tipo de tareas que se ejecutan en una RBM son:}

- Inspección y monitoreo de condiciones ambientales (temperatura, humedad relativa).

- Limpieza externa e interna de la máquina/equipo.

- Inspección externa e interna del equipo (visual, al tacto, auditiva o con instrumentación). Se deben ubicar partes sueltas, faltantes, rotas, fatigadas, defectuosas, fugas en mangueras, racores, tuberías, sobrecalentamiento, corrosión, desgaste, vibración, etc.

- Lubricación y engrase.

- Reemplazo de partes o componentes. Los reemplazos pueden haber sido previamente programados o ser el resultado de las inspecciones internas o externas previas.

- Ajuste y calibración. Puede ser necesario poner en marcha el equipo o no. Puede ser de naturaleza mecánica, eléctrica, electrónica, etc. Debe hacerse con base a normas, estándares o procedimientos pre-establecidos.

- Revisión de seguridad eléctrica (paros de emergencia, finales de carrera, interruptores de seguridad, etc.).

- Pruebas de operación del equipo. Procedimiento que se debe realizar una vez ejecutadas las tareas anteriores, en lo posible en compañía del operario del equipo.

\section{¿De dónde sale la directriz de las tareas a ejecutar en una RBM?}

- Recomendaciones del fabricante

- Listado de requerimientos LEMI

- Cronogramas de actividades

\section{¿Qué información básica debe llevar el formato de RBM?}

Código RBM, consecutivo u orden de ejecución (dentro de la máquina/equipo, dentro de la sección y dentro de las áreas de la Planta), parte o mecanismo a monitorear, insumos o materiales, tiempo estimado, instructivo de Mantenimiento asociado (si es necesario).

En el hipervínculo_http://carlos-montilla-utp.jimdo.com/complementos-libro-de-mantenimiento/ complementos-cap\%C3\%ADtulo-3-1/ se puede encontrar un ejemplo de RBM para una Planta hormigonera.

\subsubsection{Formatos y documentación básica para la administración del mantenimiento}

Este numeral pretende responder las preguntas: ¿Qué formatos van a apoyar la recolección y el procesamiento de información relativa a Mantenimiento? y ¿Cómo se va a medir la efectividad de resultados? La primera pregunta será respondida en su totalidad en este numeral, mientras que la segunda pregunta será resulta parcialmente aquí y complementada posteriormente en el Capítulo 5.

Los formatos básicos que requiere un plan de mantenimiento son: 
- Maestro de máquinas, con su respectiva codificación (numerales 3.2.1 y 3.2.2).

- Tarjeta maestra de datos TMD y su correspondiente archivo (numeral 3.2.3).

- Formatos de Hojas de vida de equipos (numeral 3.2.4).

- Listado de requerimientos o tareas LEMI (numeral 3.2.5).

- Listado de Instructivos o Estándares de mantenimiento (numeral 3.2.6).

- Tableros de control o cronogramas de mantenimiento (numeral 3.2.7).

- Listado de Rutinas básicas de mantenimiento RBM (numeral 3.2.8).

- Listado de tareas de Mantenimiento rutinario ejecutadas.

- Listados de partes de recambio y de desgaste.

- Formato de orden de trabajo.

- Listados de Órdenes de trabajo pendientes de ejecutar, en ejecución, reprogramadas y canceladas.

- Indicadores de mantenimiento (Capítulo 5).

- Control de costos y gastos (alimentación, consulta, proyección, etc.).

En los Listados de tareas de Mantenimiento rutinario ejecutadas, se almacena la información básica de las tareas de mantenimiento que no ameritan relacionarse en las Hojas de Vida (ver numeral 3.2.4). En este momento se hará una distinción entre empresas que no poseen software de Mantenimiento CMMS (ver numeral 3.10 para el concepto CMMS), y las que sí poseen software de Mantenimiento CMMS. En el caso de las primeras, y asumiendo que tienen manejo y control de información (manualmente o con hoja electrónica), dicho control se puede llevar con un sencillo cuadro como el mostrado en la Tabla 14. Una ventaja de un cuadro de estos es que permite rastrear y tabular situaciones como: consumos repetitivos de algún elemento, reparaciones repetitivas de alguna máquina/equipo, la no ejecución de alguna tarea, consumos rutinarios de componentes, identificación de responsabilidades del ejecutante en una tarea errónea, etc.

Tabla 14. Formato básico para control de Tareas de Mantenimiento rutinario [el Autor]

\begin{tabular}{|l|l|l|l|l|l|}
\hline Ítem & Fecha & $\begin{array}{c}\text { Contador u } \\
\text { horómetro }\end{array}$ & $\begin{array}{c}\mathbf{N}^{\circ} \text { OT o Descripción de } \\
\text { la tarea }\end{array}$ & Ejecutante & Observaciones \\
\hline & & & & & \\
\hline & & & & & \\
\hline
\end{tabular}

En el caso de las empresas que poseen CMMS y dependiendo del potencial del mismo, basta con cerrar las órdenes de trabajo, generar una consulta o query y analizar lo que sea de interés. Para el caso de los Listados de partes de recambio y de desgaste consultar el Capítulo 5.

Formato de Orden de Trabajo (OT). Son los documentos que se le entregan al ejecutante u operario para que proceda a ejecutar una labor de Mantenimiento. Existen muchos modelos de OT, bien sea manuales o digitales, pero mínimo deben constar de:

Fecha de elaboración, fecha en que se debe ejecutar la tarea, hora de ejecución (si es preciso), nombre del ejecutante, instructivo asociado (sea genérico o específico), máquina/equipo a intervenir, nombre y cargo de quién la programa, espacio para observaciones y espacio para la firma del ejecutante. La figura 33 presenta un pantallazo de una OT, arrojada por el CMMS MPSoftware. 
Las OT se subdividen en Estándar y No Estándar. Una OT Estándar (OTs) es aquella que resulta de aplicar un Plan de Mantenimiento Preventivo (tarea contemplada en un listado LEMI), por lo tanto tiene una frecuencia e instructivo asociados. Una OT no Estándar (OTnS) no obedece al Plan de Mantenimiento Preventivo, y regularmente no tienen asociadas frecuencias e instructivos. Una OTnS surge en una de las siguientes situaciones:

- Correctivo programado resultado de la retroalimentación de una OTs ejecutada.

- Correctivo programado resultado de observaciones de ejecutante, supervisor, jefe, etc.

- Correctivo de emergencia resultado obviamente de una falla funcional.

- Modificación de máquina/equipo.

- Reparación mayor u overhaul.

Figura 33. Orden de Trabajo emitida por un CMMS. Tomado de MPSoftware [16]

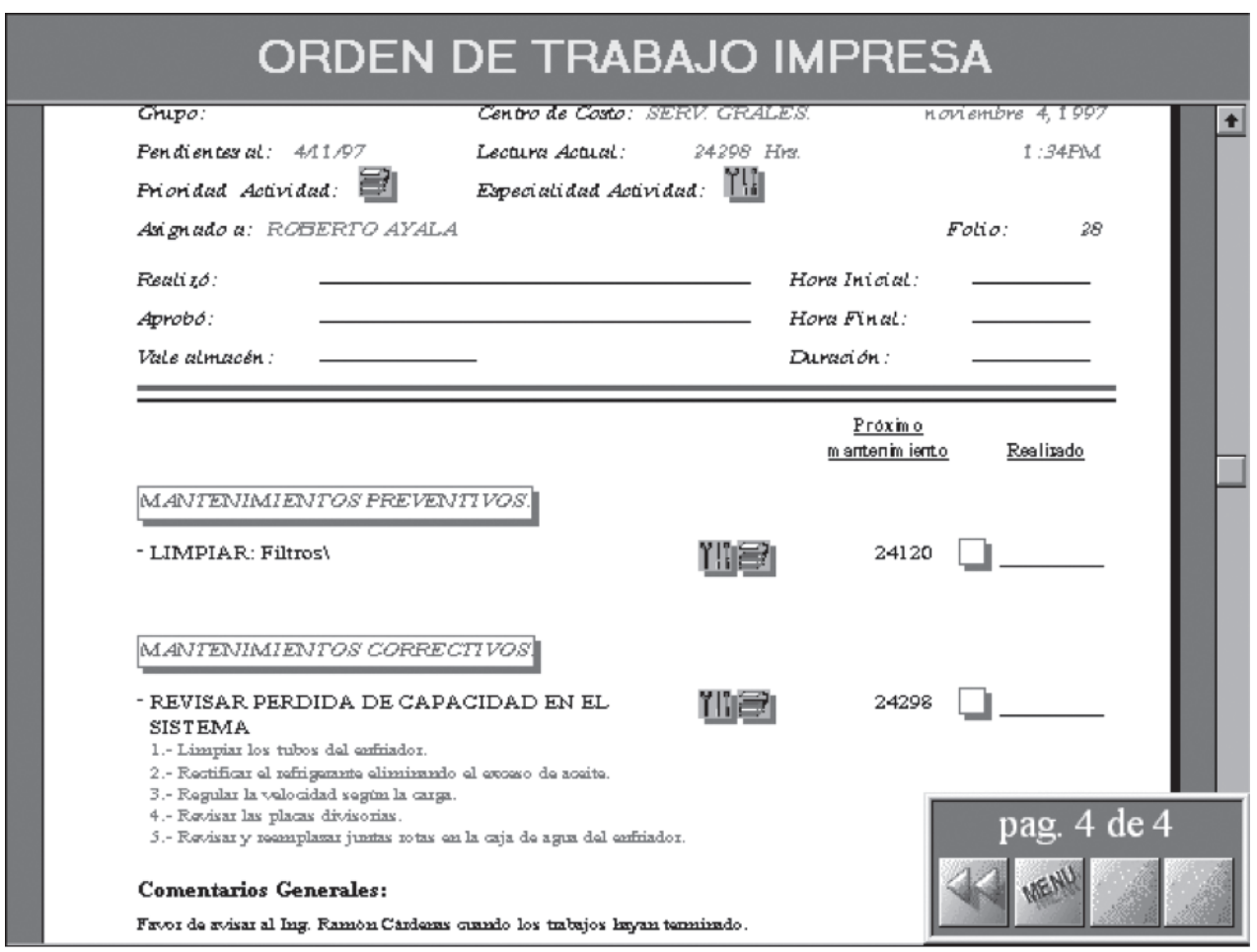

La emisión de una OTs obedece a la aplicación de las fórmulas 6, 7 y 8, dependiendo de la frecuencia que haya sido tomada como referencia para elaborar los Tableros de control (recordar numeral 3.2.7). 
Donde $F_{n e}=F_{u e}+F$

$F_{n e} \quad$ Es la fecha de la nueva ejecución.

$F_{u e} \quad$ Es la fecha de la última ejecución.

$F \quad$ Es la frecuencia en días calendario.

Donde

$$
H_{n e}=H_{u e}+F_{h}
$$

$H_{n e} \quad$ Es el horómetro de la nueva ejecución.

$H_{u e} \quad$ Es el horómetro de la última ejecución.

$F_{h} \quad$ Es la frecuencia en horas de operación.

$S_{n e}=S_{u e}+F_{s}$

Donde
$S_{n e} \quad$ Es el recorrido para la nueva ejecución.
$S_{u e} \quad$ Es el recorrido de la última ejecución.
$F_{s} \quad$ Es la frecuencia en espacio recorrido.

Con un Plan de Mantenimiento debidamente administrado es vital que un funcionario regularmente llamado Programador de Mantenimiento, esté al tanto de alimentar los contadores (horómetros, odómetros, fechas, contadores de producción, etc.), y con base a las fórmulas 6,7 y 8, determinar en qué momento surgen nuevas OTs. A las OTs y OTnS se les asignan diferentes estatus: emitida, en espera de autorización, autorizada, en espera de materiales, en ejecución, cerrada, reprogramada, cancelada. Una OT cerrada es aquella que ya se ejecutó, mientras que una OT cancelada es aquella que temporal o definitivamente no se puede ejecutar. Cuando el ejecutante ha concluido una OT debe diligenciar el formato, anotar la fecha y contador en que efectivamente se realizó, colocar las observaciones pertinentes (si hay lugar), firmar en constancia de que la labor se cumplió y devolverla al planeador.

Otras funciones adicionales del Planeador de Mantenimiento son gestionar los recursos requeridos por las OT, verificar qué Órdenes de Trabajo se emitieron y entregarlas a los ejecutantes, recibir las retroalimentaciones de las OT ejecutadas, cerrar las OT y reprogramar o cancelar OT si la situación lo amerita.

Para apoyar la labor de control de ejecución de las OT se puede utilizar un cuadro (manual o sistematizado en un CMMS) como el mostrado en la Tabla 15.

Tabla 15. Formato básico para control ejecución de OT [el Autor]

\begin{tabular}{|l|l|l|l|l|l|}
\hline Ítem & Fecha & Contador & $\mathbf{N}^{\circ}$ OT & Ejecutante & Observaciones \\
\hline & & & & & \\
\hline
\end{tabular}

En el caso de las OTnS, su emisión, control, supervisión, cierre, reprogramación y cancelación se maneja de manera homóloga al procedimiento descrito líneas arriba para las OTs.

Por último, las OT son instrumentos de realimentación que bien aprovechados sirven para evaluar posteriormente costos representados en insumos, repuestos, mano de obra y tiempos de parada de planta. 


\subsubsection{Software de mantenimiento CMMS}

Hasta hace unos años era común que los Departamentos de Mantenimiento fuesen administrados de manera manual y en copia dura (papel y carpetas físicas), es decir, sin la asistencia de los computadores. En el caso colombiano, desde comienzos de la década de 1990 se inició la ola de sistematización de procesos, entre ellos el de la administración del mantenimiento y sus diferentes tareas.

Muchas micros y pequeñas empresas colombianas, a pesar que usan computadores, tienen todos o algunos de los siguientes problemas: no tienen encargados de mantenimiento o su nivel de escolaridad y capacitación es muy bajo, no tienen con qué adquirir un software de mantenimiento económico, solo aplican mantenimiento correctivo; en la mayoría de situaciones relacionadas lo poco que administran lo hacen manualmente, es decir papelería física, en el cuaderno de un mecánico polivalente, o en una carpeta del administrador de la empresa. En el otro extremo se encuentran muchas pequeñas, medianas y grandes empresas que llevan dos y hasta tres décadas de venir sistematizando sus procesos, entre ellos la función Mantenimiento.

Un software de mantenimiento o CMMS (Computarized Maintenance Management System, por sus siglas en inglés) constituye la solución genérica para gestionar la información concerniente a Mantenimiento. Los CMMS pueden tomar configuraciones tan sencillas como una hoja electrónica Excel diseñada para tal fin, pasando por aplicaciones de Visual Basic soportadas por bases de datos Access, llegando a aplicaciones complejas embebidas en software corporativos.

Una forma de clasificar los CMMS es basándose en su capacidad, pensando en qué tamaño de empresa pueden atender; en ese orden de ideas existen CMMS para microempresas, para pequeñas y medianas empresas (MPSoftware, GIMAO) y CMMS para grandes empresas (por ejemplo el SAP y el JDE).

Los CMMS para microempresas generalmente son hojas electrónicas sencillas (en Excel regularmente) diseñadas por el encargado del Mantenimiento, cumplen un cometido básico, y como reza el adagio popular "son mejores a no tener nada". Los CMMS para pequeñas y medianas empresas son mucho más completos y complejos que los de las microempresas, y regularmente se caracterizan por que no tienen conectividad con otras dependencias de la compañía (por ejemplo con Recursos Humanos, Nómina, Contabilidad, Almacén general, etc.). Por último, Los CMMS para grandes empresas constituyen un módulo de un gran paquete computacional que gestiona la información de toda la compañía (nómina, compras, contabilidad, almacén, despachos, Mantenimiento, etc.), tanto en el caso de que hayan o no sucursales (nacionales o internacionales); un CMMS para gran empresa requiere una infraestructura de hardware y software compleja y costosa (servidor, redes, PC, licencias, personal de soporte, desarrolladores de aplicaciones, etc.).

En lo normal, un CMMS debe ser capaz de procesar información concerniente a:

- Creación de un plan de Mantenimiento (numerales 3.2.1 a 3.2.8).

- Gestión de las OT (numeral 3.2.9).

- Planeación y programación de recursos (físicos, humanos, información, etc.).

- Elaboración de indicadores de gestión.

- Gestión de costos (presupuesto).

- Elaboración de informes gerenciales. 
El proceso de elegir entre un CMMS propio (desarrollado en la empresa) o uno comercial, y en el caso del comercial elegir entre diferentes posibilidades disponibles, debe basarse en el análisis y validación los criterios generales mencionados a continuación [2]:

- Funcionalidad

- Calidad de las bases de datos

- Facilidad de modificación

- Facilidad operativa (Amigable con el usuario)

- Facilidad de actualización

- Historial previo del software

- Costo de instalación
- Compatibilidad de hardware

- Flexibilidad

- Facilidad de elaboración de consultas

- Asistencia técnica

- Documentación de respaldo

Costo adquisición hardware y software

- Facilidad de conectividad

- Portabilidad / Seguridad

A nivel académico, en la Universidad Tecnológica de Pereira se han diseñado y sistematizado planes de mantenimiento, para diversas empresas (micros, pequeñas y medianas), haciendo uso de herramientas computacionales regularmente disponibles en el sistema operativo Microsoft (Excel, Access, Visual Basic); ejemplos de estos trabajos y aplicativos de software se pueden consultar en las referencias ([17, $18,19,20,21])$.

\subsubsection{Dinámica de operación del Mantenimiento Preventivo}

Con el propósito de complementar lo concerniente a la gestión de las órdenes de trabajo se ha elaborado el diagrama de flujo presentado en la figura 34. Se sugiere al lector relacionar el análisis de este diagrama de flujo, comparándolo con el esquema de la figura 2 (numeral 1.2.3) Dinámica de un Sistema de Mantenimiento, en el entendido que el diagrama de flujo se corresponde con los cuadros Programar y Ejecutar de la figura 2. 
Figura 34. Diagrama de flujo de administración de las órdenes de trabajo [el Autor]

Solicitudes de servicio de otras dependencias, o por fuera del Plan de Mantenimiento

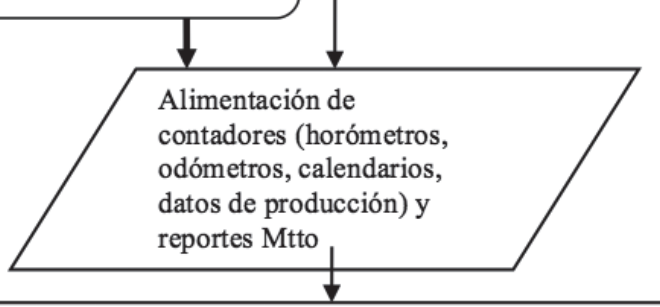

- Proceso de Validación de datos ingresados frente a frecuencias pre-establecidas

- Proceso de estudio y autorización de solicitudes por fuera del Plan de Mtto.

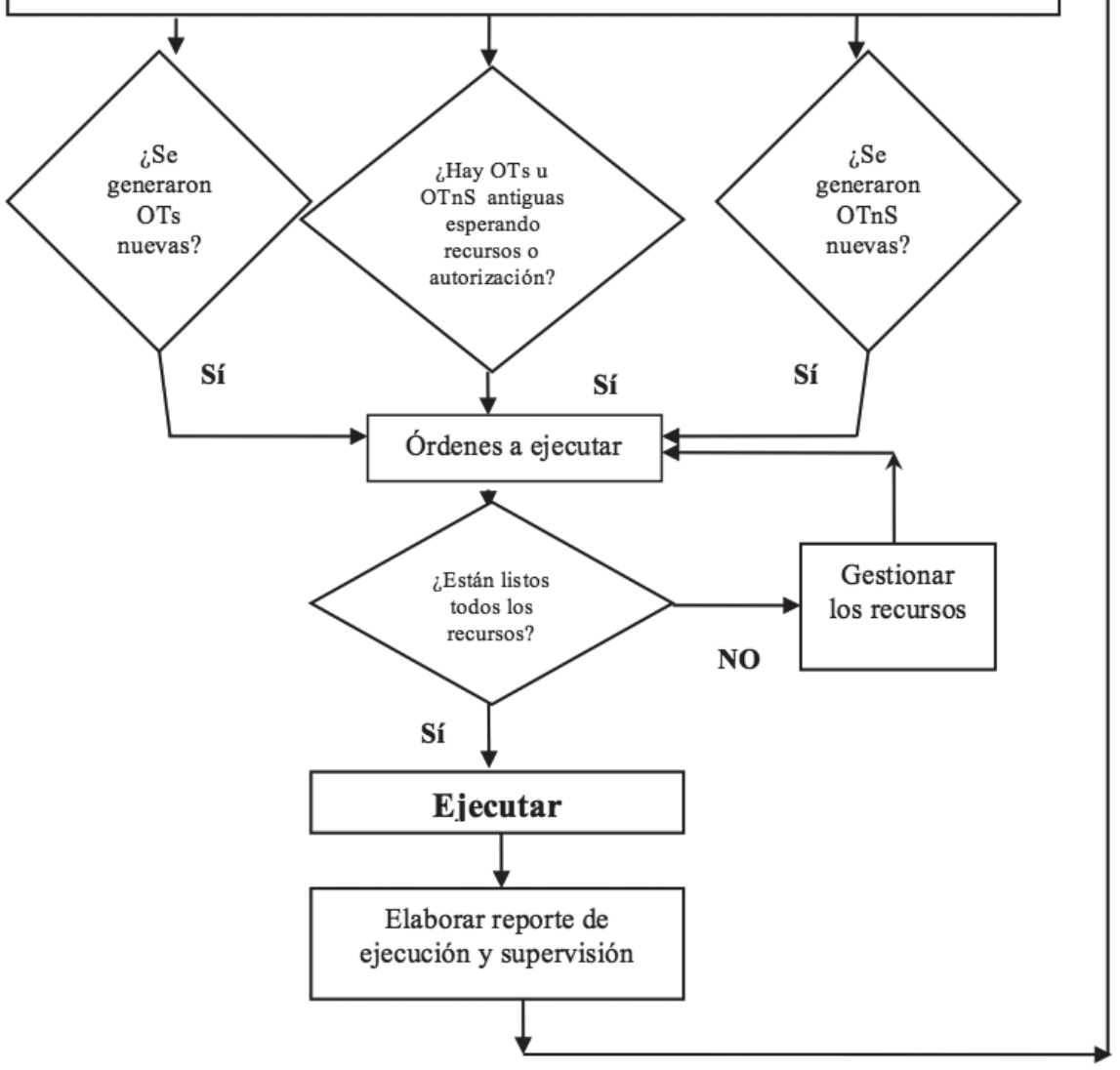




\subsection{Preguntas de consulta o análisis}

- Ubique el esquema (real o ficticio) de una planta de producción. Defina el tipo de layout de planta de dicha empresa. Establezca un sistema de codificación hasta llegar al nivel de componente. Del layout elija una máquina/equipo y un componente suyo, y explique el sistema de codificación creado.

- Explique con base a las curvas respectivas por qué no es recomendable realizar Mantenimiento Preventivo en exceso.

- ¿Las frecuencias de ejecución del Mantenimiento Preventivo son fijas o variables? Justifique la respuesta. En el evento de ser variables ¿Con base en qué varían?

- ¿De qué orden es la efectividad de resultados que se obtiene al aplicar Mantenimiento Correctivo?

- Suponiendo que uno de los funcionarios del Taller de máquinas-herramienta de la UTP diseñara una RBM diaria para las máquinas que operan bajo el principio de arranque de viruta, ¿Qué actividades probablemente propondría y cuál sería el orden de ejecución? Tenga en cuenta cuáles máquinas trabajan a diario en el taller, consulte los cursos tanto de la Facultad como de la Escuela que hacen uso del taller.

- Consulte y elabore las rutinas básicas de mantenimiento (diaria, semanal y mensual) para un camión doble-troque, con carrocería de furgón y refrigerada, para transporte intermunicipal.

- Consulte y elabore las rutinas básicas de mantenimiento (diaria, semanal y mensual) para un carro recolector de basura, es decir camión doble-troque y la caja compactadora.

\subsection{Para reflexionar: el mantenimiento en Risaralda y la competitividad}

En este apartado, y con base a los resultados de un estudio (basado en un trabajo de grado), tendiente a determinar las estrategias mantenimiento aplicadas por las grandes y medianas empresas del área metropolitana Pereira - Dosquebradas.

En el hipervínculo http://carlos-montilla-utp.jimdo.com/complementos-libro-de-mantenimiento/ complementos-cap\%C3\%ADtulo-3-1/ se puede realizar esta lectura complementaria. 
Capítulo 4 



\section{Programación y planeación en Mantenimiento}

\subsection{Introducción}

En los numerales 3.2.5, 3.2.6 y 3.2.7 se ilustraron los procedimientos para la definición de los listados de requerimientos de Mantenimiento o Listados LEMI, la elaboración de los Instructivos de Mantenimiento y la conformación de los Tableros de control; estos Tableros de control son preliminares, puesto que no tienen en cuenta la disponibilidad de recursos de la empresa y los tiempos en los cuales se puede detener el proceso productivo para ejecutar las tareas planteadas. En este orden de ideas, hay que complementar los Tableros de control preliminares con procesos de Programación y Planeación, fundamentales en Mantenimiento, puesto que permiten racionalizar (balancear) recursos y minimizar costos, en función de las actividades a realizar, del tiempo en que se puede intervenir las máquinas/ equipos y de los recursos existentes en la empresa.

\subsection{La programación del Mantenimiento}

Se entiende por Programación en Mantenimiento al conjunto de acciones tendientes a organizar la ejecución de un conjunto de tareas en un periodo de tiempo generalmente preestablecido, distribuyéndolas, con el fin de racionalizar los recursos (humanos, repuestos, herramientas). Para efectuar la programación en Mantenimiento es necesario tener en cuenta 3 variables: el tiempo programable para mantenimiento TPPM, la Carga de trabajo de Mantenimiento CTM y los Recursos (Capacidad del Departamento de Mantenimiento).

\subsubsection{Tiempo Programable Para Mantenimiento TPPM}

Se llama así a los lapsos en los cuales se puede intervenir sobre las máquinas/equipos, sin afectar el ritmo normal de producción. Recuérdese que las máquinas/equipos deben estar prioritariamente en producción, y que no puede ser intervenidas a cualquier momento; por ejemplo, hay máquinas que 
trabajan tres turnos y solo podrían ser intervenidas los fines de semana o en los cambios de turnos. En general, el TPPM se encontrará en:

- Noches, dominicales o festivos

- Lapsos entre cambios de turno

- Lapsos de alistamiento de las máquinas para hacer cambios de referencia en la producción.

- Períodos entre cosechas

\subsubsection{Carga de trabajo programable o Carga de trabajo de mantenimiento CTM}

La CTM es la suma de tiempos que se emplearían para ejecutar las tareas de Mantenimiento. La CTM consta de dos categorías principales:

\section{Mantenimiento programado o planeado}

- Mantenimiento de rutina o preventivo (los tiempos salen de los instructivos asociados al LEMI).

- Mantenimiento correctivo programado.

- Reparaciones generales programadas, que impliquen paro de la Planta (overhaul).

\section{Mantenimiento correctivo de emergencia}

- Depende principalmente de un patrón de fallas.

La figura 35 ilustra algunos comportamientos típicos de patrones de falla, los cuales están asociados a la Tecnología de fabricación de la máquina/equipo (ver numeral 1.7) y a la forma como se administre el Mantenimiento.

Figura 35. Comportamiento de algunos patrones de falla [22]

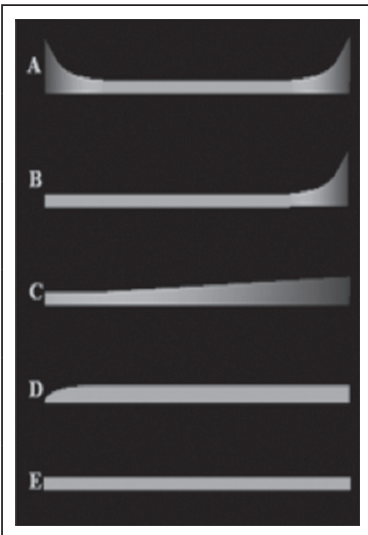

Patrón A: "la curva de la bañera". Alta mortalidad infantil, seguida de un bajo nivel de fallas aleatorias, terminando en una zona de desgaste

Patrón B: "El punto de vista tradicional". Pocas fallas aleatorias, terminando en una zona de desgaste

Patrón C: un constante incremento en la probabilidad de falla infantil, seguida de un comportamiento aleatorio de la probabilidad de fallas

Patrón D: un rápido crecimiento de la probabilidad de falla, seguido de un comportamiento aleatorio

Patrón E: fallas aleatorias. Ninguna relación entre la edad de los equipos y la probabilidad de que fallen

Patrón F: alta mortalidad infantil, seguida de un comportamiento aleatorio de la probabilidad de fallas 


\subsubsection{Recursos}

En el contexto de Programación de Mantenimiento, los Recursos se materializan en el personal, herramientas, insumos, repuestos, equipos de apoyo, etc., necesarios para la ejecución de la CTM. Dada la amplia diversidad de recursos físicos en las diferentes empresas y la dificultad que encarna tenerlos en cuenta, en el presente capítulo como Recursos se entenderán los Humanos, representados en horashombre, y se asumirá que los recursos físicos son suficientes. La programación consiste entonces en racionalizar los Recursos con miras a ejecutar la Carga de trabajo programable CTM, dentro del Tiempo programable TPPM. La racionalización se lleva a cabo aplicando un proceso de Balanceo del Tablero de control preliminar. En el presente capítulo se explicará el procedimiento para balancear Tableros de control por tiempo transcurrido.

\subsubsection{Balanceo de un Tablero de control}

El Balanceo del Tablero de control, consiste en trasladar actividades de una semana a otra, hacia la izquierda o hacia la derecha, con el fin de tratar de mantener una Carga de Trabajo de Mantenimiento CTM aproximadamente constante, evitando al máximo generar horas extras, turnos adicionales y outsourcing (trabajo contratado externamente) para ejecutar la CTM. En otras palabras, la CTM debe mostrar un comportamiento ideal como el descrito en la figura 36, lo cual está en relación con los Recursos y el TPPM. Las tareas que se muevan a la izquierda de la semana de referencia se adelantarán, y las tareas que se muevan a la derecha se atrasarán.

Figura 36. Comportamiento ideal de la Carga de Trabajo de Mantenimiento CTM versus tiempo transcurrido [el Autor]

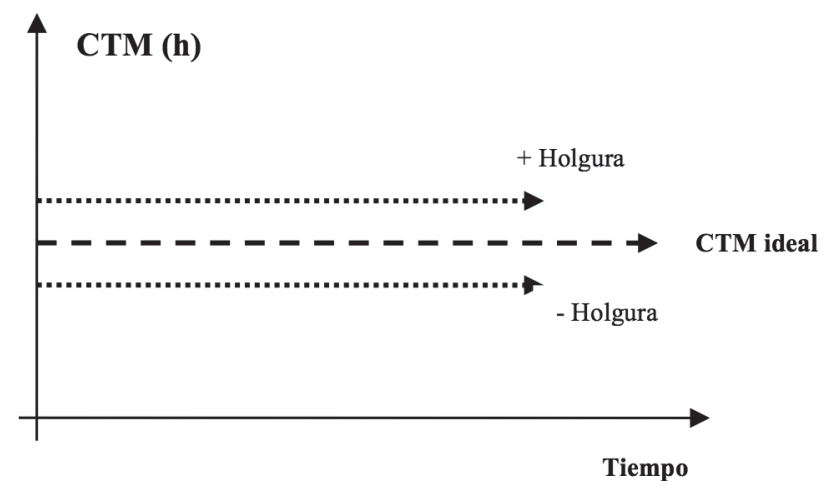

4.2.4.1. Método teórico para balancear un Tablero de control por tiempo trascurrido. No se tienen en cuenta los recursos ni el TPPM. Los pasos generales son:

a. Determinar la CTM para cada semana.

b. Determinar la media aritmética semanal de la CTM.

c. Determinar las CTM semanales teóricas máximas y mínimas, sumando y restando el 10\% a la media aritmética calculada. 
c. Mover horas hacia la derecha o hacia la izquierda, tratando que la diferencia entre las cargas de trabajo máxima y mínima finales no superen el $+/-10 \%$ calculado. No es recomendable adelantar $\mathrm{o}$ atrasar actividades por un período superior a una semana.

d. Efectuar un costeo básico.

\section{Ejemplo de Balanceo teórico de un Tablero de control}

La Tabla 16 muestra un Tablero de control, en el cual se han contemplado solamente tareas y tiempos de mantenimiento planeado (listado de requerimientos LEMI).

Tabla 16. Tablero de control anual. Adaptado de [1]

\begin{tabular}{|c|c|c|c|c|c|c|c|}
\hline Semanas & 1 & 2 & 3 & 4 & $\ldots$ & 51 & 52 \\
\hline \multicolumn{8}{|l|}{ Máquinas } \\
\hline \multirow[t]{3}{*}{ Manejadora } & $\begin{array}{l}\mathrm{L}-01 \\
1 \mathrm{~h} 20 \text { min }\end{array}$ & $\begin{array}{l}\mathrm{E}-17 \\
2 \mathrm{~h} 40 \mathrm{~min}\end{array}$ & $\begin{array}{l}\mathrm{L}-02 \\
1 \mathrm{~h} 30 \mathrm{~min}\end{array}$ & $\begin{array}{l}\mathrm{L}-10 \\
0 \mathrm{~h} 40 \mathrm{~min}\end{array}$ & $\ldots$ & $\begin{array}{l}\mathrm{L}-01 \\
1 \mathrm{~h} 20 \mathrm{~min}\end{array}$ & $\begin{array}{l}M-15 \\
3 \mathrm{~h} 40 \mathrm{~min}\end{array}$ \\
\hline & $\begin{array}{l}\mathrm{L}-12 \\
2 \mathrm{~h} 30 \text { min }\end{array}$ & & $\begin{array}{l}E-23 \\
1 \mathrm{~h} 50 \text { min }\end{array}$ & & $\ldots$ & $\begin{array}{l}\mathrm{L}-12 \\
2 \mathrm{~h} 30 \text { min }\end{array}$ & \\
\hline & $\begin{array}{l}\mathrm{M}-15 \\
3 \mathrm{~h} 40 \mathrm{~min}\end{array}$ & & & & $\ldots$ & & \\
\hline \multirow[t]{2}{*}{ Evaporadora } & $\begin{array}{l}\mathrm{L}-02 \\
1 \mathrm{~h} 30 \text { min }\end{array}$ & $\begin{array}{l}\mathrm{E}-25 \\
1 \mathrm{~h} 30 \mathrm{~min}\end{array}$ & $\begin{array}{l}\mathrm{L}-16 \\
0 \mathrm{~h} 40 \mathrm{~min}\end{array}$ & $\begin{array}{l}\mathrm{E}-10 \\
2 \mathrm{~h} 50 \mathrm{~min}\end{array}$ & $\ldots$ & $\begin{array}{l}\mathrm{L}-02 \\
1 \mathrm{~h} 30 \mathrm{~min}\end{array}$ & $\begin{array}{l}\mathrm{E}-26 \\
\text { Oh } 50 \mathrm{~min}\end{array}$ \\
\hline & $\begin{array}{l}\mathrm{L}-15 \\
1 \mathrm{~h} 40 \mathrm{~min}\end{array}$ & $\begin{array}{l}\mathrm{M}-17 \\
2 \mathrm{~h} 50 \mathrm{~min}\end{array}$ & $\begin{array}{l}\mathrm{M}-11 \\
4 \mathrm{~h} 30 \mathrm{~min}\end{array}$ & & $\ldots$ & $\begin{array}{l}\mathrm{L}-10 \\
0 \mathrm{~h} 40 \mathrm{~min}\end{array}$ & $\begin{array}{l}\mathrm{M}-18 \\
3 \mathrm{~h} 40 \mathrm{~min}\end{array}$ \\
\hline \multirow[t]{2}{*}{ Condensadora } & $\begin{array}{l}\mathrm{L}-01 \\
1 \mathrm{~h} 20 \mathrm{~min}\end{array}$ & $\begin{array}{l}\mathrm{E}-15 \\
2 \mathrm{~h} 30 \mathrm{~min}\end{array}$ & $\begin{array}{l}\mathrm{E}-18 \\
3 \mathrm{~h} 10 \text { min }\end{array}$ & $\begin{array}{l}\mathrm{M}-10 \\
8 \mathrm{~h} 50 \mathrm{~min}\end{array}$ & $\ldots$ & $\begin{array}{l}\mathrm{L}-01 \\
1 \mathrm{~h} 20 \mathrm{~min}\end{array}$ & $\begin{array}{l}M-22 \\
4 \mathrm{~h} 10 \mathrm{~min}\end{array}$ \\
\hline & $\begin{array}{l}\mathrm{M}-22 \\
4 \mathrm{~h} 10 \mathrm{~min}\end{array}$ & & & & $\ldots$ & $\begin{array}{l}M-20 \\
5 \mathrm{~h} 15 \text { min }\end{array}$ & $\begin{array}{l}\mathrm{E}-31 \\
0 \mathrm{~h} 30 \mathrm{~min}\end{array}$ \\
\hline
\end{tabular}

El desarrollo del ejemplo está disponible en http://carlos-montilla-utp.jimdo.com/complementoslibro-de-mantenimiento/complementos-cap\%C3\%ADtulo-4/

\subsubsection{Método real (heurístico) para balancear un Tablero de control por tiempo transcurrido. Los pasos generales son:}

a. Determinar el TPPM propio de la empresa.

b. Determinar los recursos (humanos y físicos) que atenderán la CTM. De manera simplificada aquí se tendrán en cuenta solo los humanos. Es necesario definir en función de la estructura del Departamento de mantenimiento de la empresa (capítulo 2), si se trabaja con operarios polivalentes ("toderos") o con cuadrillas u operarios especializados por actividad (o lubricación o electricidad o mecánica). De manera simplificada este proceso conduce a determinar el número de horas-hombre de los ejecutantes de Mantenimiento que podrán laborar durante el TPPM, bien sea global o por especialidad.

c. Determinar la CTM para cada semana, bien sea global o por especialidad. 
d. Determinar la media aritmética de la CTM, bien sea global o por especialidad.

e. Determinar las CTM semanales teóricas máximas y mínimas (global o por especialidad), sumando y restando el $10 \%$ a la media aritmética calculada.

f. Mover Instructivos o actividades completas hacia la derecha o hacia la izquierda, tratando que la diferencia entre las cargas de trabajo máxima y mínima finales no superen el +/- 10\% calculado. De nuevo, no es recomendable adelantar o atrasar actividades por un período superior a una semana.

g. Validar en cuáles semanas se podrá atender la CTM con el personal propio (con la totalidad o parte de ellos), y en cuáles será necesario pagar personal adicional, por cuánto tiempo y a cuánto costo.

h. Costeo básico.

Ejemplo de balanceo real de un Tablero de control. Se desarrollará el ejemplo, con base a la misma información de la Tabla 16.

En el hipervínculo http://carlos-montilla-utp.jimdo.com/complementos-libro-de-mantenimiento/ complementos-capitulo-1/ se puede consultar la solución del ejemplo.

En el Anexo 3 se pueden consultar los conceptos y cálculo básico del trabajo represado o backlog.

\subsection{Planeación capacidad de Mantenimiento}

Basados en la figura 2 (página 19), recuérdese que la dinámica del Mantenimiento exige unas labores de planeación, programación, ejecución, medición y comparación. La labor de programación de mantenimiento preventivo se condensa en un Tablero de control balanceado; para atender las CTM el Departamento de Mantenimiento posee unos Recursos o Capacidad de Mantenimiento, representada en hombres (internos o subcontratados), equipos, herramientas, software.

Pueden darse dos situaciones generales:

- Que la empresa esté en operación y el Backlog sea muy alto (Ver numeral 4.3), personal sobrecargado de trabajo y constantemente atendiendo correctivos de emergencia.

- La empresa va a entrar en operación y no se tiene una idea muy clara de cuál debe ser la capacidad del Departamento de Mantenimiento.

Tanto en el caso de si la empresa está en operación o si entrará en funcionamiento luego, los cuadros directivos, y particularmente el Departamento de Mantenimiento debe estar en capacidad de autoevaluarse y determinar si su Capacidad (recursos) es la adecuada a las necesidades actuales o futuras de la empresa.

La labor de definir el número de personas que debe emplear un Departamento de Mantenimiento es un proceso relativamente complejo, que depende de factores propios de la organización y de factores asociados a las máquinas/equipos. Entre los factores organizacionales se tienen: tipo de industria (Tabla 17), tamaño de la industria, el layout de planta, la existencia de sucursales, políticas de subcontratación, el ambiente físico y laboral, las políticas de Mantenimiento, el nivel de destreza y de especialización de los operarios y administrativos, la disponibilidad de repuestos, los procedimientos de ubicación de fallas y de control de trabajo, la calidad de la documentación, los recursos disponibles para la ejecución de las actividades (espacio de trabajo, talleres, máquinas, equipos de prueba, equipos de levantamiento y manejo de materiales equipos especializados, etc.), etc. 
Entre los factores asociados a las máquinas/equipos están el diseño inicial del sistema o de los subsistemas que lo conforman, la edad de las máquinas/equipos, el número y variedad de las máquinas/ equipos. El diseño inicial de las máquinas/equipos determina en gran medida los procedimientos de Mantenimiento y la duración de los tiempos de reparación, ello va en relación con la modularidad, la accesibilidad, la estandarización e intercambiabilidad de los componentes usados. Intrínsecamente el diseño inicial está afectado por la tecnología de fabricación y el costo inicial del equipo (ver numeral 1.7).

Una forma de hacer el auto-análisis mencionado líneas arriba podría ser por comparación con referentes generales por subsector económico, tal como lo muestra la Tabla 17. En dicha tabla se presenta un panorama comparativo general de los Costos Directos de Mantenimiento CDM versus los costos operativos totales de la empresa.

Otra forma de valorar el tamaño del Departamento de Mantenimiento, es con base a un histórico general en el cual del 100\% del presupuesto de Mantenimiento directo, el 70\% es absorbido por mano de obra y el $30 \%$ restante lo absorben materiales. La combinación del factor anterior y de la Tabla 17, pueden dar una idea de la cantidad de hombres requeridos en algunas industrias.

Tabla 17. \% CDM versus Costo operativo total, según el subsector económico

\begin{tabular}{|l|c|}
\hline \multicolumn{1}{|c|}{ Subsector } & $\begin{array}{c}\text { \% Costo Directo de Mantenimiento CDM vs Costo } \\
\text { operativo total }\end{array}$ \\
\hline Minería & $20-50$ \\
\hline Siderurgia & $15-25$ \\
\hline Instalaciones eléctricas & $15-25$ \\
\hline Manufactura & $5-15$ \\
\hline Procesamiento & $3-15$ \\
\hline Ensamblaje & $3-5$ \\
\hline
\end{tabular}

\section{Ejemplos:}

- Empresa alimenticia Meals de Colombia en Manizales. 650 personas en Planta, de las cuales 17 son ejecutantes de mantenimiento [23].

- Empresa confecciones D'Moda en Pereira. Aproximadamente 100 personas en Planta, de las cuales uno es polivalente para Mantenimiento.

A un nivel más profundo y analítico, la estimación del personal requerido por un Departamento de Mantenimiento (o la revisión de la cantidad actual) se puede hacer aplicando los siguientes métodos (consultar la referencia [24]):

- Promedio móvil simple

- Promedio móvil ponderado

- Análisis de regresión

- Métodos heurísticos 


\subsection{Preguntas de consulta o análisis y ejercicios}

- Cuando se balancea un Tablero de control se recomienda no atrasar o adelantar tareas por un período de más de una semana. ¿Qué relación encuentra entre esa recomendación y la clase del Backlog?

- ¿Cómo se interpretaría un Backlog cuyo valor fuese Cero?

- ¿Cómo se interpretaría un Backlog cuyo valor tendiese a infinito?

- Entre los dos valores de Backlog anteriores ¿Cuál sería mejor y por qué?

\section{Ejercicio propuesto 1}

Efectuar el balanceo real del tablero de la Tabla 16, sí:

Tiempo Programable para Mantenimiento TPPM por semana es de 6 horas continuas, de 2:00 P. M. a 8:00 P. M. los domingos.

Hay operarios especializados en cada labor (L, E, M, I).

Calcule el costo de efectuar las tareas si cada operador devenga 1,5 SMLV (ver Anexo 4).

\section{Ejercicio propuesto 2}

Un Departamento de Mantenimiento laboró 40 horas una cierta semana; de esas 40 horas, 25 corresponden a tareas de correctivo de emergencia, 5 a Correctivo Programado y 10 a Preventivo. El Programador de Mantenimiento alimentó la información en su software y encontró que hay 70 horas de Correctivo Programado en espera y 20 horas de Preventivo en espera.

Evalúe el Backlog. Defina si está dentro de lo órdenes permisibles y en caso contrario elabore propuestas que solucionen la crisis. ¿Qué opinión le merece la administración de ese Departamento de Mantenimiento?

En el Anexo 5 se puede encontrar una lectura complementaria sobre La Mantenibilidad y la ejecución de tareas de mantenimiento, y algunos consejos de Mantenimiento alrededor de los elementos estandarizados e intercambiables. 

Capítulo 5 



\section{Mantenimiento analítico (indicadores e índices)}

\subsection{Introducción}

En el Capítulo 1 se acotó que el Mantenimiento Analítico en sí mismo no es un sistema de mantenimiento, sino que se trata de una serie de metodologías transversales a los otros sistemas de Mantenimiento, para apoyar el análisis y toma de decisiones durante la gestión y administración del Mantenimiento.

El Mantenimiento Analítico se basa preferentemente en el uso de estadísticas para conformar indicadores de mantenimiento e índices de falla y de gestión para:

- Determinar la causa raíz de un problema

- Conformar un panorama de la gestión del Mantenimiento

- Facilitar la toma de decisiones

El presente capítulo tratará sobre los indicadores de Mantenimiento y los índices de falla, su importancia, construcción y aplicación básica.

\section{2. Índices de gestión de Mantenimiento}

Muchas veces no se tiene la percepción de que nuestras vidas son reguladas (y en algunos casos regidas) por indicadores, pero cuando se piensa con calma el asunto se llega a la conclusión que así ocurre (al menos en muchos ámbitos); como ejemplos claros de lo anterior se tiene: el precio del barril de petróleo, la tasa representativa del mercado (en dólares y en euros), el valor de la onza de oro, etc.

Citas de algunos científicos y pensadores expresan la importancia de las mediciones y por supuesto de los indicadores: 
"Cuando puedas medir lo que estás diciendo y expresarlo en números, sabrás algo acerca de eso; pero cuando no puedes medirlo, cuando no puedes expresarlo en números, tus conocimientos serán escasos y no satisfactorios" Lord Kelvin

"No se puede controlar lo que no se puede medir" Tom De Marco

"No se puede predecir lo que no se puede medir" Norman Fenton

Los Índices o Indicadores son relaciones cuantitativas o cualitativas que se establecen entre variables, para evaluar sus proporciones o comportamientos. Los índices de Mantenimiento son elementos informativos que permiten tomar decisiones de manera objetiva.

Los índices de Mantenimiento deben cumplir ciertas características:

Validez: Deben recopilar información relativa a un proceso productivo.

Confiabilidad: La información presentada por ellos debe ser veraz y creíble.

Especificidad: Deben establecerse con base en los objetivos del Mantenimiento, por ello deben configurarse de forma tal que permitan evaluar los objetivos del Mantenimiento.

Sensibilidad: Deben diseñarse de forma tal que muestren de manera inmediata los cambios que hay en el desempeño del elemento a evaluar (áreas, máquinas, equipos, componentes, etc.). Accesibilidad: Un buen indicador es aquel en el cual la información necesaria para construirlo es de fácil consecución y procesamiento.

Unívocos: Un indicador correctamente formulado no debe prestarse para interpretaciones distintas al momento de su evaluación.

Los índices pueden ser cuantitativos o cualitativos, pero la idea es al máximo, hacer uso de los cuantitativos, puesto que se minimiza el componente subjetivo de la evaluación. Por ejemplo si se quisiera evaluar la limpieza de un equipo (tarea básica en Mantenimiento) de manera cualitativa, se podría cualificar como Mala, Regular, Buena y Excelente, pero previamente tendría que definirse qué estado se corresponde con cada una de las cualificaciones, para evitar que lo que para un observador sea Excelente o Bueno, para otro sea Regular o Malo.

\section{Tipos de indicadores en Mantenimiento}

Se encuentran en tres grupos genéricos de índices: de Eficacia del Mantenimiento, de Administración del Mantenimiento y de Costos de Mantenimiento

\subsubsection{Indicadores de eficacia del Mantenimiento}

Son aquellos destinados a mostrarle, principalmente, al Gerente/Jefe de Mantenimiento cómo anda su gestión, desde el punto de vista de efectividad en la ejecución, es decir, disponibilidad de la Planta, número de varadas, tiempo perdido por varadas, etc. De este grupo los indicadores más ampliamente utilizados son Disponibilidad, Confiabilidad y Mantenibilidad, los cuales se describirán a continuación.

Disponibilidad (fórmula 9): capacidad de una máquina/equipo de llevar a cabo con éxito la función requerida, durante un tiempo determinado, en unas condiciones específicas. Se construye en función 
del Tiempo Programado para Producción TPP y del Tiempo de Paradas No Programadas TPNP.

$$
D=100 \mathrm{x} \frac{T P P-T P N P}{T P P}
$$

Donde

$D \quad$ es el porcentaje de disponibilidad.

TPP es el tiempo planeado para la producción.

TPNP es el tiempo de paradas no programadas.

Confiabilidad (fórmula 10): Probabilidad de que un equipo no falle durante su operación. Se evalúa por intermedio del Tiempo Promedio Entre Fallas (TPEF).

$$
T P E F=\frac{T_{o p}}{N_{a r r}}
$$

Donde

TPEF es la confiabilidad o tiempo promedio entre fallas.

$T_{o p} \quad$ es el tiempo real de operación de la planta.

$N_{\text {arr }} \quad$ es el número de arranques de planta.

Mantenibilidad (fórmula 11): Se conocen dos definiciones de diferente profundidad, pero que describen la misma situación. La mantenibilidad se evalúa con el Tiempo Promedio Para Reparar TPPR.

Definición 1. Propiedad de un Equipo o Sistema que representa la cantidad de esfuerzo requerida para conservar su funcionamiento normal o para restituirlo una vez se ha presentado un evento de falla. Se dirá que un sistema es Altamente Mantenible cuando el esfuerzo asociado a la restitución sea bajo. Sistemas Poco Mantenibles o de Baja Mantenibilidad requieren de grandes esfuerzos (horas-hombre, supervisión, repuestos, insumos) para sostenerse o restituirse.

Definición 2. Probabilidad de que un equipo pueda ser puesto en condiciones operacionales en un período de tiempo dado, cuando el mantenimiento es ejecutado de acuerdo con procedimientos preestablecidos.

$$
T P P R=\frac{T_{n o p}}{N_{a r r}}
$$

Donde

$T P P R$ es el tiempo promedio para reparar.

$T_{n o p} \quad$ es el tiempo que duraron las intervenciones de mantenimiento.

$N_{\text {arr }} \quad$ es el número de arranques de Planta.

El conjunto de indicadores de Eficacia de Mantenimiento son presentados en la Tabla 18, indicando nombre, fórmula para su cálculo y Usuarios a quienes principalmente les interesa su valor. 
Se puede apreciar de la Tabla 18 que el indicador Eficiencia Global de Equipo EGE se encuentra en negrilla, resaltando su importancia, ya que de manera combinada indica:

- Cuanto tiempo laboró el equipo (indirectamente dice cuánto duraron las varadas).

- A qué velocidad de producción operó mientras estuvo en funcionamiento.

- Si mientras operó entregó el producto con la calidad esperada.

Como un criterio generalizado se puede considerar que la disponibilidad de un equipo debe ser mayor al $90 \%$, la velocidad de producción del orden del $95 \%$, y el porcentaje de producto conforme del orden del 99\%, con lo cual la EGE de una máquina/equipo debe ser del orden del $85 \%$.

\subsubsection{Indicadores de Administración del Mantenimiento}

Este grupo de indicadores se encarga de valorar la forma como se están (o no se están) alcanzado los objetivos del Mantenimiento en función de las horas-hombre ejecutadas (o dejadas de ejecutar), es decir, es probable que la Planta se haya varado una cantidad de veces pequeña y que la calidad de la producción sea la adecuada, pero vendrían las siguientes preguntas ¿Se están ejecutando juiciosamente las OTs? ¿Qué porcentaje de OTnS se están ejecutando? ¿Ha sido necesario llamar de manera recurrente el personal de Mantenimiento a trabajar horas extras para poner a punto las máquinas/equipos y evitar una varada al día siguiente? ¿Ha sido necesario subcontratar más de lo previsto? ¿Cuántas OTs se dejaron de hacer? Etc.

Tabla 18. Indicadores de Eficacia del Mantenimiento. Adaptado de [24]

\begin{tabular}{|c|c|c|c|}
\hline $\begin{array}{c}\text { Eficacia del } \\
\text { Mantenimiento }\end{array}$ & Fórmula & Descripción variables & $\begin{array}{l}\text { Usuario del } \\
\text { Índice }\end{array}$ \\
\hline $\begin{array}{l}\% \text { Disponibilidad } \\
\text { del Equipo } D\end{array}$ & $D=100 \times \frac{T P P-T P N P}{T P P}$ & $\begin{array}{l}\text { TPP, es el tiempo planeado } \\
\text { para la producción. } \\
T P N P \text {, es el tiempo de } \\
\text { paradas no programadas. }\end{array}$ & M, P, G \\
\hline $\begin{array}{l}\% \text { Velocidad de } \\
\text { Producción } V p\end{array}$ & $V p=100 \times \frac{U_{p r}}{U_{p l}}$ & $\begin{array}{l}U_{p r} \text {, son las unidades } \\
\text { producidas. } \\
U_{p p \text { pon las }} \text { unidades } \\
\text { planeadas. }\end{array}$ & $\mathrm{M}, \mathrm{P}, \mathrm{G}$ \\
\hline $\begin{array}{l}\% \text { Producto } \\
\text { conforme } P c\end{array}$ & $P c=100 \times \frac{U_{p r}-U_{n c}}{U_{p r}}$ & $\begin{array}{l}U_{n c} \text {, son las unidades no } \\
\text { conformes. }\end{array}$ & $\mathrm{M}, \mathrm{P}, \mathrm{G}$ \\
\hline $\begin{array}{l}\text { Eficiencia global } \\
\text { del equipo } E G E\end{array}$ & $E G E=D \times V p \times P c$ & & $\mathrm{M}, \mathrm{P}, \mathrm{G}$ \\
\hline Paros por Hora $P h$ & $P h=\frac{P_{p r}}{T P P-T P N P}$ & $\begin{array}{l}P_{p r} \text {, es el número total de } \\
\text { paros de producción. }\end{array}$ & $\mathrm{M}, \mathrm{P}, \mathrm{G}$ \\
\hline
\end{tabular}




\begin{tabular}{|c|c|c|c|}
\hline $\begin{array}{l}\% \text { Trabajo no } \\
\text { programado } W_{n p}\end{array}$ & $W n p=100 \times \frac{T_{n p}}{T_{m t t o}}$ & $\begin{array}{l}T_{n p} \text {, son las horas de } \\
\text { trabajo no programado. } \\
T_{m t t o} \text { son las horas } \\
\text { totales laboradas en } \\
\text { Mantenimiento. }\end{array}$ & M, G. \\
\hline $\begin{array}{l}\% \text { Tiempo debido } \\
\text { a fallas } T_{f}\end{array}$ & $T_{f}=100 \times \frac{T_{\text {falla }}}{T P N P}$ & $\begin{array}{l}T_{\text {falla }} \text {, es el tiempo perdido } \\
\text { debido a fallas. }\end{array}$ & $\mathrm{M}, \mathrm{P}, \mathrm{G}$ \\
\hline $\begin{array}{l}\% \quad \text { Horas de } \\
\text { reparación } H_{\text {rep }}\end{array}$ & $H_{\text {rep }}=\frac{T_{\text {rep }}}{T_{\text {mtto }}}$ & $\begin{array}{l}T_{\text {rep }} \text { son las horas de } \\
\text { mantenimiento empleadas } \\
\text { en reparar averías. }\end{array}$ & $\mathrm{M}$ \\
\hline $\begin{array}{l}\text { (Confiabilidad) } \\
\text { TPEF }\end{array}$ & $T P E F=\frac{T_{o p}}{N_{a r r}}$ & $\begin{array}{l}T_{o p} \text {, es el tiempo real de } \\
\text { operación de la planta. } \\
\mathrm{N}_{\text {arr }} \text { es el número de } \\
\text { arranques de Planta. }\end{array}$ & $\mathrm{M}, \mathrm{G}$ \\
\hline$T P P R$ & $T P P R=\frac{T_{\text {falla }}}{N_{\text {arr }}}$ & $\begin{array}{l}\mathrm{N}_{\text {arr }} \text { es el número de } \\
\text { arranques de Planta. }\end{array}$ & $\mathrm{M}$ \\
\hline
\end{tabular}

\section{Convenciones de Tabla 18:}

G: Gerencia $\quad$ M: Departamento de Mantenimiento P:Departamento de producción TPP: Tiempo planeado de Producción TPNP: Tiempo de paradas no programadas

La experiencia industrial del Autor le permite afirmar en lenguaje coloquial que el trabajo que se deja de hacer en Mantenimiento y que obviamente se acumula, se convierte en un enemigo que ataca por la espalda en el momento más inoportuno e inesperado, o dicho en términos más técnicos, se pueden aplazar tareas de Mantenimiento, pero hasta cierto punto, porque los equipos se resienten y luego surgen las indeseables fallas funcionales (varadas).

Otro punto a tener en cuenta, que es costumbre malsana en ciertas organizaciones (en muchas ocasiones auspiciada por directores comerciales) es el de posponer tareas de mantenimiento de un mes a otro (o de un período contable a otro), con el fin de bajar costos de mantenimiento y mostrar unos indicadores de costos buenos; esta práctica no es recomendable por dos razones, la primera, al posponer la tarea de mantenimiento se le están infringiendo al equipo ligeros deterioros y desgastes que paulatinamente minarán los ajustes y tolerancias de fábrica, y la segunda, llegará el momento en que ocurrirá la falla funcional y lo que se "ahorró" en períodos anteriores será necesario gastarlo con creces en el período actual...

La Tabla 19 presenta el conjunto de los indicadores de administración del Mantenimiento. 


\subsubsection{Indicadores de Costos del Mantenimiento}

Este grupo de indicadores son muy importantes para la Gerencia de Planta porque cuantifican cuánto se está gastando en Mantenimiento y de qué manera (Correctivo, Preventivo, mano de obra, materiales, etc.).

Recordar que según la figura 2, y las Tablas 2 y 3 del Capítulo 1, antes del inicio de cada período (anual y mensual) es necesario elaborar presupuestos de ventas, de costos y de gastos, entre ellos obviamente el de Mantenimiento. La práctica normal (graficada en la figura 8 del numeral 1.3.3) propende a que los Costos de Mantenimiento en lo posible sean variables, por lo tanto de este grupo de indicadores es sumamente importante el indicador llamado Costo de mantenimiento por unidad producida [\$/un]; los [\$/un] permiten hacer comparaciones con períodos contables pasados, con otras sucursales o unidades de negocio o con otras empresas (si se comparte información gremial), y en caso de anormalidades entrar a determinar las causas raíz del problema. La Tabla 20 presenta el conjunto de los indicadores de Costos de Mantenimiento.

Tabla 19. Indicadores de administración del Mantenimiento. Adaptada de [24]

\begin{tabular}{|c|c|c|c|}
\hline $\begin{array}{l}\text { Administración } \\
\text { del Mantenimiento }\end{array}$ & Fórmula & Descripción variables & $\begin{array}{c}\text { Usuario } \\
\text { del } \\
\text { Îndice }\end{array}$ \\
\hline \% Cobertura Cob & $C o b=100 \times \frac{O T s-c}{O T s}$ & $\begin{array}{l}\text { OTs- } c \text {, son las órdenes de } \\
\text { trabajo estándar cerradas. } \\
\text { OTs, son las órdenes de } \\
\text { trabajo estándar planeadas. }\end{array}$ & $\mathrm{M}, \mathrm{G}$ \\
\hline $\begin{array}{l}\% \text { Seguimiento al } \\
\text { programa, } S p\end{array}$ & $S p=100 \times \frac{T_{s-m t t o}}{T_{m t t o}}$ & $\begin{array}{l}T_{s-m t t o} \text {, es el tiempo laborado } \\
\text { en mantenimiento, según } \\
\text { el plan. } \\
T_{\text {mtto }} \text { son las horas } \\
\text { totales laboradas de } \\
\text { Mantenimiento }\end{array}$ & $\mathrm{M}, \mathrm{G}$ \\
\hline $\begin{array}{c}\% \text { Eficacia } \\
\text { Mantenimiento, } E_{\text {mtto }}\end{array}$ & $E_{m t t o}=100 \times \frac{T_{s}}{T_{m t t o}}$ & $\begin{array}{l}T_{s} \text {, es el tiempo estándar } \\
\text { programado para } \\
\text { Mantenimiento. }\end{array}$ & $\mathrm{M}, \mathrm{G}$ \\
\hline $\begin{array}{c}\text { \% Trabajo pendiente, } \\
W_{\text {pend }}\end{array}$ & $W_{\text {pend }}=100 \times \frac{T_{s}}{T_{s-m t t o}}$ & & $\mathrm{M}, \mathrm{G}$ \\
\hline $\begin{array}{c}\% \text { Horas extras por mes, } \\
\% T_{\text {extra }}\end{array}$ & $\% T_{\text {extra }}=100 \times \frac{T_{\text {extra }}}{T_{\text {mtto }}}$ & $\begin{array}{llr}T_{\text {extra }} \text { son las horas } \\
\text { extras laboradas } \\
\text { Mantenimiento. }\end{array}$ & $M, G$ \\
\hline
\end{tabular}




\begin{tabular}{|c|c|c|c|}
\hline $\begin{array}{c}\% \text { Horas subcontratadas } \\
\text { por mes, } \% T_{\text {out }}\end{array}$ & $\% T_{\text {out }}=100 \times \frac{T_{\text {out }}}{T_{\text {mtto }}}$ & $\begin{array}{l}T_{\text {out }} \text { son las horas } \\
\text { de } \\
\text { subcontratadas. }\end{array}$ & $\mathrm{M}, \mathrm{G}$ \\
\hline $\begin{array}{l}\text { \% Productividad } \\
\text { laboral, } P_{l a b}\end{array}$ & $P_{l a b}=100 \times \frac{T_{s-m t t o}}{T_{m t t o}}$ & & $\mathrm{M}, \mathrm{G}$ \\
\hline $\begin{array}{c}\text { \% Utilización laboral, } \\
U_{l a b}\end{array}$ & $U_{l a b}=100 \times \frac{T_{\text {prod }}}{T_{s}}$ & $\begin{array}{l}T_{\text {prod }} \text { son las horas de } \\
\text { trabajo productivo. }\end{array}$ & $\mathrm{M}, \mathrm{G}$ \\
\hline $\begin{array}{l}\text { Índice de productividad } \\
\text { compuesta IPC }\end{array}$ & $I P C=\frac{1}{100} \times P_{l a b} \times U_{l a b}$ & $\begin{array}{llll}P_{l a b}, \quad \text { es } & \text { el } & \% & \text { de } \\
\text { productividad laboral. }\end{array}$ & $\mathrm{M}, \mathrm{G}$ \\
\hline
\end{tabular}

Tabla 20. Indicadores de Costos de Mantenimiento. Adaptada de [24]

\begin{tabular}{|c|c|c|c|}
\hline $\begin{array}{c}\text { Costos del } \\
\text { Mantenimiento }\end{array}$ & Fórmula & Descripción variables & $\begin{array}{l}\text { Usuario } \\
\text { del } \\
\text { Índice }\end{array}$ \\
\hline $\begin{array}{l}\text { Valor agregado a la } \\
\text { producción VAP }\end{array}$ & $V A P=C P-C_{m}$ & $\begin{array}{l}C P \text {, es el costo total de } \\
\text { producción. } \\
C_{m} \text { es el costo de } \\
\text { materiales. }\end{array}$ & $\mathrm{M}, \mathrm{P}, \mathrm{G}$ \\
\hline$\%$ Costo de Mtto, $\% C M$ & $\% C M=100 \times \frac{C M}{V A P}$ & $\begin{array}{l}C M, \text { es el costo total de } \\
\text { mantenimiento. }\end{array}$ & $\mathrm{M}, \mathrm{P}, \mathrm{G}$ \\
\hline $\begin{array}{l}\text { Costo de Mtto por } \\
\text { unidad de Producción } \\
C_{m-\mathrm{u}}\end{array}$ & $C_{m-u}=\frac{C M}{U_{p r}}$ & & $\mathrm{M}, \mathrm{P}, \mathrm{G}$ \\
\hline $\begin{array}{l}\% \text { Mano Obra Mtto, } \\
\% C_{m o}\end{array}$ & $\% C_{m o}=\frac{C_{m o}}{C M}$ & $\begin{array}{l}C_{m o} \text {, el costo de la mano de } \\
\text { obra de Mantenimiento. }\end{array}$ & M \\
\hline $\begin{array}{l}\text { Relación costo } \\
\text { materiales y costo mano } \\
\text { de obra } C_{\text {mat-mo }}\end{array}$ & $C_{m a t-m o}=\frac{C_{m a t}}{C_{m o}}$ & $\begin{array}{lcr}C_{\text {mat }}, & \text { es } \quad \text { el } & \text { costo } \\
\text { de } & \text { materiales } & \text { de } \\
\text { Mantenimiento. } & \end{array}$ & M \\
\hline $\begin{array}{l}\text { Relación costo } \\
\text { materiales y costo total } \\
\text { de Mtto } C_{\text {mat } C M}\end{array}$ & $C_{m a t}-C M=\frac{C_{m a t}}{C M}$ & & M \\
\hline
\end{tabular}




\begin{tabular}{|c|c|c|c|}
\hline Costo hora Mtto $C_{H M}$ & $C_{H M}=\frac{C M-C_{m a t}}{T_{m t t o}}$ & & M, P, G. \\
\hline $\begin{array}{l}\text { Relación costo de } \\
\text { supervisión } C s\end{array}$ & $C_{s}=100 \times \frac{C_{\sup }}{C M}$ & $\begin{array}{llll}C_{\text {sup }} \text { es el } & \text { costo } & \text { de } \\
\text { supervisión } & \text { de } & \text { los } \\
\text { trabajos. } & & \\
\end{array}$ & $\mathrm{M}$ \\
\hline $\begin{array}{l}\text { Costo Mtto Prev versus } \\
\text { Mtto Correctivo } C_{c-p}\end{array}$ & $C_{c-p}=100 \times \frac{C_{p r e v}}{C_{c e}}$ & $\begin{array}{l}C_{\text {prev }} \text { es el costo del } \\
\text { M a n t e n i m i e n t o } \\
\text { preventivo; } \\
C_{c e} \text { es el costo del } \\
\text { correctivo de emergencia } \\
\text { efectuado. }\end{array}$ & M, P, G. \\
\hline $\begin{array}{l}\text { Tasa rotación Inventario } \\
T_{r i}\end{array}$ & $T_{r i}=$ & $\begin{array}{l}I_{p i} \text { es el costo promedio } \\
\text { invertido en inventario. }\end{array}$ & M, G. \\
\hline
\end{tabular}

\subsubsection{Ejemplo de cálculo de indicadores}

De un proceso productivo se conoce la siguiente información, correspondiente al mes de noviembre de 2015:

La empresa trabaja dos turnos diarios 16 horas por jornada y la producción planeada para el mes es de 60000 un. Las unidades reales producidas fueron 54 000, de las cuales 1059 no pasaron los controles de calidad. Para los 25 días hábiles del mes se planearon 25 OT de Mantenimiento Preventivo, con una intensidad de $2 \mathrm{~h}$ cada OT (para ejecutar al final de cada jornada).

En el mes hubo 8 varadas, todas imputables a Mantenimiento, las cuales totalizaron 60 horas. Puesto que hubo 8 varadas, se dejaron de hacer 6 órdenes de trabajo preventivas y se generaron 8 órdenes de trabajo emergentes, las cuales se suplieron con personal contratista.

Los gastos totales de Mantenimiento fueron de $\$ 162000000$ de pesos, el costo de producción promedio por pieza de $\$ 12000$, y el costo promedio de venta de cada unidad producida es $\$ 15000$.

El desarrollo de este ejercicio puede ser consultado en http://carlos-montilla-utp.jimdo.com/ complementos-libro-de-mantenimiento/complementos-cap\%C3\%ADtulo-5/

\subsection{Fuentes de información para la construcción de índices}

Dependiendo del tamaño de la empresa, de su nivel organizativo, de si poseen software de Mantenimiento y aparte de eso corporativo, etc. dependerá de dónde se extraiga la información de los indicadores.

En el caso de las grandes empresas que manejan software corporativo (numeral 3.2.10) es relativamente simple porque al momento de emitir las órdenes de trabajo se les anexa un vale de almacén con 
los elementos a consumir (con sus cantidades y costos), y al finalizar el mes o el año, se bloquea temporalmente el software, y contablemente se corre un query o consulta, que dependiendo de cómo haya sido configurado puede hasta entregar los indicadores; en el peor de los casos el query entregará valores totales por rubros contables (filtros y lubricantes, consumibles, fundiciones, etc.) y por el lado de mantenimiento se corre un query relativo a órdenes de trabajo (tipos, cantidades). Con la anterior información se elaboran y presentan fácilmente los indicadores.

En el caso de las medianas empresas el asunto es más complejo porque o no tienen software de mantenimiento o el que tienen regularmente no está ligado a la información contable, por lo tanto es necesario pedir al Departamento de Contabilidad que emita los informes respectivos, compararlos con los reportes de mantenimiento ( $\mathrm{i}$ ue regularmente no se corresponden!), conciliar la información, consultar lo referente a mantenimiento (órdenes de trabajo, tipos, cantidades) y proceder a construir y presentar los indicadores.

En el caso de las pequeñas empresas es mucho más compleja la situación, porque usualmente la poca cultura organizacional que poseen no llega al nivel de manejar indicadores, y en caso contrario, los administradores de Mantenimiento regularmente no poseen información sistematizada o la tienen muy incompleta o parcializada, por lo tanto los pocos indicadores que se construyen se hacen a mano y regularmente dejan muchas dudas de su veracidad.

\subsection{Algunos indicadores de producción relacionados con Mantenimiento}

En la práctica de la profesión es normal y necesario el relacionar variables de producción y de operación de las máquinas/equipos, que aunque no tienen que ver de manera directa con Mantenimiento, sí pueden mostrar de manera indirecta que hay problemas en la gestión y ejecución del Mantenimiento; dichos indicadores tienen que ver con el rendimiento de partes de desgaste, partes de recambio, combustibles y consumibles, en relación con las unidades producidas.

\subsubsection{Partes de desgaste P. D.}

Las P. D. son cualquier parte o componente que es susceptible de ser reemplazada debido a su normal (o anormal) desgaste. Se entiende aquí el desgaste como pérdida de espesor, peso, forma, dimensiones, etc., durante la operación del equipo, debido a que la P.D. está en contacto con el producto que transita por el equipo. Ej. Cuchillas, troqueles, matrices, placas de fundición, revestimientos, láminas de desgaste, dientes de balde retro/cargador/buldócer, llantas, etc.

Para el control de estos elementos se manejan cuadros del estilo de la Tabla 21, la cual regularmente no se basa en horas laboradas, sino en unidades producidas o en distancia recorridas, para el caso de equipo móvil. 
Tabla 21. Cuadro para control de partes de desgaste [el Autor]

\begin{tabular}{|c|c|c|c|c|c|}
\hline \multicolumn{2}{|c|}{ Nombre Parte de desgaste a controlar: P.D. 1 } \\
\hline $\begin{array}{c}\text { Fecha } \\
\text { último } \\
\text { cambio }\end{array}$ & $\begin{array}{c}\text { km o unidades } \\
\text { producidas al } \\
\text { último cambio (a) }\end{array}$ & $\begin{array}{c}\text { Fecha } \\
\text { nuevo } \\
\text { cambio }\end{array}$ & $\begin{array}{c}\text { km o unidades } \\
\text { producidas al } \\
\text { cambio actual (b) }\end{array}$ & $\begin{array}{c}\text { Rendimiento } \\
\text { (b) - (a) }\end{array}$ & Observaciones \\
\hline & & & & & \\
\hline & & & & & \\
\hline
\end{tabular}

Con el diligenciamiento del cuadro anterior se llega al establecimiento de estándares de rendimiento, que en determinado momento pueden mostrar problemas de calidad de la P.D., de montaje, de operación de la máquina, problemas con la materia prima, etc.

\subsubsection{Partes de recambio}

Una parte de recambio es cualquier parte o componente que es susceptible de ser reemplazada debido a su normal (¡o anormal!) deterioro durante la operación del equipo. Se debe entender que a diferencia de las P. D. las partes de recambio no están en contacto con el producto que transita por el equipo, Ejemplos: Rodamientos, sellos, acoples, repuestos máquina, etc. Para su control se puede conformar un cuadro similar a la Tabla 21.

\subsubsection{Combustibles}

Lo que se pretende es llevar un control de consumo de combustibles (diesel, gasolina, coque, gas, etc.) versus unidades producidas o distancias recorridas. De igual manera a lo que sucede con el control de P.D., el alcanzar un estándar de consumo de combustible y observar desviaciones alrededor de dicho valor permite rápidamente entrar a determinar problemas de Mantenimiento, de operación, de deterioro de los equipos, de hurto, etc. Para este control se puede tomar como base un cuadro como el presentado en la Tabla 22.

\section{5. Índices de fallas}

Los índices de fallas son herramientas utilizadas en Mantenimiento para estudiar y analizar situaciones problemáticas, generalmente problemas repetitivos a los cuales no se les ha encontrado su origen o causa última o causa raíz. Los índices de fallas más conocidos son: Análisis de Pareto, Diagrama Causa - Efecto o de Ishikawa o de Espina de Pescado.

\subsubsection{Análisis de Pareto}

Vilfredo Pareto (1848 - 1923) fue un sociólogo y economista italiano, quién aplicó la formulación matemática a la teoría económica y dio a la sociología una metodología positivista. El nombre de Diagrama de Pareto fue dado por Joseph Juran en honor al economista Pareto, quien realizó un estudio sobre la distribución de la riqueza, en el cual descubrió que la minoría de la población poseía la mayor parte de la riqueza y la mayoría de la población poseía la menor parte de la riqueza. Con esto estableció la llamada "Ley de Pareto" según la cual la desigualdad económica es inevitable en cualquier sociedad. 
Tabla 22. Cuadro para control de consumo de combustibles [el Autor]

\begin{tabular}{|c|c|c|c|c|}
\hline \multicolumn{3}{|c|}{ Equipo a controlar: } & \multicolumn{2}{|l|}{ Mes o período: } \\
\hline $\begin{array}{c}\text { Consecutivo } \\
\text { Tanqueo }\end{array}$ & $\begin{array}{c}\text { Fecha } \\
\text { tanqueo }\end{array}$ & $\begin{array}{c}\text { Cantidad } \\
\text { tanqueada } \mathrm{T}_{\mathrm{i}}\end{array}$ & $\begin{array}{l}\mathrm{km} \text { o unidades } \\
\text { producidas entre } \\
\text { tanqueos } \mathrm{km}\end{array}$ & Observaciones \\
\hline 1 & & $V(\mathrm{~km})_{1}$ & $S(\mathrm{~km})_{1}$ & \\
\hline \multicolumn{5}{|l|}{$\ldots$} \\
\hline \multirow[t]{2}{*}{$\mathrm{N}$} & & $V(\mathrm{~km})_{\mathrm{N}}$ & $S(\mathrm{~km})_{\mathrm{N}}$ & \\
\hline & \multicolumn{2}{|c|}{$\begin{array}{l}\text { Volumen total tanqueo mes } V_{t} \\
\qquad V_{t}=\sum_{i=1}^{N} V i\end{array}$} & $\begin{array}{c}\text { Espacio total } \\
\text { recorrido } S_{r e c} \\
S_{r e c}=k m_{N}-k m_{1}\end{array}$ & $\begin{array}{l}\text { Rendimiento R } \\
\qquad R=\frac{S_{r e c}}{V_{t}}\end{array}$ \\
\hline
\end{tabular}

Juran aplicó este concepto a la calidad, obteniéndose lo que hoy se conoce como la regla 80/20. Según este concepto, si se tiene un problema con muchas causas, se puede decir que el $20 \%$ de las causas resuelven el $80 \%$ del problema y el $80 \%$ de las causas solo resuelven el $20 \%$ del problema. Por lo tanto, el Análisis de Pareto es una técnica que separa los "pocos vitales" de los "muchos triviales". Una gráfica de Pareto es utilizada para separar gráficamente los aspectos significativos de un problema de los triviales (pocos vitales, muchos triviales), de manera que el equipo de trabajo sepa hacia dónde dirigir sus esfuerzos para mejorar.

\section{Algunos ejemplos de tales minorías vitales son:}

- La minoría de devoluciones que representa la mayoría de quejas de la clientela.

- La minoría de compradores que representen la mayoría de las ventas.

- La minoría de productos, procesos, o características de la calidad causantes del grueso de desperdicio o de los costos de reproceso.

- La minoría de vendedores que está vinculado a la mayoría de partes impugnadas.

- La minoría de problemas causantes del grueso del retraso de un proceso.

- La minoría de productos o servicios (20\%) que representan la mayoría (80\%) de las ganancias obtenidas (esta es la razón por la cual la mayoría de negocios solo venden lo de moda o lo "de combate" y lo demás es difícil y costoso conseguirlo).

- La minoría de elementos (20\%) que representan al grueso (80\%) del costo de un inventario.

\section{Se recomienda el uso del Diagrama de Pareto para:}

- Identificar oportunidades de mejora

- Mejorar la calidad de un producto o servicio.

- Analizar las diferentes agrupaciones de datos.

- Buscar las causas principales de los problemas y establecer la prioridad de las soluciones.

- Evaluar los resultados de los cambios efectuados a un proceso (el antes y el después).

- Cuando los datos puedan clasificarse en categorías y el rango de cada categoría es importante. 
En el caso de Mantenimiento el análisis de Pareto establece que unas pocas causas claves, son las responsables de la mayoría de los problemas, o en otras palabras "El 80\% de las fallas de una máquina se concentra en el $20 \%$ de las partes de la misma". Si se corrigen esas causas "claves", se tiene más probabilidad de éxito en la gestión de Mantenimiento.

Para ejecutar un análisis de Pareto se procede de la siguiente manera:

1) Se establecen las frecuencias de las distintas causas que originan el problema (uso de estadísticas de falla).

2) Se jerarquizan los porcentajes de las causas, desde el más alto valor al menor y se calcula además el porcentaje acumulativo (que es el primer porcentaje más el segundo, el tercero más el segundo y el primero y así sucesivamente).

3) En el eje horizontal (X) se representan las diferentes causas, de mayor a menor frecuencia.

4) En el eje vertical (Y) se representan los porcentajes individuales de $0 \%$ a $100 \%$.

5) Se construye una gráfica de barras (histograma), basada en dichos porcentajes. El ancho de cada barra no es importante, pero debe ser el mismo para todas las categorías.

6) Se construye una curva con los porcentajes acumulativos, la cual iniciará en $0 \%$ y culminará en $100 \%$, justo encima del punto central de la última barra de histograma.

7) Se traza una línea horizontal desde el $80 \%$ en el eje Y, y cuando corte la curva de porcentaje acumulativo, se baja hasta el eje X. A la izquierda de esta línea se tendrán las causas importantes (originadas en el $20 \%$ de las partes importantes) y a la derecha se tendrán las causas triviales (originadas en el $80 \%$ de las partes no importantes).

8) Analizar los pocos vitales y tomar acciones.

\section{Ejemplo:}

\section{Análisis de paros en sala calderas}

Un estudio de paros no programados ocurridos en una sala de calderas compuesta de seis calderas, fue ejecutado a lo largo de seis meses de operación (43 200horas) de las mismas, arrojo los resultados condensados en la Tabla 23.

Tabla 23. Resultado seguimiento fallas en calderas. Adaptada de [2]

\begin{tabular}{|l|c|}
\hline \multicolumn{1}{|c|}{ Fallas } & No de fallas $^{|c|}$ \\
\hline En quemadores & 120 \\
\hline Controles de nivel de agua & 90 \\
\hline Bombas de agua & 36 \\
\hline Instrumentación & 21 \\
\hline Líneas de combustible & 21 \\
\hline Hogar & 12 \\
\hline
\end{tabular}

La información presentada en la Tabla 23 es fácilmente asequible en un Departamento de mantenimiento. La Tabla 24 condensa el paso 2 y la información previa para ejecutar el paso 6 de la metodología propuesta. El análisis de Pareto arroja el gráfico mostrado en la figura 37, en donde se aprecia que el 
$80 \%$ de las fallas se generan en las categorías A, B y parte de la C, es decir, los quemadores, los controles de nivel de agua y en las bombas de agua, con lo que queda muy claro que serían en estos subsistemas donde el Departamento de Mantenimiento deberá hacer un trabajo fuerte de análisis y correcciones.

En general, reducir los problemas más significativos (las barras más largas en una Gráfica Pareto) servirá más para una mejora general que reducir los más pequeños. Con frecuencia, un aspecto tendrá el $80 \%$ de los problemas. En el resto de los casos, entre dos y tres aspectos serán responsables por el $80 \%$ de los problemas; sí ha ocurrido en el presente ejemplo. En relación con los estilos gerenciales de Resolución de Problemas y Toma de Decisiones, se puede ver como la utilización de esta herramienta puede resultar una alternativa excelente para un "Gerente estilo Bombero", quien constantemente a la hora de resolver problemas sólo "apaga incendios", es decir, pone todo su esfuerzo en los "muchos triviales".

Tabla 24. Categorización y cálculo de porcentajes acumulativos. Adaptada de [2]

\begin{tabular}{|c|l|c|c|l|}
\hline Categorías & \multicolumn{1}{|c|}{ Fallas } & $\begin{array}{c}\mathbf{N}^{\mathbf{0}} \mathbf{d e} \\
\text { fallas }\end{array}$ & \% respecto total & Cálculo \% acumulativo \\
\hline A & Quemadores & 120 & $40 \%$ & $0 \%+40 \%=40 \%$ \\
\hline B & Controles de nivel de agua & 90 & $30 \%$ & $40 \%+30 \%=70 \%$ \\
\hline C & Bombas de agua & 36 & $12 \%$ & $70 \%+12 \%=82 \%$ \\
\hline D & Instrumentación & 21 & $7 \%$ & $82 \%+7 \%=89 \%$ \\
\hline E & Líneas de combustible & 21 & $7 \%$ & $89 \%+7 \%=96 \%$ \\
\hline F & Hogar & 12 & $4 \%$ & $96 \%+4 \%=100 \%$ \\
\hline
\end{tabular}

Figura 37. Diagrama de Pareto para fallas en salas de calderas [el Autor]

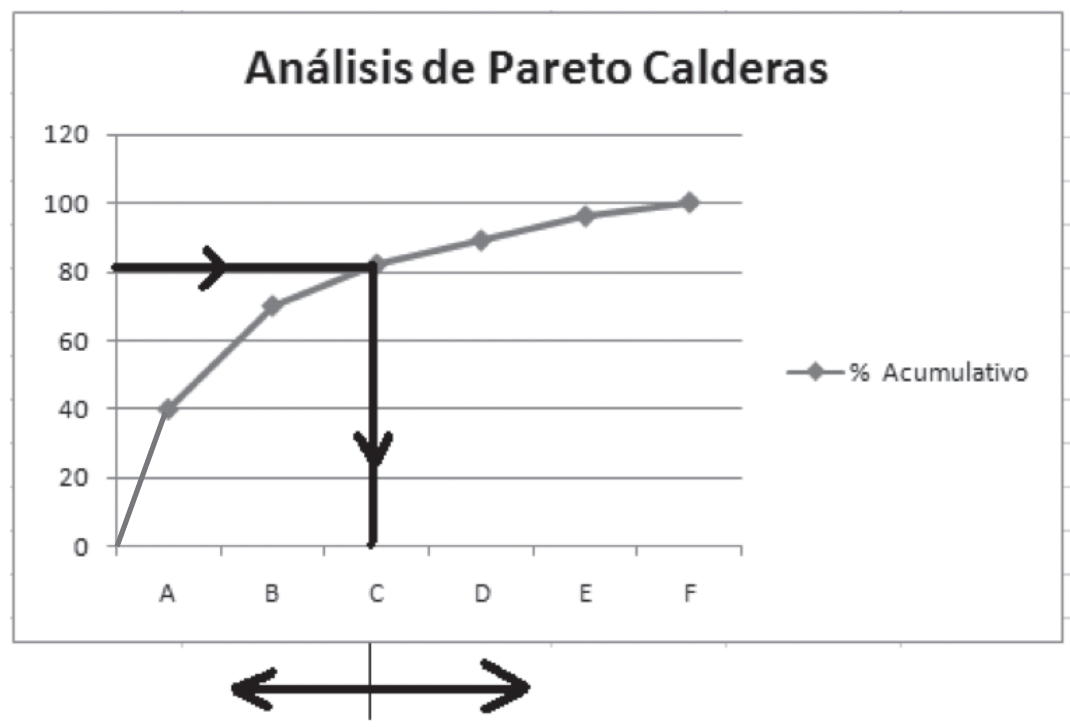

Causas importantes

Causas triviales 
Para muchos lectores podrá parecer muy simple y hasta trivial el análisis de Pareto, pero es prudente recordar que cuando se labora en la industria, la carga de trabajo del día a día (informes por entregar, $e$-mail por responder, proveedores que atender, visitas a la planta, etc.) puede llegar a ser muy asfixiante y una herramienta como la mostrada será de gran ayuda.

Un análisis de Pareto se puede complementar si se desea con un análisis del tipo diagrama de Ishikawa o espina de pescado o $5 \mathrm{M}$ (numeral 5.5.2), el cual permitirá determinar la causa última de las causas vitales.

\subsubsection{El Diagrama de Causa - Efecto, o Diagrama de Ishikawa o Espina de Pescado o de las 5M}

Es una herramienta que permite identificar las causas-raíz (causas últimas) de un problema, bien sea en un proceso productivo, en una máquina/equipo o en una empresa prestadora de servicios. El Diagrama causa-efecto permite ubicar las causas raíz de un problema, en función de la partición (de manera lógica y concisa) de los diferentes factores que intervienen en el proceso.

El Diagrama causa-efecto sirve para resolver problemas de Ingeniería tales como:

- Baja productividad de los trabajadores.

- Excesivo tiempo muerto.

- Excesivo ausentismo.

- Excesivos errores en el registro de datos.

- Daños, fallas y reparaciones repetitivas.

- Trabajos pendientes.

Su esencia se basa en la premisa de que en un problema en un proceso productivo puede tener unas causas principales o mayores, representadas en:

$$
\begin{aligned}
& \text { - Maquinaria } \\
& \text { - Mano de Obra } \\
& \text { - Método } \\
& \text { - Materia prima } \\
& \text { - Metrología }
\end{aligned}
$$

El aporte de cada ítem es el siguiente:

Maquinaria. Representa todo lo que tiene que ver con la máquina/equipo en sí, es decir, mal elegido, mal alistado, en mal estado, mal calibrado, mal ajustado, mal programado, etc.

Mano de obra. Hace referencia al Ser, es decir, a la persona: su estado de ánimo, el ambiente laboral, su Actitud frente al trabajo.

Método. Estudia la forma en que se hacen las cosas. Depende mucho de la capacitación y de la formación del operario y no con la actitud (la cual se valora en Mano de Obra).

Materia prima o Materiales. Estudia el aporte de la materia prima, como por ejemplo, materia prima mal seleccionada, en mal estado, por fuera de parámetros, mal dimensionada, etc. 
Metrología. Analiza el aporte que hacen los instrumentos de medición en el problema en estudio. Mal seleccionado, en mal estado, mal utilizado, mal ajustado, mal calibrado, etc.

El Diagrama causa-efecto consta de encabezado y espina de pescado.

Encabezado: Titulo, fecha de realización, área de la empresa, integrantes del equipo de estudio.

Espina de pescado (figura 38):

- Rectángulo principal, se ubica a la derecha del diagrama, y allí se escribe el problema, la característica de calidad o defecto a estudiar.

- Línea principal o espina central (columna vertebral).

- Líneas inclinadas que llegan a la línea central. Enlazan las causas mayores con la línea principal.

- Rectángulos secundarios, en los extremos de las líneas inclinadas. En estos se escriben las causas mayores que tienen relación sobre el efecto estudiado.

- Líneas secundarias (espinas). Dan cuenta de cada una de las causas menores que provocan la causa mayor.

Figura 38. Diagrama de Ishikawa o Espina de pescado [el Autor]

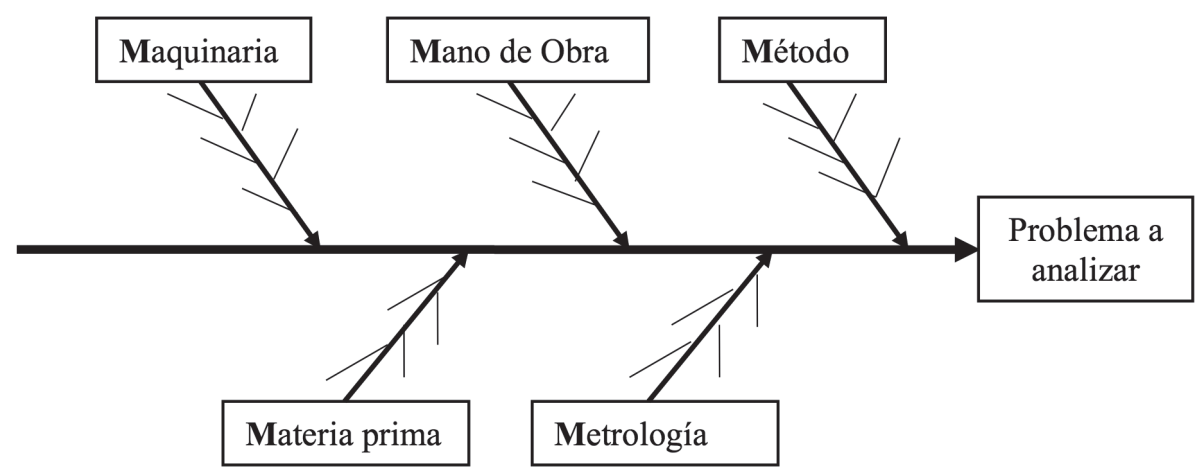

Es importante aclarar que regularmente la aplicación del Diagrama causa - efecto debe ser hecha por un equipo multidisciplinario (producción, Mantenimiento, Administración, Recursos humanos, Seguridad Industrial, Salud ocupacional, etc.), puesto que se tocan diferentes aspectos técnicos, administrativos, personales, económicos, etc., y el análisis podría quedar sesgado si por ejemplo un funcionario técnico analiza aspectos personales o un administrador analiza y decide sobre aspectos técnicos.

El método consiste en desagregar el problema hasta determinar la causa (o causas) que lo están provocando; a esta causa se le llama causa raíz. A partir de la configuración mostrada en la figura 38 se comienza a desglosar cada una de las causas mayores, colocando líneas o flechas secundarias con causas menores. A partir de este análisis se puede llegar a determinar cuál es el peso de cada una de las causas mayores y menores en el problema estudiado. Una vez determinadas las causas raíz 
de un problema, es necesario entrar a plantear soluciones, implementarlas, y posteriormente realizar mediciones que permitan validar el efecto de las correcciones.

Una misma causa menor puede estar aportando en varias líneas inclinadas de causas mayores. Por ejemplo, un instrumento de medición mal seleccionado aportará en la causa mayor Metrología, pero también deberá aparecer en la causa mayor Método, si es verificable que el operario estaba mal capacitado para elegir el instrumento, y si además el operario tenía mala actitud (por ejemplo por una calamidad doméstica) entonces aparecerá también en Mano de obra.

Una variante del Diagrama de Ishikawa es su aplicación al sector servicios, en donde ya no se habla de 5M, sino de 5P (en Ingles), es decir, Personal (Personal), Provisiones (Provisions), Procedimientos (Procedures), Puestos (Position) y Clientes (Purchaser).

Tomando como base el ejemplo desarrollado en el numeral 5.5.1 en donde la causa más importante resultó ser los Quemadores, el diagrama de Ishikawa respectivo podría resultar en:

- Maquinaria. Quemadores mal seleccionados para el gasto o tipo y cantidad de combustible utilizado.

- Mano de Obra. Operario desmotivado que no pone a punto los quemadores.

- Método. Mala capacitación del personal encargado de seleccionar, operar y mantener los quemadores.

- Materia prima. Quemadores de mala calidad o con materiales inadecuados para el tipo de combustible a quemar.

- Metrología. Quemadores mal calibrados

En una hipotética situación real, y suponiendo que el equipo de trabajo determinó que en definitiva los quemadores estuvieron mal seleccionados, esta sería la causa raíz del problema, y una posible solución podría ser brindar una capacitación al jefe de mantenimiento sobre selección de quemadores, y que trabaje coordinadamente con el Departamento de compras, al momento de elegir los próximos quemadores.

\subsection{Preguntas de consulta o análisis y ejercicios propuestos}

- ¿Será posible que el Control de partes de desgaste arroje información sobre defectos en la materia prima utilizada en el proceso? Explique.

- Consulte sobre la composición y principio de operación de una trituradora de mandíbulas para molienda de piedra. Explique cómo se podría llevar un control del rendimiento de la mandíbula fija y la mandíbula móvil.

- Ejercicio propuesto. Un fabricante de refrigeradores desea analizar cuáles son las categorías de los defectos más frecuentes que aparecen en las unidades que salen de la línea de producción. Para esto, empezó por clasificar todos los defectos posibles en sus diversos tipos, para el período correspondiente a Julio/2011 y los resultados aparecen en la Tabla 25.

- Se propone aplicar el análisis de Pareto, para determinar las causas importantes y las triviales. Hacer uso de hoja electrónica Excel y elaborar un gráfico en Excel como el mostrado en la figura 62 . 
Tabla 25. Tipos de fallas y frecuencias para refrigeradores [25]

\begin{tabular}{|l|l|l|l||}
\hline Tipo de Defecto & Detalle del Problema & Frec. & Categoría \\
\hline Empaque Defecto & Empaque roto o deforme que no ajusta & 9 & \\
\hline Pintura Defecto & Defectos de pintura en superficies externas & 5 & \\
\hline Gavetas Defecto. & Gavetas interiores con rajaduras & 1 & \\
\hline Mala Nivelación & La heladera se balancea y no se puede nivelar & 1 & \\
\hline Motor no arranca & El motor no arranca después de ciclo de parada & 1 & \\
\hline Motor no detiene & No para el motor cuando alcanza Temperatura & 36 & \\
\hline No enfría & El motor arranca pero la heladera no enfría & 27 & \\
\hline No funciona & Al enchufar no arranca el motor & 2 & \\
\hline Otros & Otros Defectos no incluidos en los anteriores & 0 & \\
\hline Puerta no cierra & La puerta no cierra correctamente & 2 & \\
\hline Rayas & Rayas en las superficies externas & $\mathbf{8 8}$ & \\
\hline \hline Total: & \multicolumn{2}{|l||}{} & \\
\hline
\end{tabular}

- Ejercicio propuesto. Elaborar el Diagrama de Ishikawa para la categoría B: Control de nivel de agua en calderas, del ejemplo mostrado en el numeral 5.5.1.

\subsection{Para reflexionar. un estudio de caso en la empresa colombiana de petróleos Ecopetrol}

En este apartado se presenta un ejemplo real de aplicación del método de Ishikawa, asimismo, de todos los percances y sobrecostos causados por su no aplicación.

En el hipervínculo http://carlos-montilla-utp.jimdo.com/complementos-libro-de-mantenimiento/ complementos-cap\%C3\%ADtulo-5/ se puede realizar esta lectura complementaria. 

Capítulo 6 



\section{Apuntes sobre mantenimiento predictivo PdM}

\subsection{Introducción}

El Mantenimiento Predictivo PdM (Predictive Maintenance) es una estrategia de Mantenimiento orientada a predecir la ocurrencia de fallas, con base en evidenciar los síntomas de falla que presenta una máquina, midiendo y analizando los cambios en variables de operación de la misma. El PdM corresponde a una evolución del Mantenimiento Preventivo.

La figura 39 ilustra una representación del comportamiento general del Mantenimiento Predictivo aplicado a una variable cualquiera. Se observa que se han definido los intervalos de medición y el rango de control. Los primeros resultados están dentro del rango de control, a pesar que $\mathrm{F}_{3}$ esté justo en el límite superior (¡una alarma!). Posteriormente en $\mathrm{F}_{5}$ la variable se sale del rango de control y será necesario que se programe una parada para una inspección más rigurosa, y se efectúen ajustes o reparaciones en caso de ser necesario. Una vez hecha la intervención se mide de nuevo, y se observa que en $\mathrm{F}_{\mathrm{n}}$ ha retornado al rango de control y en lo sucesivo el procedimiento debe continuar.

Figura 39. Comportamiento esperado de una variable controlada en Mantenimiento Predictivo [el Autor]

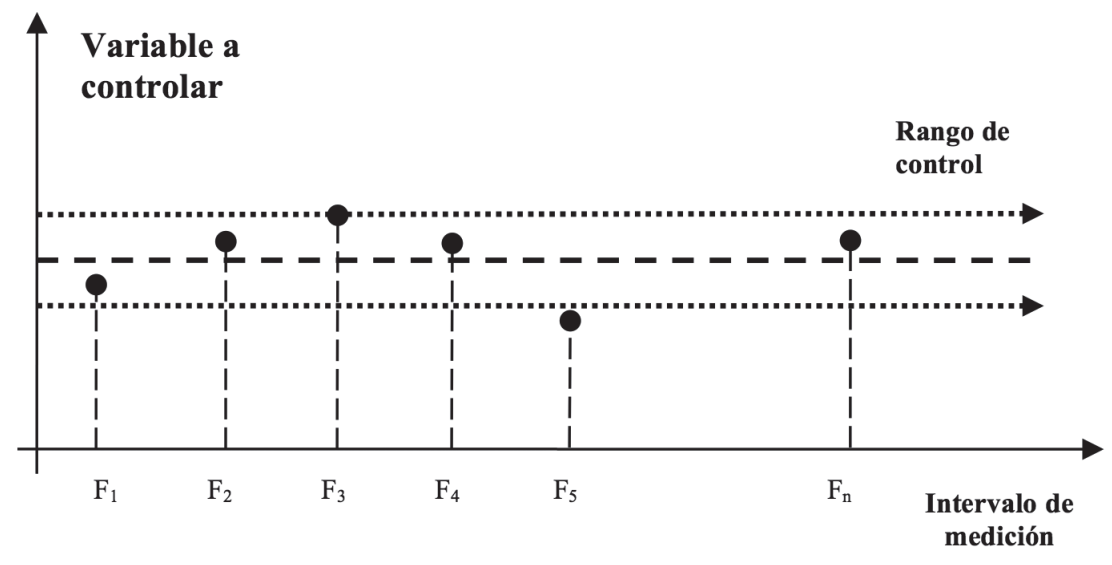


En el PdM se utilizan pruebas y ensayos (técnicas) específicos tales como:

- Termografías.

- Tintas penetrantes.

- Análisis de vibraciones.

- Análisis de aceites en uso.

- Ensayos no destructivos clásicos: radiografías, ultrasonido activo, partículas magnéticas.

De manera general, y partiendo de una línea base de Cero Predictivo, se puede llegar a su ejecución sistemática, aplicando el siguiente procedimiento:

- Definir variables a seguir (deben ser importantes o sensibles para el proceso productivo).

- Definir pruebas y ensayos (técnicas) a aplicar.

- Fijar los rangos de operación o de control de la variable a estudiar y los intervalos a los cuales se realizarán las mediciones.

- Definir si las mediciones se harán con personal y equipos propios, o vía de subcontrataciones [26].

- Realizar periódicamente las mediciones, verificando que la variable a controlar esté dentro del rango predefinido.

- Cualquier desviación por fuera del rango de control es indicativo de fallas en gestación (fallas potenciales), por lo tanto es necesario entrar a tomar acciones (revisar, inspeccionar, ajustar, calibrar, programar trabajos de Mantenimiento correctivo, etc.), antes que la falla potencial se convierta en falla funcional.

Las mediciones en PdM pueden ser puntuales (acorde a una frecuencia pre-establecida) o mediciones "totales". En las mediciones totales se utilizan sistemas de adquisición de datos y la medición es online, y ya se habla entonces de Mantenimiento Basado en la Condición o CBM

A continuación se hará una descripción de algunas de las Pruebas y Ensayos más ampliamente aplicadas en PdM. Es conveniente recordar que en una prueba se expone o incentiva un cuerpo o material con algún cuerpo o ambiente externo, y se espera una repuesta (positiva o negativa) de comportamiento del cuerpo de interés frente a la incentivación. En el caso del Ensayo se habla regularmente de un procedimiento más elaborado, probablemente regido por Normas o Estándares, se hacen uso de instrumentos de medición, se obtienen lecturas, las cuales pueden ser interpretadas en sí mismas, o llevadas a un modelo matemático para su posterior análisis.

\subsection{Ensayos termográficos}

Principio: El espectro electromagnético posee regiones visibles y no visibles para el ojo humano. Sólo parte del rango de longitudes de onda de la luz es visible para el ojo humano, específicamente el rango comprendido entre los 400nm y los 750nm (ver figura 40); por debajo de los $400 \mathrm{~nm}$ se encuentran los rayos ultravioleta, y por encima de los $750 \mathrm{~nm}$ se encuentran los rayos infrarrojos, que corresponden a una manifestación de energía infrarroja o térmica o calor; tanto ultravioletas como infrarrojos son invisibles al ojo humano. A diferencia de la luz visible, en el mundo infrarrojo, todo aquello con temperatura por encima del cero absoluto emite calor.

La Termografía es una técnica que mediante el uso de una cámara sensible a la franja infrarroja, capta y mide la energía térmica emitida por un obieto, de manera que logra la diferenciación v localización de 
áreas calientes o frías mediante el análisis de la parte infrarroja del espectro electromagnético. Dicho en otras palabras la Termografía es una medición indirecta de temperatura a través de la medición de la emisividad.

Figura 40. Espectro de longitudes de onda visibles por el ojo humano [27]

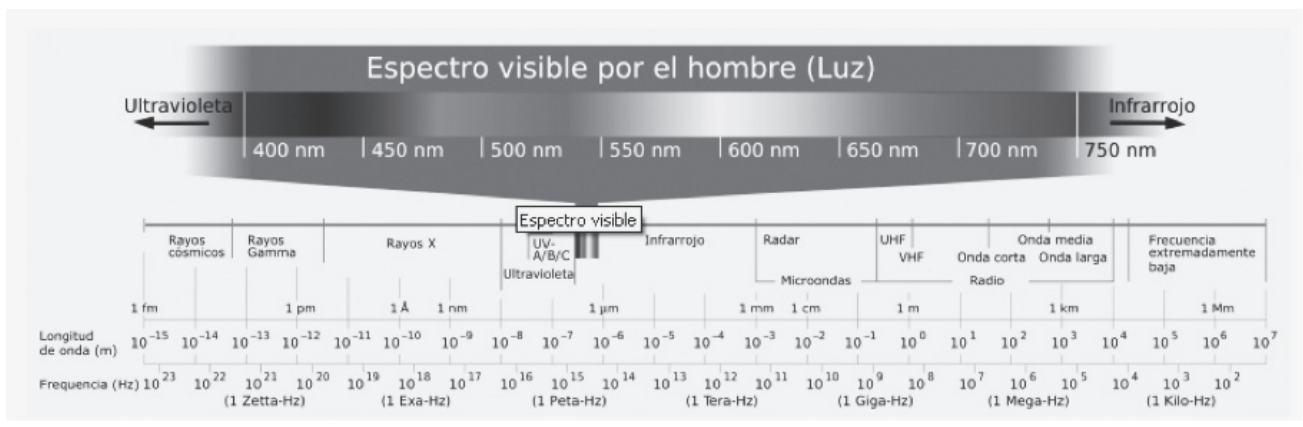

La mayoría de cámaras termográficas, basan su operación en la utilización de un instrumento llamado bolómetro (inventado por Langley hacia1880), el cual mide en todas las longitudes de onda, la cantidad total de radiación electromagnética que viene de un objeto. Un bolómetro (figura 41) consiste de un cuerpo absorbente de calor, conectado a un sumidero de calor (un objeto mantenido a temperatura constante) a través de un material aislante. El resultado es que cualquier radiación absorbida por el detector aumenta su temperatura por encima del sumidero de calor que actúa de referencia. La radiación absorbida se mide por lo tanto a partir del contraste de temperatura entre el detector y la referencia.

Figura 41. Estructura genérica de un bolómetro [28]

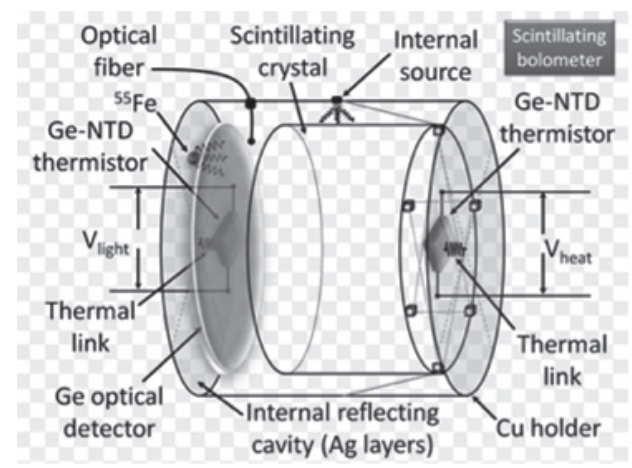

La Termografía es una técnica bastante utilizada, sobre todo en empresas grandes, porque permite localizar problemas que en circunstancias normales no serían detectados, gracias a la captura y visualización instantánea de imágenes térmicas, y con la medición de temperatura que entrega, localiza fallas en gestación o desarrolladas, sin necesidad de entrar en contacto con el equipo, de desenergizarlo, de detener su operación, de desarmarlo. Las fallas localizadas deberán ser corregidas posteriormente usando las técnicas convencionales (correctivos programados). 
Existen dos tipos generales de termografías, la pasiva y la activa. En la pasiva, la energía necesaria para incentivar el bolómetro, proviene del objeto en estudio (horno, motor, ser vivo, fruta, etc.); dicho en otras palabras, el elemento a estudiar debe estar en operación. En el caso de la activa, el objeto en estudio por sí mismo no irradia calor (en comparación con el ambiente que lo rodea), razón por la cual es necesario incentivarlo con una fuente externa (circuito eléctrico, fuente de calor, etc.), para que irradie y pueda ser medido y analizado. La termografía activa aplica principalmente en el estudio de materiales.

Los campos de aplicación de la Termografía son muy amplios. A continuación se presenta una gama de aplicaciones:

\section{Sistemas eléctricos (Pasiva)}

- Instalaciones eléctricas en general

- Líneas de baja, media y alta tensión

- Contactos en las centrales de control de motores CCM

- Transformadores de potencia y corriente

- Fusibles

- Escobillas

\section{Sistemas mecánicos rotatorios (Pasiva)}

- Rodamientos y chumaceras

- Bombas de agua, ventiladores, molinos, etc.

- Motores de combustión interna

- Turbinas

\section{Materiales / Mantenimiento / Análisis estructural (Activa)}

- Inspección de fuselajes de avión

- Discontinuidades sub-superficiales y superficiales como la corrosión

- Deficiencias en espesores de recubrimiento

- Falta de adhesión en materiales compuestos

- Daños por Impacto en materiales compuestos

- Medida del espesor o profundidad en materiales compuestos

- Porosidad en materiales compuestos

- Adherencia de parche en materiales compuestos

- Perdida de espesor en metales (cañerías, recipientes etc.)

- Evaluación de uniones y empalmes en metales

- Acumulación de sarro en metales

- Adherencia de la pintura

- Corrosión bajo pintura

- Análisis dinámico de fatiga

- Evaluación de la soldadura por puntos

- Vacío, oclusión de aire y deformaciones en material plástico (Polímeros) 


\section{Sistemas Térmicos (calentamiento, enfriamiento) - Pasiva}

- Hornos y calderas

- Instalaciones frigoríficas (Perdidas de frío)

- Reactores

- Intercambiadores de calor

- Torres de enfriamiento

- Perdidas en válvulas y líneas de líquidos/vapores

La figura 42 presenta la vista general de una cámara termográfica Wuhan Guide TP8S (como las que posee la Universidad Tecnológica de Pereira). Esta cámara posee un rango de medición de $-20^{\circ} \mathrm{C}$ a 600 ${ }^{\circ} \mathrm{C}$, y una resolución de $0,01^{\circ} \mathrm{C}$.

En la figura 43 se aprecia un ejemplo de los dos tipos de imágenes que entrega una cámara termográfica. En la (a), se aprecia la imagen infrarroja con su respectiva paleta de temperaturas, mientras que en (b) se aprecia la imagen visual respectiva.

Figura 42. Vista general de una cámara termográfica Wuhan Guide TP8S

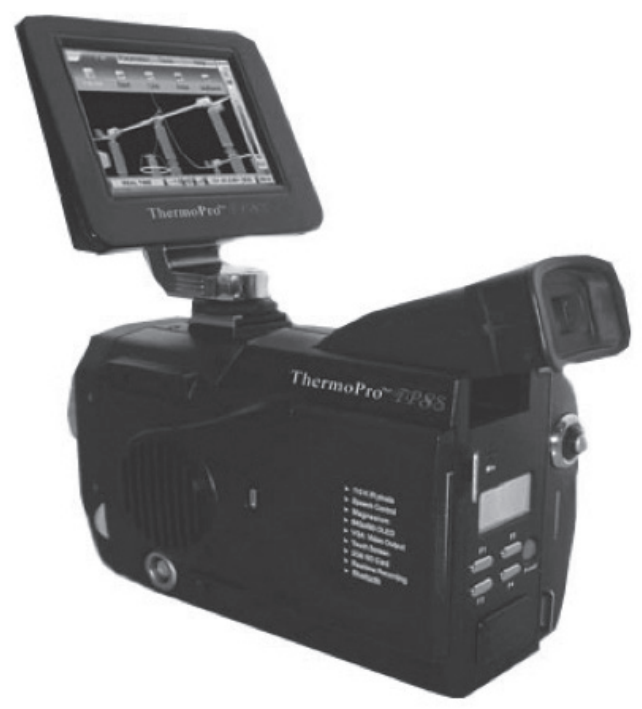


Figura 43. Ejemplo de una imagen termográfica. (a) Imagen infrarroja. (b) Imagen visual [el Autor]

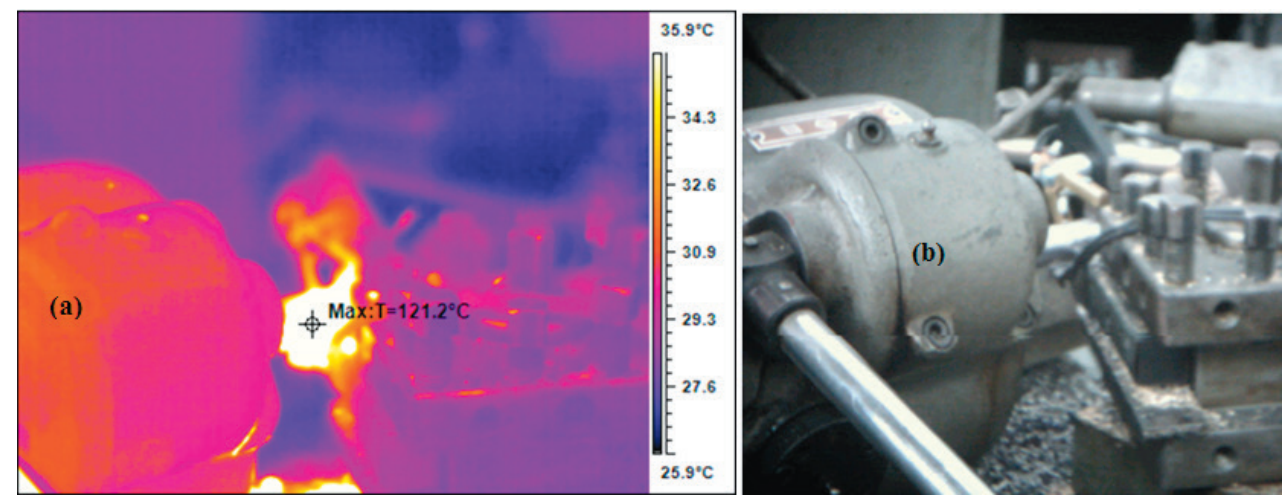

En la Tabla 6 (numeral 1.5.4) se relacionaron las diferentes ventajas y desventajas del Mantenimiento Predictivo. Entre las desventajas, y para el caso de los ensayos termográficos, se destacan:

- Alto costo de adquisición del equipo, sin embargo hay empresas que prestan el servicio, para aplicarlo a equipos y situaciones críticas.

- Una Termografía dice dónde está el problema, pero no necesariamente la causa, es decir, la imagen adquirida debe ser convenientemente interpretada por personal calificado, para determinar tipo y causa del problema, así como la acción a tomar.

\subsection{Prueba de líquidos o tintas penetrantes}

El método o prueba de líquidos penetrantes LP, se basa en la propiedad física conocida como Capilaridad. Recuérdese que la capilaridad es la propiedad de los cuerpos sólidos de atraer y hacer subir por sus paredes hasta cierto límite el líquido que las moja, como el agua, y de repeler y formar a su alrededor un hueco o vacío con el líquido que no las moja, como el mercurio.

Recuérdese que cuando interactúan un líquido y un sólido se presentan dos tipos de fuerzas: Las fuerzas de cohesión intermolecular y las fuerzas de adhesión líquido-pared. En el caso que las fuerzas de cohesión molecular sean superiores a las de adhesión líquido-pared, el fluido no ascenderá por la pared, o en otras palabras no habrá capilaridad, o el líquido no moja (caso del mercurio). En el caso que las fuerzas de cohesión molecular sean inferiores a las de adhesión líquido-pared, el fluido ascenderá por la pared, o en otras palabras habrá capilaridad, o el líquido moja la pared (caso del agua).

La prueba real con LP, consiste en la aplicación de tres tipos de líquidos o tintas sobre una superficie donde se sospecha hay fisuras (rodamientos, ejes, engranajes, carcasas), dichos líquidos son: Limpiador, Penetrador y Revelador; es obvio que se sospecha de la existencia de la fisura, pero no es visible de lo contrario no tiene sentido la prueba.

En primera instancia (figura 44) se aplica el líquido Limpiador (regularmente incoloro), para remover grasa, suciedad, óxido, y se limpia la superficie. Seguidamente se aplica el líquido Penetrador 
(regularmente de color rojo), el cual posee buenas características de penetración. Una vez ha transcurrido un tiempo específico (determinado por el fabricante), para que el líquido penetrador recién aplicado, se aloje considerablemente en cualquier abertura superficial existente, se debe realizar una limpieza del exceso de líquido penetrante depositado en la superficie externa.

A continuación, se aplica un líquido absorbente, comúnmente llamado Revelador (normalmente de color amarillo), el cual absorberá el líquido que haya penetrado en las aberturas superficiales. Si hay fisura, el líquido revelador, se adherirá a las paredes de la fisura puesto que su fuerza de adhesión es superior a la del líquido penetrador, y finalmente, la menor fuerza de adhesión del líquido penetrante propiciará que ascienda por la fisura hasta la superficie.

Por último, viene la etapa de observación, las áreas en las que se observe la presencia de líquido penetrante después de la aplicación del líquido absorbente, son áreas que poseen discontinuidades superficiales (grietas, perforaciones, etc.).

Figura 44. Ilustración del ensayo de tintas penetrantes [29]

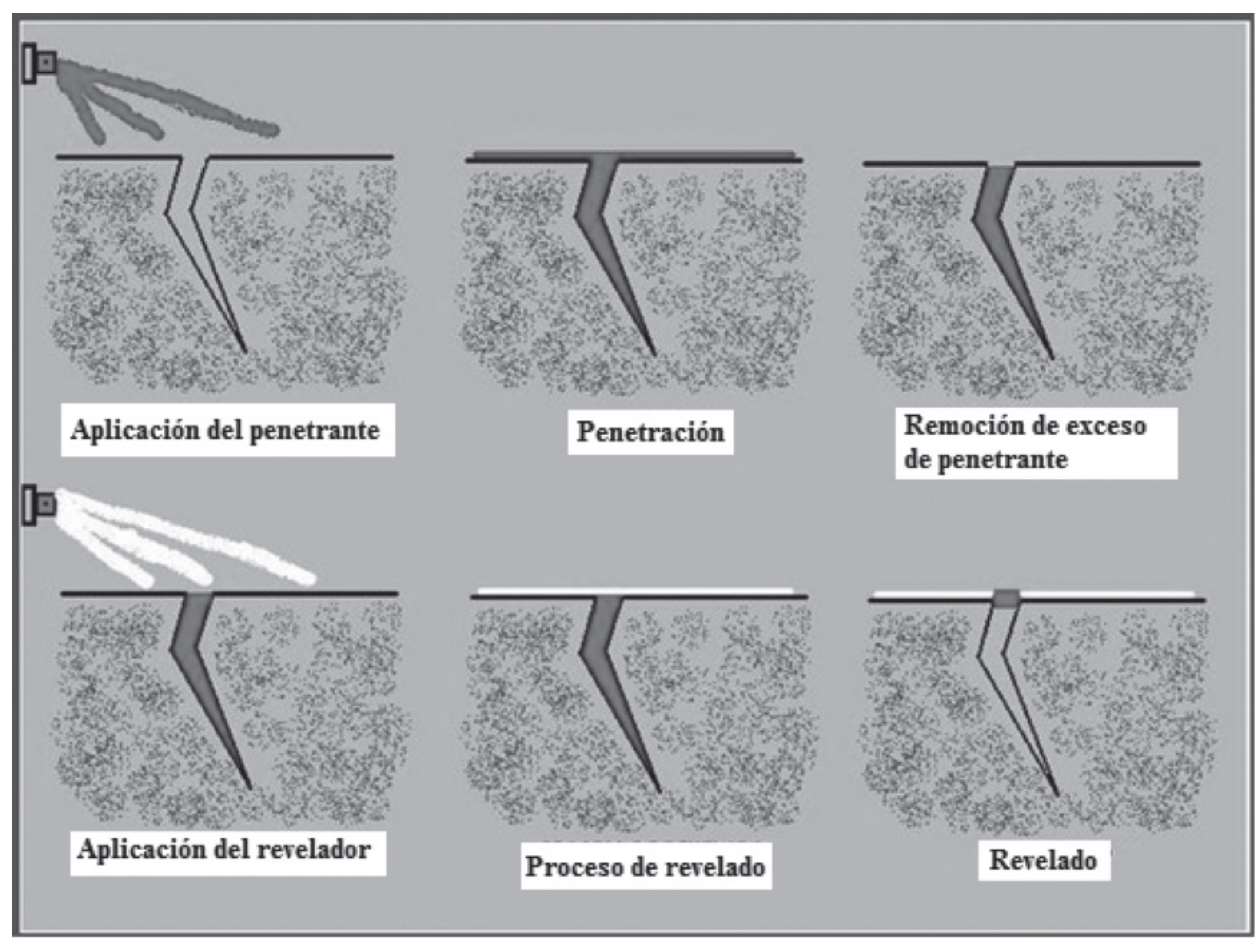

La prueba de Tintas penetrantes dice si hay o no hay falla estructural (soldaduras, ejes, piñones, etc.), es decir, determina si hay una fractura/fisura que llegue a la superficie, y en dónde está ubicada. Una información más amplia alrededor de las pruebas con tintas penetrantes puede ser consultada en la referencia [30]. En la figura 45 se presenta el resultado de una aplicación de tintas penetrantes hecha en clase a un troquel. La línea roja indica la existencia de una fisura. 


\subsection{Medición y análisis de vibraciones}

Como se mencionó en el Capítulo 1, para producir máquinas de mayor velocidad de producción es necesario disminuir masas en movimiento y pesos muertos de estructuras (máquinas menos robustas y más esbeltas), lo que conlleva a que las estructuras sean más sensibles al efecto de las vibraciones generadas por desalineaciones, desbalances, elementos rodantes defectuosos, etc. Lo anterior llevó al desarrollo de técnicas de medición y análisis de vibraciones, para prevenir fallas funcionales y sus consecuencias negativas.

Figura 45. Resultado de prueba de tintas penetrantes a un troquel [3]

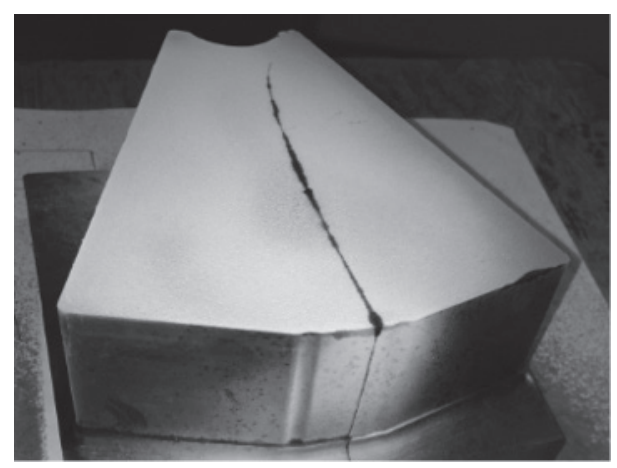

La palabra vibración se refiere a los movimientos oscilatorios (hacia delante y hacia atrás) de las estructuras, de los sistemas mecánicos o de sus componentes. Por lo general, la vibración se caracteriza en términos de Amplitud, Frecuencia, velocidad y aceleración. La Tabla 26 presenta un resumen de las principales fuentes de vibración en los equipos, en función de si la máquina es nueva o ha sido usada durante algún tiempo. Recuérdese que: “Todo cuerpo que vibra produce ruido”.

Tabla 26. Fuentes de vibración en maquinaria y estructuras [el Autor]

\begin{tabular}{|l|l|}
\hline \multicolumn{1}{|c|}{ Máquina nueva } & \multicolumn{1}{c|}{ Máquina usada } \\
\hline Mala cimentación & Daño cimentación \\
\hline Mala instalación (pata suelta) & Fallas sujeción (pata suelta) \\
\hline $\begin{array}{l}\text { Mala selección o instalación de sistemas de } \\
\text { amortiguación (resortes, absorbedores de } \\
\text { vibración) }\end{array}$ & Daños en resortes, absorbedores, tornillería \\
\hline Mala alineación al momento de montar & $\begin{array}{l}\text { Desalineación por soltura mecánica (tornillería o } \\
\text { elementos de sujeción) }\end{array}$ \\
\hline
\end{tabular}




\begin{tabular}{|l|l|}
\hline Piezas nuevas y desbalanceadas & $\begin{array}{l}\text { Piezas que se desbalancean por suciedad, golpes, } \\
\text { pérdidas de material, reparaciones indebidas, etc. }\end{array}$ \\
\hline Ejes con elementos excéntricos & Malas reparaciones que generan excentricidades \\
\hline $\begin{array}{l}\text { Elementos rodantes nuevos deteriorados } \\
\text { por mal montaje }\end{array}$ & Elementos rodantes defectuosos o mal lubricados. \\
\hline Tolerancias de mecanización indebidas & $\begin{array}{l}\text { Tolerancias de mecanización indebidas durante } \\
\text { reparaciones. Desajustes por desgaste paulatino }\end{array}$ \\
\hline $\begin{array}{l}\text { Vibración y ruido por soltura mecánica } \\
\text { entre piezas que se mueven relativamente } \\
\text { entre sí }\end{array}$ & $\begin{array}{l}\text { Vibración y ruido por soltura mecánica entre piezas } \\
\text { que se mueven relativamente entre sí }\end{array}$ \\
\hline
\end{tabular}

\subsubsection{Algunos términos y definiciones}

\subsubsection{Desalineación (figura 46).}

No colinealidad entre los ejes de dos máquinas que se acoplan y transmiten movimiento axialmente. La desalineación puede ser angular, paralela o combinada. Se corrige con equipos para alineamiento para maquinaria. La alineación es una técnica con sus equipos y métodos propios.

Figura 46. Desalineación angular y espectro de vibración asociado [31]

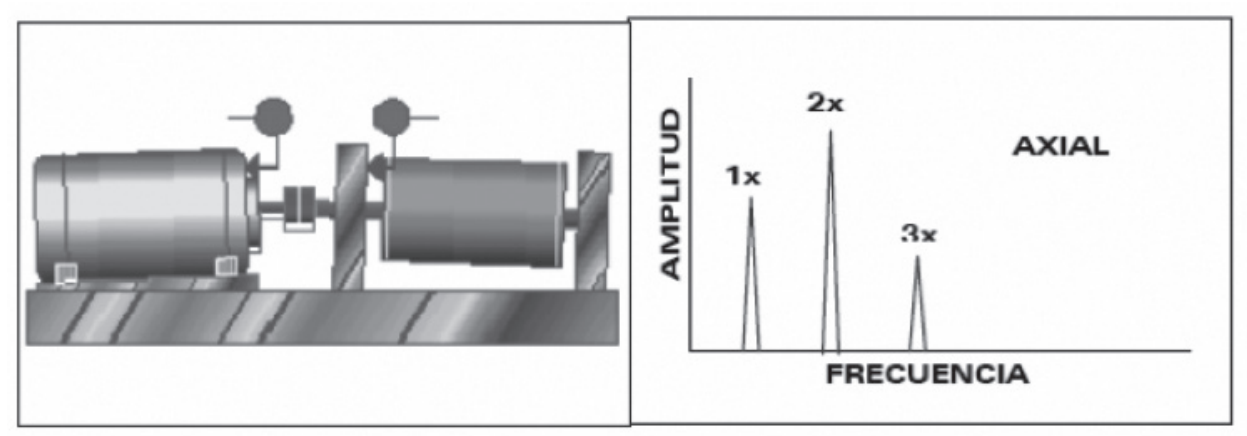

\subsubsection{Desbalanceo (figura 47).}

No distribución homogénea de la masa de un cuerpo rotatorio. No coincidencia del centro de masas con el centro geométrico de la pieza. Se corrige, bien sea adicionando una masa $m$, a $180^{\circ}$ de donde se determinó que está la concentración indebida de masa, o mecanizando (retirando) la masa anormal (poco usual). Al igual que la alineación, el balanceo es una técnica con sus equipos y métodos propios. 
Figura 47. Esquema de una pieza balanceada y una desbalanceada [31]

\section{Centro de masas no coincide con el centro geométrico}

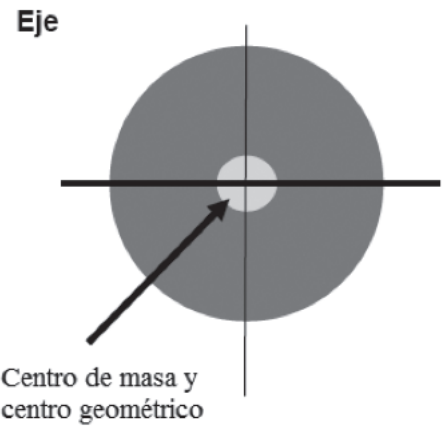

Balanceado

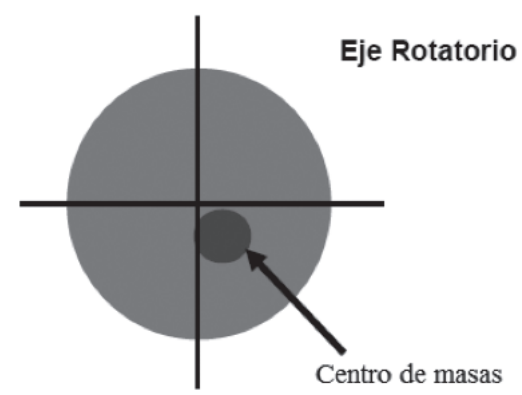

Desbalanceado

\subsubsection{Excentricidad (figura 48).}

No coincidencia de las líneas de centros, del eje de rotación de la pieza y de la maza (polea, piñón, volante de inercia, etc.); en otras palabras, defecto geométrico de concentricidad. La excentricidad se puede corregir por mecanizado o con el recambio de la pieza (polea, piñón, catalina, sprockets, etc.).

Figura 48. Excentricidad y espectro de vibración asociado [31]

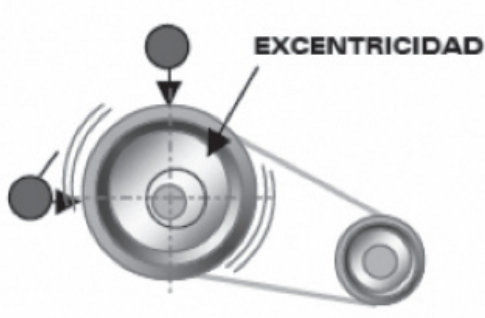

6.4.1.4. Soltura mecánica.

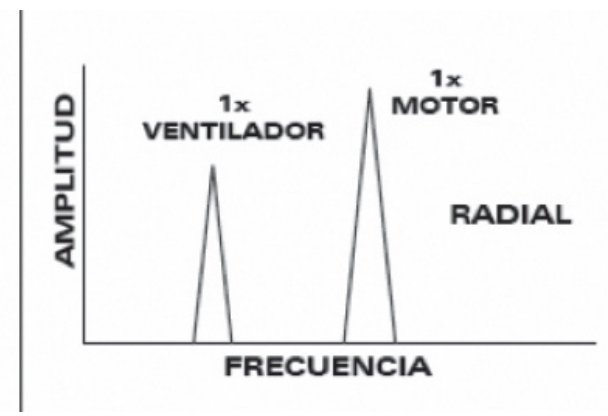

Fenómeno causante de vibración y ruido, originado por tornillería (o elementos de fijación) suelta, rota o faltante, en la estructura de una máquina. Puede aparecer como efecto del trabajo normal de la máquina o como consecuencia de otros fenómenos (desalineación, desbalanceo, etc.). Para corregir la soltura mecánica se recambia o aprieta la tornillería suelta, faltante o defectuosa, esto en el caso de que sea causada por la operación normal del equipo, en caso contrario es necesario corregir las otras causas primero. 
6.4.1.5. Resonancia (figura 49).

Fenómeno por el cual se igualan las frecuencias de oscilación natural de un sistema (estando la máquina/equipo en reposo) y la frecuencia forzada (en operación). La ocurrencia de este fenómeno es sumamente nocivo, porque las amplitudes de ambas ondas se suman y pueden llevar a la destrucción del sistema.

Figura 49. Excentricidad y espectro de vibración asociado [el Autor]

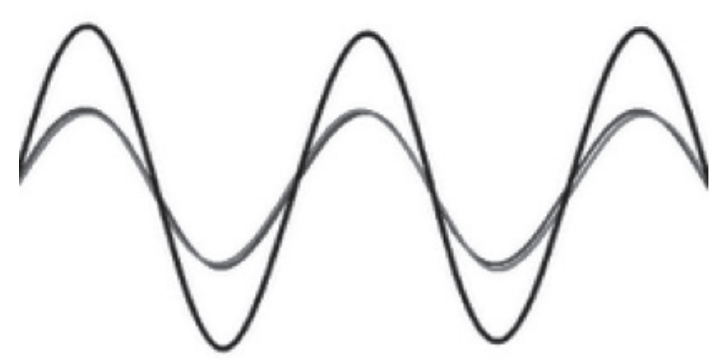

\subsubsection{Fenómeno de pata suelta.}

Fenómeno por el cual algunos de los puntos de apoyo (patas) de la base de una máquina (motor eléctrico, torno, reductor, etc.) no son coplanarios. Este situación aparentemente tan trivial es una fuente de vibraciones muy grande, porque si el mecánico no conocedor del fenómeno, aprieta una pata levantada forzándola a que quede coplanaria; con esta acción por un lado estará exponiendo la estructura a que se rompa (regularmente las carcasas son de fundición, y por ende muy rígidas), y por otro lado está precargando la máquina/equipo induciendo la aparición de vibración y ruido.

\subsubsection{Niveladores y empujadores (figura 50).}

Elementos propios de una estructura/bastidor bien concebida, y que permiten elevarla/descenderla en un plano vertical, o correrla adelante/atrás, en un plano horizontal. Los niveladores y empujadores son vitales para un fácil y adecuado alineamiento de una pareja de máquinas/equipos. 
Figura 50. Bastidor de máquina/equipo con niveladores y empujadores [31]

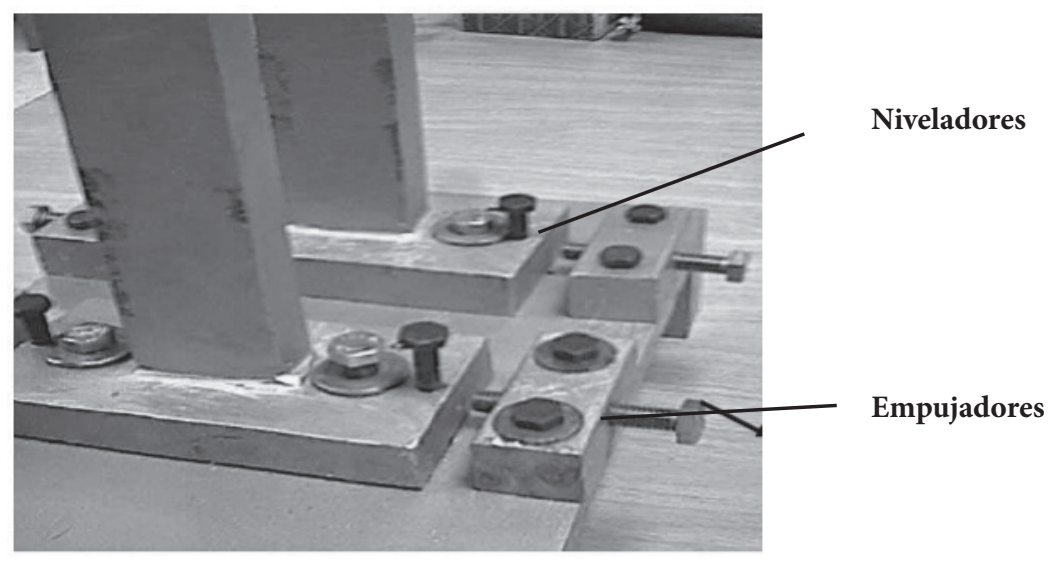

\subsubsection{Efectos de las vibraciones}

Las vibraciones excesivas pueden tener efectos adversos en el personal, el equipo y las estructuras.

\section{Personas.}

El ruido que generan es incómodo, pueden alterar su estado de ánimo (mal genio, estrés, nerviosismo), pueden interferir con su habilidad para hacer algo o concentrarse en tareas mentales, pueden hacer difícil que la gente efectúe movimientos precisos o que efectúen lecturas correctas de los instrumentos $\mathrm{y}$, en casos extremos, pueden conducir a la inhabilidad física (enfermedad de Raynaud o dedos blancos causado por los compresores de romper carreteras,) y a accidentes laborales.

\section{Máquinas y equipos}

Puede reducir la vida de sus componentes (rodamientos, chumaceras), sobre todo aquellos con cargas muy grandes o velocidades altas. Las herramientas de las máquinas sujetas a vibraciones excesivas producen malos acabados. Algunos equipos de precisión (sistemas ópticos, microscopios, calibradores) no pueden ser utilizados adecuadamente en presencia de vibraciones.

\section{Estructuras.}

Los esfuerzos oscilatorios inducidos en las conexiones de las estructuras de construcción (puentes, edificios) y conexiones mecánicas (tornillos de sujeción, tubería, cables, soldaduras) tienden a producir fallas en estos dispositivos debido a fatiga estructural. La vibración afloja tornillos conduciendo gradualmente al desajuste general de la máquina. En casos puntuales de combinación de vibración y resonancia, se puede llegar al caso extremo de fatiga y falla catastrófica de las estructuras (civiles o mecánicas).

Cabe anotar que no siempre la vibración es nociva, existen industrias y equipos en las que la vibración es deseable y necesaria, por ejemplo, las cribas o zarandas son indispensables en la industria alimenticia para clasificar granos (molidos o naturales) de acuerdo a su tamaño o granulometría, lo mismo que en Trituración de agregados, producción de cemento, fabricación tubos de cemento, vibradores para limpieza de tolvas, etc. En estas industrias lo que hay que garantizar es que los equipos vibren acorde a unos ciertos valores de frecuencia y amplitud. 


\subsubsection{Medición y control de la vibración}

\subsubsection{Medición.}

En control de vibración, lo que hay que garantizar no es que no haya vibración (puesto que físicamente es imposible), sino que ella no supere ciertos montos. Los valores de vibración que se consideran aceptables son determinados por normas. La Tabla 27 presenta los límites permisibles de vibración, de acuerdo a la Norma ISO 10816-1995, expresada en mm/s.

Tabla 27. Criterio provisional de vibración para un grupo específico de máquinas según la norma ISO 10816 - 1995 [32]

\begin{tabular}{|c|c|c|c|c|}
\hline $\begin{array}{c}\text { Velocidad de vibración } \\
\text { valor eficaz RMS } \\
(\mathrm{mm} / \mathrm{s})\end{array}$ & Clase I & Clase II & Clase III & Clase IV \\
\hline 0,28 & \multirow{3}{*}{ Normal } & \multirow{4}{*}{ Normal } & \multirow{5}{*}{ Normal } & \multirow{6}{*}{ Normal } \\
\hline 0,45 & & & & \\
\hline 0,71 & & & & \\
\hline 1,12 & \multirow{2}{*}{ Admisible } & & & \\
\hline 1,8 & & \multirow[b]{2}{*}{ Admisible } & & \\
\hline 2,8 & \multirow{2}{*}{ Límite } & & \multirow{2}{*}{ Admisible } & \\
\hline 4,5 & & \multirow[b]{2}{*}{ Límite } & & \multirow{2}{*}{ Admisible } \\
\hline 7,1 & \multirow{5}{*}{$\begin{array}{c}\text { No } \\
\text { permisible }\end{array}$} & & \multirow{2}{*}{ Limite } & \\
\hline 11,2 & & \multirow{4}{*}{ No permisible } & & \multirow{2}{*}{ Limite } \\
\hline 18 & & & \multirow{3}{*}{ No permisible } & \\
\hline 28 & & & & \multirow{2}{*}{ No permisible } \\
\hline 45 & & & & \\
\hline
\end{tabular}

Nota: El valor eficaz o RMS (Root Mean Square), es el valor de una onda variable, que produce el mismo efecto (en potencia), que su equivalente en onda continua o directa.

Clase I: Componentes individuales de máquinas y motores, íntegramente conectado a la máquina completa, con condiciones normales de operación, motores de potencia menor a 15 $\mathrm{kW}$.

Clase II: Máquinas de dimensión mediana, motores entre (15 - 75) kW sin cimentación especial; máquinas hasta $300 \mathrm{~kW}$ con soporte especial.

Clase III: Máquinas grandes con inercias giratorias instaladas en cimientos rígidos y pesos que son relativamente rígidos en la dirección de la medición de la vibración.

Clase IV: Máquinas grandes que operan a velocidades superiores a la velocidad crítica o a la frecuencia natural.

La medición de vibraciones se puede llevar a cabo con medidores portátiles tipo bolsillo (para mediciones puntuales, sin representación del espectro de onda) o con equipos de arquitectura más 
compleja (medición, acondicionamiento de señales, procesamiento de información y presentación de información al usuario) como el DSP Logger MX 300 (figura 51) de la Facultad de Ingeniería Mecánica de la UTP. Un equipo de estos convenientemente utilizado, determinará si la fuente de vibración es por desbalanceo, por desalineación, por soltura mecánica, por elemento rodante defectuosos, etc., con lo cual se pasará a programar los correctivos necesarios (balanceo, alineación, apriete, lubricación, cambio de elementos rodantes, etc.).

Figura 51. Equipo para medición y análisis de vibraciones UTP [el Autor]

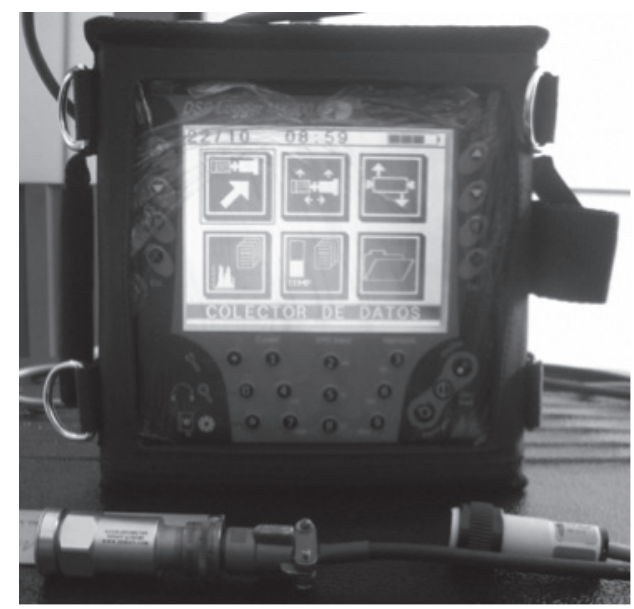

6.4.3.2. Corrección de la vibración. En vibración también se cumple la Ley de Pareto condensada en el postulado: El $80 \%$ de los problemas de vibración se originan en el $20 \%$ de las causas, representadas en problemas de alineación de ejes. El otro 80\% de las causas se distribuyen en: desbalanceo, excentricidades, elementos rodantes defectuosos, problemas de lubricación, piezas sueltas, tolerancias de mecanización indebidas, desajustes excesivos, partes mal aseguradas, etc. Es evidente entonces que si una empresa posee sus equipos bien alineados, indirectamente está resolviendo el $80 \%$ de los problemas de vibraciones (y los sobrecostos asociados a ellas). La metodología general de la medición y control de las vibraciones es la descrita en la figura 52, siguiendo el orden cardinal referenciado allí. 
Figura 52. Dinámica general de la medición y control de vibraciones [el Autor]

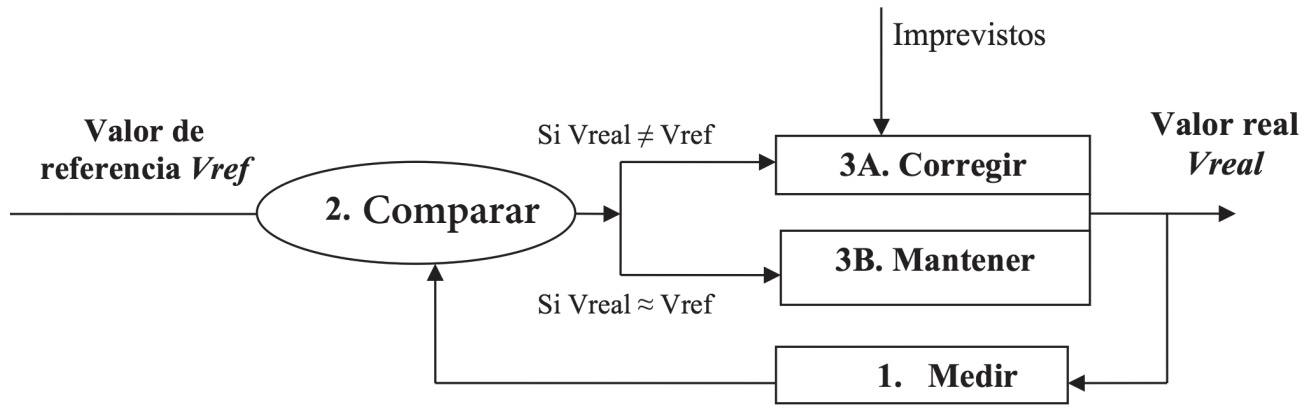

\subsubsection{Corrección de la desalineación.}

Existen diversos métodos para alinear ejes, pero los más utilizados son los presentados en la figura 53, es decir, regla de precisión, comparadores invertidos y alineación láser. Cada uno de los métodos anteriores posee sus potencialidades y limitaciones, en cuanto a exactitud, simplicidad, costo de implementación y capacitación del personal a cargo.

Figura 53. Comparación de los métodos de alineación. Adaptado de [31]

\begin{tabular}{|c|c|c|c|}
\hline Método & $\begin{array}{l}\text { Regla de precisión } \\
\text { <+- }\end{array}$ & $\begin{array}{c}\text { Comparadores } \\
\text { invertidos } \\
Q\end{array}$ & Láser \\
\hline $\begin{array}{l}\text { Entrenamiento } \\
\text { requerido por el } \\
\text { operador }\end{array}$ & $\begin{array}{l}\text { Años de experiencia. "El } \\
\text { mago" }\end{array}$ & $\begin{array}{l}\text { Semanas o meses. Un } \\
\text { especialista }\end{array}$ & $\begin{array}{l}\text { Unas pocas horas. } \\
\text { Cualquier persona }\end{array}$ \\
\hline $\begin{array}{l}\begin{array}{l}\text { Facilidad de } \\
\text { ejecución }\end{array} \\
\end{array}$ & Alta & Baja & intermedia \\
\hline $\begin{array}{l}\text { Tiempo de } \\
\text { ejecución }\end{array}$ & Muy bajo & Muy alto & Bajo \\
\hline $\begin{array}{l}\text { Calidad de la } \\
\text { alineación }\end{array}$ & Máximo 4 mils en $10 \mathrm{~mm}$ & $\begin{array}{l}\text { Máximo } 0,4 \text { mils en } \\
100 \mathrm{~mm}\end{array}$ & $\begin{array}{l}\text { Máximo } 0,04 \text { mils en } \\
1000 \mathrm{~mm}\end{array}$ \\
\hline
\end{tabular}

La figura 54 presenta un esquema básico del montaje real de los comparadores invertidos, realizado con equipo Update International de la UTP. 
Figura 54. Equipo de alineamiento, método de los comparadores invertidos [el Autor]
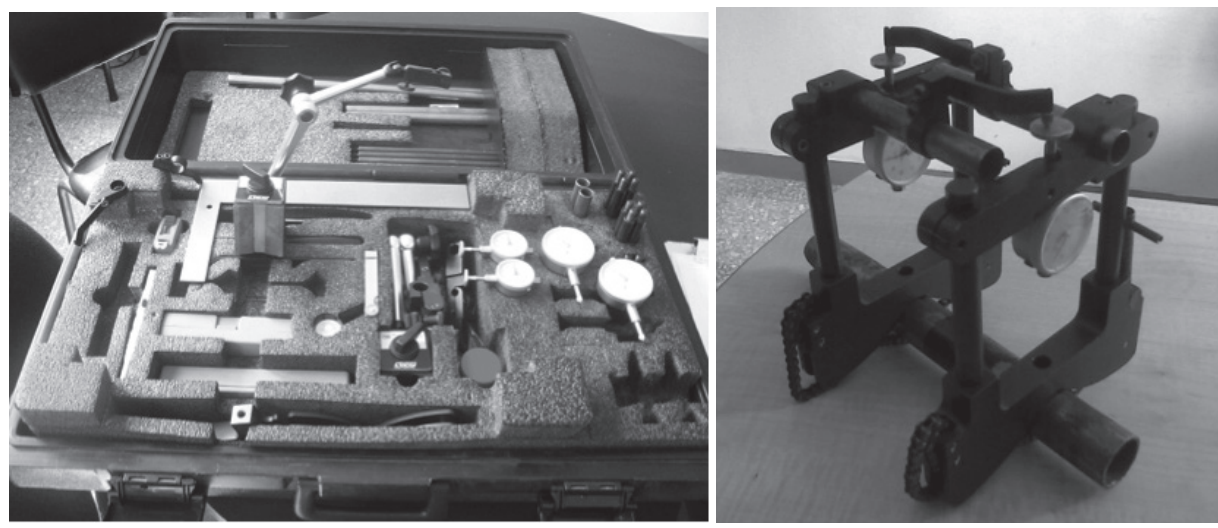

Sin importar cuál de los tres métodos se aplique, durante un proceso de alineamiento se debe seguir este orden:

- Verificar estado de absorbedores, tornillería, acoples. Cambiar en caso de ser necesario.

- Corregir pata suelta (utilizar comparadores de carátula para medirla y adicionar lainas, espaciadores o shims).

- Pre-alinear (utilizar niveladores y empujadores).

- Corregir desalineación angular y corregir desalineación paralela (combinada)

- Medir y mantener

\subsubsection{Corrección del desbalanceo.}

Primeramente se deben tener claros la potencia y velocidad de operación de la máquina/equipo en estudio. Con un equipo del estilo del DSP Logger (mostrado en la figura 99) se debe hacer un montaje como el mostrado en la figura 103. Se debe hacer una medición de la vibración inicial del sistema, y comparar contra los valores de la Tabla 27; seguidamente se adiciona una masa de prueba y nuevamente se mide, con lo cual internamente el equipo hace cálculos e indica cuánta masa se debe adicionar y en qué fase (ángulo con respecto a un punto de referencia). Esta descripción es por supuesto muy simple y somera, en mayor profundidad sería necesario tomar un curso o Seminario de Vibraciones mecánicas o consultar a mayor profundidad las referencias [31] y [33].

En la figura 55 se aprecia que se hace uso de dos acelerómetros, lo cual coincide con un balanceo en dos planos. La Tabla 28 ilustra los criterios necesarios para decidir si se aplica balanceo estático o en un plano (con un solo acelerómetro), en dos planos o dinámico (con dos acelerómetros) o en múltiples planos. 
Figura 55. Montaje en máquina balanceadora, para realizar balanceo en dos planos de un ventilador [el Autor]

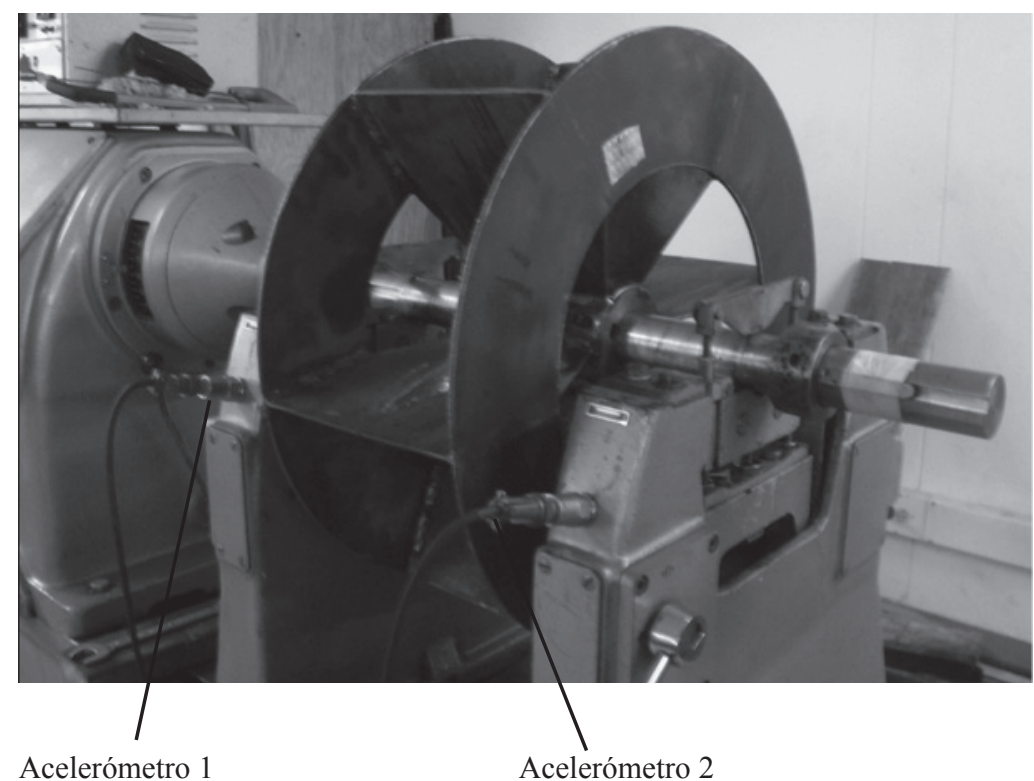

Tabla 28. Modelos para balanceo [32]

\begin{tabular}{|c|c|c|c|c|}
\hline \multirow{2}{*}{ Modelo Rotor } & \multirow{2}{*}{ Relación $L / D$} & \multicolumn{2}{|c|}{ Modelos de balanceo } \\
\cline { 3 - 5 } & & Un plano & Dos planos & $\begin{array}{c}\text { Múltiples } \\
\text { planos }\end{array}$ \\
\hline & & & & \\
\hline
\end{tabular}




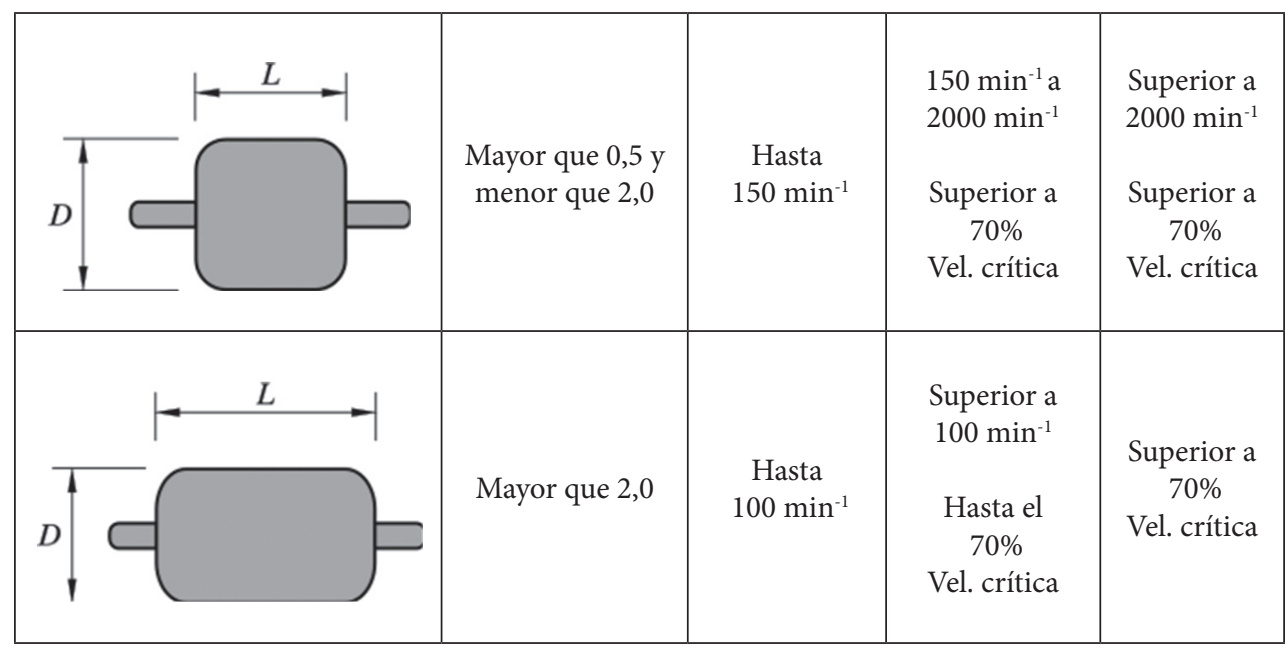

Nota: La velocidad crítica en ejes rotatorios, es aquella para la cual ocurre su máxima deformación, debido a su peso propio (eje sin carga externa) y por efectos de la velocidad angular. Existen tantas velocidades críticas como grados de libertad (masas) posea el eje. El cálculo más trivial de la primera velocidad crítica (regularmente la más importante) se efectúa con la fórmula 12. Para cálculos más completos de las velocidades críticas existen los Métodos de: Rayleigh, de la fórmula de frecuencias y de Dunkerley.

$$
f_{n}=\sqrt{\frac{K}{m}}=\sqrt{\frac{g}{\delta}}
$$

Donde,

$\begin{array}{ll}K & \text { es la constante de rigidez del sistema rotacional. } \\ m & \text { es la masa del sistema rotacional. } \\ g & \text { es la constante gravitacional. } \\ \delta & \text { es la deformación del eje. } \\ f_{n} & \text { es la frecuencia natral del sistema rotacional. }\end{array}$

\subsection{Análisis de aceites en uso}

En este apartado se puede consultar una información básica sobre el Ensayo mencionado.

En el sitio web http://carlos-montilla-utp.jimdo.com/complementos-libro-de-mantenimiento/ complementos-cap\%C3\%ADtulo-6/ se puede consultar la esencia de la técnica Análisis de aceites en uso.

En el Anexo 6 se puede consular una información relativamente amplia sobre aceites, grasas y los aspectos básicos de la lubricación. 
6.6. Un estudio de caso. Análisis de falla en rodamiento de motor eléctrico en ladrillera (Cartago - Valle del cauca), con prueba combinada de balanceo y análisis termográfico

En el hipervínculo http://carlos-montilla-utp.jimdo.com/complementos-libro-de-mantenimiento/ complementos-cap\%C3\%ADtulo-6/ se puede realizar esta lectura complementaria. 

Capítulo 7 



\section{Apuntes sobre Mantenimiento Productivo Total TPM}

\subsection{Introducción}

El Mantenimiento Productivo Total (Total Productive Maintenance por sus siglas en inglés) es el sistema de Mantenimiento en el cual hay compromiso y colaboración en todos los niveles de la Compañía, incluyendo la gerencia, con el fin de maximizar la productividad. Se entiende por productividad la maximización de la relación entre los productos o servicios obtenidos, a partir de unos recursos. En términos simples ser productivo es producir lo máximo con lo mínimo, respetando la calidad.

De manera similar al Mantenimiento Predictivo, el TPM surgió como una evolución del Mantenimiento Preventivo. El término TPM se puede desagregar y analizar la contribución de cada uno de los componentes, para alcanzar el incremento de la productividad.

Mantenimiento: Conservación de las instalaciones en buen estado con acciones como reparar, limpiar, apretar, lubricar y dedicar tiempo a estas tareas básicas

Productivo: Destinado a la producción, con enfoque de no penalizarla. Noción de rendimientoeficacia de las acciones de mantenimiento y mejora continuada.

Total: participación de toda la fuerza de trabajo de la empresa y considerando todos los aspectos relacionados a las máquinas/equipos.

A diferencia de los sistemas de Mantenimiento preliminares (Correctivo, Programado, Preventivo, Predictivo), el TPM no se centra en las máquinas/equipos; inicialmente se enfoca en las personas para sensibilizarlas, capacitarlas, cambiarles para bien su actitud en el trabajo, su visión de la vida; posteriormente estas personas centrarán su atención en la producción (instalaciones, procesos, máquinas y equipos), con miras a incrementar la productividad, y por ende a ser más competitivos como personas y como organización. En fases avanzadas el TPM debe ser una filosofía de vida, y no de trabajo (tal como ocurre en Japón). 
El TPM maneja un concepto en materia de mantenimiento, basado en los siguientes cinco principios fundamentales:

- Participación de todo el personal, desde la alta dirección hasta los operarios de planta. Incluir a todos y cada uno de ellos permite garantizar el éxito del objetivo.

- Creación de una cultura corporativa orientada a la obtención de la máxima eficacia en el sistema de producción y gestión de los equipos y maquinarias. De tal forma se trata de llegar a la eficacia global.

- Implantación de un sistema de gestión de las plantas productivas de manera tal que se facilite la eliminación de las pérdidas antes de que se produzcan y se consigan los objetivos propuestos.

Implantación del mantenimiento preventivo como medio básico para alcanzar el objetivo de cero pérdidas mediante actividades integradas en pequeños grupos de trabajo y apoyado en el soporte que proporciona el Mantenimiento Autónomo.

- Aplicación de los sistemas de gestión a todos los aspectos, diseño, producción, desarrollo, ventas, postventa y dirección.

\subsection{Siglas y términos a tener en cuenta en TPM}

ЏIT: Just In Time (Justo a Tiempo). Estrategia técnico-administrativa que propende a mantener el mínimo de inventarios (tanto de materia prima como de producto intermedio y producto terminado), ya que ello representa dinero retenido, lucro cesante.

Kaizen: Palabra Japonesa que engloba toda una Filosofía empresarial y de vida, la cual se puede resumir en "No debe pasar un día sin que se haya hecho alguna clase de mejoramiento en algún lugar de la Compañía”. Un término equivalente es: Mejoramiento continuo. El Kaizen también se puede tomar como mejoramiento continuo hasta alcanzar la calidad total.

TQM: Total Quality Management. Control Total de la Calidad. Calidad es hacer las cosas bien $\mathrm{y}$ a la primera.

\subsection{Origen y evolución del TPM}

El TPM surgió en Japón, en la década de 1960, gracias a los esfuerzos y directrices del Japan Institute of Plant Maintenance (JIPM) como una estrategia de Mantenimiento industrial, basada en el mejoramiento del sistema de Mantenimiento Preventivo, destinada a lograr la eliminación de las seis grandes pérdidas de las máquinas/equipos, para poder hacer factible la producción Just in Time, la cual tiene como objetivo la eliminación sistemática de desperdicios.

Las seis grandes pérdidas se hallan directa o indirectamente relacionadas con las máquinas/equipos de las industrias, dando lugar a reducciones en la eficiencia del sistema productivo, en tres aspectos fundamentales:

- Averías y tiempos de preparación que ocasionan tiempos muertos o de vacío.

- Funcionamiento a velocidad reducida y los tiempos en vacío, todo lo cual genera pérdidas de velocidad del proceso.

- Pérdidas de productos y procesos defectuosos ocasionados por los defectos de calidad y repetición del trabajo. 
Mejorar los tres aspectos mencionados anteriormente tiene relación directa con mejorar los indicadores Disponibilidad, Porcentaje de producto conforme, Confiabilidad y Mantenibilidad, trabajados en el Capítulo 6. El TPM adopta como filosofía el principio de Kaizen o mejoramiento continuo aplicados al mantenimiento y a la gestión de equipos.

Previo a la aparición del TPM propiamente dicho, en la década de 1960 tuvo lugar la aparición del Mantenimiento Productivo. El Mantenimiento Productivo incluye los principios del Mantenimiento Preventivo, pero le agrega un Plan de Mantenimiento para toda la vida útil del equipo, más labores e índices destinados a mejorar la confiabilidad y mantenibilidad (ver capítulo 6). La aplicación del TPM comenzó a incrementarse en Japón durante la década de 1970. El TPM involucra a todos los empleados, desde los cargos altos hasta los operarios de planta. También agrega a conceptos antes desarrollados como el Mantenimiento preventivo, y nuevas herramientas tales como las Mejoras de Mantenibilidad, la Prevención de Mantenimiento y la detección analítica de fallas.

Para dar una idea del transcurrir de las empresas, antes y después del TPM, a continuación se hará una síntesis. La empresa tradicional suele estar dotada de sistemas de gestión basados en la producción de series largas, con poca variedad de productos, tiempos de preparación o alistamiento largos, tiempos de entrega de producto terminado largos, operarios con una formación muy especificada, control de calidad basado en la inspección de producto (recordar el flow shop). Cuando dicha empresa ha precisado emigrar desde este sistema a otros más ágiles y menos costosos, ha necesitado mejorar los tiempos de entrega, los costes y la calidad simultáneamente, es decir, la competitividad, lo que le ha supuesto entrar en la dinámica de gestión contraria a cuanto se ha mencionado: series cortas de múltiples productos, en tiempos de operaciones cortas, con trabajadores polivalentes y calidad basada en procesos que llegan a sus resultados "en la primera", tal como debe ocurrir en Manufactura flexible (Ver figura 56).

Figura 56. Relación variedad de partes versus volumen de producción, en función del sistema de manufactura [34]

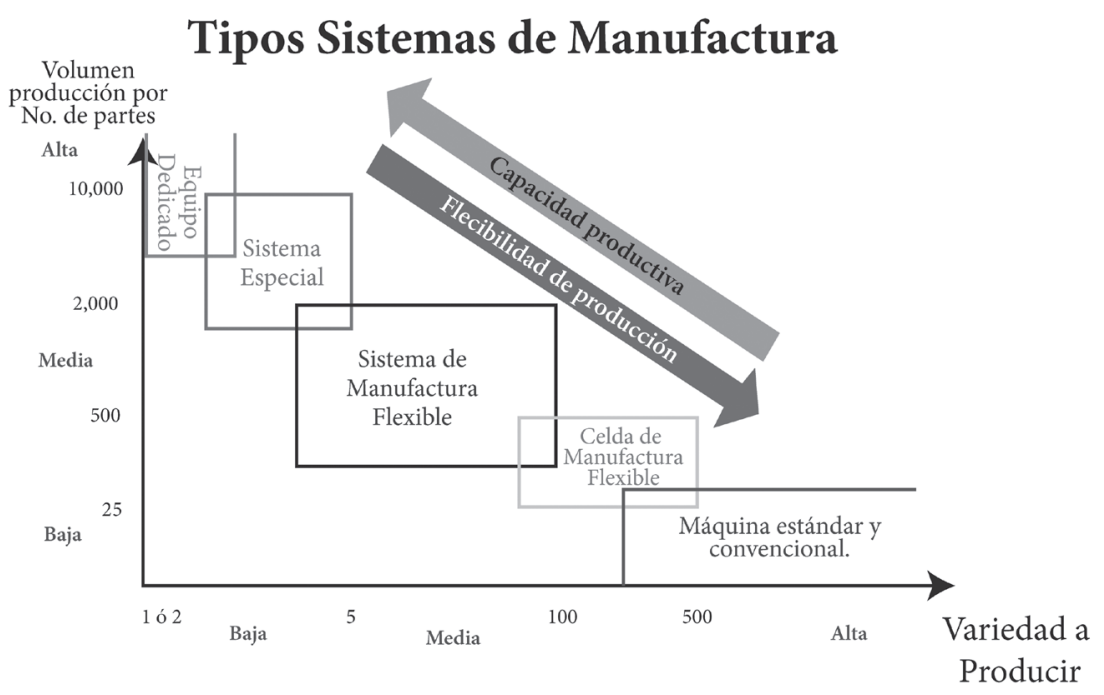


La competitividad se basa en estrategias tales como: mejorar el mantenimiento de los equipos, cambio rápido de herramientas, reducción de tiempos de preparación, mejora del layout de la Planta y oficinas, mejorar los niveles de calidad, control y reducción del consumo de energía, mayor participación de los empleados vía círculos de calidad, círculos de incremento de la productividad y sistemas de sugerencias. Una de las consecuencias de mejorar el mantenimiento es la reducción de inventarios de producto en proceso y producto terminado, que sirva de colchón ante las averías probables.

El resultado final que se persigue con la implementación del TPM es lograr un conjunto de equipos e instalaciones productivas más eficaces, una reducción de las inversiones necesarias en ellos y un aumento en la flexibilidad del sistema productivo. Dado que estamos en un mundo globalizado y competitivo, TPM es uno de los sistemas fundamentales para lograr la eficiencia total, la cual es la base para alcanzar la competitividad total. Debido a la tendencia actual a mejorar la competitividad es necesario ser eficiente en calidad, tiempo y coste de la producción, por lo que conjuntamente se debe aplicar el TPM y el TQM.

La aplicación del TPM garantiza a las empresas resultados en cuanto a la mejora de la productividad de los equipos, mejoras corporativas, mayor capacitación del personal y transformación del puesto de trabajo.

Entre los objetivos principales del TPM se tienen:

- Reducción de averías en los equipos

- Reducción del tiempo de espera y de preparación de los equipos

- Utilización eficaz de los equipos existentes

- Control de la precisión de las herramientas y equipos

- Promoción y conservación de los recursos naturales y economía de energéticos

- Formación y entrenamiento del personal

El TPM en términos prácticos pretende lograr en una planta: Cero averías, Cero Setup o tiempo de alistamiento, Cero defectos, Cero despilfarros, Cero accidentes y Cero contaminación.

Estas pérdidas, como filosofía, deben ser eliminadas o llevadas a cero.

\subsection{Los ocho pilares fundamentales del TPM}

Para alcanzar una aplicación exitosa y continuada del TPM, se debe seguir la aplicación sistemática de los ocho pasos generales mostrados en la figura 57.

Pilar 1: Mejora Focalizada. Tiene como objetivo eliminar las grandes pérdidas del proceso productivo, gracias a la aplicación de metodologías que permitan llegar a la causa-raíz del problema, cuantificarlo, poner metas y alcanzarlas, así como conservar y transferir el conocimiento adquirido en este proceso. 
Figura 57. Los ocho pilares del TPM [35]

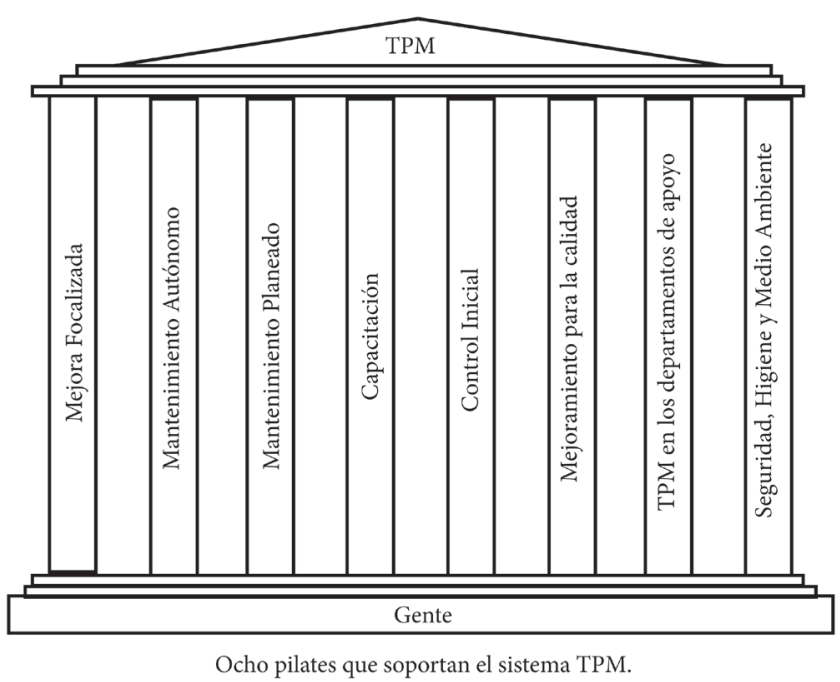

Pilar 2: Mantenimiento Autónomo. Se busca hacer partícipe al operario de la conservación, mantenimiento y/o mejora de la máquina donde trabaja de manera que pueda detectar a tiempo las fallas potenciales. El Mantenimiento Autónomo puede entre otros aspectos, prevenir la contaminación por agentes internos y externos, las roturas de ciertas piezas, los desplazamientos y los errores en la manipulación con sólo instruir al operario en Limpiar, Lubricar, revisar y reportar (ver numeral 7.6).

Pilar 3: Mantenimiento Planeado. Pretende mantener las máquinas/equipos/procesos en un estado "óptimo", aplicando actividades sistemáticas y metódicas para construir y mejorar continuamente". Se procura que el operario diagnostique la falla mayor (de las menores se encarga él mismo de resolverlas) y la indique convenientemente para facilitar la detección de la avería al personal de mantenimiento encargado de repararla.

Pilar 4: Capacitación. Puesto que el operario toma un papel protagónico en el proceso productivo, y adicionalmente debe realizar funciones que en el sistema tradicional no efectuaba, entonces debe ser convenientemente capacitado. La capacitación debe hacerse extensiva en lo posible a todo el personal de la propia empresa. Este pilar pretende adicionalmente: formar personal competente en máquinas/equipos y en la mejora continua de su área de responsabilidad, estimular el autodesarrollo del personal, desarrollar recursos humanos que puedan satisfacer las necesidades de trabajo futuras, estimular la formación sistemática del personal.

Pilar 5: Control inicial. Se busca reducir el deterioro de las máquinas/equipos y mejorar los costos de su mantenimiento en el momento que se compran y se incorporan al proceso productivo. El aprendizaje adquirido en unas máquinas/equipos debe ser aplicado en la puesta a punto y operación de los nuevos, para que sean fiables, fáciles de mantener, fáciles de operar y seguros. 
Pilar 6: Mejoramiento para la calidad. Pretende alcanzar la meta de calidad de cero defectos en la producción, para lo cual la máquina/equipo debe presentar también cero defectos. Se deben tomar acciones preventivas para alcanzar un proceso y equipo cero defectos.

Pilar 7: TPM en los Departamentos de apoyo. Puesto que la meta última del TPM es maximizar la productividad, entonces se deben eliminar las pérdidas en los procesos administrativos de apoyo, aumentando su eficiencia. Este pilar pretende generar comunicación y un equilibrio entre las actividades primarias de la cadena de valor y las actividades de soporte.

Pilar 8: Seguridad, Higiene y medio ambiente. Se deben aplicar políticas y medidas para garantizar un ambiente laboral sin accidentes y sin contaminación. La contaminación en el ambiente de trabajo puede llegar a producir un mal funcionamiento de una máquina o viceversa. Muchos de los accidentes de trabajo son ocasionados por la mala distribución de las máquinas/equipos y herramientas en el área de trabajo, o por el mal estado de las instalaciones, utillajes o herramentales.

\subsection{Las cinco eses o $5 \mathrm{~S}$}

Las $5 \mathrm{~S}$ es una metodología de mejoramiento continuo que pretende reducir los costos por pérdidas de tiempo y energía, mejorar la calidad de la producción, minimizar los riesgos de accidentes o sanitarios, incrementar la seguridad industrial y mejorar las condiciones de trabajo al igual que elevar la moral del personal. La metodología 5 S consta de cinco fases, cada una de las cuales comienza por $\boldsymbol{S}$ (en Japonés).

Seiri: Seleccionar. Eliminación de todo lo innecesario (figura 58). "Lo que no sirve estorba”.

Figura 58. Proceso de clasificación de aceites, grasas, filtros y herramientas [36]

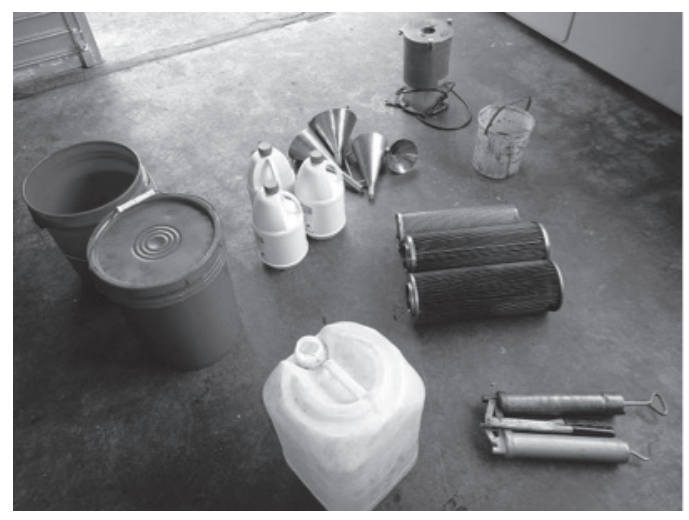

Seiton: Organizar. Un lugar para cada cosa y cada cosa en su lugar. Es un principio de funcionalidad. Todo objeto que se utiliza en una labor debe volver a su sitio original. La figura 59 muestra un ejemplo concreto del antes y después al aplicar Seiton. 
Figura 59. El antes y el después al aplicar Seiton a un Taller de lubricación [36]
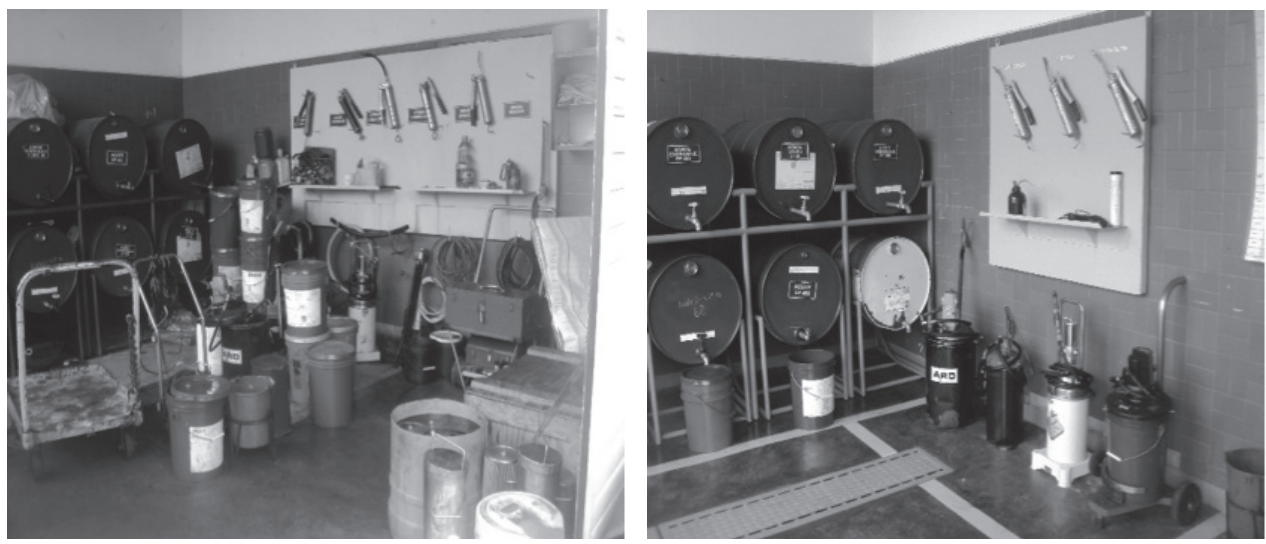

La figura 60 presenta ejemplos simples de organización de repuestos e insumos. La implementación de esta medida no es costosa, y elimina el típico "tarro de los tornillos" del mecánico tradicional, en el que regularmente no encuentra lo que necesita, y a cambio pierde tiempo valioso.

Figura 60. Ejemplo de aplicación de Seiton para organizar repuestos [6]
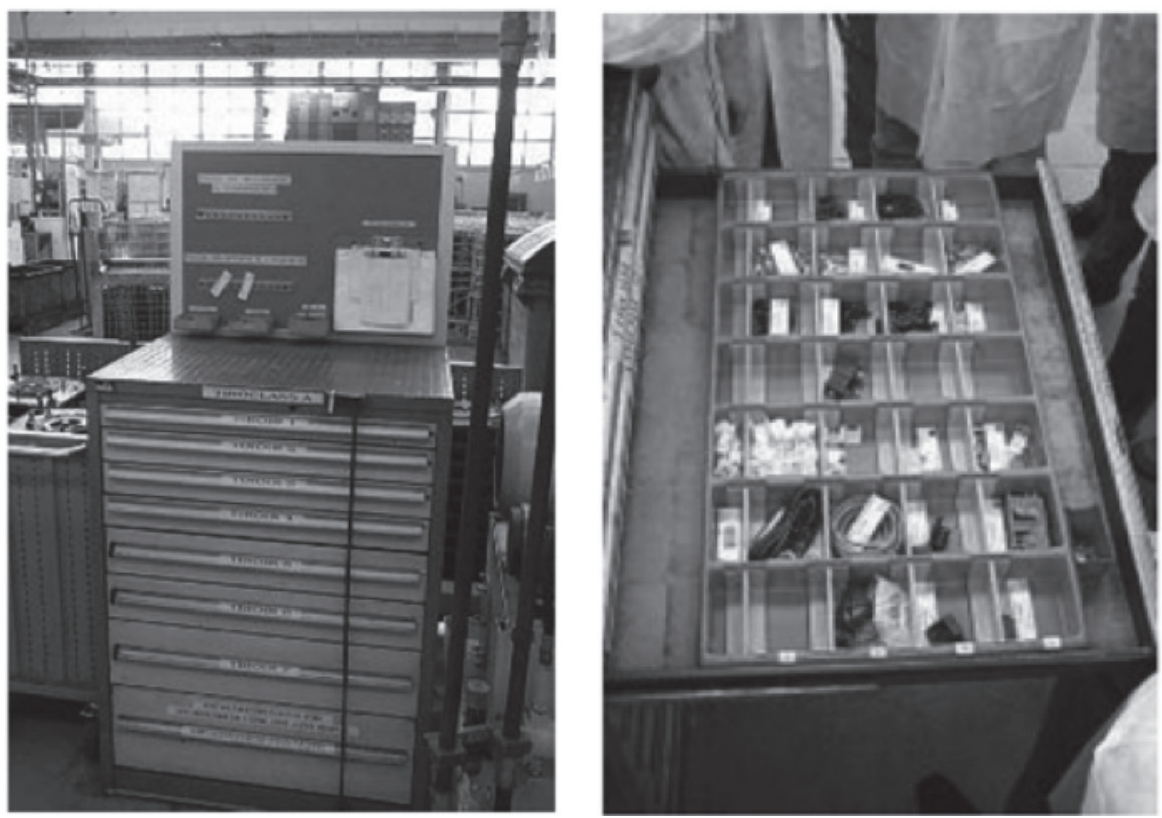

Seiso: Limpiar. Retirar la suciedad acumulada de mi sitio de trabajo, incluyendo las máquinas. Esta limpieza deber hacerse tanto durante el tiempo de producción como al finalizar la jornada. La figura 61 
muestra un ejemplo concreto del antes y después al aplicar SEISO. Axioma de las 5S, "Un lugar limpio no es el que más se limpia, sino el menos se ensucia"

Figura 61. El antes y el después al aplicar Seiso a un Taller de lubricación [36]
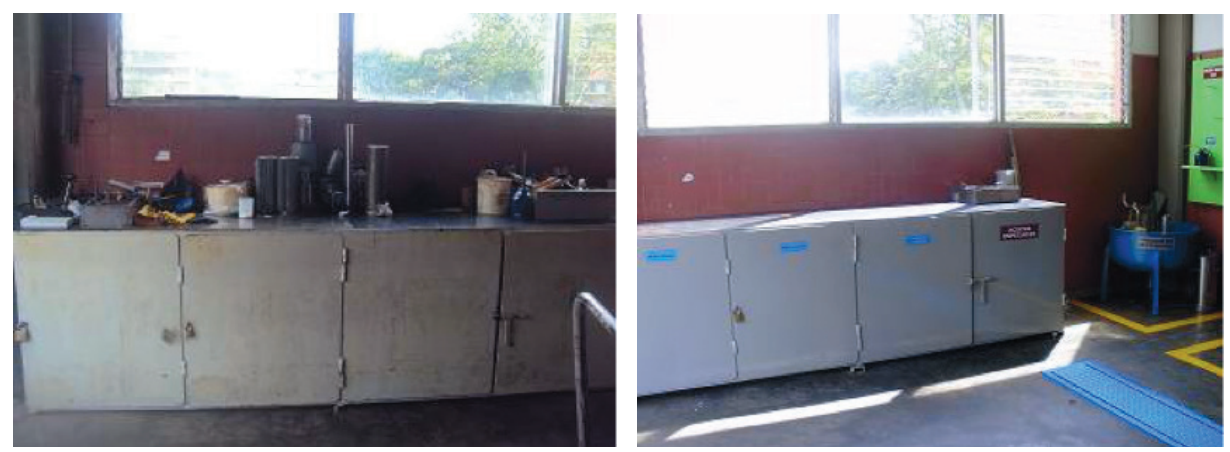

Seiketsu: Estandarizar. Una vez definidos y alcanzados los niveles de organización y limpieza, estos deben ser mantenidos en el tiempo, es decir, no ejecutar estas tareas solo cuando hayan visitas ilustres o cuando a los jefes se les ocurre darse una pasadita por la fábrica o las oficinas. Una forma de garantizar el SEIKETSU es programando y ejecutando brigadas de limpieza y orden, con su debido cronograma.

Shitsuke: Sostener. Capacitar y concienciar a la gente para que de manera autónoma realice estas tareas cotidianamente. La figura 62 ilustra una conservación en el tiempo del orden, el aseo y la organización en un taller de lubricación al cual se le aplicaron las 5 S.

Figura 62. Aplicación de Shitsuke en un taller de lubricación [36]

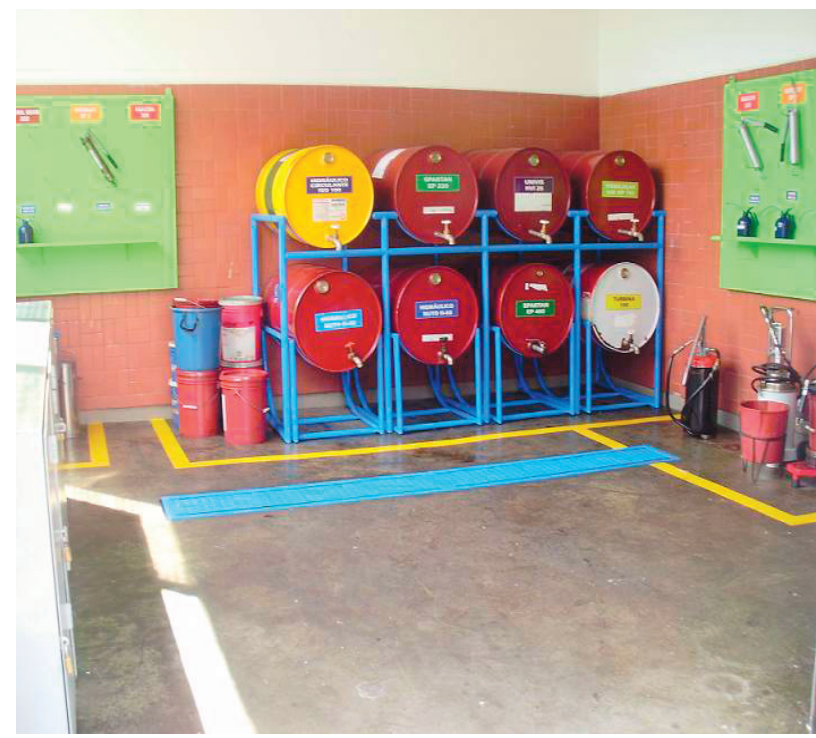




\subsection{Mantenimiento Autónomo}

Estrategia básica de Mantenimiento que se caracteriza por la participación activa por parte de los operarios en el proceso de prevención con el objetivo de evitar averías y deterioro de sus máquinas y equipos. Para alcanzar el Mantenimiento Autónomo tiene especial trascendencia la aplicación práctica de las 5S. Una característica básica del Mantenimiento Autónomo (o de primer nivel), es que son los operarios de producción quienes lo llevan a cabo. Algunas de las tareas fundamentales son: limpieza, inspección, lubricación, aprietes y ajustes.

\subsubsection{Objetivos del Mantenimiento Autónomo}

El Mantenimiento Autónomo busca alcanzar los seis objetivos descritos a continuación.

- Emplear la máquina/equipo como instrumento para el aprendizaje y adquisición de conocimiento.

- Desarrollar nuevas habilidades para el análisis de problemas y creación de un nuevo pensamiento sobre el trabajo, mediante una operación correcta y permanente que evite el deterioro.

- Mejorar el funcionamiento de la máquina/equipo con el aporte creativo del operador.

- Construir y mantener la máquina/equipo en condiciones óptimas.

- Mejorar la seguridad en el trabajo.

- Mejorar la moral en el ambiente de trabajo.

\subsubsection{Pasos para la implementación del Mantenimiento Autónomo}

Los pasos descritos a continuación permiten alcanzar una división adecuada y sana entre los Departamentos de producción y mantenimiento, delimitando deberes y responsabilidades, y eliminado el típico pensamiento tradicional de "Yo opero, tú reparas" y transformarlo en "Yo soy responsable de mi máquina/equipo".

\subsubsection{Limpieza inicial.}

En este paso inicial confluyen tanto el mantenimiento autónomo como las 5S. La figura 63 presenta un ejemplo de limpieza inicial y conservación de la misma. En esta aplicación particular y muy exitosa de TPM (ver referencia [6]), aplican el principio sencillo de "pintura clara para las máquinas/objetos que se ensucian", para que sea fácilmente detectable la condición de suciedad". Los procesos de limpieza permiten al operador de la máquina descubrir deficiencias y posibles causas actuales y potenciales. 
Figura 63. Aplicación inicial y continuidad de limpieza [6]

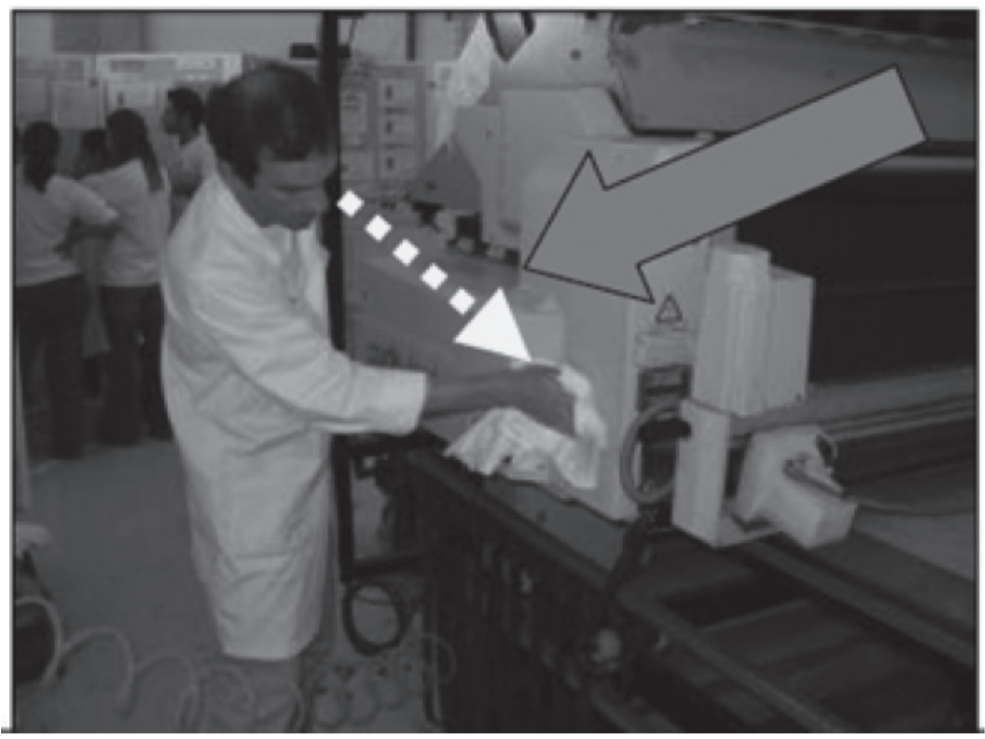

7.6.2.2. Eliminación de fuentes de contaminación y áreas inaccesibles.

Aparte de la mala impresión que ofrece un área inaccesible y contaminada, puede ser causante de accidentes laborales o industriales, y encubrir fallas potenciales. La figura 64 ejemplariza la no aplicación de este paso.

Figura 64. Contra-ejemplo de no eliminación de fuentes de contaminación y conservación de áreas accesibles [6]
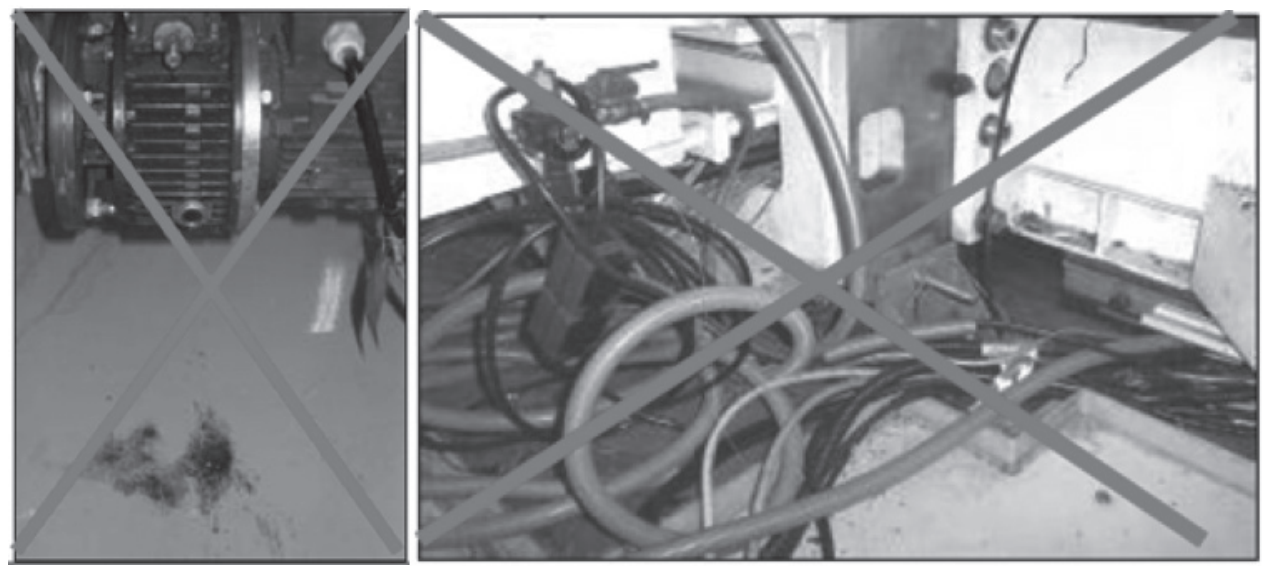


\subsubsection{Definir estándares para condiciones básicas e inspección general.}

Este paso tiene como fin diseñar y la elaborar Estándares que ayuden a mejorar los métodos de los técnicos en las intervenciones de Mantenimiento, haciendo más efectivo y seguro el trabajo que realizan. El producto de la aplicación de este paso es la elaboración de Estándares de mantenimiento, Estándares de ajustes críticos y levantamiento información de piezas de desgaste para las diferentes líneas de producción. La figura 65 presenta un ejemplo de Estándares de ajustes en equipos críticos.

\subsubsection{Inspección autónoma, desarrollando listas de verificación del Mantenimiento autónomo.}

Las inspecciones autónomas se pueden ayudar con pequeñas medidas visuales y de bajo costo, como marcas, instrumentación con colores por rangos de operación. La figura 66 presenta algunos ejemplos prácticos de estas medidas.

\subsubsection{Organización y mantenimiento del lugar de trabajo, estandarizando los elementos del mismo.}

Una medida sencilla posterior a la definición de los elementos estandarizados que debe poseer un puesto de trabajo, es utiliza "cuadros de sombra de las herramientas" (como los mostrados en la figura 67) para llevar su control.

Figura 65. Ejemplo un estándar de Mantenimiento en una industria alimenticia [37]

Objetivo: Garantizar el correcto funcionamiento de las mordazas de la galletera para que se realice un correcto sellado del papel y no se produzcan defectos de calidad o un paro mecánico.

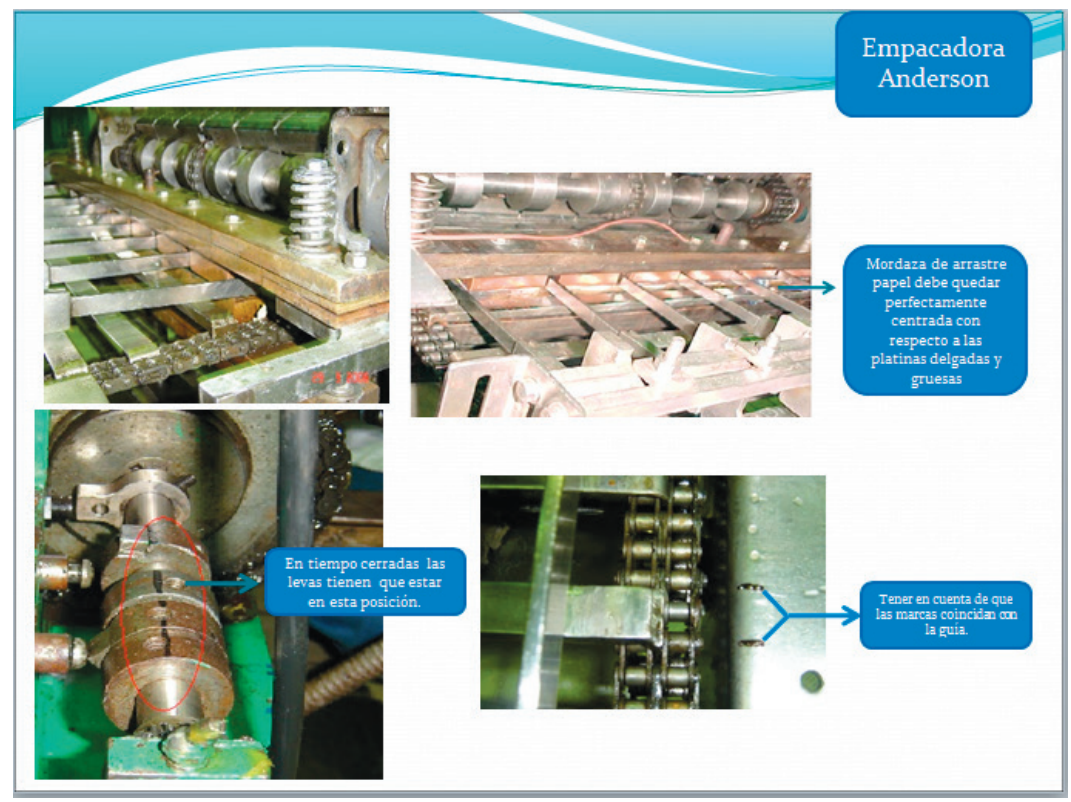


Figura 66. Ejemplos de inspección autónoma [6]

\section{TPM EVIDENTE}

Indicadores en los manómetros

Puntos móviles

Protecciones transparentes
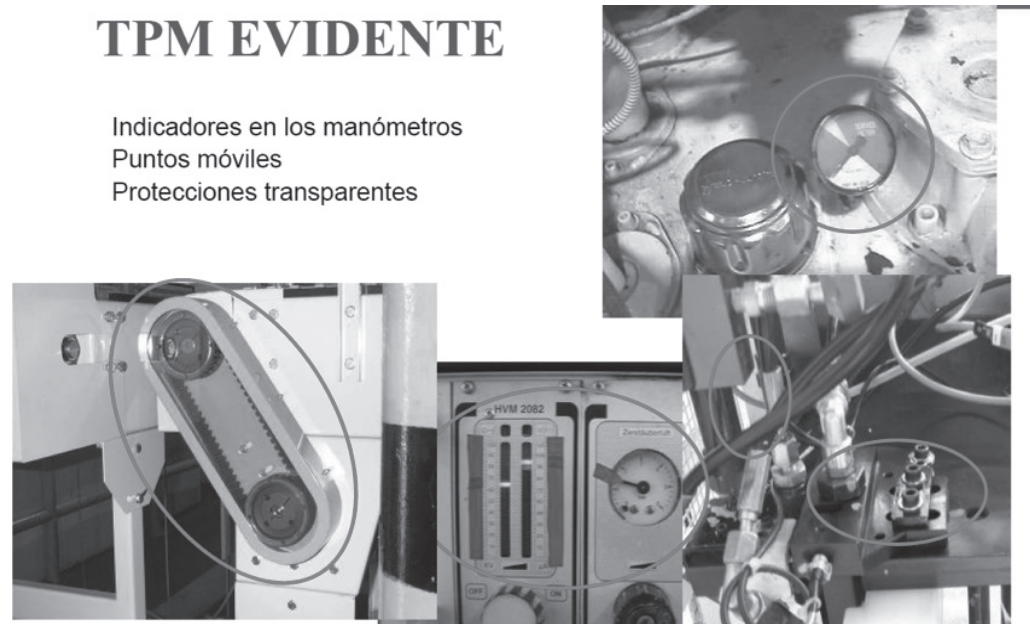

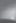

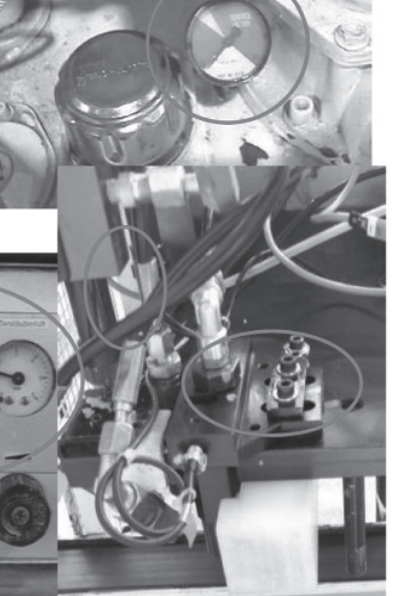

Figura 67. Ejemplos de uso de cuadros de sombra para la organización del lugar de trabajo [6]
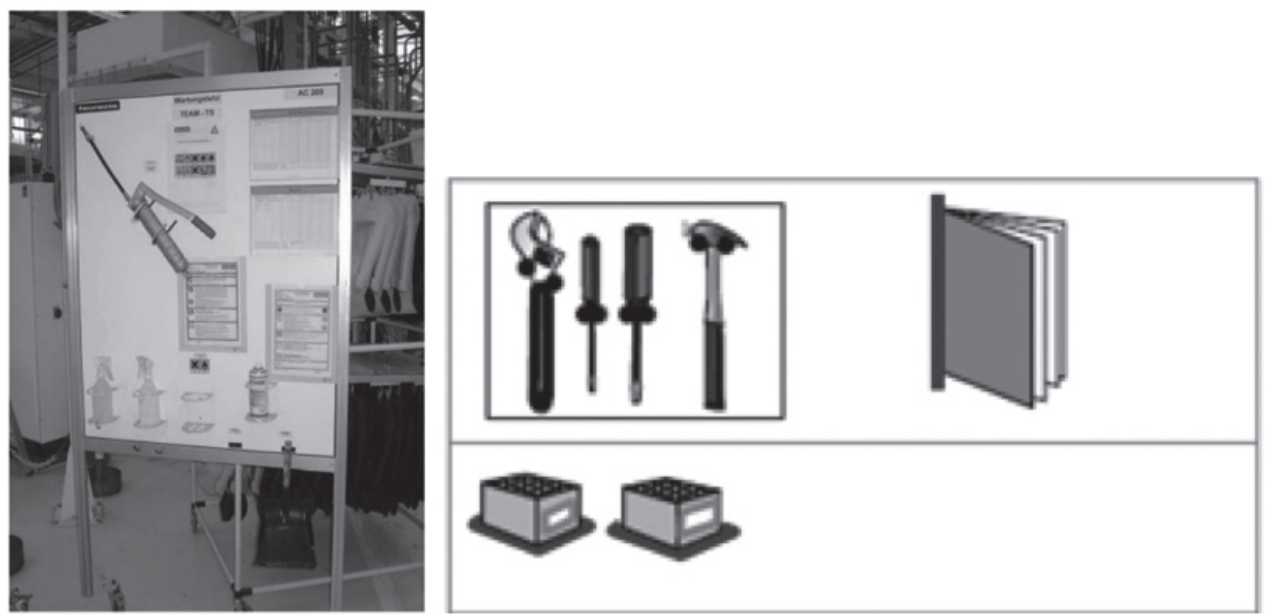

7.6.2.6. Implementación del programa de Mantenimiento Autónomo, desarrollando metas para la compañía.

En esencia se diseñan y aplican rutinas de inspección y se definen metas (indicadores), para validar el cumplimiento de los objetivos. Las figuras 68 y 69 ilustran ejemplos de rutas de inspección en Mantenimiento autónomo, mientras que la figura 70 ilustra una comunicación 
visual (a todo el personal) de cumplimiento de metas de la empresa, en el caso específico de Tiempo promedio entre fallas TBF (ver capítulo 6).

Figura 68. Ejemplo de implementación del Mantenimiento Autónomo [6]

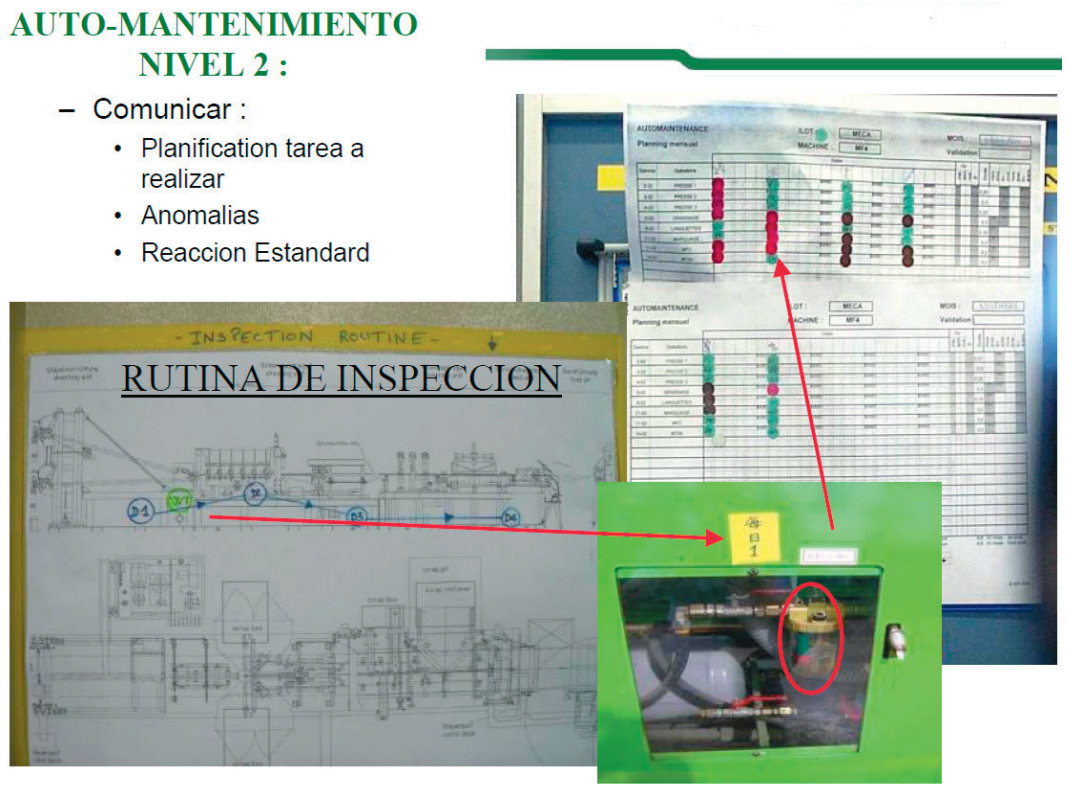

Figura 69. Ejemplo de implementación del Mantenimiento Autónomo [6]

\section{Rutina de inspección}

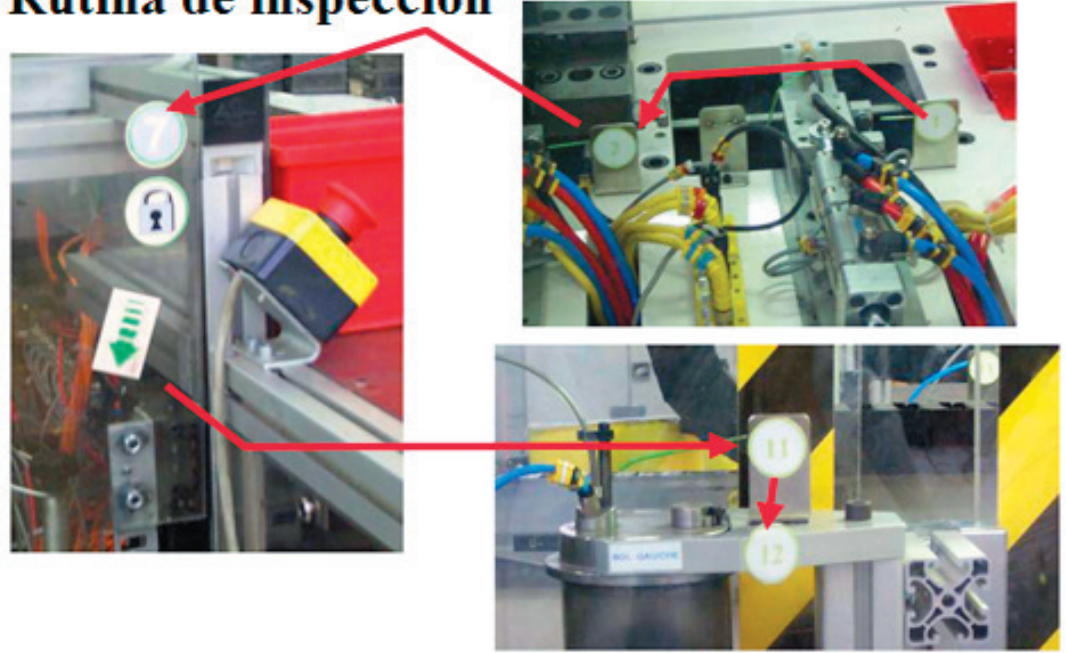


Figura 70. Ejemplo de comunicación visual de indicadores y metas en Mantenimiento Autónomo [6]

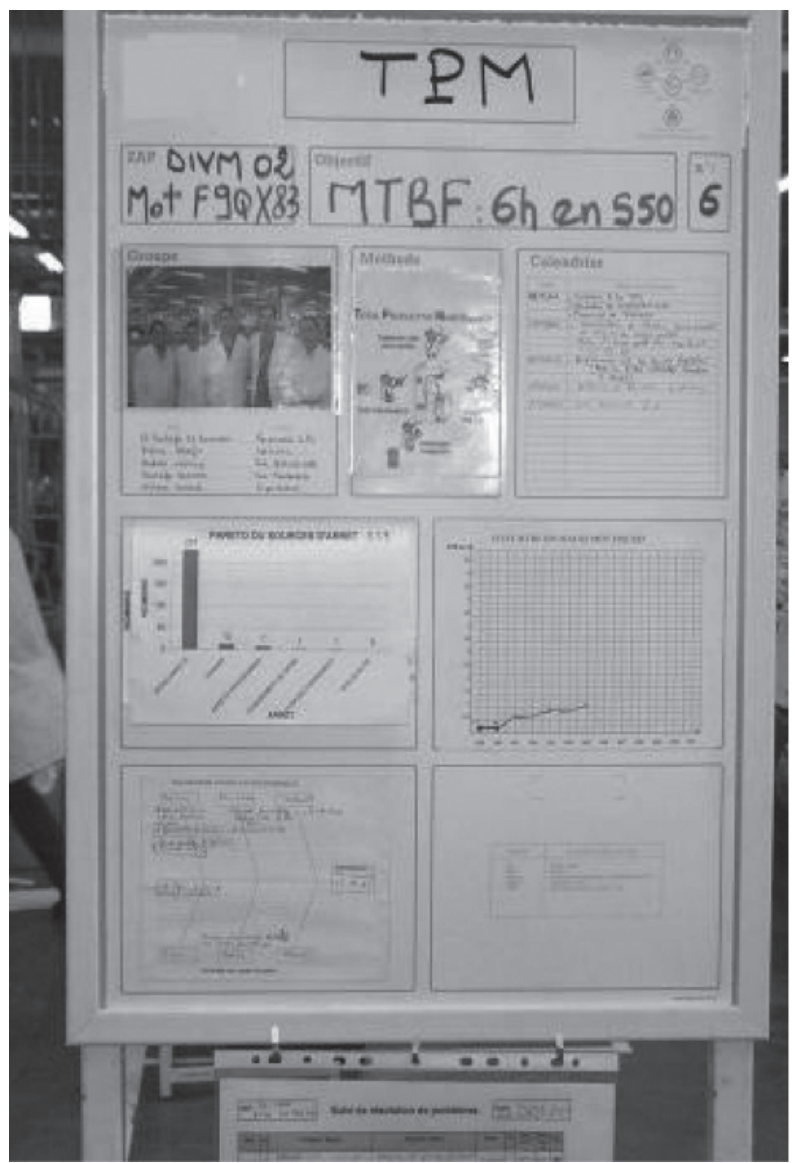

\subsection{Fases y etapas en la implementación del TPM}

Las ventajas de aplicar TPM son evidentes y están basadas en medidas simples que regularmente no implican grandes inversiones por parte de la empresa, no obstante, el éxito en su implementación dista mucho de ser rápido y fácil, como pueden pensar muchos gerentes de visión cortoplacista. En la implementación de un programa de TPM se deben enfrentar varios retos como el de alcanzar compromiso por parte de toda la organización, vencer la resistencia al cambio y lograr el cambio de mentalidad en las personas, que facilitará su adaptación a los cambios que traerán mejoras en la producción, el mantenimiento, los equipos, la calidad, la satisfacción del cliente, los empleados, la seguridad, el medio ambiente, etc. Para alcanzar el TPM se deben romper paradigmas, barreras ideológicas y culturales, además empezar a ver a mantenimiento como una gran inversión y no como un gasto. 
La Tabla 29 presenta las fases y etapas generales requeridas para implementar exitosamente y de manera duradera el TPM en una empresa. Un proceso de implementación de TPM es largo y puede durar de 2 a 3 años, en un esfuerzo continuado de la organización.

Tabla 29. Fases y etapas para la implementación del TPM en una organización

\begin{tabular}{|c|l|}
\hline \multicolumn{1}{|c|}{ FASE } & \multicolumn{1}{|c|}{ ETAPA } \\
\hline Preparación & Decisión de aplicar TPM en la empresa \\
\hline & Campaña de información y sensibilización \\
\hline & Formación de comités \\
\hline & Análisis de las condiciones existentes (diagnóstico) \\
\hline & Planificación \\
\hline Implantación & Capacitación \\
\hline & Implantación de las 3Y: Motivación, competencia y entorno de trabajo. \\
\hline & Determinación y cálculo de relaciones e indicadores \\
\hline & Experiencia piloto \\
\hline & Implementación de las 5S \\
\hline & Aplicación del Mantenimiento Autónomo \\
\hline Evaluación & Aplicación del Mantenimiento planificado \\
\hline Estandarización & Análisis de resultados obtenidos \\
\hline & $\begin{array}{l}\text { Se estandarizan los resultados obtenidos y se da comienzo a un nuevo } \\
\text { proceso continuo de mejoras en materia de confiabilidad y durabilidad. }\end{array}$ \\
\hline
\end{tabular}

\subsection{Observaciones respecto del TPM}

- Entre Japón y Colombia hay unas diferencias abismales en los aspectos culturales y de idiosincrasia. Lo que para un japonés es natural y normal en términos de orden, aseo y respeto, para muchos colombianos no lo será. Lo anterior se convierte en un escollo de primera mano para la implementación del TPM en empresas colombianas.

- El adagio popular reza "Del dicho al hecho hay mucho trecho". Esto se cumple en el TPM, en donde en el papel todo suena "muy bonito", pero la materialización de la implementación es dispendiosa y presenta muchas dificultades.

- Un camino para alcanzar el TPM, sería primero implementar las 5S, luego Mantenimiento Autónomo y por último (al cabo probablemente de muchos meses) afrontar la implementación formal del TPM (ver numeral 7.7). El haber implementado las 5S elevará las probabilidades de éxito del Mantenimiento Autónomo, y con esto las posibilidades de éxito al implementar posteriormente TPM

- A pesar de que el Mantenimiento Autónomo y las $5 S$ forman parte del TPM, no es indispensable haber tomado la decisión de implementar TPM para poder aplicarlos. Ciertas empresas 
aplican las $5 \mathrm{~S}$ como un medio de mejoramiento continuo, y Mantenimiento Autónomo como un complemento al Mantenimiento Preventivo, mejorando los resultados de sus procesos, entre ellos el clima laboral.

- Sería una locura pretender implementar TPM en una empresa cuya estrategia de Mantenimiento principal sea el Correctivo. Usualmente se espera que el MP esté en un buen nivel para pasar al TPM (por organización, hábitos, infraestructura, capacitación, etc.). 
Capítulo 8 



\section{Apuntes sobre Mantenimiento Centrado en la Confiabilidad RCM}

\subsection{Introducción}

El Mantenimiento Centrado en la Confiabilidad RCM (Reliability Centered Maintenance por sus siglas en inglés) es una filosofía de gestión de Mantenimiento, que optimiza la confiabilidad operacional de un sistema que funciona bajo condiciones de trabajo definidas, en función de cuán críticos son los activos, tomando en cuenta los posibles efectos que originarán los modos de falla de dichos activos, sobre la seguridad, al ambiente o a las operaciones [5].

En este sistema de Mantenimiento se pone especial énfasis en el funcionamiento global del sistema, más que en el de cada máquina/equipo individualmente; una máquina/equipo no es intrínsecamente importante, sino por la función que desempeñe dentro de un proceso productivo. En RCM la palabra clave es la Confiabilidad o Fiabilidad (Reliability).

El objetivo del RCM es determinar el estado crítico de los equipos de cualquier proceso y, basados en esta información implementar un Mantenimiento Preventivo/Predictivo para las organizaciones [39].

El TPM tiene como objetivo final incrementar la Productividad de una organización, mientras que el RCM se centra en garantizar la Confiabilidad de un proceso/equipo. Empresas de clase mundial han logrado mezclar exitosamente las dos estrategias, llevando las crisis y fallas a un nivel cercano a cero, con los correspondientes beneficios (incremento de la capacidad de producción, desarrollo del trabajo en equipo, minimización de costos, mejora constante de los procesos).

\subsection{Siglas y términos a tener en cuenta en RCM}

Confiabilidad: Probabilidad que una máquina/quipo no falle durante su operación. Se evalúa por intermedio del tiempo promedio entre fallas TPEF (fórmula 13). 


$$
T P E F=\frac{T_{o p}}{N_{a r r}}
$$

Donde

TPEF es la confiabilidad o tiempo promedio entre fallas.

$T_{o p} \quad$ es el tiempo real de operación de la planta.

$N_{a r r} \quad$ es el número de arranques de planta.

Mantenibilidad: Probabilidad que una máquina/equipo pueda ser puesto en condiciones operacionales en un período de tiempo dado, cuando el Mantenimiento es ejecutado de acuerdo con procedimientos pre-establecidos. Se puede evaluar por intermedio del Tiempo Promedio para reparar TPPR (fórmula $14)$.

$$
T P P R=\frac{T_{\text {nop }}}{N_{\text {arr }}}
$$

Donde

$T P P R$ es la mantenibilidad o tiempo promedio para reparar.

$T_{o p} \quad$ es el tiempo de no operación de la planta.

Narr es el número de arranques de planta.

Función: propósito para el cual fue adquirido un componente/equipo/máquina. Debe ser definido para cada contexto operacional particular (ver numeral 8.3). La función debe expresarse de forma tal que pueda cuantificarse su pérdida. En otras palabras, la función debe expresarse en variables de ingeniería, inherentes al contexto operacional en estudio.

Falla funcional: Tipo de desperfecto o avería que reduce a cero la capacidad de cualquier elemento físico de satisfacer un criterio de funcionamiento deseado. Dicho de otra manera, es el tipo de falla por la cual un equipo deja de funcionar totalmente.

Falla parcial (potencial): Tipo de desperfecto o avería, o condiciones físicas identificables que indican que va a ocurrir una falla funcional. Estas fallas están por encima o por debajo de los parámetros identificados para cada función. Por ejemplo, el elemento no cumple un estándar o parámetro establecido de su servicio.

Modo de falla: corresponde a la descripción de las fallas funcionales/potenciales que pueden ocurrir. Posteriormente los modos de falla pueden ser clasificados en categorías (por mecánica, electricidad, instrumentación, etc.). Al definir el modo de falla se debe tener clara la causa u origen de la falla, para no confundir un modo de falla con un síntoma.

Efecto: síntoma generado por la ocurrencia de una falla potencial o funcional (ruido, vibración, goteo o fuga, elevación o disminución de una temperatura, etc.).

Causa: es el medio por el cual un elemento particular del proyecto o proceso resulta en un modo de falla. 
El hecho de definir función, falla (funcional y potencial), modo de falla, efecto y causa, mejora significativamente los niveles de comprensión del componente/equipo/máquina (ver Anexo 4), y permite descubrir errores de procedimiento y mejorar la seguridad y operatividad de los equipos.

Consecuencia: efecto adverso último sobre el consumidor o usuario, generado por una falla funcional. Consumidor o usuario puede ser un usuario final (externo a la empresa) o la próxima operación dentro de un proceso productivo (usuario interno). RCM considera cuatro tipos de consecuencias y su definición dirá si vale la pena prevenir la ocurrencia de una falla en particular:

- Consecuencias por fallas ocultas o no evidentes. El ejercicio de descubrir este tipo de fallas reduce el riesgo de exponer una organización a fallas con consecuencias serias y hasta catastróficas

- Consecuencias sobre la seguridad y el medio ambiente. RCM pone la afectación a las personas y al medio ambiente por encima de las demás afectaciones.

- Consecuencias operacionales. Se cuantifican las afectaciones a la producción (cantidad, calidad, en el servicio, adicionales a la reparación normal de la máquina/equipo).

- Consecuencias no operacionales. Reparaciones normales,

Gravedad o severidad de la falla (G): indica como la falla afecta al usuario o cliente. La gravedad debe ser evaluada desde el punto de vista de la seguridad industrial, daños al medio ambiente, la producción, daños a la misma máquina/equipo, la calidad. La gravedad guarda estrecha relación con la consecuencia, y numéricamente se le dará el manejo descrito en el numeral 8.4.

Frecuencia (F): es la probabilidad de ocurrencia de la falla. Idealmente debiera extraerse a partir de estadísticas de falla, en caso contrario debe conocerse con muy buena aproximación el patrón de falla del proceso/máquina/equipo/componente y la fase por la cual está pasando actualmente.

Detectabilidad (D): indica el grado de facilidad en la detección de la falla dentro de los diferentes subsistemas, componentes y partes de la máquina/equipo.

\subsection{Origen y evolución del RCM}

En la década de 1950 en EE. UU., la frecuencia de ocurrencia de accidentes en vuelos aéreos era de sesenta por cada millón de despegues [40]; de estos accidentes dos terceras partes se debían a fallas de los equipos y el crecimiento de los viajes aeronáuticos estaba en pleno auge. Si esa frecuencia fuera escalada a las condiciones actuales, se estaría hablando de un promedio de sesenta accidentes por mes y dos accidentes por día, en algún lugar del mundo, y teniendo en cuenta que la cantidad actual de vuelos de más de cien pasajeros es muy grande respecto de 1950, el panorama de la seguridad aérea sería escalofriante.

Dado este panorama, Stanley Nowlan y Howard Heap iniciaron una investigación muy concienzuda y meticulosa, sobre la accidentalidad de la aviación comercial de EE. UU. El estudio tenía como meta mejorar la seguridad aérea; la investigación duró aproximadamente veinte años y se condensó en el libro "Reliability Centered Maintenance" [40], mismo que dio nombre al sistema de mantenimiento objeto de este capítulo. Con base a este libro la Air Transport Association of America ATA publicó en 1968 el documento llamado Evaluación del Mantenimiento y desarrollo del programa MSG - 1. Este documento sirvió de base para la planeación de programas de mantenimiento para fabricantes de aviones y aerolíneas. Con base en el MSG - 1, se publicó en 1980 el MSG - 3, el cual posteriormente fue revisado y actualizado en 1988 y en 1993. 
El panorama actual de la accidentalidad de las aerolíneas en el mundo es alrededor de dos accidentes por cada millón de despegues [40]. Esta variación se debe en gran medida a los cambios de paradigmas propiciados por los resultados de los estudios de Nowlan y Heap, volviendo a la aviación en la forma más segura de viajar. Algunos de los cambios de paradigma rotos por el estudio en mención son:

- La relación entre la edad de un componente y su desgaste (principalmente donde hay contacto con la materia prima, producto intermedio o terminado) o deterioro no es lineal.

- No todos los equipos/componentes se comportan de acuerdo a la "curva de la bañera" (Curva A de la Tabla 30).

- Hay conexión entre la confiabilidad de un componente y la edad operacional.

- Cuanto más a menudo se revise menor es la probabilidad de falla.

- Un equipo posee de fábrica una capacidad para cumplir o no una función o cometido, y Mantenimiento no puede garantizar por sí mismo que esa capacidad sea aumentada.

Algunos de los nuevos paradigmas arrojados por el RCM son:

- $\quad$ No existe un único modelo de patrón de falla (el de "la bañera"), sino que son seis patrones diferentes.

- Los modelos de patrón de falla dependen de la complejidad de las máquinas/equipos. Entre más complejos sean los equipos se comportarán de acuerdo a los patrones $\mathrm{E}$ y F, mientras que entre más simples sean, se comportarán de acuerdo a los modelos A, B y C.

- $\quad$ El RCM encontró que los efectos y consecuencias de una falla dependen de cada entorno productivo en particular, es decir reconoció el concepto de la trilogía máquina - operador medio ambiente (ver numeral 1.5.2) o contexto operacional.

- La función que un equipo provee no es única, sino que depende del contexto operacional.

- Cada componente/equipo/máquina posee de fábrica su propia combinación de modos de falla y su propia intensidad de falla (confiabilidad inherente). Estos se pueden alterar (para mal) al introducirlo en un contexto operacional o trilogía máquina - operador - medio ambiente particular.

- Puesto que un componente/equipo/máquina es la suma de sus partes, cada una de las cuales poseen su propia confiabilidad, entonces será imposible obtener una confiabilidad superior (e incluso igual) a la del componente de mejor confiabilidad. La confiabilidad global es posible cuantificarla, gracias a los aportes y herramientas provistas por la Estadística y la Teoría de la Confiabilidad.

- Cualquier intento de definir un programa / plan o política de mantenimiento debe comenzar por la definición de las funciones o estándares de funcionamiento esperados en un contexto operacional.

- Mantenimiento lo único que puede hacer es garantizar que el componente/equipo/máquina provea su capacidad incorporada o su confiabilidad inherente.

En la Tabla 30 se grafica el comportamiento de los seis patrones de falla descritos por el RCM. 
Tabla 30. Patrones de Falla de componentes de la industria aeronáutica de EE. UU [40]

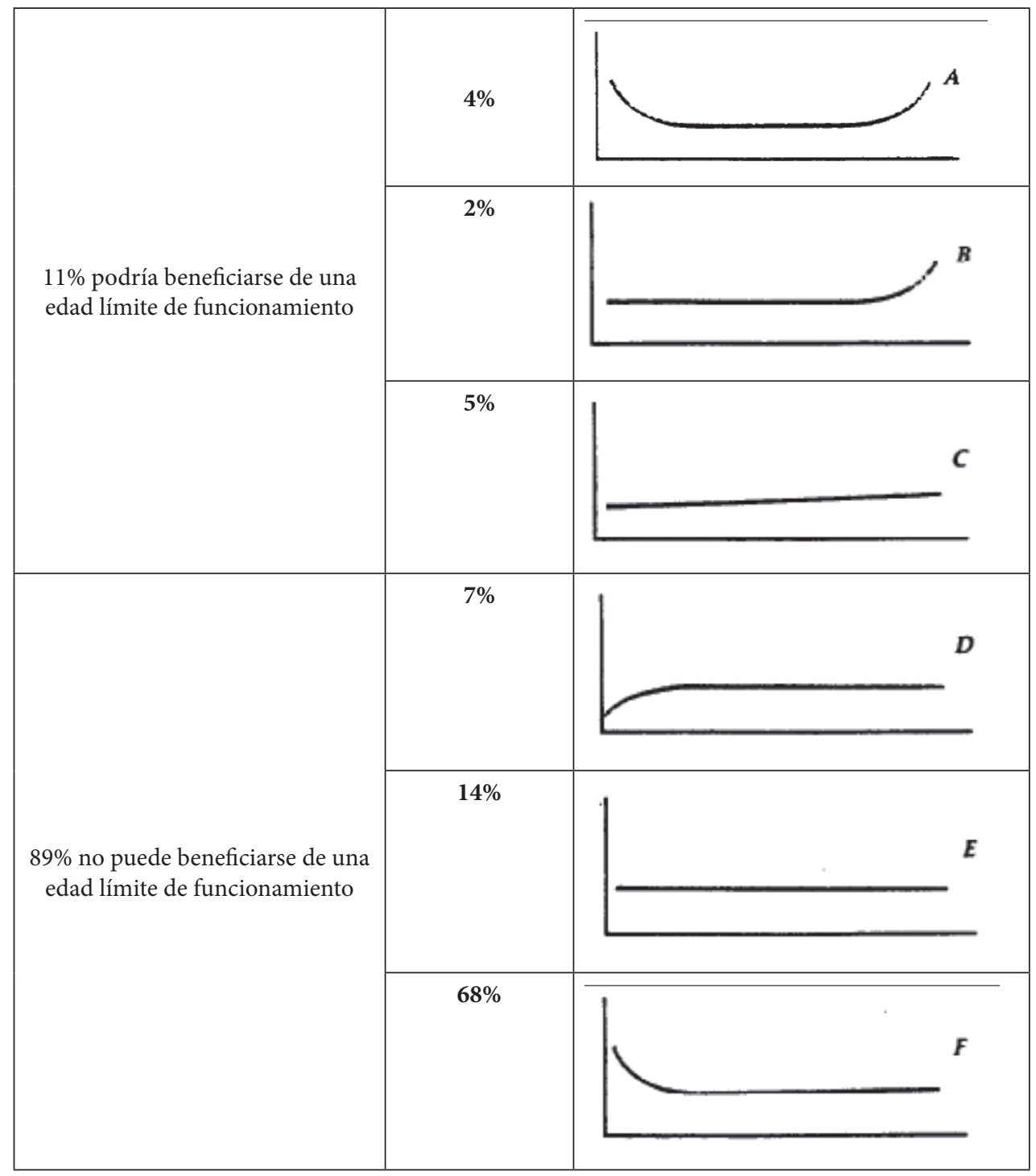


Curva A: Curva de la bañera. La máquina/equipo/componente posee alta mortalidad infantil, es decir tienen una probabilidad inicial de falla alta, luego de lo cual se estabilizan, para finalizar la vida útil en una zona de desgaste acelerada.

Curva B: El patrón de falla "ideal” y tradicional antes del RCM. Pocas fallas a lo largo de la vida útil, culminando en una zona de desgaste elevado.

Curva C: Un constante incremento de la probabilidad de falla infantil, seguida de un comportamiento aleatorio de la probabilidad de falla.

Curva D: Rápido crecimiento de la probabilidad de falla, seguida de un comportamiento aleatorio.

Curva E: Fallas aleatorias, sin ninguna relación entre la edad y la probabilidad de falla.

Curva F: Alta mortalidad infantil, seguida de un comportamiento de aleatorio de la probabilidad de fallos.

Solo en los patrones de Falla A, B, y C hay una relación predecible entre el desgaste del componente y su vida útil, sumando en los tiempos del estudio el $11 \%$ de los equipos/componentes de la industria aeronáutica. Por otro lado, los patrones que muestran un relación aleatoria entre la edad y el desgaste, es decir los patrones D, E y F, totalizaban el 89\% de los equipos/componentes de dicha industria [40]; esta elevada aleatoriedad propició el advenimiento y desarrollo del Mantenimiento Predictivo en la década de 1970, con el objetivo de anticiparse y predecir la ocurrencia de fallas. El estudio de Nowlan y Heap [40] mostró que a mayor complejidad del equipo/componente, el comportamiento sus patrones de falla obedecían a los modelos E y F. Con todo este panorama de nuevos conceptos, conocimientos, paradigmas tradicionales rotos y nuevos paradigmas, fue diseñada la metodología RCM, la cual será descrita en el numeral 8.4.

\subsection{Metodología de aplicación}

A continuación se describe un modelo de aplicación de RCM en un proceso productivo completo y grande (gran empresa Capítulo 2).

\subsubsection{Efectuar un Análisis de criticidad CA}

Un análisis de criticidad permite identificar las áreas y secciones o grupos (ver numeral 3.2.2) más críticas de la planta. Una vez definidas estas, el $C A$ permite definir las máquinas/equipos más críticos dentro de dichas áreas o secciones. Las máquinas/equipos serán llamados sistemas.

Un $C A$ se obtiene aplicando la fórmula 15, por áreas, posteriormente por secciones, y luego por máquinas/equipos. La Gravedad $G$ debe ser definida por equipos de trabajo multidisciplinarios (producción, mantenimiento, control de calidad, salud ocupacional, seguridad industrial, división financiera, etc.). Hasta donde sea posible es pertinente conocer el patrón de falla de la máquina/equipo y su Frecuencia de falla $F$, que idealmente debe definirse con base a estadísticas de falla. Una guía muy seria para la selección de los valores de G y F es la mostrada por las Tabla 31 y 32. 


$$
C A=G \times F
$$

Donde

$C A$ es el valor del análisis de criticidad.

$G \quad$ es la gravedad de la ocurrencia de una falla en un área o sección.

$F \quad$ es la frecuencia de ocurrencia de la falla.

Tabla 31. Categorías de Gravedad o severidad [40]

\begin{tabular}{|c|c|c|}
\hline Clasificación & Efecto & Comentario \\
\hline 1 & Ninguno & $\begin{array}{l}\text { No hay razón para esperar que una falla tenga efecto } \\
\text { alguno sobre la seguridad, la salud, el medio ambiente o } \\
\text { la misión. }\end{array}$ \\
\hline 2 & Muy bajo & $\begin{array}{l}\text { Interrupción menor a la función de las instalaciones. } \\
\text { Reparación de la falla puede ser realizada durante el } \\
\text { llamado del problema }\end{array}$ \\
\hline 3 & Bajo & $\begin{array}{l}\text { Interrupción menor a la función de las instalaciones. } \\
\text { Reparación de la falla puede ser más larga que el llamado } \\
\text { del problema, pero no retrasa la misión. }\end{array}$ \\
\hline 4 & $\begin{array}{l}\text { Bajo a } \\
\text { moderado }\end{array}$ & $\begin{array}{l}\text { Moderada interrupción a la función de las instalaciones. } \\
\text { Alguna parte de la misión puede necesitar ser reprocesada } \\
\text { o el proceso es atrasado. }\end{array}$ \\
\hline 5 & Moderado & $\begin{array}{l}\text { Moderada interrupción a la función de las instalaciones. } \\
100 \% \text { de la misión puede requerir ser reprocesada o el } \\
\text { proceso es atrasado. }\end{array}$ \\
\hline 6 & $\begin{array}{l}\text { Moderado } \\
\text { a alto }\end{array}$ & $\begin{array}{l}\text { Moderada interrupción a la función de las instalaciones. } \\
\text { Alguna parte de la misión se pierde. Significativa espera } \\
\text { para restaurar la función. }\end{array}$ \\
\hline 7 & Alto & $\begin{array}{l}\text { Elevada interrupción a la función de las instalaciones. } \\
\text { Alguna parte de la misión se pierde. Significativa espera } \\
\text { para restaurar la función. }\end{array}$ \\
\hline 8 & Muy alto & $\begin{array}{l}\text { Elevada interrupción a la función de las instalaciones. } \\
\text { Alguna parte de la misión se pierde. Significativa espera } \\
\text { para restaurar la función. }\end{array}$ \\
\hline 9 & Peligroso & $\begin{array}{l}\text { Potencial problema de seguridad, salud o ambiental. Fallas } \\
\text { pueden ocurrir con advertencia. }\end{array}$ \\
\hline 10 & Peligroso & $\begin{array}{l}\text { Potencial problema de seguridad, salud o ambiental. } \\
\text { Fallas pueden ocurrir sin advertencia. }\end{array}$ \\
\hline
\end{tabular}


Tabla 32. Categorías de Probabilidad de ocurrencia [40]

\begin{tabular}{|c|c|l|}
\hline Clasificación & Efecto & \multicolumn{1}{|c|}{ Comentario } \\
\hline $\mathbf{1}$ & $\begin{array}{c}1 / 10 \\
000\end{array}$ & $\begin{array}{l}\text { Remota probabilidad de ocurrencia; irrazonable esperar } \\
\text { que la falla pueda ocurrir. }\end{array}$ \\
\hline $\mathbf{2}$ & $1 / 5000$ & $\begin{array}{l}\text { Baja razón de falla. Similar a los diseños del pasado, tuvieron } \\
\text { bajas razones de falla para ciertos volúmenes/cargas. }\end{array}$ \\
\hline $\mathbf{3}$ & $1 / 2000$ & $\begin{array}{l}\text { Baja razón de falla. Similar a los diseños del pasado, tuvieron } \\
\text { bajas razones de falla para ciertos volúmenes/cargas. }\end{array}$ \\
\hline $\mathbf{4}$ & $1 / 1000$ & $\begin{array}{l}\text { Razón de falla ocasional. Similar a los diseños del pasado, } \\
\text { tuvieron bajas razones de falla para ciertos volúmenes/ } \\
\text { cargas }\end{array}$ \\
\hline $\mathbf{5}$ & $1 / 500$ & $\begin{array}{l}\text { Moderada razón de falla. Similar a los diseños del pasado, } \\
\text { tuvieron bajas razones de falla para ciertos volúmenes/ } \\
\text { cargas. }\end{array}$ \\
\hline $\mathbf{6}$ & $1 / 200$ & $\begin{array}{l}\text { Moderada a alta razón de falla. Similar a los diseños } \\
\text { del pasado, tuvieron bajas razones de falla para ciertos } \\
\text { volúmenes/cargas. }\end{array}$ \\
\hline $\mathbf{1 0}$ & $1 / 10+$ & $\begin{array}{l}\text { Alta razón de falla. Similar a los diseños del pasado, tuvieron } \\
\text { altas razones de falla, que causaron problemas. }\end{array}$ \\
\hline Muy alta razón de falla. Mucha certeza de causar problemas. \\
\hline
\end{tabular}

\subsubsection{Determinar la criticidad de los subsistemas}

Una vez detectadas las máquinas/equipos críticos se pasa a realizarles un Análisis de Modo y Efecto de la Falla AMEF o Failure Mode and effect Analysis FMEA, el cual busca determinar los subsistemas críticos, para posteriormente plantear estrategias de solución. El AMEF es una metodología que pretende determinar el Índice de Riesgo o Número de Prioridad de Riesgo NPR, aplicando el procedimiento descrito a continuación y luego la Fórmula 16.

Análisis AMEF. Aplicar la metodología descrita a continuación, asegura que se respondan satisfactoriamente y en la secuencia indicada una serie de preguntas, que proporcionarán un conocimiento del proceso productivo y de la función de las máquinas/equipos, referenciados a un contexto productivo o contexto operacional:

a. ¿Cuáles son las funciones y los modelos ideales de rendimiento del recurso en el actual contexto operativo (Funciones principales y secundarias)? 
b. ¿En qué formas no puede cumplir sus funciones (fallas funcionales y potencionales)? Se trata de describir los modos de falla funcionales y potenciales (¿en qué condiciones el equipamiento falla?

c. ¿Qué ocasiona cada falla funcional? es decir, definir la causa. Posteriormente clasificar las fallas en categorías o modos de falla (mecánicas, eléctricas, lubricación, instrumentación), haciendo la respectiva descripción.

d. ¿Qué sucede cuando ocurre cada falla (efectos y consecuencias de la falla)?

Recordar qué efecto es diferente de consecuencia.

Con esto se describe el efecto potencial de la falla, y surgen otras preguntas: ¿ocurrirá parada de la producción? ¿Ocurre reducción de la producción? ¿La calidad del producto es afectada? ¿Cuáles son los daños provocados? El responder las preguntas anteriores ayudará a determinar las consecuencias (sobre la seguridad personal, sobre el medio ambiente, sobre la producción, sobre la calidad, etc.) y la Gravedad.

e. ¿Cuál es la Gravedad o Severidad de la falla? Tabla 33.

f. ¿Cuál es la Frecuencia de la falla? Tablas 32 (opcional) y 33.

g. ¿Cuál es la Detectabilidad de la falla? Tabla 33.

h. Una vez respondidas las preguntas anteriores, se debe calcular el NPR (fórmula 16).

$$
N P R=\mathrm{F} \times \mathrm{G} \times \mathrm{D}
$$

\section{Donde}

$N P R$ es el número de prioridad de riesgo.

$F \quad$ es la frecuencia de ocurrencia de la falla, en un subsistema.

$G \quad$ es la gravedad de la ocurrencia de una falla.

$D \quad$ es la detectabilidad o facilidad para encontrar la falla.

i. De acuerdo al valor de NPR obtenido, y con la ayuda de la Tabla 33, definirá la criticidad del subsistema.

\subsubsection{Toma de decisiones a partir de los análisis arrojados}

Una vez definidos los subsistemas más críticos, entonces debe pasarse al desarrollo de planes de acción para eliminar o corregir el problema potencial. Se debe responder la pregunta ¿Qué debe hacerse para predecir o prevenir cada falla (tareas proactivas e intervalos de labores? En este punto son de mucha ayuda los análisis causa-raíz o espina de pescado y puede haber apoyo de la cadena de razonamiento lógico de la figura 71, propuesta en la guía para aplicación de RCM propuesta por la NASA [41], en cuanto a la determinación del modo de proceder con respecto a los escenarios de falla encontrados, llegando a cinco soluciones posibles:

- Aceptar el riesgo de la falla.

- Instalar unidades redundantes o en paralelo.

- Definir actividades de Mantenimiento Preventivo PM.

- Programar actividades de Mantenimiento Predictivo PdM.

- Proponer rediseño del sistema. 
Tabla 33. Valores recomendados para la evaluación de NPR [39]

\begin{tabular}{|l|l|c|}
\hline Componente del NPR & \multicolumn{1}{|c|}{ Clasificación } & Peso \\
\hline \multirow{5}{*}{ Gravedad de la falla $(G)$} & Apenas imperceptible & 2 a 3 \\
\cline { 2 - 3 } & Poca importancia & 4 a 6 \\
\cline { 2 - 3 } & Moderadamente grave & 7 a 8 \\
\cline { 2 - 3 } & Grave & 9 a 10 \\
\cline { 2 - 3 } & Extremadamente grave & 1 \\
\hline \multirow{5}{*}{ Frecuencia de ocurrencia } & Improbable & 2 a 3 \\
\cline { 2 - 3 } & Muy pequeña & 4 a 6 \\
\cline { 2 - 3 } & Pequeña & 7 a 8 \\
\cline { 2 - 3 } & Media & 9 a 10 \\
\cline { 2 - 3 } & Alta & 1 \\
\hline \multirow{5}{*}{ Detectabilidad (D) } & Alta & 2 a 5 \\
\cline { 2 - 3 } & Moderada & 6 a 8 \\
\cline { 2 - 3 } & Pequeña & 9 \\
\cline { 2 - 3 } & Muy pequeña & 10 \\
\cline { 2 - 3 } & Improbable & 1 a 50 \\
\hline Índice de Riesgo (NPR) & Bajo & 50 a 100 \\
\cline { 2 - 3 } & Medio & 100 a 200 \\
\cline { 2 - 3 } & Alto & 200 a 1000 \\
\cline { 2 - 3 } & Muy alto & \\
\hline
\end{tabular}

Aceptación del riesgo de la falla. Cuando no resulta viable por razones de prioridad, costos y variabilidad de las frecuencias de falla, aplicar tareas de Mantenimiento Preventivo, se asume el riesgo de la falla y se estudia la posibilidad de realizar un monitoreo constante del sistema, subsistema o componente, aplicando tareas básicas de lubricación y servicio.

Tareas de Mantenimiento Preventivo. Ampliamente usado en los campos industrial y automovilístico. Industrial: inspecciones antes, durante y al finalizar la jornada; cambios, ajustes, calibraciones a determinadas frecuencias (horas de servicio, horas transcurridas, unidades producidas, etc.). Automovilístico: revisiones diaria antes de la salida de cada equipo y durante periodos determinados por la distancia recorrida y recomendados en su gran mayoría por el fabricante del vehículo. En general, se recomienda realizar tareas de MP si el costo de ejecutarlas durante un cierto período de interés es menor a los costos de reparar y al de las consecuencias operacionales.

Tareas de Mantenimiento Predictivo. Es común en el mantenimiento industrial hacerse de métodos de predicción de fallas, como los análisis de vibraciones, análisis termográficos, pruebas de tintas penetrantes, etc. En el mantenimiento de automóviles, las herramientas más poderosas son las alarmas 
dispuestas en el tablero de control del vehículo que permiten un monitoreo constante del equipo y los análisis de aceite usado (Capítulo 6 y Anexo 5).

Rediseño del sistema. Por lo general aplicado en mantenimiento industrial, específicamente en el movimiento de fluidos; este tipo de propuesta hace modificaciones de forma y funcionamiento en el sistema, las cuales son meritoriasson meritorias, previos análisis de costos. En el mantenimiento vehicular, es posible aplicar esta propuesta haciéndole llegar a los proveedores de vehículos, las apreciaciones que uno tiene de sus productos y de igual forma, cuando se tiene la opción de escoger las marcas de los componentes del vehículo como el motor, la caja, los filtros, etc., se puede diseñar una configuración "óptima", con componentes durables, mayores periodos de mantenimiento preventivo y mejor desempeño. En general, se recomienda rediseñar el sistema, si no se puede encontrar una tarea o grupo de tareas que puedan reducir el riesgo a un valor aceptable.

Por último, y como una opción B, se debe trazar un panorama en el sentido de ¿Qué debe hacerse si una tarea proactiva adecuada no puede ser encontrada o se aplicó pero el efecto no fue el esperado (Acciones por defecto o remediales)? Estas acciones por defecto o remediales son propias de cada contexto operativo.

Instalación de unidad redundante. Consiste en proveer al sistema de un equipo alterno, el cual se ponga en marcha en caso de falla de alguno de los componentes y realice un reemplazo temporal. Ampliamente aplicado en mantenimiento industrial. No aplica en equipos automovilísticos, debido a que los componentes principales de los vehículos son unitarios y no es común el contar con subsistemas o componentes de emergencia. 
Figura 71. Cadena de razonamiento RCM [41]

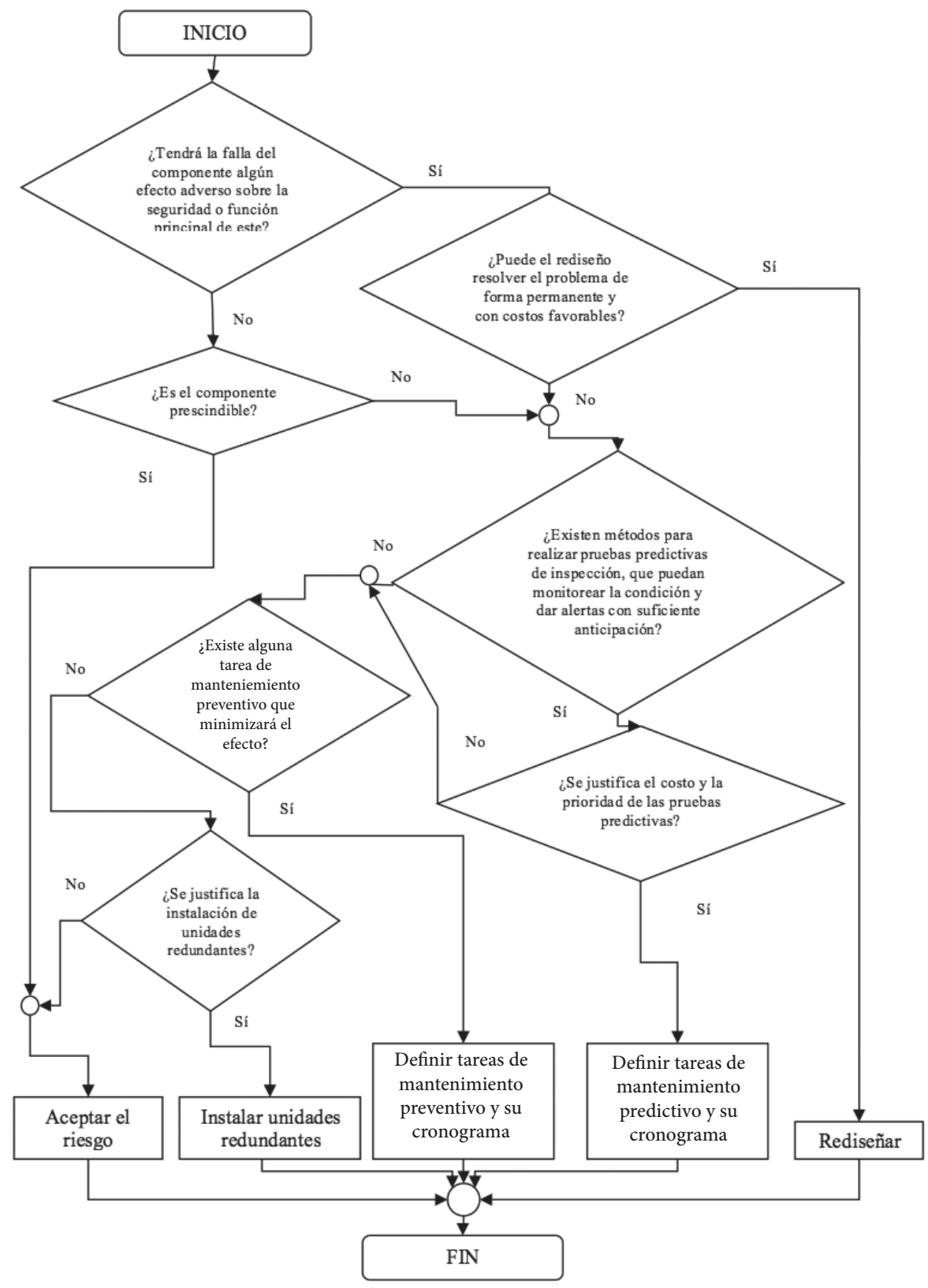




\subsubsection{Ventajas de aplicar RCM}

RCM nació para mejorar la seguridad en la industria aeronáutica (una industria de servicio), y efectivamente lo ha logrado, pero también ha mostrado resultados muy exitosos en industrias del sector primario, secundario y de servicios tales como: Minería, plantas petroquímicas, plantas de gas, bombas y compresores en sitios remotos, plantas de fundición y refinación de metales, plantas de pulpa de papel, plantas alimenticias y de bebidas, flotas de camiones de transporte [39].

Algunas ventajas generales de aplicar el RCM son:

- Mejoramiento de la seguridad y el cuidado del medio ambiente. Recordar que RCM prioriza la afectación a las personas y al entorno.

- Mejoramiento de los rendimientos operativos, porque se reduce significativamente la cantidad y severidad de las fallas, y como se adquiere un mejor conocimiento de las máquinas/equipos, se simplifican y mejoran los procedimientos operativos a pie de máquina.

- Disminución de los costos totales de Mantenimiento rutinario, porque se reduce la cantidad y complejidad de las tareas de Mantenimiento.

- Se propicia el trabajo multidisciplinario, promoviendo el trabajo en equipo con relaciones armoniosas y colaborativas entre diversas dependencias de la compañía.

- Se garantiza el cumplimiento de la vida útil de las máquinas/equipos al aplicar Mantenimiento Predictivo.

- Si RCM se aplicara en una empresa que tiene implementado el Mantenimiento Preventivo, la carga de trabajo rutinaria preventiva se puede reducir entre un $40 \%$ y un $70 \%$. La razón de esta reducción es que el Mantenimiento Preventivo aplica a los diversos equipos, concienzudamente a cada cierta frecuencia, las tareas recomendadas por el fabricante y las sugeridas por la experiencia, sin importar mucho la criticidad de la máquina dentro del proceso productivo, mientras que en el RCM, primeramente se desarrolla un análisis de criticidad $C A$ por áreas y secciones para identificar las máquinas/equipos más críticos, seguidamente se aplica el análisis AMEF para determinar la criticidad (NPR) de cada subsistema dentro de las máquinas/equipos críticos, y por último se concentran los esfuerzos en dichos subsistemas. Si RCM se aplicara para desarrollar un nuevo sistema de Mantenimiento en una empresa, el resultado sería que la carga de trabajo de mantenimiento será mucho menor que si el sistema se hubiese desarrollado por los métodos convencionales (sistema LEMI).

- Se crea (si no se disponía) o se mejora la base de datos mantenimiento, gracias a la adecuada aplicación de los análisis AMEF y de la elaboración y documentación de los consecuentes planes de acción.

\subsubsection{RCM y TPM como sistemas de Mantenimiento Complementarios}

No obstante que el TPM y RCM persiguen objetivos diferentes, es decir, mientras el primero premia la Productividad, el segundo premia la Confiabilidad del proceso productivo en un cierto contexto operativo, es posible identificar aspectos y métodos comunes a ambos sistemas:

- Ambos requieren de la aprobación y compromiso de la alta gerencia para su implementación. - Ambos requieren de la colaboración de todo el personal de la empresa, para que sea exitosa y duradera su implementación. 
- Ambos propician y necesitan de trabajo en equipo.

- Ambos aplican Mantenimiento Preventivo. TPM es una mejora y evolución del MP, y lo aplica de manera tradicional, es decir de manera rigurosa y a veces en exceso. En el RCM, el MP aparece como una de cinco soluciones posibles, pero con una salvedad, aparece "optimizado" o adelgazado.

En este punto, el TPM le puede aportar herramientas complementarias a RCM, en el sentido de la aplicación de políticas y planes de mejoramiento continuo (5S, Mantenimiento, autónomo, capacitación, cultura de trabajo en equipo), mientras que el RCM le puede aportar su mirada sistemática y crítica para aplicar la cantidad necesaria de MP en los subsistemas de las máquinas/procesos críticos.

\subsection{Ejercicio propuesto}

La figura 72 ilustra el esquema general para producción de panela utilizando vapor.

- Hacer las consultas necesarias y aplicar el método propuesto en el Anexo 4, numeral A4.2, para la comprensión del funcionamiento del equipo.

- Explicar las ventajas del sistema asistido por vapor, frente al de hornilla tradicional.

Aplicar la metodología RCM propuesta en el numeral 8.4 para determinar la criticidad (NPR) de los subsistemas del sistema de producción de panela utilizando vapor. Puesto que se analizará al interior de un equipo, se omitirá el análisis de criticidad descrito en el numeral 8.4.1.

\section{Subsistema 1 a analizar \\ Subsistema 2 a analizar}

\section{Función sistema}

\section{Función subsistema 1}

Función subsistema 2

Fallas funcionales cada subsistema (listado)

Fallas potenciales cada subsistema (listado)

Modos de falla cada subsistema
: Bomba de condensado.

: Bomba de jugo.

\section{Defina:}

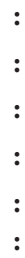

De los listados elaborados, para cada subsistema elija una falla funcional en particular:

Subsistema 1:

Subsistema 2:

\section{Para cada falla funcional defina:}

Efectos

Consecuencias

Causas

Gravedad (Tabla 33)

Frecuencia (Tabla 33)

Detectabilidad (Tabla 33) 
NPR:

Aplique la cadena de razonamiento lógico de la figura 71 y proponga un Plan de Acción acorde al resultado o solución hallada.

Figura 72. Sistema de producción de panela utilizando vapor [3]

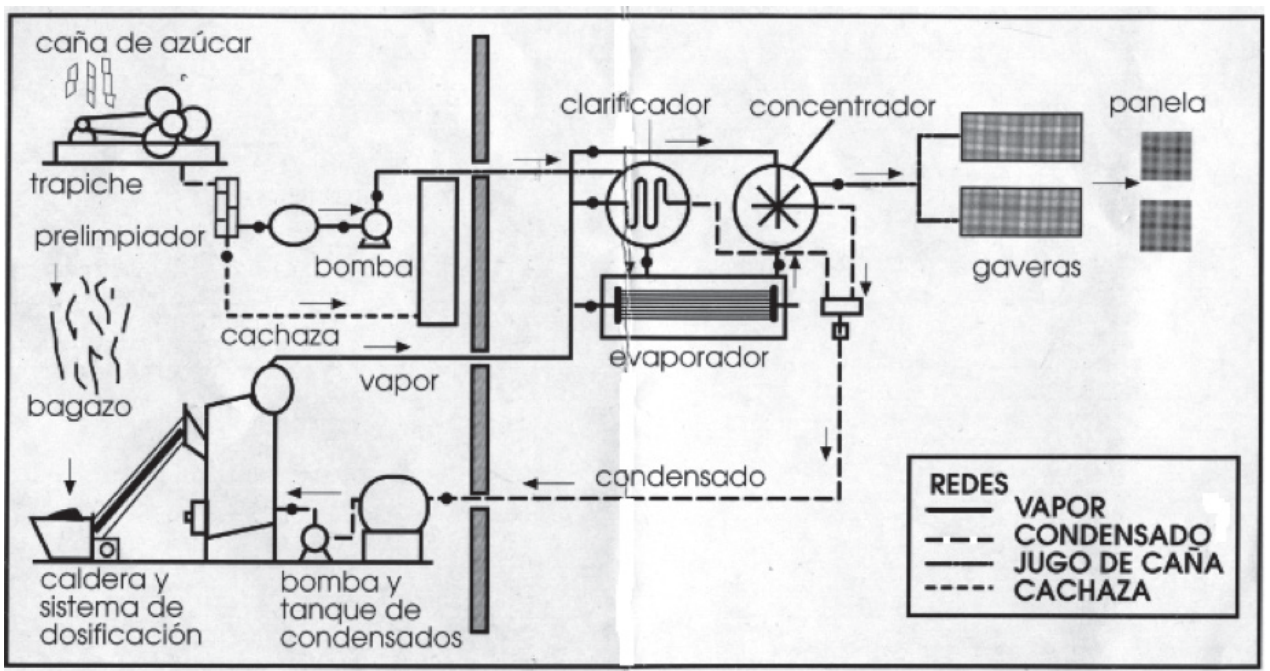

\subsection{Caso de estudio. Ejemplo de aplicación parcial de RCM}

En este apartado se puede consultar el resultado de aplicación parcial de la metodología RCM, con el fin de filtrar los equipos críticos de una empresa de servicios. Este ejercicio permitió identificar los equipos sobre los cuales, debían centrar de manera prioritaria los esfuerzos y labores del personal de mantenimiento.

Esta lectura complementaria se puede consultar en: $h t t p: / / c a r l o s-m o n t i l l a-u t p . j i m d o . c o m / c o m p l e m e n t o s-$ libro-de-mantenimiento/complementos-cap\%C3\%ADtulo-8/

En la bibliografía [42] se puede consultar un caso de aplicación de RCM a una flota de camiones de cargar interdepartamental, y en la bibliografía [43] se puede consultar un caso muy exitoso de aplicación de RCM en una planta minera de gran envergadura. 

Capítulo 9 



\section{Apuntes sobre Mantenimiento Basado en el Riesgo RBM}

\subsection{Introducción}

El Mantenimiento Basado en el Riesgo RBM (Risk Based Maintenance RBM por sus siglas en inglés) es un sistema de mantenimiento cuyo objetivo es reducir el riesgo general de ocurrencia de fallas catastróficas en las instalaciones industriales, hasta llevarlo a un nivel aceptable de acuerdo a normas. El RBM es muy apropiado cuando se trata con instalaciones donde se transportan, producen y manejan productos tóxicos o peligrosos (petroquímicas, plantas nucleares, desechos biológicos, etc.).

A diferencia del TPM (donde se premia la Productividad) y del RCM (donde prima la Confiabilidad), el RBM estudia los procesos productivos y los evalúa en función de la probabilidad de ocurrencia de una falla catastrófica (aquella que afecta la salud de las personas, el medio ambiente y las instalaciones) y de las consecuencias que acarrearía su ocurrencia (figura 10, numeral 1.5.7). En RBM se direccionan los recursos de la organización hacia las instalaciones/máquinas/equipos que un análisis Probabilidad Riesgo determine que son los más peligrosos. El área verde (figura 10) indica que hay poca probabilidad que una máquina/equipo $A$ falle de manera catastrófica y en el caso que ocurriese, las consecuencias serían poco importantes. Por el contrario, para una máquina/equipo $B$, ubicado en la región roja indicaría una alta probabilidad de que ocurra una falla catastrófica, y las consecuencias serían elevadas, por lo tanto a la máquina $B$ hay que aplicarle planes de acción más elaborados y asignarle mayores recursos que a la máquina $A$. La dirección y aplicación del RBM lo hacen equipos multidisciplinarios de profesionales.

\subsection{Algunos antecedentes del manejo del riesgo}

\subsubsection{Normatividad sobre riesgo en instalaciones industriales}

Antes de la década de 1980 no había en el mundo reglamentación clara sobre disposición final de residuos peligrosos, y muy hábil y convenientemente los países industrializados enviaban sus desechos tóxicos a los países más pobres de África, Asia o América. 
- A finales de la década de 1980, los países industrializados comenzaron a definir normas sobre disposición de residuos, y se tomó conciencia de que disponer residuos adecuadamente acarreaba unos altos costos. Son conocidos incidentes de buques cargados con residuos peligrosos, deambulando por diversos puertos del mundo y siendo rechazados, como los buques Katrin B y Pelícano.

- Convención de Basilea. Firmada en 1989. Entró en rigor en 1992. Fue firmada por más de 170 países. Emitió Normas para el control de los movimientos transfronterizos de los desechos peligrosos y su posterior eliminación. Estas normas estaban dirigidas a la protección de la salud y el medio ambiente.

- Acuerdo de Estocolmo. Firmado en 2001. Entró en rigor en 2004. Fue firmada por más de 172 países. Este acuerdo definió políticas para el manejo de Contaminantes Orgánicos persistentes $(C O P s)$ y para tratamiento de sustancias tóxicas tales como pesticidas, $P C B$ 's (policloruro de bifenilo), dioxinas y furanos.

\subsubsection{Algunos mega-accidentes previos a las convenciones}

Antes de la firma de la Convención de Basilea y del acuerdo de Estocolmo ocurrieron algunos megaaccidentes, los cuales serán ilustrados de manera somera, para dar una idea al lector de lo que es un mega-accidente.

\section{Accidente del superpetrolero Exxon Valdez (figuras 73 y 74)}

Alaska, E.E. U.U. 1989. Derrame de 37000 ton de petróleo crudo, durante una labor errática de atraque del buque, lo cual causó su encallamiento.

Consecuencias inmediatas: Cero muertes. $2000 \mathrm{~km}$ costa afectados. Costo: US 2500 millones. Causa probable: el capitán del superpetrolero estaba ebrio y condujo mal la operación de atraque en el puerto. Su licencia como marino fue suspendida de por vida.

Consecuencia a largo plazo: La afectación a la fauna y flora costera ha sido irreversible. A 2014, al excavar a unos cuantos $\mathrm{cm}$ de profundidad en la playa aun hay petróleo crudo.

Figura 73. Intentos fallidos de contener el derrame de petróleo del Exxon Valdez [44]

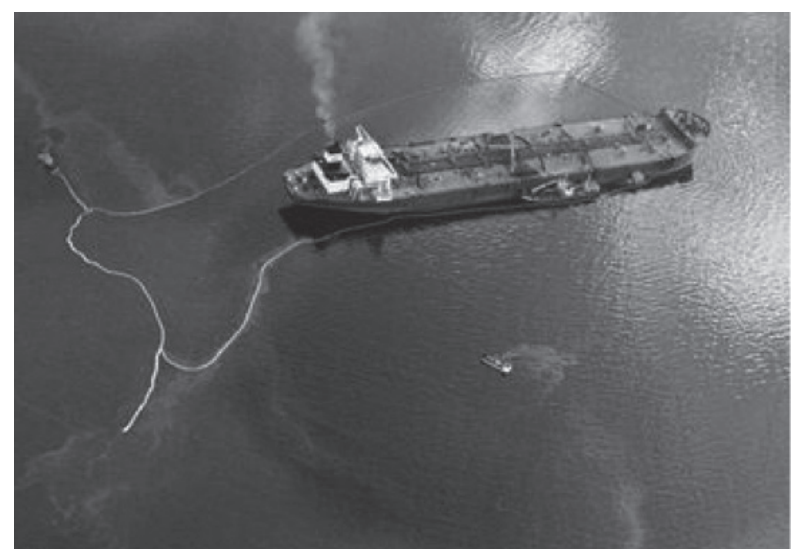


Figura 74. Limpieza de las orillas de Prince William Sound (Alaska - EE UU) [45]

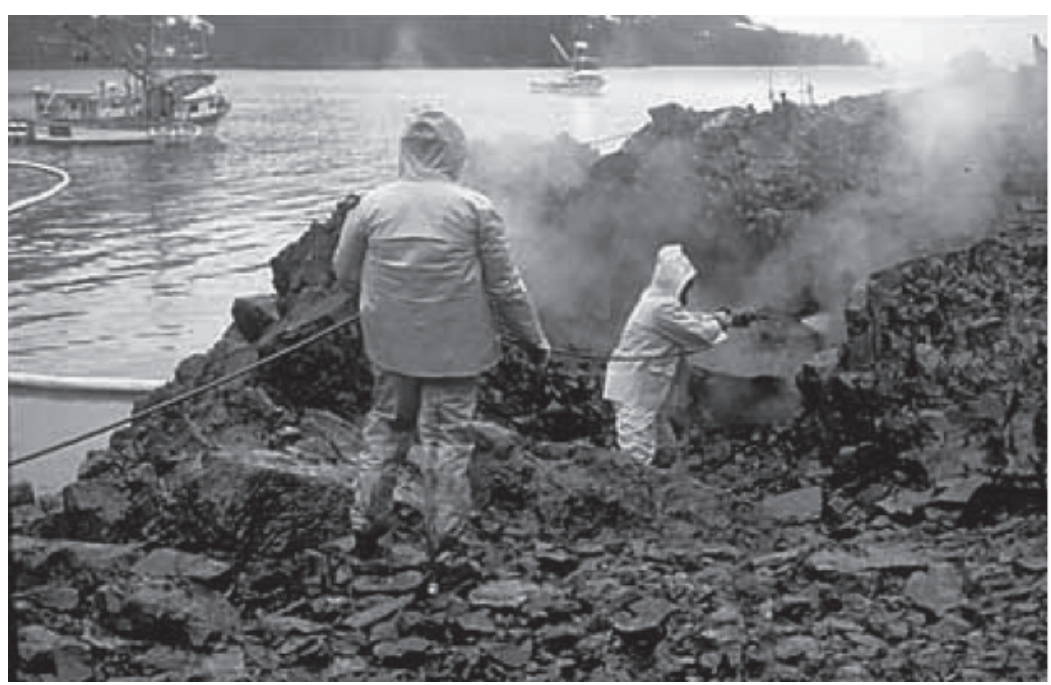

Accidente Bhopal, India. 1984 (figuras 75 y 76)

Planta de pesticidas Union Carbide (Eveready). Planta construida en el estado de Madhya por Union Carbide para producir pesticidas. El principal componente intermedio en el proceso era el Isocianato de Metilo (MIC). Se presentó una fuga de 42 toneladas de MIC, que se convirtieron en cianuro de hidrógeno. Se formó una nube tóxica a baja altura y sumamente letal. La nube en cuestión mató a la población que encontró a su paso, antes de diluirse.

Consecuencias inmediatas: 8000 muertes. La planta fue abandonada y la empresa no respondió.

Causa probable: Falta de precauciones durante tareas de limpieza y mantenimiento de la Planta. Los sistemas de control de fugas y derrames estaban inoperantes por jahorro de costos en mantenimiento! Consecuencia a largo plazo: 25000 muertes más en largo plazo. 600000 afectados a muy largo plazo. Al cabo de los años, en 2010 hubo un juicio cuya sanción fue una multa de $€ 8900$ y 2 años de cárcel a siete directivos de la empresa 
Figura 75. Esquema general de accidente en la Planta Union Carbide [46]

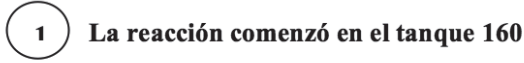

El último tanque designado como sistema buffer de seguridad, se encontraba a máxima capacidad.

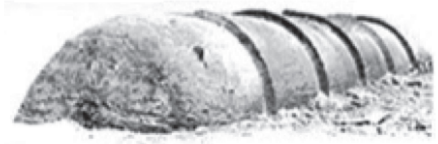

Detectores de temperatura y presión.

No se encontraban debidamente calibrados, por lo que no detectaron los cambios operados
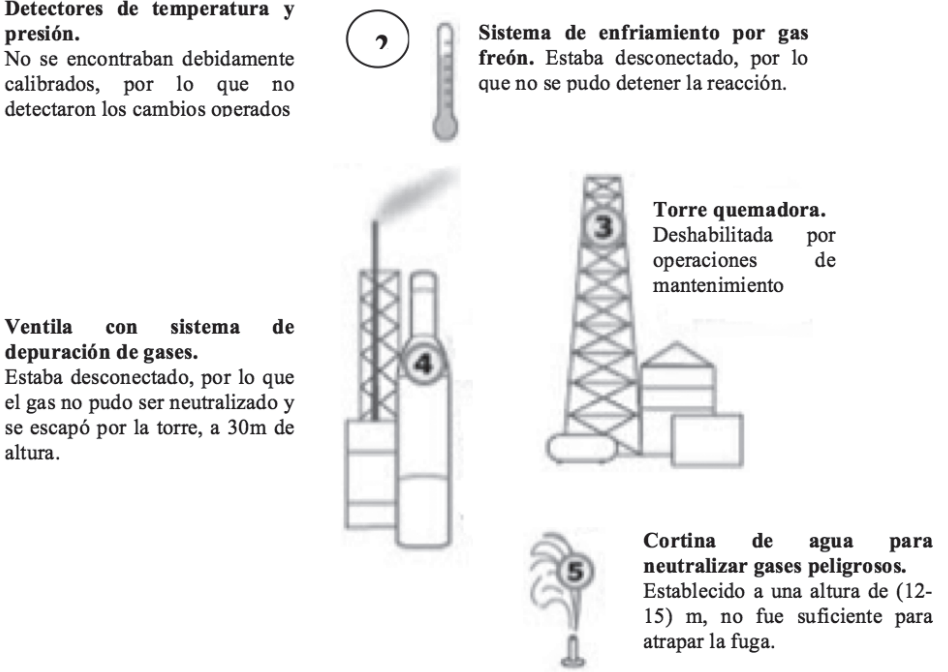

Figura 76. Nube tóxica de MIC sobre Bhopal [47]

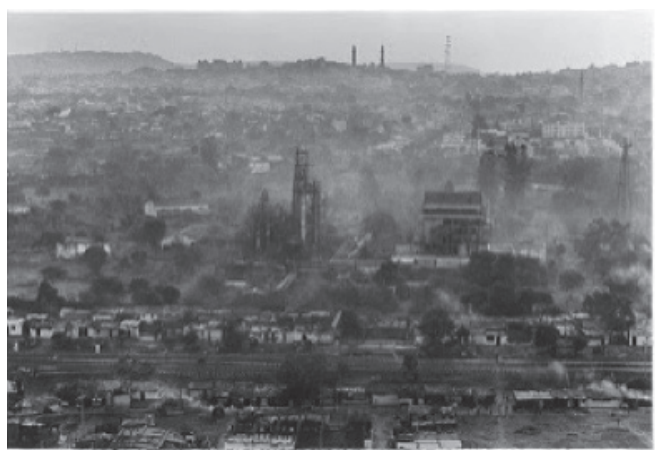

\section{Accidente nuclear de Chernóbyl (actual Ucrania - antigua URSS). 1986 (figuras 77)}

Planta nuclear con fines pacíficos (para generar electricidad industrial), contaba con cuatro reactores. En uno de los reactores se condujo una prueba de seguridad industrial, simulando una ausencia de 
energía eléctrica para enfriar el núcleo del mismo; la prueba fue mal conducida y se llevó al reactor más allá de la temperatura de control con lo cual el sistema se hizo no lineal e inestable, finalmente estalló y produjo la mayor catástrofe nuclear de la historia de la humanidad. La energía liberada fue 500 veces superior a la de Hiroshima - Japón en 1945. Los trabajos de contención posterior al accidente evitaron una explosión que hubiera podido tener efectos apocalípticos sobre toda Europa.

Consecuencias inmediatas: 31 muertes. Severa contaminación de un área de $30 \mathrm{~km}$ de radio.

Causa probable: Ignorancia y prepotencia del funcionario que dirigió la prueba de seguridad industrial. Falta de protocolos de seguridad precisos.

Consecuencia a largo plazo: 135000 muertes en el largo plazo. Mutaciones genéticas. Costo: US 200 000 millones. Factor de colapso de la antigua Unión Soviética. La Planta fue encerrada en un sarcófago gigantesco para confinar la radiación, pero hoy día está a punto de colapsar, por lo que desde 2004 con recursos internacionales se lleva a cabo la construcción de un nuevo sarcófago. (figura 78).

Figura 77. Imagen aérea de la planta de Chernóbil, posterior a la explosión [48]

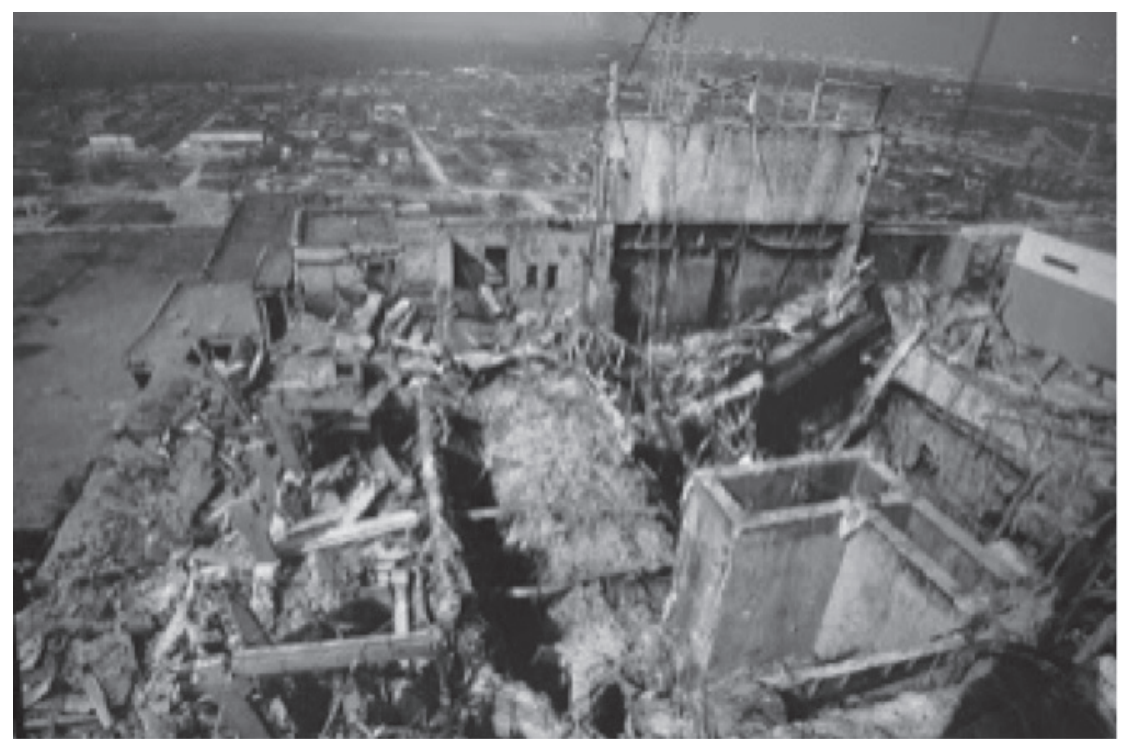


Figura 78. Imagen del sarcófago que actualmente se construye, para contener la radiación del reactor siniestrado [49]

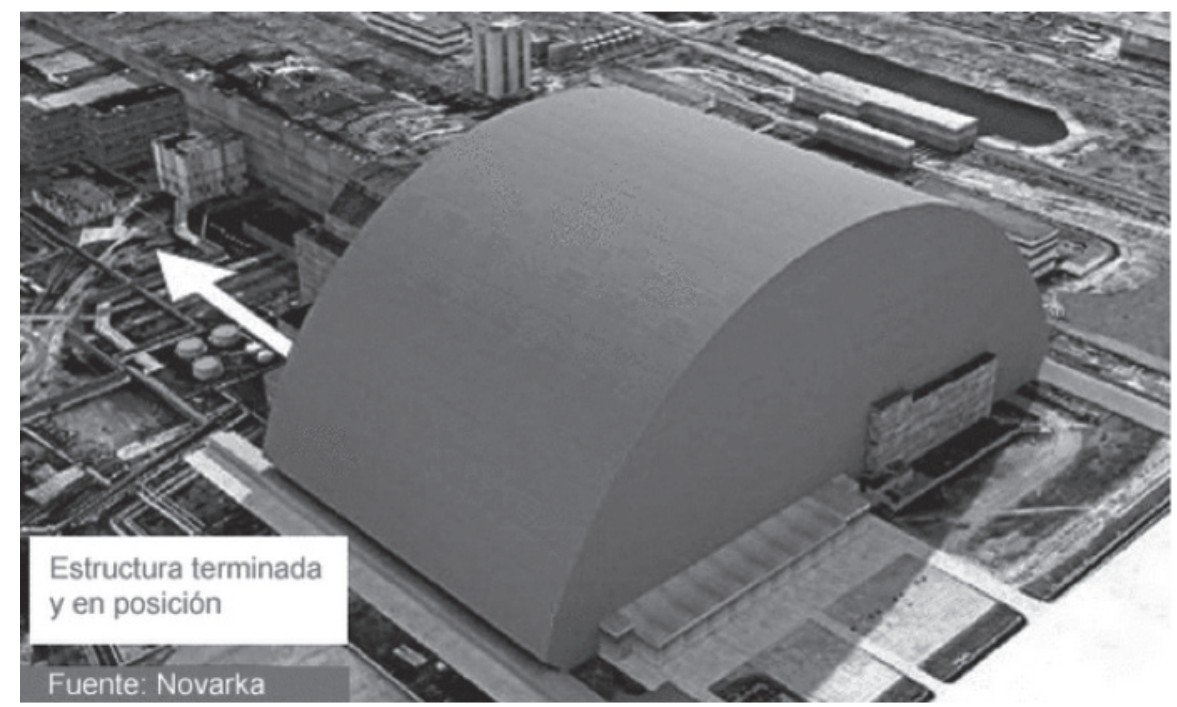

\subsubsection{Algunas Premisas en RBM}

- El Riesgo es inherente a toda actividad humana.

- El Riesgo no se puede eliminar, pero se puede disminuir la probabilidad de ocurrencia de una catástrofe y las posibles consecuencias cuando ocurra.

- Las Compañías deben garantizar la seguridad a sus trabajadores y al medio ambiente.

- No puede haber desarrollo sostenible sin preservar la seguridad.

\subsection{Algunos términos y definiciones a tener en cuenta en RBM}

Riesgo: medida de la probabilidad y consecuencia de un efecto adverso (sobre las personas, medio ambiente, máquinas/equipos/instalaciones, actividad productiva o de servicios).

Safety Integrity Level SIL: Nivel de integridad de seguridad. Es una medida del desempeño que debe alcanzar un sistema instrumentado de seguridad. No es una medida del riesgo de un proceso. Ejemplo, "Nuestro proceso es SIL 3".

Sistema Instrumentado de Seguridad SIS: Un SIS es un sistema independiente a una planta o proceso, compuesto de sensores, procesadores y elementos finales de control, con la finalidad de llevar el proceso a un estado seguro cuando ciertas y predeterminadas condiciones han sido violadas. Cada SIS tendrá un SIL asociado. 


\subsection{Metodología general para la definición y aplicación de un Plan de Mantenimiento RBM}

La figura 79 presenta un diagrama de flujo general que ilustra un modelo de desarrollo, aplicación y evaluación de un Plan de Mantenimiento RBM. Cabe resaltar que RBM hace uso de herramientas estadísticas, las cuales no se presentarán, razón por la cual lo reseñado es meramente descriptivo.

Figura 79. Metodología general a seguir en RBM [50]

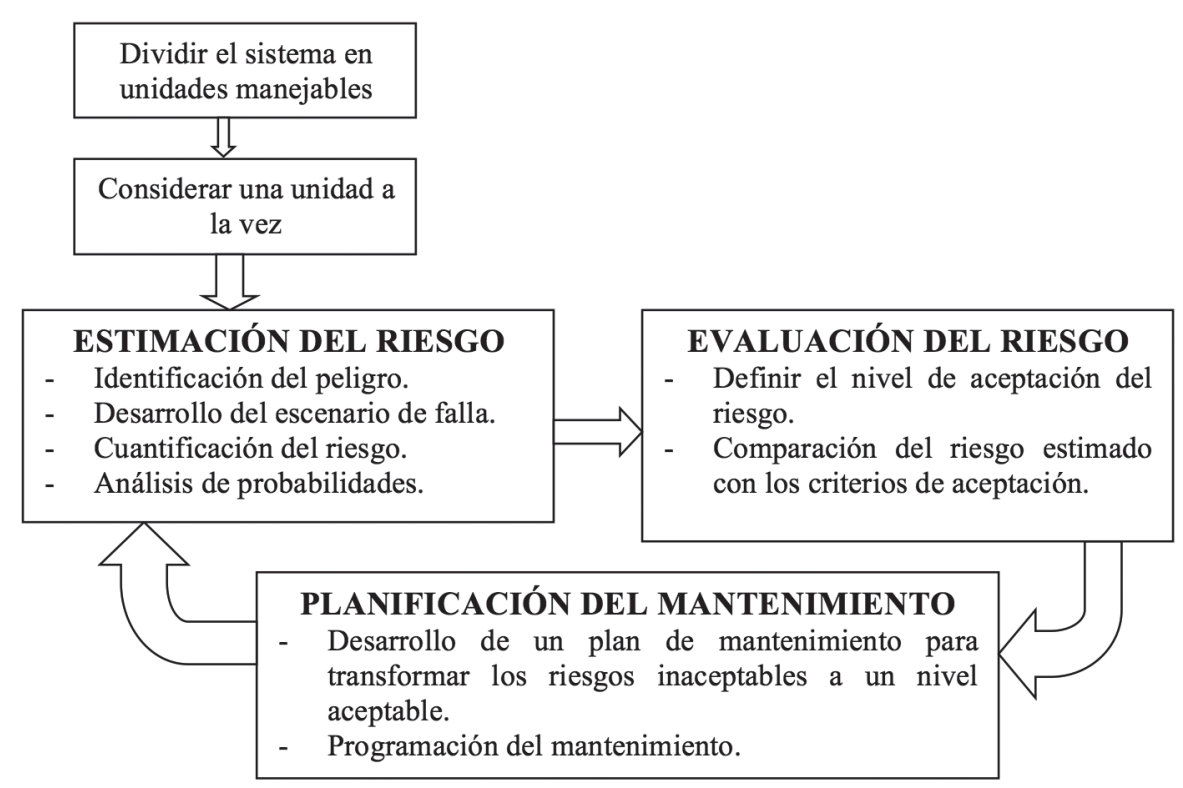

Es necesario tener en cuenta que el Riesgo se calcula de acuerdo a la fórmula 17:

$$
R=F \times C
$$

Donde

$$
\begin{array}{ll}
R & \text { es el riesgo. } \\
F & \text { es la frecuencia o probabilidad de ocurrencia de una avería. } \\
C & \text { es la consecuencia que acarrea la ocurrencia de la avería. }
\end{array}
$$

De la figura 79, la actividad principal Estimación del Riesgo puede ser desagregada en otras actividades, tal como lo muestra la figura 80. De nuevo, de la figura 79, la actividad principal Evaluación del Riesgo puede ser desagregada en otras actividades, tal como lo muestra la figura 81. Está resaltado el cuadro Definir claramente el criterio de aceptación del Riesgo, es decir, definir el SIL del proceso. 
Figura 80. Diagrama de flujo para la Estimación del riesgo [50]

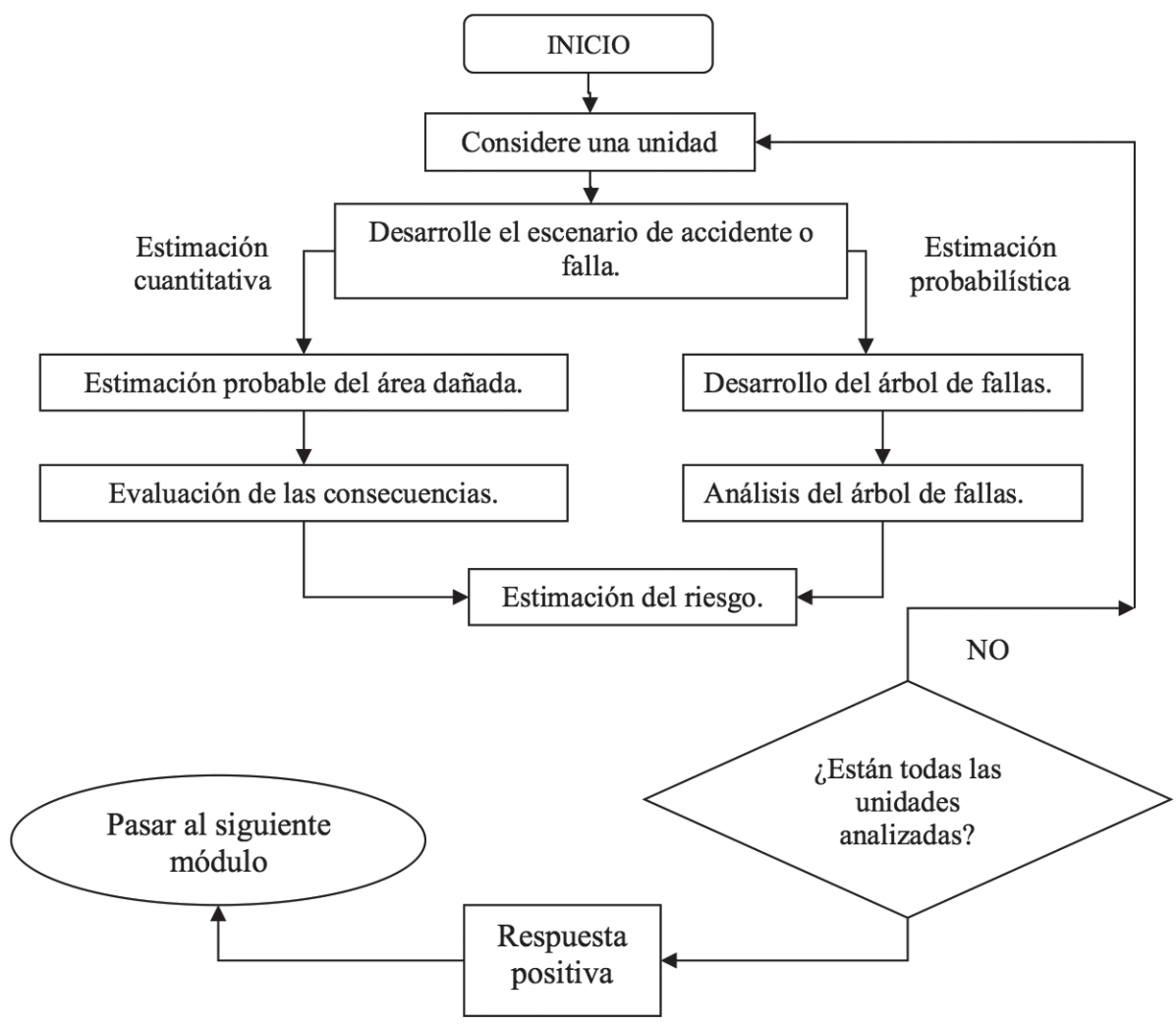

Por último, de la figura 79, la actividad principal Planeación del Mantenimiento puede ser desagregada en otras actividades, tal como lo muestra la figura 82.

Los resultados parciales de la metodología propuesta en las figuras 80,81 y 82 se pueden condensar en lo mostrado por la figura 83. Allí, y con el conocimiento del proceso se llega a definir el Riesgo inherente al proceso. Posteriormente, y habiendo definido el Nivel de Riesgo aceptable o tolerable (de acuerdo a Normas y Estándares), se procede a rediseñar el proceso y a aplicar otras medidas de forma tal que el Riesgo se reduce; no obstante la reducción del Riesgo, aun está alejado del Nivel de riesgo aceptable, entonces hacen su aparición los Sistemas Integrados de Seguridad SIS, con el objetivo garantizar que el Riesgo se lleve a niveles aceptables o tolerables ( Recordar que el Riesgo no se puede llevar a un valor $\mathbf{0}$ ). 
Figura 81. Diagrama de flujo para la Evaluación del Riesgo [50]

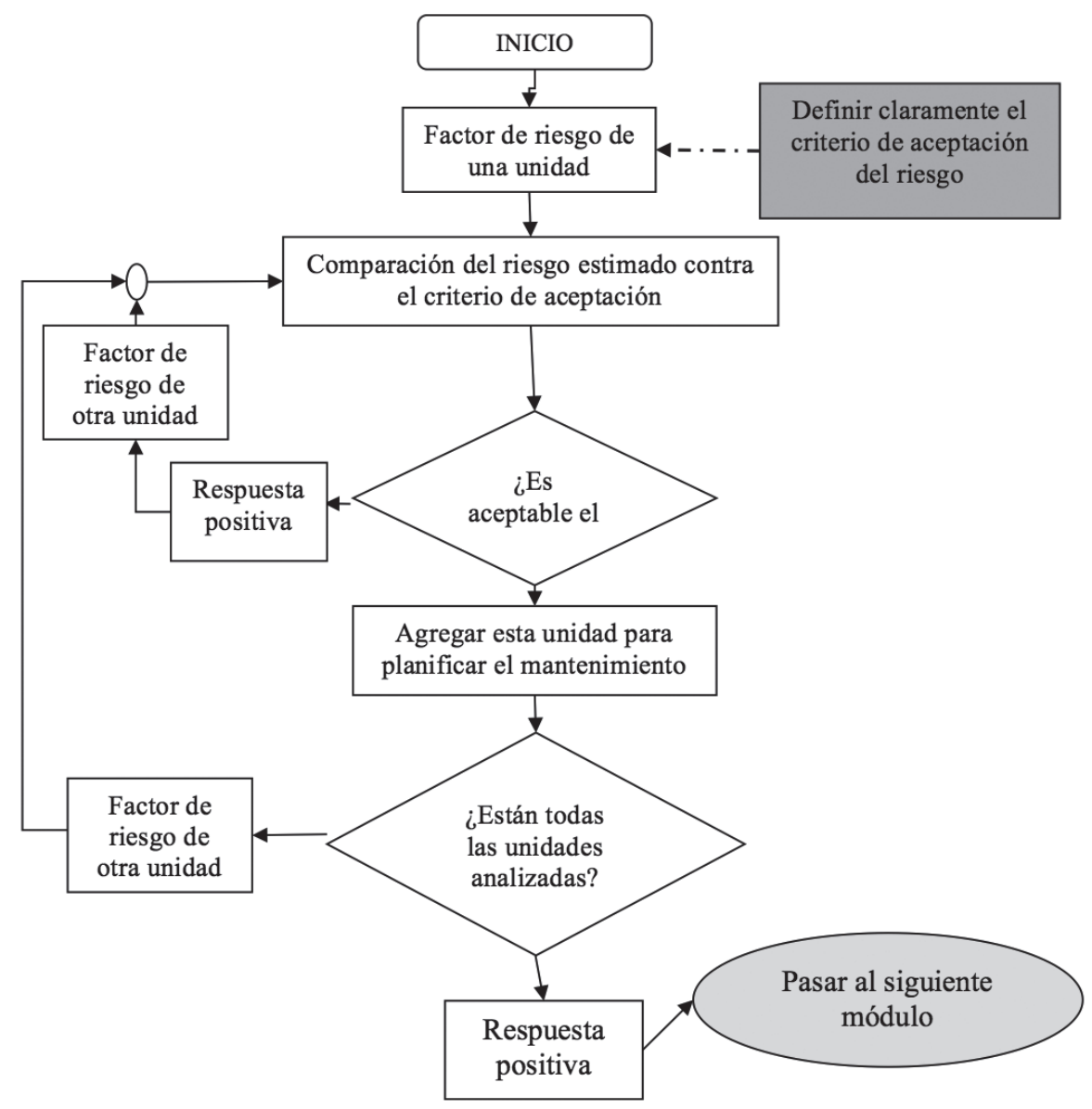


Figura 82. Diagrama de flujo para la Planeación del Mantenimiento [50]

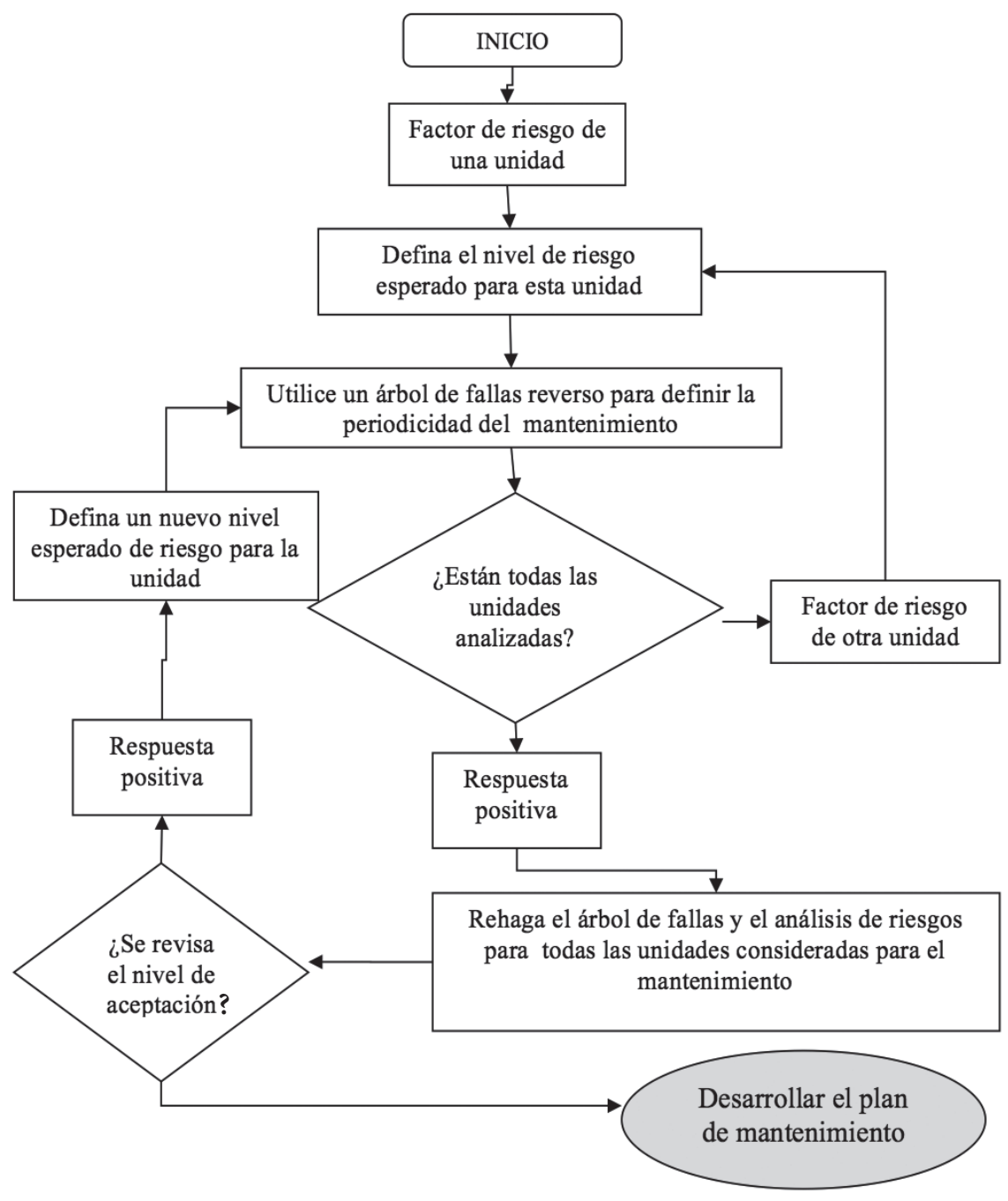

Ahora bien, con base en la definición de SIL dada en 9.3, este posee cuatro valores estandarizados, de 1 a 4, siendo SIL 1 el de mayor probabilidad de falla u ocurrencia y por ende el de menor Factor de reducción de riesgo, y por el contrario el SIL 4 el de menor probabilidad de falla u ocurrencia y consecuentemente el de mayor factor de reducción de riesgo (Tabla 34). 
Figura 83. Esquema de ¿Cómo reducir el Riesgo a un nivel aceptable? [51]

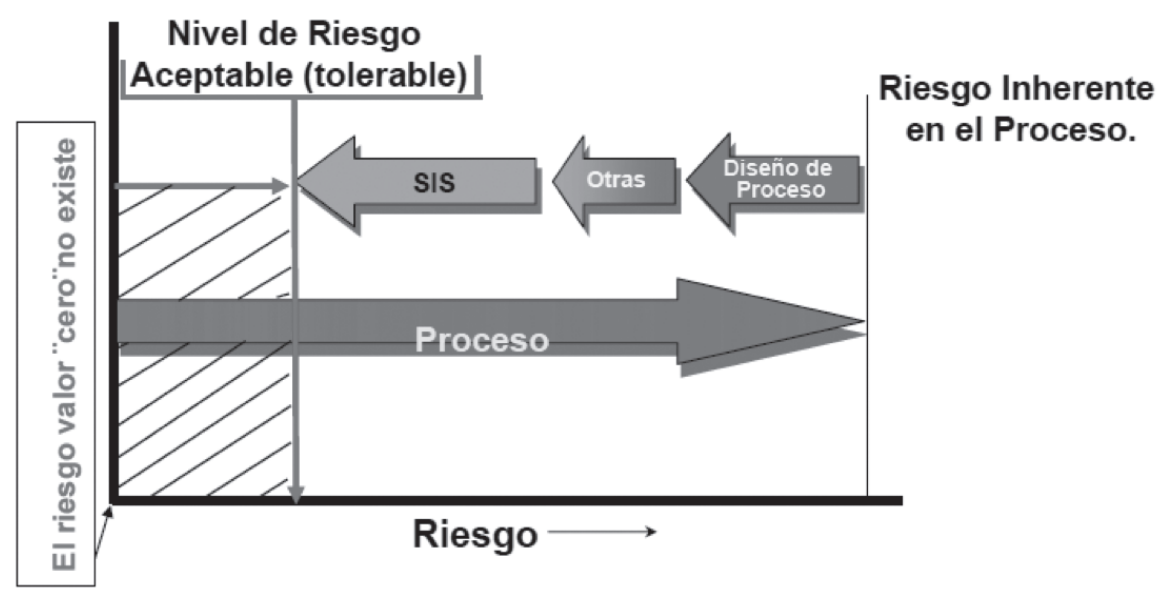

Tabla 34. Valores estandarizados de SIL y características asociadas [51]

\begin{tabular}{|c|c|c|}
\hline $\begin{array}{c}\text { Nivel de integridad en } \\
\text { seguridad }\end{array}$ & $\begin{array}{c}\text { Probabilidad de falla por año en } \\
\text { demanda (modo de demanda en } \\
\text { operación) }\end{array}$ & $\begin{array}{c}\text { Factor de Reducción de } \\
\text { Riesgo }\end{array}$ \\
\hline SIL 4 & $\geq 10^{-5}$ hasta $<10^{-4}$ & 100.000 hasta 10.000 \\
\hline SIL 3 & $\geq 10^{-4}$ hasta $<10^{-3}$ & 10.000 hasta 1000 \\
\hline SIL 2 & $\geq 10^{-3}$ hasta $<10^{-2}$ hasta $<10^{-1}$ & 1.000 hasta 100 \\
\hline SIL 1 & 100 hasta 10 \\
\hline
\end{tabular}

La figura 84 muestra por un lado que el Factor de reducción de riesgo es el inverso de la Probabilidad de Falla en demanda, y por otro lado presenta las equivalencias de niveles SIL en varios Estándares. Obsérvese en particular el estándar IEC 61508.

Contémplese esta situación: Se dispone de un sistema SIL 3, cuya disponibilidad mínima es del 99,90\% (figura 140 para IEC 61508), o en otras palabras, la probabilidad de fallar es del 0,01\% o de 0,0001. Como una primera impresión, podría pensarse que este sistema es "sumamente bueno"... Para juzgar esta impresión no hay valoraciones absolutas, todo depende de qué contexto se esté analizando. Un sistema real, que posea un SIL 3, y a modo de ejemplo, podría verse reflejado en las dos situaciones descritas a continuación:

Situación 1. Un Sistema con SIL 3 al fallar podría permitir que el sistema de agua potable de la Ciudad de México se contaminara por el lapso de 1 hora/mes. 
Situación 2. Un Sistema con SIL 3 controlando los aterrizajes del aeropuerto internacional de la Ciudad de México, podría llevar a la ocurrencia de dos aterrizajes inseguros/día.

¿A cuál de los dos escenarios le gustaría que estuvieran expuestos su familia y Usted? Probablemente su respuesta sea al primero, pero con seguridad que no tiene idea del dolor causado por una disentería o por padecer el ataque del ébola...

Figura 84. Equivalencias de SIL en varios estándares [51]

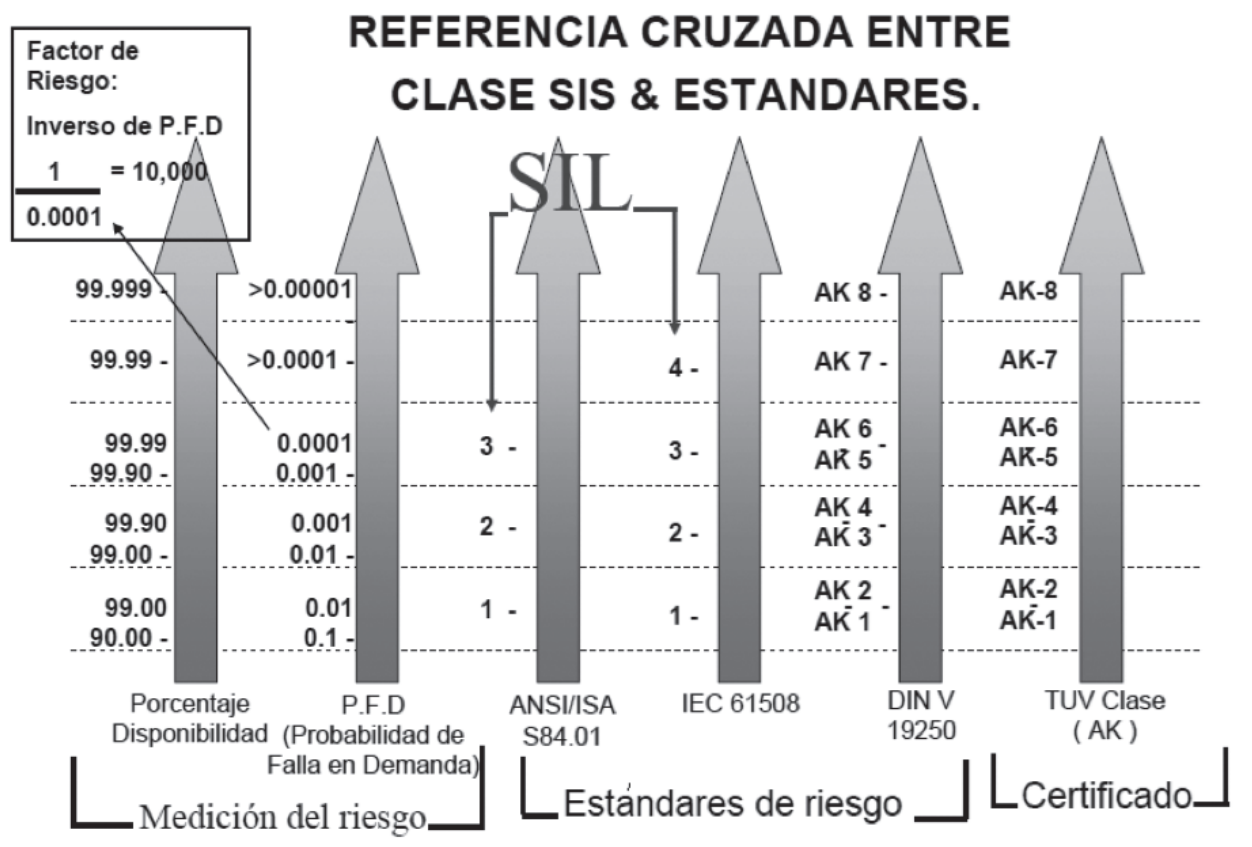

\subsection{Explicación de la actuación de un SIS}

Como se definió en 9.3, un SIS es un sistema independiente o externo a una planta o proceso, con el fin de garantizar que el riesgo no sobrepase cierto $S I L$, si determinadas condiciones son violadas. Podría entenderse un SIS como un sistema de seguridad redundante en una planta que ya posee ciertas alarmas y dispositivos de seguridad. La figura 85 presenta un recipiente a presión alimentado por una tubería, en el cual se desea garantizar que la presión en su interior no supere un determinado monto llamado presión normal. En el evento que la presión supere la presión normal deberá actuar una alarma de alta presión, y si en el caso que la presión sobrepase el valor de alta presión, entonces deberá actuar un sistema de paro de emergencia SPE y detener el sistema, para evitar la ocurrencia de un evento catastrófico. 
Figura 85. Planta de proceso a controlar [51]

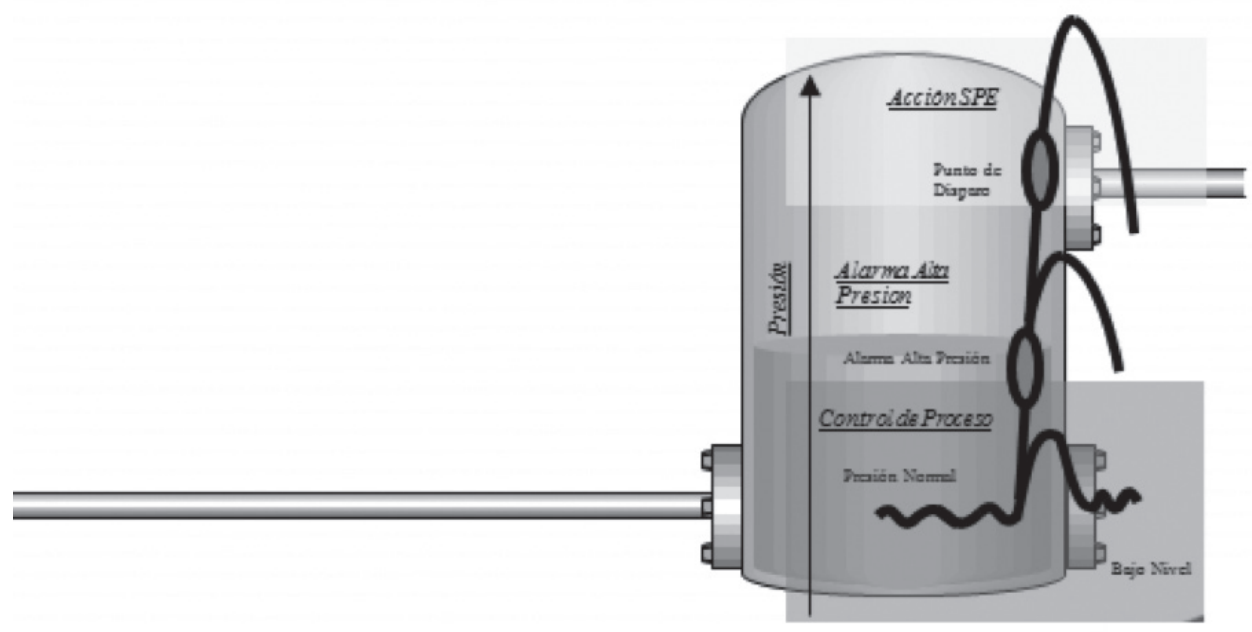

El sistema que posibilitará la operación básica de control del sistema de interés, obedece a la arquitectura de un sistema de control realimentado o feedback (figura 86).

Figura 86. Esquema general sistema de Control realimentado o feedback [52]

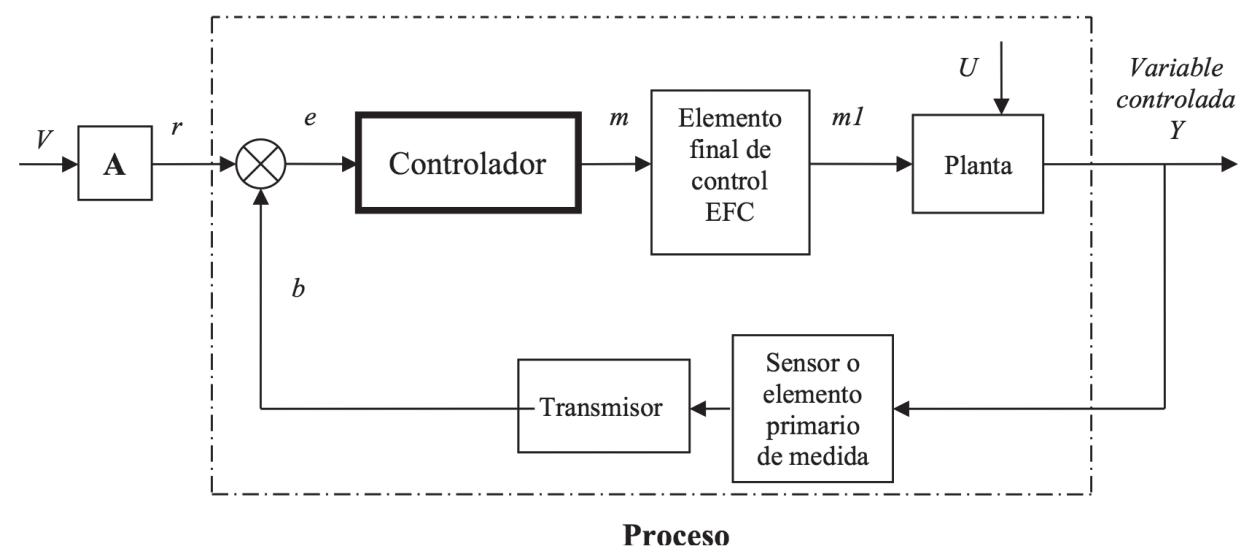

La figura 87 presenta el esquema del sistema de control feedback, propuesto para el sistema real de la figura 85 , y basado en el esquema de la figura 86. 
Figura 87. Sistema de Control feedback para el tanque de la figura 85

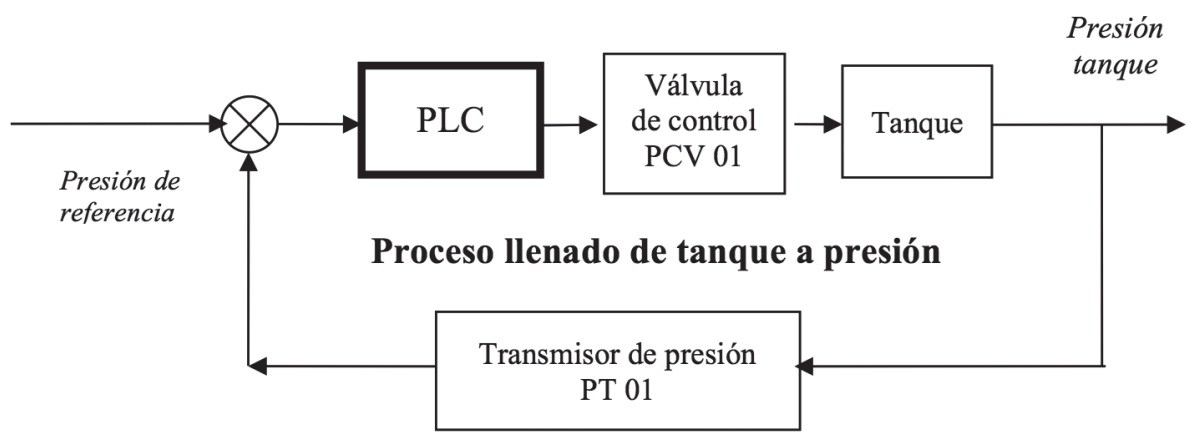

En la figura 88 se presenta la materialización del sistema de control previsto en la figura 87. La simbología utilizada corresponde a la Norma ISA S5.1 de la Instrument Society of America ISA. Obsérvese que se ha instalado la válvula de seguridad PSV 01, la cual no pertenece al lazo de control pero deberá cumplir la función ¿what if? Obsérvese también que el lazo de control se ha montado adicionalmente en un control supervisor SPC, con el objeto de supervisar a distancia, cambiar parámetros del proceso o detenerlo a voluntad.

Figura 88. Sistema de Control feedback real para el tanque de la figura 85 [51]

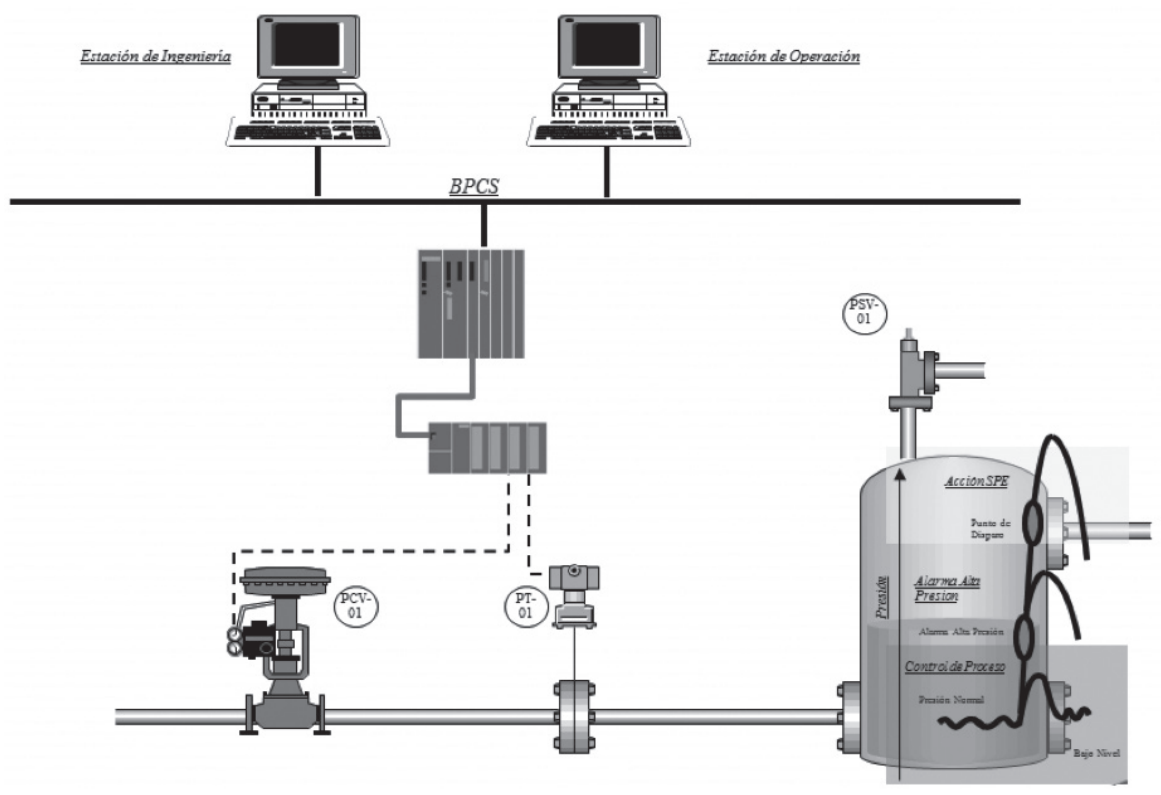


No debe pensarse en ningún momento que el sistema mostrado en la figura 88 es 100\% seguro, puesto que ninguno de sus componentes posee una confiabilidad del 100\%, y mucho menos su combinación. Por ejemplo, si se quisiera conocer la confiabilidad de la válvula PSV 01, se debería consultar su manual o por defecto el fabricante (si es responsable) debería proveer esta información, y se debería hacer lo propio con el transmisor, la válvula de control, PLC, etc. Conociendo la información anterior y aplicando herramientas de la Teoría de confiabilidad se podría conocer la probabilidad de falla del sistema.

Ahora bien, hasta este momento no ha aparecido el aporte sistémico del RBM. En la figura 89 se presentan los componentes del SIS:

- Un PLC adicional, exclusivamente dedicado al SIS.

- Una válvula solenoide SDY 01, para forzar en una situación extrema a la PCV 01 a cerrarse.

- Un transmisor de presión PT 02, montado sobre la tubería de entrada al tanque.

- Un interruptor de presión accionado por sobrepresión PSHH 01, ubicado al interior del tanque.

- Líneas electrónicas independientes a las inicialmente disponibles (color rojo).

Figura 89. Planta de proceso protegida por un SIS [51]

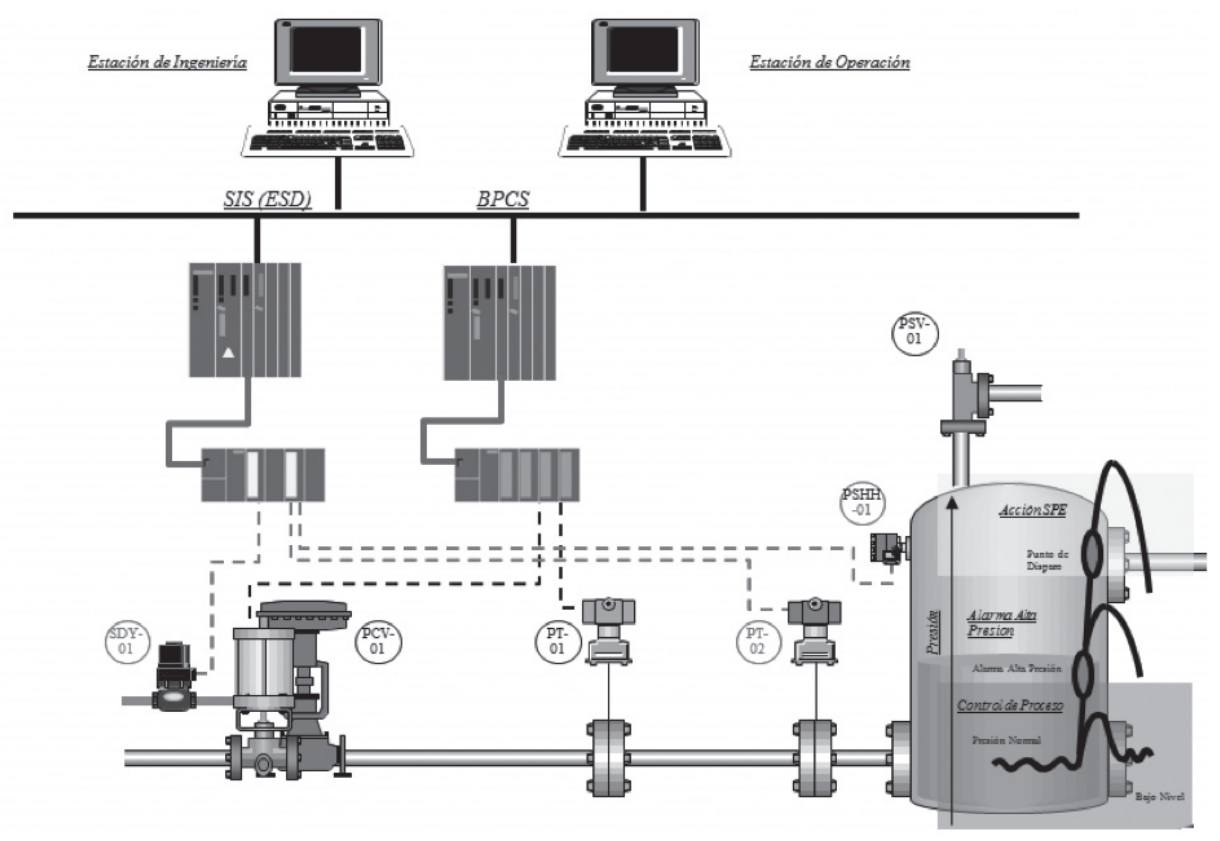


Como se puede apreciar la arquitectura del SIS es completamente independiente a la del lazo de control inicial, y dependiendo de la calidad y características de sus componentes debe minimizar la ocurrencia de una emergencia, elevando el SIL a un valor previsto para la planta en particular.

Por último en este panorama sobre RBM (ver figura 90), si falla el SIS, la planta deberá poseer unas protecciones físicas adicionales, el personal de planta deberá haber sido entrenado para responder a una emergencia, se debería recibir ayuda de la comunidad de emergencia externa a la planta, y si aun no es sufiente, entonces inevitablemente sobrevendrá la catástrofe, pero el camino será largo...

Figura 90. Niveles de protección antes que ocurra la catástrofe [51]

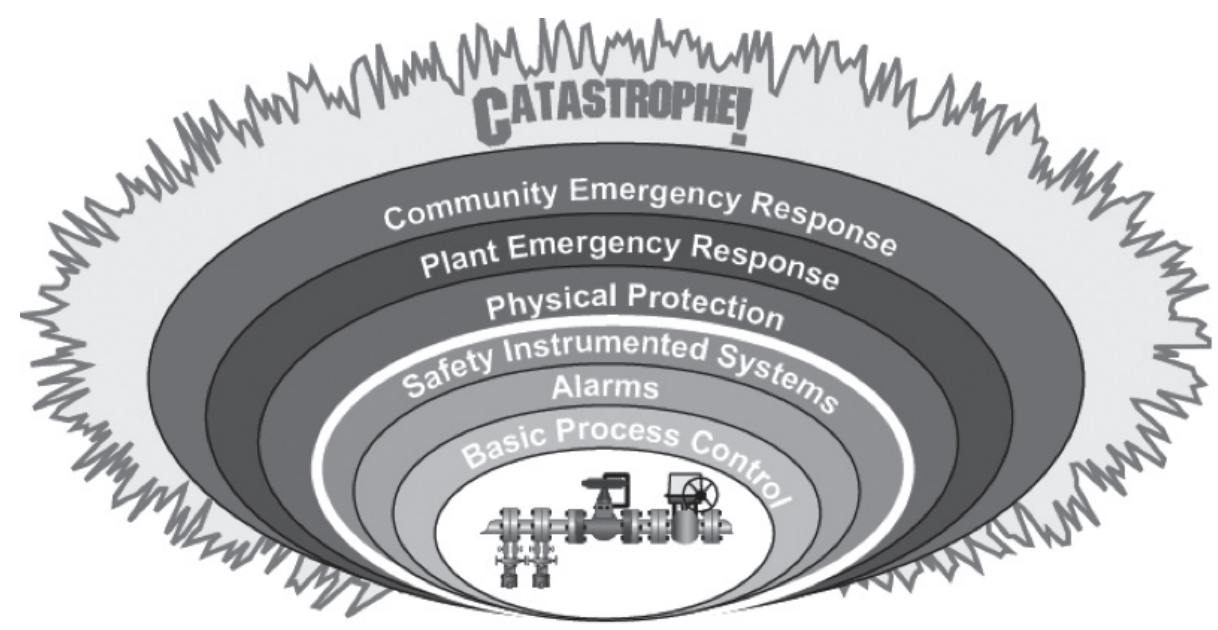

\subsection{Algunas normas y estándares relacionados con prevención y manejo del riesgo}

- HSE - PES. Programmable Electronic Systems in safety related applications, Parts 1 \& 2, U.K. Health \& Safety Executive. 1987.

- AIChE - CCPS. Guidelines for Safe Automation of Chemical Process. Center for Chemical Process Safety by The American Institute of Chemical Engineers. 1993.

- IEC 61508. Functional safety of electrical/electronic/programmable electronic safety-related systems. 1998. (BS EN 61508:2002).

- IEC 61511. Functional safety - Safety instrumented systems for the process industry sector. 2003. (BS EN 61511:2003).

- ANSI/ISA-84.00.01-2004 (IEC 61511 Mod). Functional safety: Safety instrumented systems for the process industry sector. 2004.

- NFPA 85. Boiler and Combustion Systems Hazard Code. National Fire Protection Association. 2004.

- API RP 556. Recommended Practice for instrumentation and control for fired heaters and steam generators. American Petroleum Institute. 1997.

- OSHAS. 29 CFR 1910.119 - Process Safety Management of Highly Hazardous Chemicals. 


\subsection{Tema de consulta y reflexión}

- Se recomienda al lector consultar, analizar y reflexionar alrededor de las siguientes preguntas:

- Si una Planta no está altamente instrumentada y no posee sistemas SIS ¿Entonces no es posible paliar el riesgo?

- ¿Qué es un programa RESPEL?

- ¿Para qué sirve un programa RESPEL en una empresa?

- Consulte algunos ejemplos de RESPEL comunes

- ¿Qué pasa con un producto RESPEL mal manejado?

- ¿Qué es un COPASST?

- ¿Quiénes integran un COPASST y cuáles son sus funciones principales?

- ¿Cómo pueden interactuar el COPASST y el RESPEL para minimizar el riesgo en las instalaciones de una Planta? 

Capítulo 10 



\section{Selección de un modelo o política de Mantenimiento}

A lo largo de los nueve capítulos anteriores se ha dado una mirada al amplio mundo del Mantenimiento, y se quiere en este capítulo hacer énfasis en algunos aspectos puntuales que ayudarán a reafirmar muy importantes conceptos generales y a adquirir una visión de conjunto sobre el grueso de los temas tratados.

Para el propósito mencionado se ha traído de nuevo a colación la figura 11 (página 39), que muestra: la evolución histórica del Mantenimiento a lo largo de cuatro generaciones bien definidas, las características principales de cada generación y los Sistemas de Mantenimiento (tratados a lo largo del libro) presentes en cada generación histórica.

A continuación se presenta una situación, que le puede ocurrir a un novel profesional (y que siendo estudiante universitario debe avizorarla): "ingeniero o tecnólogo $\boldsymbol{K}$.... Usted debe hacer parte del equipo de montaje de $X$ planta nueva, y posteriormente deberá hacerse cargo del Mantenimiento de la misma.

Ante esta situación con seguridad surgirán las siguientes dos preguntas (al margen de otras más particulares):

A. ¿Qué sistema o combinación de sistemas de Mantenimiento de los que conozco (al menos en el papel) debo emplear?

B. ¿Cuándo debo definir el Plan de Mantenimiento e iniciar la aplicación de las primeras tareas?

La respuesta a la Pregunta $B$ es muy rápida y simple. El momento para definir el Plan de Mantenimiento e iniciar su aplicación, es antes de que la Planta comience a operar.

¿Por qué? Por múltiples razones: 
- La mala selección de un proceso/máquina/equipo y/o un mal montaje son un problema que será un recuerdo para la empresa contratista de montajes, pero será una realidad muy traumática para quien quede a cargo de Mantenimiento, porque afectará negativamente, y de manera permanente y sistemática el desempeño de la planta. En la mayoría de montajes quedan errores y pendientes que usualmente deben ser subsanados por el personal de la planta, y quien vaya a aquedar a cargo de Mantenimiento debe conocerlos de antemano.

- Una vez que se marcha la empresa de montajes, el personal de Planta queda a cargo de hacerla funcionar, muchas veces en simultánea con el entrenamiento de los operadores y los mantenedores. Es una etapa de aprendizaje y estrés para todo el personal, donde regularmente el proceso productivo sufre muchas alteraciones mientras como se dice en la jerga popular "se asienta". La prioridad para las directivas en esta etapa inicial es que la planta funcione y produzca, ante todo en el contexto tan competitivo en que se vive actualmente.

- Como se pudo apreciar a lo largo de la obra, y en particular (figura 2, página 22) con la dinámica de Planear, Programar, Ejecutar, Medir y Comparar, acarrea labores dispendiosas, y tratar de hacerlas de manera precipitada en medio del día a día del arranque, no es muy exitoso, en particular porque los recursos para el Mantenimiento (herramientas, filtros, lubricantes, repuestos genéricos, repuestos específicos importantes, etc.) debieron haberse adquirido con antelación, ajustándose a los procesos y tiempos reales de compra en una empresa (que pueden ser de varios días en los mejores casos).

- Muchas empresas nuevas no tienen en cuenta las situaciones anteriores, y usualmente sucede que al iniciar operaciones la planta, ya han acumulado Backlog ejecutable y no ejecutable (ver numeral 4.3), infringiéndole desgastes innecesarios a máquinas/equipos nuevos o en buen estado y en el peor de los casos, ocurriendo fallas funcionales. En la realidad se presentan muchos casos de empresas que inician operaciones y la labor principal se vuelve como se dice en el argot del mantenimiento "apagar incendios", mientras que las labores proactivas, preventivas y predictivas pasan a un segundo o tercer plano.

Ahora, la respuesta a la Pregunta $\boldsymbol{A}$ no es tan rápida y simple como la respuesta a la Pregunta $\boldsymbol{B}$. Una primera tentación sería responder con base a la figura 14 (página 42), en la que se recuerda que cada sistema de Mantenimiento posee unas efectividades asociadas, siendo la mayor la ofrecida por el Mantenimiento Basado en el Riesgo RBM; bordeando el 90\%, y la menor, la ofrecida por el Mantenimiento básico, rondando el 46\%.

Si el novel profesional se guía por las efectividades, elegiría TPM, RCM o RBM, pero en esta elección tan fácil y $\tan$ "soñada" subyacen varias preguntas:

- ¿Está la empresa interesada y comprometida con sistemas de Mantenimiento en los cuales debe participar toda la organización?

- ¿Están el personal y la organización capacitados y maduros para implementar TPM, RCM y RBM?

- ¿Por el tipo de proceso/máquinas/equipos que posee la empresa será necesario implementar RBM por ejemplo?

Si no fue esta la situación que se presentó y se decidió aplicar Mantenimiento predictivo, igualmente surgen muchas preguntas, y se le propone al lector que anticipe algunas de ellas. 
Con estas pocas líneas, lo que se está planteando es que la elección en la Pregunta B puede ser muy compleja y la probabilidad de desacierto muy alta, razón por la cual se presenta una guía o metodología propuesta por Duffua [53], para definir la rigurosidad y profundidad de las tareas de Mantenimiento. A esta metodología se le han hecho algunos aportes propios en lo concerniente a tener en cuenta el Riesgo (Capítulo 9). Se trata de una metodología elaborada, y muy efectiva basada en 3 pasos:

- Definir la criticidad de la máquina/equipo en el proceso productivo.

- Estudiar el Riesgo que encarna la operación de la máquina/equipo en estudio.

- Definir el modelo de Mantenimiento a aplicar.

- Validar condiciones adicionales.

Es necesario aclarar que el término Modelo de Mantenimiento no debe entenderse como los Sistemas de Mantenimiento (Capítulo 1). El Modelo de mantenimiento está asociado, como se dijo líneas arriba con la rigurosidad y profundidad, y podría entenderse más como política de Mantenimiento. Duffua reconoce 5 modelos de mantenimiento, los cuales se describirán brevemente a continuación:

- Modelo correctivo. Aplicable a máquinas/equipos de muy bajo nivel de criticidad (prescindibles), cuyas averías no implican problemas económicos o técnicos, por lo tanto no es rentable dedicar recursos a su Mantenimiento. Los equipos que queden cobijados por este modelo pueden sufrir fallas funcionales y no interferirán con la producción. Incluye tareas de inspección, lubricación y reparación si ocurre la avería.

- Modelo condicional. Aplicable a máquinas/equipos de poco uso o equipos importantes en el proceso productivo, pero que su probabilidad de falla es muy baja. Incluye las tareas Inspección, lubricación y reparación, pero adicionalmente se le programan una serie de pruebas y ensayos al equipo que determinarán que se considere o no la ejecución de un Correctivo programado.

- Modelo sistemático. Aplicable a máquinas/equipos de disponibilidad media y de baja importancia en el proceso productivo, por lo tanto si se averían pueden causar algunos trastornos. Este modelo se basa en definir unas tareas que se ejecutarán a una frecuencia fija (así la máquina/equipo esté en buen estado) y se complementa con las tareas propias del modelo condicional. Es importante aclarar que un equipo puede requerir aplicar modelo condicional a algunos de sus subsistemas, mientras que en otros requerir algunos de los otros modelos relacionados.

- Modelo de alta disponibilidad. Aplicable a máquinas/equipos cuya disponibilidad debe estar por encima del $90 \%$, o dicho en otros términos la criticidad del equipo en el proceso productivo es muy grande. Regularmente se aplica en equipos para los cuales se programa una parada anual o puesta a cero u overhaul, y durante el año se realizan inspecciones, lubricaciones, ajustes y reparaciones provisionales que no impliquen parada del equipo. Una diferencia importante con los modelos anteriores es que aplica técnicas predictivas para determinar con suficiente antelación fallas potenciales, y en caso tal realizar reparaciones provisionales (sin detener el equipo), programar repuestos y recursos y si es del caso adelantar la parada general. Durante la parada general o puesta a cero se realizan modificaciones, cambios de partes en mal estado o susceptibles de fallar (los cuales deben tener vida útil del orden de dos años), se deben corregir las reparaciones provisionales efectuadas previamente, ajustar, calibrar, probar y poner a punto la máquina/equipo, de forma tal que se garantice el trabajo por el siguiente período anual. 
Una vez que se defina el Modelo de Mantenimiento, se debe hacer una validación de otras dos situaciones: la normatividad legal sobre la operación de las máquinas/equipos, y el carácter de subcontratado o propio, respecto del personal que atenderá el Mantenimiento de la Planta.

En la parte legal, es necesario verificar si a algunos de los equipos de la planta se les debe efectuar algún tipo de pruebas o revisiones legales prescritas por entidades gubernamentales bajo leyes específicas. Ejemplo, Instalaciones contra-incendios, instalaciones de alta y media tensión, equipos y aparatos a presión, algunos sistemas de elevación de cargas o de personas, medición en fuentes contaminantes, revisión técnico-mecánica de vehículos, etc.

Por último, en cuanto al tipo de vinculación con la empresa, es importante precisar de manera anticipada si las tareas a programar podrán ser efectuadas por personal propio o si es necesario acudir a personal especializado externo a la empresa (outsourcing); esta decisión se toma con base a dos criterios, la falta de conocimientos del personal propio y en la ausencia de equipos o maquinaria especializada para las labores. El diagrama de flujo de la figura 91 presenta el procedimiento gráfico para realizar la elección del Modelo de Mantenimiento.

En la figura 91, las cantidades $\$ X$ y $\$ Y$, deben ser definidas por cada empresa en particular, a no ser que exista información gremial de referencia. 
Figura 91. Elección de un Modelo de Mantenimiento [53]

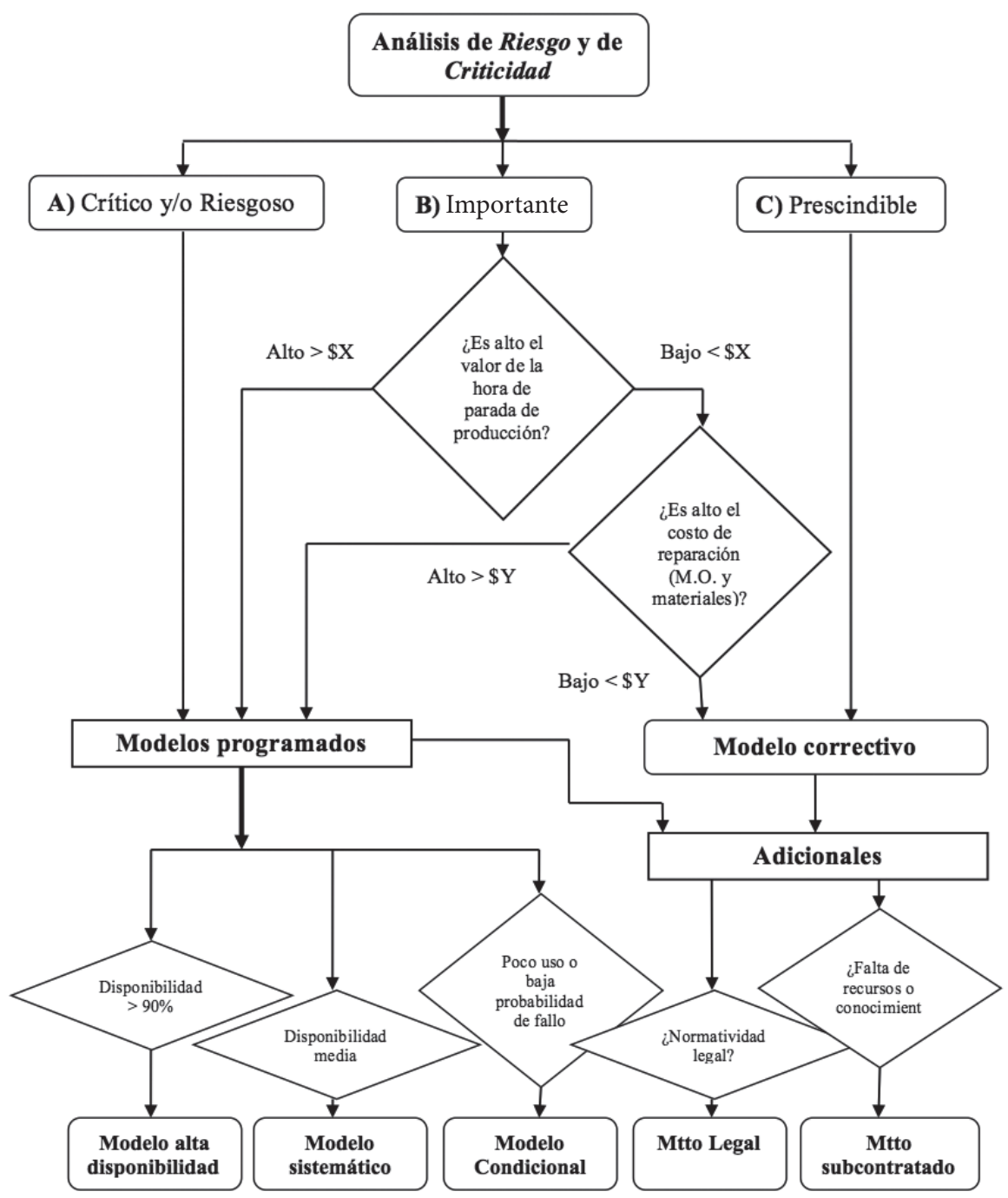

En la Tabla 35 se presenta un paralelo de las características de cada modelo de mantenimiento y algunos ejemplos de aplicación. 
Tabla 35. Panorama de los Modelos de Mantenimiento [el Autor]

\begin{tabular}{|c|c|c|c|c|c|}
\hline 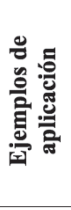 & & 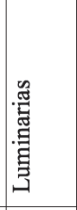 & 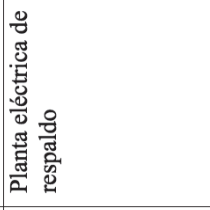 & 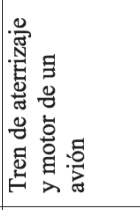 & 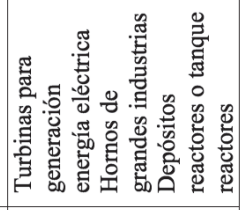 \\
\hline \multirow{8}{*}{ 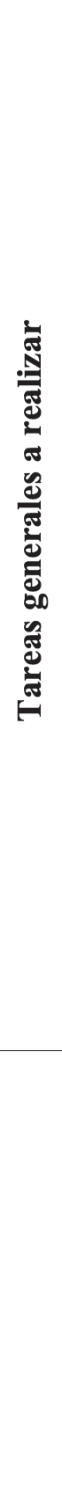 } & 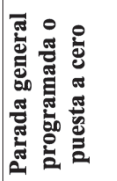 & & & & $x$ \\
\hline & 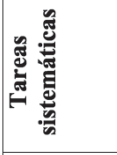 & & & $x$ & $x$ \\
\hline & 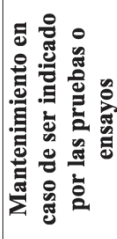 & & $x$ & $x$ & $x_{1}$ \\
\hline & 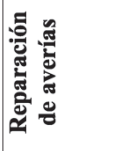 & $x$ & $x$ & $x$ & $x_{1}$ \\
\hline & 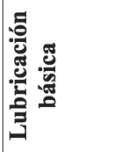 & $x$ & $x$ & $x$ & $x$ \\
\hline & 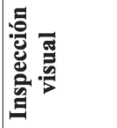 & $x$ & $x$ & $x$ & $x$ \\
\hline & 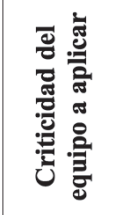 & 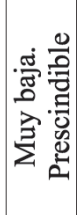 & 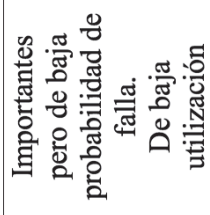 & 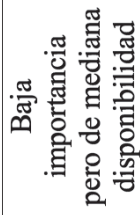 & 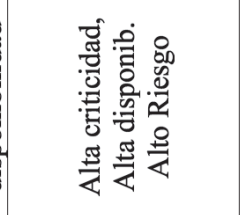 \\
\hline & 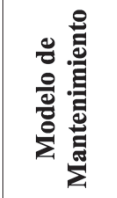 & 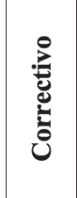 & 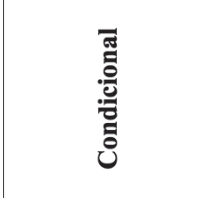 & 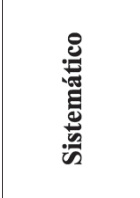 & 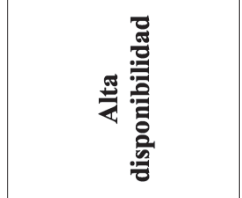 \\
\hline
\end{tabular}


De manera complementaria, y para crear conexión entre los sistemas de Mantenimiento y los Modelos de Mantenimiento, se ha elaborado la Tabla 36, en la que se muestra una guía general de los sistemas de Mantenimiento empleados en cada modelo de mantenimiento.

Tabla 36. Modelos de Mantenimiento y sistemas de Mantenimiento [el Autor]

\begin{tabular}{|c|c|}
\hline Modelo de Mantenimiento & Sistemas de Mantenimiento \\
\hline Correctivo & $\begin{array}{l}\text { Mantenimiento Autónomo } \\
\text { Correctivo programado }\end{array}$ \\
\hline Condicional & $\begin{array}{l}\text { Mantenimiento Autónomo } \\
\text { Correctivo programado } \\
\text { Mantenimiento Programado básico } \\
\text { Mantenimiento Preventivo básico } \\
\text { Aportes básicos de Predictivo }\end{array}$ \\
\hline Sistemático & $\begin{array}{l}\text { Mantenimiento Autónomo } \\
\text { Correctivo programado } \\
\text { Mantenimiento Programado } \\
\text { Mantenimiento Preventivo } \\
\text { Mantenimiento Predictivo }\end{array}$ \\
\hline Alta disponibilidad & $\begin{array}{l}\text { Correctivo programado } \\
\text { Mantenimiento Programado } \\
\text { Mantenimiento Preventivo } \\
\text { Mantenimiento Predictivo } \\
\text { Mantenimiento Productivo Total } \\
\text { Mantenimiento centrado en la Confiabilidad } \\
\text { Mantenimiento basado en el Riesgo }\end{array}$ \\
\hline
\end{tabular}





\section{Bibliografía}

[1] Herrera S., Humberto (2006). Mantenimiento Industrial. Pereira. Universidad Tecnológica de Pereira.

[2] Pérez, Carlos. M. (1992). Gerencia de Mantenimiento y sistemas de información. Memorias para cursos dictados con la asociación de Ingenieros Mecánicos y UPB. Medellín.

[3] Montilla, Carlos A. (2015). Notas de clase curso Mantenimiento Industrial. Pereira. Universidad Tecnológica de Pereira.

[4] Monchy, Francois (1990). Teoría y prácticas del mantenimiento Industrial. Barcelona: Editorial Masson.

[5] Smith, Anthony R. Hinchcliff, Glenn R. (1991). RCM - Gateway to world class maintenance. Burlington, USA. Editorial Elsevier Butterworth-heinemann.

[6] Valie, Claude (2008). Mantenimiento y Producción dentro del Lean Manufacturing. Bogotá. Congreso internacional de Mantenimiento ACIEM.

[7] HSB Global Standards Reliability Technologies. Consultado en marzo 2006. Disponible en: www.bitpipe.com

[8] Montilla, Carlos A. Zuluaga, Yohana. Parra, Santiago (2009). "Determinación de las estrategias de mantenimiento utilizadas por las grandes y medianas empresas del área metropolitana Pereira - Dosquebradas". Revista Scientia et Technica Año XV, No 41, Universidad Tecnológica de Pereira. ISSN 0122-1701, pp 357-362.

[9] Asociación Colombiana de Ingenieros ACIEM (2009). "Estudio estado del arte, Mantenimiento en Colombia 2008”. Bogotá, En http://www.aciem.org/home/Pdfs/Consulta_Comisiones/ Estado_del_Arte_Mantenimiento_Col_2008.pdf.

[10] "Economía de Colombia". Disponible en: http://es.wikipedia.org/wiki/Econom\%C3\%ADa de_Colombia. Consultado en junio de 2014

[11] Corporación para el desarrollo de las microempresas. Observatorio colombiano de las microempresa OCM. Bogotá, abril de 2007. "Estadísticas de la microempresa en Colombia, análisis comparativo 1990 - 2005”.

[12] Departamento administrativo nacional de Estadística DANE (2005). Censo general. 
[13] Arroyave M., Javier (2009). Desarrollo de un plan de mantenimiento preventivo para la planta de secado de la Cooperativa de Caficultores de Manizales. Universidad Tecnológica de Pereira. Trabajo de grado.

[14] Compresores de pistón/ portátiles. Consultado en junio de 2010. Disponible en: http://agfri. com/index.php?main_page=product_info\&cPath $=5$ _19\&products_id $=114$

[15] Compresores de pistón estacionarios. Consultado en junio de 2010. Direct industry. Disponible en: http://www.directindustry.es/prod/atlas-copco-compresseurs/compresores-piston-sinaceite-estacionarios-8358-234495.html

[16] Software de Mantenimiento MPSoftware. Versión demo.

[17] Restrepo M., Julián (2005). Pereira. Nicholas M. Sebastián. Programa básico de mantenimiento preventivo para la celda de manufactura flexible de la Facultad de Ingeniería Industrial. Trabajo de grado. Universidad Tecnológica de Pereira.

[18] Ríos G., Alexander. Carvajal G., Guillermo (2008). Desarrollo de una aplicación computacional para la implementación de programas de mantenimiento preventivo. Trabajo de grado. Universidad Tecnológica de Pereira.

[19] Sanabria M., José. López V., Juan (2009). Pereira. Desarrollo de un software de administración de mantenimiento preventivo para los elementos mecánicos del sistema cable aéreo Manizales de la empresa Ingecable S. A. Trabajo de grado. Universidad Tecnológica de Pereira.

[20] Gaviria R., Álvaro. Rivera V., Juan (2011). Pereira. Diseño y sistematización en Excel del plan de mantenimiento preventivo para la sección de tanques de gasolina de la planta Suzuki motor de Colombia S. A. Trabajo de grado. Universidad Tecnológica de Pereira.

[21] Ávila, C., Jaime. Gutiérrez F., Sebastián (2011). Elaboración y sistematización de un plan de mantenimiento preventivo para la planta de producción de la empresa Flexco S. A. Pereira. Trabajo de grado. Universidad Tecnológica de Pereira.

[22] Benoit, E. Luis. Elmann, Suerio y asociados. "Lo que más nos debería preocupar del mantenimiento". Disponible en: http:/www.mantenimientomundial.com/sites/mmnew/bib/ notas/preocupar.pdf.Consultado en junio de 2010.

[23] Ospina P., Diego (2011). Pereira. Diseño de estándares de mantenimiento para la empresa Meals de Colombia S. A. Trabajo de grado. Universidad Tecnológica de Pereira.

[24] Isaza V., Luis. (2005). Pereira. Manual para la implementación de un Departamento de Mantenimiento basado en la filosofía del Mantenimiento Productivo Total y a norma ISO 2001. Trabajo de grado. Universidad Tecnológica de Pereira.

[25] “Análisis y diagramas de Pareto". Disponible en: http://www.slideshare.net/jeffertyni/anlisis-ydiagramas-de-pareto. Consultado en junio de 2010.

[26] Santamaría H., Ricardo. Guzmán L., Hugo (2008). Bogotá. La Integralidad del predictivo como herramienta para el mantenimiento. Tecnología avanzada para el mantenimiento S. A. de C.V. Queretaro - México. Taller presentado en el X Congreso Internacional de Mantenimiento ACIEM 2008, pág. 76 a 82.

[27] “El espectro visible”. Disponible en: http://es.wikipedia.org/wiki/Espectro_visible. Consultado en junio de 2014

[28] “Detección de partículas con bolómetros centelleantes. El experimento de Rosebud". Disponible en: http://www.unizar.es/lfnae/rosebud/paginas/p0300.html. Consultado en junio de 2014.

[29] “Asesoría profesional en inspección. Ensayo de tintas penetrantes". Disponible en: http:// endases.mex.tl/frameset.php?url=/photo_26975_L-QUIDOS-PENETRANTES.html. Consultado en 2014.

[30] Carvajal M., Jhon E. (2012). Pereira. Elaboración de guías para prácticas básicas de mantenimiento predictivo (cámara termográfica, detector de discontinuidades por ultrasonido y tintas penetrantes). Trabajo de grado. Universidad Tecnológica de Pereira. 
[31] Gaviria, Alonso (2009). Pereira. Memorias de Seminario de Mantenimiento Predictivo: Medición y Análisis de vibraciones, Alineación de Maquinaria, Balanceo y Análisis Termográfico. Universidad Tecnológica de Pereira.

[32] Quintero R., Héctor (2014). Pereira. Notas de clase curso de Vibraciones Mecánicas. Universidad Tecnológica de Pereira.

[33] Tabares D., Juan S. (2012). Pereira. Elaboración de guías para prácticas básicas de mantenimiento predictivo (análisis de vibraciones, alineamiento de maquinaria y nivel de ruido). Trabajo de grado. Universidad Tecnológica de Pereira.

[34] "Automatización de la manufactura. Elementos de un sistema de manufactura". Disponible en: http://manufacturabustos.blogspot.com/. Consultado en junio de 2014

[35] "Electro-industria. Mantenimiento productivo total TPM". Disponible en: http://www.emb.cl/ electroindustria/articulo.mvc?xid=1520. Consultado en junio de 2014.

[36] Velásquez G., Jhon F. (2011). Pereira. Diseño e implementación de un programa de lubricación para las Plantas 4 y 5 de Buencafé liofilizado de Colombia, bajo el enfoque de TPM. Trabajo de grado. Universidad Tecnológica de Pereira.

[37] Ospina P., Diego A. (2011). Pereira. Diseño de estándares de mantenimiento para la empresa Meals de Colombia S. A. sede Manizales. Trabajo de grado. Universidad Tecnológica de Pereira.

[38] Kardec, Alan. Nascif, Julio (2002). Mantenimiento: Función estratégica. Rio de Janeiro. Qualitymark Editora Ltda.

[39] Moubray, John (1991). Reliability-Centered Maintenance. Oxford, England. ButterworthHeinemann Ltd.

[40] Nowlan, Stanley; Heap, Howard (1978). Reliability Centered Maintenance. San Francisco California. Braun-Brumfield, Inc.

[41] Agencia Nacional Aeroespacial NASA de E.E. U.U. National aeronautics and space administration reliability centered maintenance guide for facilities and collateral equipment. February 2000. Disponible en: https://www.youtube.com/ watch? $\mathrm{v}=\mathrm{C} 8 \mathrm{E} 1 \mathrm{~S} 3 \mathrm{eS0I}$ \& list=PLWYLFwsXjB1AFOw96gEGbByQvitwmJbya\&index $=50$

[42] Silva M., Carlos E. (2007). Pereira. Diseño de un sistema de mantenimiento para equipos móviles de transporte de carga terrestre. Trabajo de grado. Universidad Tecnológica de Pereira.

[43] Da Costa B., Martin (2008). Bogotá. Aplicación de la metodología RCM en los equipos de criticidad A, para la actualización de los planes de mantenimiento de la refinería de zinc Votorantim metáis - Unidad Cajamarquilla Perú. Congreso internacional de Mantenimiento ACIEM.

[44] “Alaska sufre el Exxon Valdez 25 años después. Ecoportal-net” Disponible en: http://www. ecoportal.net/Eco-Noticias/Alaska_sufre_el_Exxon_Valdez_25_anos_despues. Consultado en junio de 2014.

[45] “Desastre del Exxon Valdez". Disponible en:http://es.wikipedia.org/wiki/Desastre_del_Exxon_ Valdez. Consultado en junio de 2014.

[46] “Gestión de calidad y el accidente en Bhopal, India”. Disponible en: http://qualitydigestespanol. blogspot.com/2011/02/gestion-de-calidad-y-el-acccidente-en.html. Consultado en junio de 2014.

[47] “Desastres del siglo XX. Desastre de Bhopal". Disponible en: http://desastresdelsigloxx. blogspot.com/2012/06/desastre-de-bhopal-1984.html. Consultado en junio de 2014.

[48] "Desastres del siglo XX. Accidente de Chernóbyl (Ucrania)". Disponible en: http:// desastresdelsigloxx.blogspot.com/2012/06/accidente-de-chernobil-ucrania-de-1986.html. Consultado en junio de 2014.

[49] BBC Mundo. "El superdomo que pondrá punto final a Chernobyl”. En: http://www.bbc.com/ mundo/noticias/2015/04/150323_chernobyl_domo_sem_lp.Consultado en agosto 13 de 2015. 
[50] Espinosa F., Fernando. “Charlas para la gestión del mantenimiento: Mantenimiento basado en el riesgo”. Disponible en: http://www.academia.edu/6336664/Charlas_para_la_gesti\%C3\%B3n_ del_mantenimiento. Consultado en junio de 2014.

[51] Valencia, Andrés F. (2010). Popayán. Sistemas instrumentados de seguridad. International Society of Automation ISA, Colombia Section. VI Seminario de Automática, tendencias científicas y tecnológicas. Universidad del Cauca.

[52] Montilla C.A. (2009). Notas de clase curso Instrumentación y control. Pereira. Universidad Tecnológica de Pereira.

[53] Duffuaa, Salih. Raouf, A. Dixon, John (2005). Sistemas de mantenimiento, planeación y control. México D. C. Editorial Limusa Wiley. Primera edición. 


\section{Sobre el Autor}

Carlos Alberto Montilla Montaña es Ingeniero Mecánico de la Universidad Tecnológica de Pereira UTP; laboró 7 años en la industria, en Departamentos de producción y mantenimiento. Posteriormente trabajo 3 años como independiente, al tiempo que adelantaba sus estudios de magister en Sistemas automáticos de producción en la UTP.

Posteriormente laboró como profesor transitorio tiempo completo (por contratos) en la Facultad de Ingeniería Mecánica de la UTP. Desde el año 2006 es profesor de planta en la UTP, Facultad de Tecnología, programa de Tecnología Mecánica. Durante este tiempo también ha impartido clases en el programa de Ingeniería Mecatrónica de la UTP.

En su experiencia académica ha impartido diferentes asignaturas de las áreas de Procesos de Manufactura y Sistemas dinámicos.

Por más de 9 años ha sido profesor de la asignatura de Mantenimiento industrial, al tiempo que ha dirigido una cantidad importante de trabajos de grado relacionados con Mantenimiento Industrial, a nivel de Tecnología e Ingeniería.

Actualmente está desarrollando su tesis doctoral, alrededor del tema "Estudio y aplicación del fenómeno de la electroplasticidad en procesos de torneado de metales".

Su hoja de vida, perfil investigador, proyectos y publicaciones pueden ser consultados con mayor detalle en los sitios web:

\section{CVLac:}

http://scienti1.colciencias.gov.co:8081/cvlac/visualizador/generarCurriculoCv.do?cod_ $\mathrm{rh}=0000822663$

\section{Perfil Linkedln:}

https://www.linkedin.com/pub/carlos-alberto-montilla-monta\%C3\%B1a/17/612/414

Pereira, diciembre de 2015. 
Este libro terminó de imprimirse en abril del 2016, en los talleres gráficos de Publiprint S.A.S., bajo el cuidado del autor.

Pereira, Risaralda, Colombia. 
La Editorial de la Universidad Tecnológica de Pereira tiene como política la divulgación del saber científico, técnico y humanístico para fomentar la cultura escrita a través de libros y revistas científicas especializadas.

Las colecciones de este proyecto son: Trabajos de investigación, Ensayos, Textos Académicos y Tesis Laureadas.

Este libro pertenece a la Colección Textos Académicos. 
Este libro texto introduce a estudiantes de Ingeniería y Tecnología, a la teoría y práctica básica de la administración del Mantenimiento industrial, campo sumamente importante en las organizaciones productivas modernas y donde se ocupan laboralmente la mayoría de egresados de Ingeniería y afines.

Este trabajo es el resultado de la experiencia adquirida por el autor durante nueve años de servicio a la industria, y nueve años de experiencia docente en el campo específico de Mantenimiento.

En la forma que fue concebido y redactado el libro, es susceptible de ser leído y comprendido no solo por estudiantes universitarios, sino también por otros profesionales y personas ajenas al ámbito académico directo, pero con interés en el amplio mundo del Mantenimiento. 